\author{
Universidade de São Paulo \\ Instituto de Astronomia, Geofísica e Ciências Atmosféricas \\ Departamento de Ciências Atmosféricas
}

Camila Bertoletti Carpenedo

\title{
Interações entre os ciclones extratropicais e a variabilidade extrema do gelo marinho nos mares de Bellingshausen-Amundsen e no mar de Weddell, Antártica
}

São Paulo 
Camila Bertoletti Carpenedo

\section{Interações entre os ciclones extratropicais e a variabilidade extrema do gelo marinho nos mares de Bellingshausen-Amundsen e no mar de Weddell, Antártica}

Dissertação apresentada ao Departamento de Ciências Atmosféricas do Instituto de Astronomia, Geofísica e Ciências Atmosféricas da Universidade de São Paulo como requisito parcial para a obtenção do título de Mestre em Ciências.

Área de concentração: Meteorologia Orientador: Prof. Dr. Adilson Wagner Gandu

Versão corrigida. A versão original se encontra arquivada no Serviço de PósGraduação do IAG. 
Aos meus pais, Lidia e Natalino, e ao теu irmão Tiago. 


\section{AGRADECIMENTOS}

Inicialmente agradeço aos meus pais, Lidia e Natalino, e ao meu irmão Tiago, que me apoiaram indefinidamente em todos os momentos da minha vida. Cada ensinamento que vocês me deram me fortificou e me consolou nos momentos de dificuldades. A saudade é grande, mas está valendo apena!

Com muito amor agradeço ao Roger Delavi Araújo, que é muito mais do que meu namorado, é um grande amigo e companheiro, nos bons e maus momentos. Todo o amor, carinho, amizade e respeito que você tem por mim me faz cada dia mais feliz!

Agradeço ao meu orientador Prof. Dr. Adilson Wagner Gandu pela oportunidade de trabalhar com uma área de pesquisa que é uma paixão desde a minha graduação.

Agradeço especialmente à minha amiga e colega de laboratório Nathalie Tissot Boiaski, por toda a sua dedicação e paciência em me ajudar nas várias etapas dessa dissertação. Serei eternamente grata por tudo o que você fez por mim!

Agradeço aos meus amigos do laboratório GEM, ao Fábio Ullmann Furtado de Lima e à Tatiane Reis Martins, pela convivência, pelas mateadas, pelas dicas com o IDL e pelas discussões sobre Antártica. Eu vou sentir muitas saudades de tudo isso!

Agradeço à Profa. Dra. Leila Maria Vespoli de Carvalho pelas inúmeras sugestões, pelo incentivo em aprender a programar e pelo apoio em vários momentos do trabalho.

Agradeço ao Prof. Dr. Tércio Ambrizzi pelas sugestões no meu exame de qualificação.

Agradeço às minhas grandes amigas Bruna Segalin e Flávia Matioli da Silva. Com vocês eu aprendi o verdadeiro valor de uma amizade. Muito obrigada por todos os momentos que vivemos juntas!

Agradeço a todos os meus amigos do IAG, em que cada um foi importante de um jeito diferente na minha vida durante esses dois anos. Uma característica em comum a todos? A parceria no bandejão!

Agradeço ao meu grande amigo Prof. Francisco Eliseu Aquino, que sempre me incentivou em seguir a carreira acadêmica e nunca me deixou desistir. Você nunca poupou esforços pra que eu participasse de eventos científicos e sempre me disponibilizou os vários livros de gelo marinho, que só o CPC/IGEO/UFRGS tem! Agradeço também ao Prof. Dr. Jefferson Cardia Simões, que foi quem me oportunizou financeiramente a participação em vários eventos.

Agradeço a todos os funcionários do IAG, que sempre foram competentes e facilitaram muito a minha vida.

Agradeço à CAPES/PROEX (Programa de Meteorologia) pelo auxílio financeiro. 
"Try not to become a man of success, but rather a man of value."

Albert Einstein 


\section{RESUMO}

\section{CARPENEDO, C. B. Interações entre os ciclones extratropicais e a variabilidade extrema do gelo marinho nos mares de Bellingshausen-Amundsen e no mar de Weddell,} Antártica. 2012. 152 p. Dissertação (Mestrado em Meteorologia) - Instituto de Astronomia, Geofísica e Ciências Atmosféricas, Universidade de São Paulo, São Paulo, 2012.

O sistema atmosfera-gelo marinho é complexo e fortemente acoplado. Em uma região de transição entre a cobertura de gelo marinho e o mar aberto a interação entre esse sistema é particularmente intensa, sendo significativa o suficiente para influenciar a circulação atmosférica de grande escala e a distribuição de gelo marinho. Assim, o objetivo principal deste trabalho foi analisar as interações entre os ciclones extratropicais e a variabilidade extrema do gelo marinho nos setores dos mares de Bellingshausen-Amundsen (MBA) e do mar de Weddell (MW), no período de verão e inverno austral entre 1989 e 2007. Foram utilizados dados de extensão de gelo marinho do NSIDC/NASA; campos atmosféricos da superfície até os altos níveis da troposfera das reanálises do ERA-Interim (ECMWF); composição de imagens de satélite do canal infravermelho do SSEC; Índice de Niño Oceânico do CPC/NOAA. As anomalias de alta frequência (período de 2-10 dias) e interanual (período maior que 370 dias) foram obtidas aplicando-se a transformada rápida de Fourier nas séries temporais (1989-2007). Os extremos de gelo marinho foram obtidos através do primeiro e terceiro quartil da distribuição dos dados. As características da circulação atmosférica de alta frequência e interanual associadas aos eventos extremos negativos (ENGM) e positivos (EPGM) de gelo marinho, na mesma escala de tempo, foram obtidas através de composições defasadas das anomalias dos campos atmosféricos. Para evidenciar e exemplificar os padrões encontrados nas composições de alta frequência apresenta-se uma análise sinótica de estudo de casos para o setor dos MBA durante o inverno austral, em eventos ENGM e EPGM, separando os casos em fases distintas do fenômeno tropical El Niño. Foi utilizada a estatística de ciclones do Automatic Cyclone Tracking, da Universidade de Melbourne, para analisar a ocorrência de ciclones associados aos períodos de mínima e máxima extensão de gelo marinho na escala interanual. Os resultados mostram que no verão e inverno austral, os eventos ENGM de alta frequência no setor dos MBA e do MW estão associados com as anomalias dos campos atmosféricos, na mesma escala temporal, que se assemelham a um trem de ondas ocorrido a partir de três dias anteriores ao evento extremo. A anomalia ciclônica no oeste e a anomalia anticiclônica no leste do setor resultam em uma anomalia de ventos de norte e, consequentemente, a anomalias positivas de temperatura do ar. Essa configuração anômala contribui para os eventos ENGM através do derretimento do gelo marinho e do seu próprio transporte em direção às latitudes maiores pelos ventos de norte anômalos. As anomalias de alta frequência dos campos atmosféricos em todos os casos (composições defasadas) de eventos EPGM apresentam fases opostas em relação aos eventos ENGM. Portanto, fases distintas do trem de ondas induzem na modulação de extremos de gelo marinho opostos. Em relação às análises sinóticas dos eventos ENGM e EPGM em fases distintas do fenômeno El Niño, verificou-se que em períodos de El Niño há uma intensificação do jato subtropical e um enfraquecimento do jato polar no Pacífico Sul. Há uma menor atuação dos ciclones extratropicais, predominando o sistema de cristas e cavados. $\mathrm{Na}$ 
fase de La Niña há um reforço do jato polar e uma intensa atividade ciclônica sobre os MBA. No evento ENGM (EPGM) há uma associação entre os ventos de norte (de sul) com a vanguarda (retaguarda) dos sistemas ciclônicos em superfície. Na fase Neutra verificou-se uma intensificação do jato polar e uma atuação do sistema de cristas/cavados e de sistemas ciclônicos em superfície. $\mathrm{Na}$ análise da influência da circulação atmosférica interanual na variabilidade extrema do gelo marinho, na mesma escala de tempo, observou-se que a fase quente (fria) do ENSO provavelmente está associada com eventos ENGM (EPGM) nos MBA e com eventos EPGM (ENGM) no MW. Sobre a influência da variabilidade interanual da extensão do gelo marinho na atividade ciclônica, nas composições de anomalias interanuais de PNMM em relação aos eventos ENGM nos MBA $($ lag = 0) no verão, há um predomínio de anomalias positivas de pressão ao nível médio do mar (PNMM) sobre grande parte do Oceano Austral, o que contribuiria para uma menor profundidade e raio dos sistemas em superfície. Já em relação aos eventos ENGM no MW, verifica-se que no lag $=0$ há um predomínio de anomalias negativas de PNMM no Oceano Austral, o que contribuiria para um aumento da profundidade e raio dos ciclones.

Palavras-chave: gelo marinho antártico, ciclones extratropicais, variabilidade de alta e baixa frequência. 


\begin{abstract}
CARPENEDO, C. B. Interactions between the extratropical cyclones and extreme variability of sea ice in the Amundsen-Bellingshausen Seas and in the Weddell Sea, Antarctic. São Paulo: Institute of Astronomy, Geophysics and Atmospheric Sciences, University of São Paulo, 2012, 152 p. Master Dissertation in Meteorology.
\end{abstract}

The sea ice-atmosphere system is complex and tightly coupled. In a transition region between the coverage of sea ice and open ocean the interaction between this system is particularly intense, being significant enough to influence large-scale atmospheric circulation and sea ice distribution. Thus, the main objective of this study was to analyze the interactions between extratropical cyclones and extreme variability of sea ice in the sectors of the BellingshausenAmundsen Seas (BAS) and the Weddell Sea (WS), in the period of austral summer and winter between 1989 and 2007. We used sea ice extent data from NSIDC/NASA; atmospheric fields (surface to higher tropospheric levels) from ERA-Interim reanalysis; SSEC IR satellite image composition; and the Oceanic Niño Index CPC/NOAA. Anomalies of high-frequency (2-10 days) and interannual (longer than 370 days) were obtained by applying a fast Fourier transform in the time series (1989-2007). The extremes of sea ice were obtained from the first and third quartile of the data distribution. The characteristics of high-frequency atmospheric circulation and interannual associated with negative (NESI) and positive (PESI) extreme events of sea ice at the same time scale, were obtained from the lagged composites of the anomalies of atmospheric fields. To highlight and illustrate the patterns found in the composites of high frequency presents a synoptic analysis of case studies for the sector of the BAS during the austral winter at NESI and PESI events, separating the cases in different stages of the tropical El Niño phenomenon. Was used a statistical cyclone of Automatic Cyclone Tracking, from University of Melbourne, to analyze the occurrence of cyclones associated with periods of minimum and maximum extent of sea ice in the interannual scale. The results show that in the austral summer and winter, the NESI events of high frequency in the sector of the BAS and the WS are associated with the anomalies of atmospheric fields in the same timescale that resemble a wave train occurring from three days before the extreme event. The cyclonic anomaly in the west and anticyclonic anomaly in the east sector result in an anomaly of north winds and, consequently, the positive anomalies of air temperature. This anomalous configuration contributes for events NESI by sea ice melting and its own transport to higher latitudes by anomalous north winds. Synoptic atmospheric fields anomalies, in all PESI event cases are in opposite phases to NESI events. Therefore, different phases of the circumpolar wave train induce modulation of concurrent sea ice extremes. Regarding the synoptic analysis of events NESI and PESI in different phases of El Niño, it was found that during periods of El Niño it has a strengthening of the subtropical jet and a weakening of the polar jet in the South Pacific. There is less activity of extratropical cyclones, and the predominant system of ridge and troughs. In the La Niña case studies, has a strengthening of 
the polar jet and an intense cyclonic activity over the BAS. In the NESI (PESI) event there is an association between the north (south) winds at the vanguard (rear) of the cyclone systems at surface. In the Neutral phase case studies, there is an intensification of the polar jet and performance of the system of ridge/troughs and cyclonic systems at surface. In the analysis of the influence of interannual atmospheric circulation on extreme variability of sea ice, at the same time scale, it was observed that the warm (cold) phase of ENSO are probably associated with NESI (PESI) events at BAS and with PESI (NESI) events in the WS. On the influence of interannual variability of sea ice extent in the cyclonic activity, in the composites of interannual anomalies of mean sea level pressure (MSLP) in relation to NESI events in the BAS (lag $=0)$ in the summer, there is a predominance of positive anomalies of MSLP over much of the Southern Ocean, which would contribute to a lower depth and radius of the surface systems. In relation to NESI events in WS, it appears that in the lag $=0$ there is a predominance of negative anomalies of MSLP in the Southern Ocean, which would contribute to an increase in depth and radius cyclones.

Keywords: Antarctic sea ice, extratropical cyclones, high and low frequency variability. 


\section{LISTA DE FIGURAS}

Figura 1.1: Mapa da Antártica enfatizando os mares que a circundam, suas principais regiões e sua posição centrada no polo sul geográfico da Terra (AHLERT; AQUINO, 2009).

Figura 1.2: (a) Modelo de circulação geral da atmosfera, em que se destaca a célula de circulação polar sobre as altas latitudes (CIMSS, 2011); (b) Escoamento médio em superfície sobre a Antártica, em que se observam os ventos catabáticos, com forte componente de leste próximo à costa (KING; TURNER, 1997).

Figura 1.3: Climatologia da PNMM (hPa) das reanálises do ERA-Interim sobre o Oceano Austral e adjacências, para o período de (a) verão (JFM) e (b) inverno (JAS), entre 1989 e 2007.

Figura 1.4: Concentração média do gelo marinho antártico para os meses de (a) fevereiro e (b) setembro, entre 1979 e 2006 (CAVALIERI; PARKINSON, 2008). .06

Figura 1.5: Movimento médio do gelo marinho antártico em julho de 1979 a 1997. Os vetores mostram a deriva do gelo marinho (velocidade e direção), sobrepostos aos campos de concentração de gelo marinho e de PNMM (SCHMITT, 2006). .08

Figura 1.6: Padrão de circulação atmosférica esquemático em resposta a eventos (a) quentes e (b) frios de ENSO sobreposto à composição de TSM em evento de El Niño e La Niña, respectivamente (YUAN, 2004). .14

Figura 2.1: Setores do Oceano Austral (modificado de Cavalieri e Parkinson, 2008)..... 19

Figura 2.2: Curva de regressão de $y$ sobre $x$, em que os pontos dados são $\left(x_{1}, y_{1}\right), \ldots,\left(x_{n}, y_{n}\right)$. Para determinado valor de $x_{n}$ haverá uma diferença entre o valor $y_{n}$ e o correspondente valor "ajustado", determinado pela curva $C$. Denotamos tal diferença por $d_{n}$, chamada de desvio, erro ou resíduo (SPIEGEL, 1977, p. 371)....

Figura 2.3: Ciclo anual obtido a partir da média diária (linha vermelha) e ajustado pelo primeiro e segundo harmônico (tracejado preto) para os setores (a) dos MBA e (b) do MW..22

Figura 2.4: (a) Anomalias totais (linha preta), de alta frequência (linha vermelha) e interanuais (linha azul) de gelo marinho no setor (a) dos MBA e (b) do MW, entre janeiro de 1989 e dezembro de 2007.

Figura 2.5: (a) Persistência dos eventos ENGM (barra preta) e EPGM (barra vermelha) e (b) número de eventos ENGM (barra preta) e EPGM (barra vermelha) de alta frequência, no setor dos MBA, durante o verão de 1989 a 2007.

Figura 2.6: (a) Persistência dos eventos ENGM (barra preta) e EPGM (barra vermelha) e (b) número de eventos ENGM (barra preta) e EPGM (barra vermelha) de alta frequência, no setor dos MBA, durante o inverno de 1989 a 2007. .28

Figura 2.7: (a) Persistência dos eventos ENGM (barra preta) e EPGM (barra vermelha) e (b) número de eventos ENGM (barra preta) e EPGM (barra vermelha) de alta frequência, no setor do MW, durante o verão de 1989 a 2007.

Figura 2.8: (a) Persistência dos eventos ENGM (barra preta) e EPGM (barra vermelha) e (b) número de eventos ENGM (barra preta) e EPGM (barra vermelha) de alta frequência, no setor do MW, durante o inverno de 1989 a 2007. 
Figura 2.9: Persistência dos eventos ENGM (barra preta) e EPGM (barra vermelha) no setor dos MBA, durante o (a) verão e (b) inverno austral, de 1989 a 2007. Cada barra corresponde a um evento.

Figura 2.10: Persistência dos eventos ENGM (barra preta) e EPGM (barra vermelha) no setor do MW, durante o (a) verão e (b) inverno austral, de 1989 a 2007. Cada barra corresponde a um evento.

Figura 2.11: Densidade de ciclones [número de sistemas por $10^{3}\left({ }^{\circ} \text { lat }\right)^{-2}$ ] no Hemisfério Sul, no período de verão austral: (a) janeiro, (b) fevereiro e (c) março; e de inverno austral: (d) julho, (e) agosto e (f) setembro, entre 1989 e 2007

Figura 2.12: Raio dos ciclones ( ${ }^{\circ}$ lat) no Hemisfério Sul, no período de verão austral: (a) janeiro, (b) fevereiro e (c) março; e de inverno austral: (d) julho, (e) agosto e (f) setembro, entre 1989 e 2007

Figura 2.13: Profundidade dos ciclones $(\mathrm{hPa})$ no Hemisfério Sul, no período de verão austral: (a) janeiro, (b) fevereiro e (c) março; e de inverno austral: (d) julho, (e) agosto e (f) setembro, entre 1989 e 2007. 38

Figura 3.1: Composição do desvio padrão de PNMM no lag = 0 em eventos (a) ENGM e (b) EPGM no setor dos MBA durante o inverno austral (1989-2007).

Figura 3.2: Composição do desvio padrão de vento meridional a $10 \mathrm{~m}$ no lag $=0$ em eventos (a) ENGM e (b) EPGM no setor dos MBA durante o inverno austral (1989-2007)......

Figura 3.3: Composição do desvio padrão de temperatura do ar a $2 \mathrm{~m}$ no lag $=0$ em eventos (a) ENGM e (b) EPGM no setor dos MBA durante o inverno austral (1989-2007).

Figura 3.4: Composição do desvio padrão de PNMM no lag = 0 em eventos (a) ENGM e (b) EPGM no setor dos MBA durante o verão austral (1989-2007)

Figura 3.5: Composição do desvio padrão de vento meridional a $10 \mathrm{~m}$ no lag $=0$ em eventos (a) ENGM e (b) EPGM no setor dos MBA durante o verão austral (1989-2007). . .44

Figura 3.6: Composições defasadas das anomalias de alta frequência de PNMM (hPa) durante os eventos (a) ENGM e (b) EPGM no setor dos MBA, no lag = -6, lag = -3, lag = 0 e lag $=+3$, período de inverno austral (1989-2007). Linhas contínuas (tracejadas) indicam valores positivos (negativos) de anomalias. Áreas coloridas são significativas ao nível de $95 \%$.

Figura 3.7: Similar à Figura 3.6, mas para as anomalias de alta frequência de vento zonal a $10 \mathrm{~m}(\mathrm{~m} / \mathrm{s})$ .48

Figura 3.8: Similar à Figura 3.6, mas para as anomalias de alta frequência de vento meridional a $10 \mathrm{~m}(\mathrm{~m} / \mathrm{s})$.

Figura 3.9: Similar à Figura 3.6, mas para as anomalias de alta frequência de temperatura do ar a $2 \mathrm{~m}\left({ }^{\circ} \mathrm{C}\right)$.

Figura 3.10: Composições defasadas das anomalias de alta frequência de PNMM (hPa) durante os eventos (a) ENGM e (b) EPGM no setor do MW, no lag = -6, lag = -3, lag = 0 e lag $=+3$, no período de inverno austral (1989-2007). Linhas contínuas (tracejadas) indicam valores positivos (negativos) de anomalias. Áreas coloridas são significativas ao nível de $95 \%$.

Figura 3.11: Similar à Figura 3.10, mas para as anomalias de alta frequência de vento zonal a $10 \mathrm{~m}(\mathrm{~m} / \mathrm{s})$. 
Figura 3.12: Similar à Figura 3.10, mas para as anomalias de alta frequência de vento meridional a $10 \mathrm{~m}(\mathrm{~m} / \mathrm{s})$

Figura 3.13: Similar à Figura 3.10, mas para as anomalias de alta frequência de temperatura do ar a $2 \mathrm{~m}\left({ }^{\circ} \mathrm{C}\right)$.

Figura 3.14: Composições defasadas das anomalias de alta frequência de PNMM (hPa) durante os eventos (a) ENGM e (b) EPGM no setor dos MBA, no lag = -6, lag = -3, lag = 0 e lag $=+3$, no período de verão austral (1989-2007). Linhas contínuas (tracejadas) indicam valores positivos (negativos) de anomalias. Áreas coloridas são significativas ao nível de $95 \%$...

Figura 3.15: Similar à Figura 3.14, mas para as anomalias de alta frequência de vento zonal a $10 \mathrm{~m}(\mathrm{~m} / \mathrm{s})$

Figura 3.16: Similar à Figura 3.14, mas para as anomalias de alta frequência de vento meridional a $10 \mathrm{~m}(\mathrm{~m} / \mathrm{s})$.

Figura 3.17: Similar à Figura 3.14, mas para as anomalias de alta frequência de temperatura do ar a $2 \mathrm{~m}\left({ }^{\circ} \mathrm{C}\right)$......

Figura 3.18: Composições defasadas das anomalias de alta frequência de PNMM (hPa) durante os eventos (a) ENGM e (b) EPGM no setor do MW, no lag $=-6$, lag $=-3$, lag $=0$ e lag $=+3$, no período de verão austral (1989-2007). Linhas contínuas (tracejadas) indicam valores positivos (negativos) de anomalias. Áreas coloridas são significativas ao nível de $95 \%$

Figura 3.19: Similar à Figura 3.18, mas para as anomalias de alta frequência de vento zonal a $10 \mathrm{~m}(\mathrm{~m} / \mathrm{s})$

Figura 3.20: Similar à Figura 3.18, mas para as anomalias de alta frequência de vento meridional a $10 \mathrm{~m}(\mathrm{~m} / \mathrm{s})$

Figura 3.21: Similar à Figura 3.18, mas para as anomalias de alta frequência de temperatura do ar a $2 \mathrm{~m}\left({ }^{\circ} \mathrm{C}\right)$.

Figura 3.22: Anomalia de alta frequência de (a, b) PNMM, (c, d) vento zonal e (e, f) vento meridional a $10 \mathrm{~m},(\mathrm{~g}, \mathrm{~h})$ temperatura do ar a $2 \mathrm{~m},(\mathrm{i}, \mathrm{j})$ altura geopotencial em $500 \mathrm{hPa},(\mathrm{k}, \mathrm{l})$ altura geopotencial e (m, n) vento zonal em $200 \mathrm{hPa}$ no lag $=-3(08 / 09 / 2004)$ e no lag $=0$ (11/09/2004) no evento ENGM.

Figura 3.23: Dia 08/09/2004 às 12 UTC: (a) PNMM (linha contínua, em hPa) e VR em 1000 $\mathrm{hPa}$ (sombreado, em $10^{-5} \mathrm{~s}^{-1}$ ); (b) temperatura do ar a $2 \mathrm{~m}$ (sombreado, em ${ }^{\circ} \mathrm{C}$ ) e vento horizontal a $10 \mathrm{~m}$ (vetores, em m/s); (c) altura geopotencial em $500 \mathrm{hPa}$ (sombreado, em m) e VR em $500 \mathrm{hPa}$ (sombreado, em $10^{-5} \mathrm{~s}^{-1}$ ); (d) composições de imagens de satélites no infravermelho.

Figura 3.24: Dia 09/09/2004 às 12 UTC: (a) PNMM (linha contínua, em hPa) e VR em 1000 $\mathrm{hPa}$ (sombreado, em $10^{-5} \mathrm{~s}^{-1}$ ); (b) temperatura do ar a $2 \mathrm{~m}$ (sombreado, em ${ }^{\circ} \mathrm{C}$ ) e vento horizontal a $10 \mathrm{~m}$ (vetores, em m/s); (c) altura geopotencial em $500 \mathrm{hPa}$ (sombreado, em m) e VR em $500 \mathrm{hPa}$ (sombreado, em $10^{-5} \mathrm{~s}^{-1}$ ); (d) composições de imagens de satélites no infravermelho.

Figura 3.25: Dia 10/09/2004 às 12 UTC: (a) PNMM (linha contínua, em hPa) e VR em 1000 $\mathrm{hPa}$ (sombreado, em $10^{-5} \mathrm{~s}^{-1}$ ); (b) temperatura do ar a $2 \mathrm{~m}$ (sombreado, em ${ }^{\circ} \mathrm{C}$ ) e vento horizontal a $10 \mathrm{~m}$ (vetores, em m/s); (c) altura geopotencial em $500 \mathrm{hPa}$ (sombreado, em m) e 
VR em $500 \mathrm{hPa}$ (sombreado, em $10^{-5} \mathrm{~s}^{-1}$ ); (d) composições de imagens de satélites no infravermelho...

Figura 3.26: Dia 11/09/2004 às 12 UTC: (a) PNMM (linha contínua, em hPa) e VR em 1000 $\mathrm{hPa}$ (sombreado, em $10^{-5} \mathrm{~s}^{-1}$ ); (b) temperatura do ar a $2 \mathrm{~m}$ (sombreado, em ${ }^{\circ} \mathrm{C}$ ) e vento horizontal a $10 \mathrm{~m}$ (vetores, em m/s); (c) altura geopotencial em $500 \mathrm{hPa}$ (sombreado, em m) e VR em $500 \mathrm{hPa}$ (sombreado, em $10^{-5} \mathrm{~s}^{-1}$ ); (d) composições de imagens de satélites no infravermelho. .73

Figura 3.27: Anomalia de alta frequência de (a, b) PNMM, (c, d) vento zonal e (e, f) vento meridional a $10 \mathrm{~m},(\mathrm{~g}, \mathrm{~h})$ temperatura do ar a $2 \mathrm{~m},(\mathrm{i}, \mathrm{j})$ altura geopotencial em $500 \mathrm{hPa},(\mathrm{k}, \mathrm{l})$ altura geopotencial e $(\mathrm{m}, \mathrm{n})$ vento zonal em $200 \mathrm{hPa}$ no lag $=-3(11 / 09 / 1999)$ e no lag $=0$ (14/09/1999) no evento ENGM. .75

Figura 3.28: Dia 11/09/1999 às 12 UTC: (a) PNMM (linha contínua, em hPa) e VR em 1000 $\mathrm{hPa}$ (sombreado, em $10^{-5} \mathrm{~s}^{-1}$ ); (b) temperatura do ar a $2 \mathrm{~m}$ (sombreado, em ${ }^{\circ} \mathrm{C}$ ) e vento horizontal a $10 \mathrm{~m}$ (vetores, em m/s); (c) altura geopotencial em $500 \mathrm{hPa}$ (sombreado, em m) e VR em $500 \mathrm{hPa}$ (sombreado, em $10^{-5} \mathrm{~s}^{-1}$ ); (d) composições de imagens de satélites no infravermelho...

Figura 3.29: Dia 12/09/1999 às 12 UTC: (a) PNMM (linha contínua, em hPa) e VR em 1000 $\mathrm{hPa}$ (sombreado, em $10^{-5} \mathrm{~s}^{-1}$ ); (b) temperatura do ar a $2 \mathrm{~m}$ (sombreado, em ${ }^{\circ} \mathrm{C}$ ) e vento horizontal a $10 \mathrm{~m}$ (vetores, em m/s); (c) altura geopotencial em $500 \mathrm{hPa}$ (sombreado, em m) e VR em $500 \mathrm{hPa}$ (sombreado, em $10^{-5} \mathrm{~s}^{-1}$ ); (d) composições de imagens de satélites no infravermelho.

Figura 3.30: Dia 13/09/1999 às 12 UTC: (a) PNMM (linha contínua, em hPa) e VR em 1000 $\mathrm{hPa}$ (sombreado, em $10^{-5} \mathrm{~s}^{-1}$ ); (b) temperatura do ar a $2 \mathrm{~m}$ (sombreado, em ${ }^{\circ} \mathrm{C}$ ) e vento horizontal a $10 \mathrm{~m}$ (vetores, em m/s); (c) altura geopotencial em $500 \mathrm{hPa}$ (sombreado, em m) e VR em $500 \mathrm{hPa}$ (sombreado, em $10^{-5} \mathrm{~s}^{-1}$ ); (d) composições de imagens de satélites no infravermelho.

Figura 3.31: Dia 14/09/1999 às 12 UTC: (a) PNMM (linha contínua, em hPa) e VR em 1000 $\mathrm{hPa}$ (sombreado, em $10^{-5} \mathrm{~s}^{-1}$ ); (b) temperatura do ar a $2 \mathrm{~m}$ (sombreado, em ${ }^{\circ} \mathrm{C}$ ) e vento horizontal a $10 \mathrm{~m}$ (vetores, em m/s); (c) altura geopotencial em $500 \mathrm{hPa}$ (sombreado, em $\mathrm{m}$ ) e VR em $500 \mathrm{hPa}$ (sombreado, em $10^{-5} \mathrm{~s}^{-1}$ ); (d) composições de imagens de satélites no infravermelho.

Figura 3.32: Anomalia de alta frequência de (a, b) PNMM, (c, d) vento zonal e (e, f) vento meridional a $10 \mathrm{~m},(\mathrm{~g}, \mathrm{~h})$ temperatura do ar a $2 \mathrm{~m},(\mathrm{i}, \mathrm{j})$ altura geopotencial em $500 \mathrm{hPa},(\mathrm{k}, \mathrm{l})$ altura geopotencial e (m, n) vento zonal em $200 \mathrm{hPa}$ no lag $=-3(20 / 09 / 2005)$ e no lag $=0$ (23/09/2005) no evento ENGM.

Figura 3.33: Dia 20/09/2005 às 12 UTC: (a) PNMM (linha contínua, em hPa) e VR em 1000 $\mathrm{hPa}$ (sombreado, em $10^{-5} \mathrm{~s}^{-1}$ ); (b) temperatura do ar a $2 \mathrm{~m}$ (sombreado, em ${ }^{\circ} \mathrm{C}$ ) e vento horizontal a $10 \mathrm{~m}$ (vetores, em m/s); (c) altura geopotencial em $500 \mathrm{hPa}$ (sombreado, em m) e VR em $500 \mathrm{hPa}$ (sombreado, em $10^{-5} \mathrm{~s}^{-1}$ ); (d) composições de imagens de satélites no infravermelho.

Figura 3.34: Dia 21/09/2005 às 12 UTC: (a) PNMM (linha contínua, em hPa) e VR em 1000 $\mathrm{hPa}$ (sombreado, em $10^{-5} \mathrm{~s}^{-1}$ ); (b) temperatura do ar a $2 \mathrm{~m}$ (sombreado, em ${ }^{\circ} \mathrm{C}$ ) e vento horizontal a $10 \mathrm{~m}$ (vetores, em m/s); (c) altura geopotencial em $500 \mathrm{hPa}$ (sombreado, em m) e VR em $500 \mathrm{hPa}$ (sombreado, em $10^{-5} \mathrm{~s}^{-1}$ ); (d) composições de imagens de satélites no infravermelho. 
Figura 3.35: Dia 22/09/2005 às 12 UTC: (a) PNMM (linha contínua, em hPa) e VR em 1000 $\mathrm{hPa}$ (sombreado, em $10^{-5} \mathrm{~s}^{-1}$ ); (b) temperatura do ar a $2 \mathrm{~m}$ (sombreado, em ${ }^{\circ} \mathrm{C}$ ) e vento horizontal a $10 \mathrm{~m}$ (vetores, em m/s); (c) altura geopotencial em $500 \mathrm{hPa}$ (sombreado, em $\mathrm{m}$ ) e VR em $500 \mathrm{hPa}$ (sombreado, em $10^{-5} \mathrm{~s}^{-1}$ ); (d) composições de imagens de satélites no infravermelho.

Figura 3.36: Dia 23/09/2005 às 12 UTC: (a) PNMM (linha contínua, em hPa) e VR em 1000 $\mathrm{hPa}$ (sombreado, em $10^{-5} \mathrm{~s}^{-1}$ ); (b) temperatura do ar a $2 \mathrm{~m}$ (sombreado, em ${ }^{\circ} \mathrm{C}$ ) e vento horizontal a $10 \mathrm{~m}$ (vetores, em m/s); (c) altura geopotencial em $500 \mathrm{hPa}$ (sombreado, em m) e VR em $500 \mathrm{hPa}$ (sombreado, em $10^{-5} \mathrm{~s}^{-1}$ ); (d) composições de imagens de satélites no infravermelho.

Figura 3.37: Anomalia de alta frequência de (a, b) PNMM, (c, d) vento zonal e (e, f) vento meridional a $10 \mathrm{~m},(\mathrm{~g}, \mathrm{~h})$ temperatura do ar a $2 \mathrm{~m},(\mathrm{i}, \mathrm{j})$ altura geopotencial em $500 \mathrm{hPa},(\mathrm{k}, \mathrm{l})$ altura geopotencial e $(\mathrm{m}, \mathrm{n})$ vento zonal em $200 \mathrm{hPa}$ no lag $=-3(17 / 09 / 1997)$ e no lag $=0$ (20/09/1997) no evento EPGM.

Figura 3.38: Dia 17/09/1997 às 12 UTC: (a) PNMM (linha contínua, em hPa) e VR em 1000 $\mathrm{hPa}$ (sombreado, em $10^{-5} \mathrm{~s}^{-1}$ ); (b) temperatura do ar a $2 \mathrm{~m}$ (sombreado, em ${ }^{\circ} \mathrm{C}$ ) e vento horizontal a $10 \mathrm{~m}$ (vetores, em m/s); (c) altura geopotencial em $500 \mathrm{hPa}$ (sombreado, em m) e VR em $500 \mathrm{hPa}$ (sombreado, em $10^{-5} \mathrm{~s}^{-1}$ ); (d) composições de imagens de satélites no infravermelho. .88

Figura 3.39: Dia 18/09/1997 às 12 UTC: (a) PNMM (linha contínua, em hPa) e VR em 1000 $\mathrm{hPa}$ (sombreado, em $10^{-5} \mathrm{~s}^{-1}$ ); (b) temperatura do ar a $2 \mathrm{~m}$ (sombreado, em ${ }^{\circ} \mathrm{C}$ ) e vento horizontal a $10 \mathrm{~m}$ (vetores, em m/s); (c) altura geopotencial em $500 \mathrm{hPa}$ (sombreado, em m) e VR em $500 \mathrm{hPa}$ (sombreado, em $10^{-5} \mathrm{~s}^{-1}$ ); (d) composições de imagens de satélites no infravermelho.

Figura 3.40: Dia 19/09/1997 às 12 UTC: (a) PNMM (linha contínua, em hPa) e VR em 1000 $\mathrm{hPa}$ (sombreado, em $10^{-5} \mathrm{~s}^{-1}$ ); (b) temperatura do ar a $2 \mathrm{~m}$ (sombreado, em ${ }^{\circ} \mathrm{C}$ ) e vento horizontal a $10 \mathrm{~m}$ (vetores, em m/s); (c) altura geopotencial em $500 \mathrm{hPa}$ (sombreado, em m) e VR em $500 \mathrm{hPa}$ (sombreado, em $10^{-5} \mathrm{~s}^{-1}$ ); (d) composições de imagens de satélites no infravermelho.

Figura 3.41: Dia 26/09/1997 às 12 UTC: (a) PNMM (linha contínua, em hPa) e VR em 1000 $\mathrm{hPa}$ (sombreado, em $10^{-5} \mathrm{~s}^{-1}$ ); (b) temperatura do ar a $2 \mathrm{~m}$ (sombreado, em ${ }^{\circ} \mathrm{C}$ ) e vento horizontal a $10 \mathrm{~m}$ (vetores, em m/s); (c) altura geopotencial em $500 \mathrm{hPa}$ (sombreado, em m) e VR em $500 \mathrm{hPa}$ (sombreado, em $10^{-5} \mathrm{~s}^{-1}$ ); (d) composições de imagens de satélites no infravermelho.

Figura 3.42: Anomalia de alta frequência de (a, b) PNMM, (c, d) vento zonal e (e, f) vento meridional a $10 \mathrm{~m},(\mathrm{~g}, \mathrm{~h})$ temperatura do ar a $2 \mathrm{~m},(\mathrm{i}, \mathrm{j})$ altura geopotencial em $500 \mathrm{hPa},(\mathrm{k}, \mathrm{l})$ altura geopotencial e $(\mathrm{m}, \mathrm{n})$ vento zonal em $200 \mathrm{hPa}$ no lag $=-3(14 / 09 / 1999)$ e no lag $=0$ (17/09/1999) no evento EPGM.

Figura 3.43: Dia 14/09/1999 às 12 UTC: (a) PNMM (linha contínua, em hPa) e VR em 1000 $\mathrm{hPa}$ (sombreado, em $10^{-5} \mathrm{~s}^{-1}$ ); (b) temperatura do ar a $2 \mathrm{~m}$ (sombreado, em ${ }^{\circ} \mathrm{C}$ ) e vento horizontal a $10 \mathrm{~m}$ (vetores, em m/s); (c) altura geopotencial em $500 \mathrm{hPa}$ (sombreado, em m) e VR em $500 \mathrm{hPa}$ (sombreado, em $10^{-5} \mathrm{~s}^{-1}$ ); (d) composições de imagens de satélites no infravermelho.

Figura 3.44: Dia 15/09/1999 às 12 UTC: (a) PNMM (linha contínua, em hPa) e VR em 1000 $\mathrm{hPa}$ (sombreado, em $10^{-5} \mathrm{~s}^{-1}$ ); (b) temperatura do ar a $2 \mathrm{~m}$ (sombreado, em ${ }^{\circ} \mathrm{C}$ ) e vento horizontal a $10 \mathrm{~m}$ (vetores, em m/s); (c) altura geopotencial em $500 \mathrm{hPa}$ (sombreado, em m) e 
VR em $500 \mathrm{hPa}$ (sombreado, em $10^{-5} \mathrm{~s}^{-1}$ ); (d) composições de imagens de satélites no infravermelho..

Figura 3.45: Dia 16/09/1999 às 12 UTC: (a) PNMM (linha contínua, em hPa) e VR em 1000 $\mathrm{hPa}$ (sombreado, em $10^{-5} \mathrm{~s}^{-1}$ ); (b) temperatura do ar a $2 \mathrm{~m}$ (sombreado, em ${ }^{\circ} \mathrm{C}$ ) e vento horizontal a $10 \mathrm{~m}$ (vetores, em m/s); (c) altura geopotencial em $500 \mathrm{hPa}$ (sombreado, em m) e VR em $500 \mathrm{hPa}$ (sombreado, em $10^{-5} \mathrm{~s}^{-1}$ ); (d) composições de imagens de satélites no infravermelho.

Figura 3.46: Dia 17/09/1999 às 12 UTC: (a) PNMM (linha contínua, em hPa) e VR em 1000 $\mathrm{hPa}$ (sombreado, em $10^{-5} \mathrm{~s}^{-1}$ ); (b) temperatura do ar a $2 \mathrm{~m}$ (sombreado, em ${ }^{\circ} \mathrm{C}$ ) e vento horizontal a $10 \mathrm{~m}$ (vetores, em m/s); (c) altura geopotencial em $500 \mathrm{hPa}$ (sombreado, em m) e VR em $500 \mathrm{hPa}$ (sombreado, em $10^{-5} \mathrm{~s}^{-1}$ ); (d) composições de imagens de satélites no infravermelho.

Figura 3.47: Anomalia de alta frequência de (a, b) PNMM, (c, d) vento zonal e (e, f) vento meridional a $10 \mathrm{~m},(\mathrm{~g}, \mathrm{~h})$ temperatura do ar a $2 \mathrm{~m},(\mathrm{i}, \mathrm{j})$ altura geopotencial em $500 \mathrm{hPa},(\mathrm{k}, \mathrm{l})$ altura geopotencial e $(\mathrm{m}, \mathrm{n})$ vento zonal em $200 \mathrm{hPa}$ no lag $=-3(24 / 09 / 2000)$ e no lag $=0$ (27/09/2000) no evento EPGM.

Figura 3.48: Dia 24/09/2000 às 12 UTC: (a) PNMM (linha contínua, em hPa) e VR em 1000 $\mathrm{hPa}$ (sombreado, em $10^{-5} \mathrm{~s}^{-1}$ ); (b) temperatura do ar a $2 \mathrm{~m}$ (sombreado, em ${ }^{\circ} \mathrm{C}$ ) e vento horizontal a $10 \mathrm{~m}$ (vetores, em m/s); (c) altura geopotencial em $500 \mathrm{hPa}$ (sombreado, em m) e VR em $500 \mathrm{hPa}$ (sombreado, em $10^{-5} \mathrm{~s}^{-1}$ ); (d) composições de imagens de satélites no infravermelho.

Figura 3.49: Dia 25/09/2000 às 12 UTC: (a) PNMM (linha contínua, em hPa) e VR em 1000 $\mathrm{hPa}$ (sombreado, em $10^{-5} \mathrm{~s}^{-1}$ ); (b) temperatura do ar a $2 \mathrm{~m}$ (sombreado, em ${ }^{\circ} \mathrm{C}$ ) e vento horizontal a $10 \mathrm{~m}$ (vetores, em m/s); (c) altura geopotencial em $500 \mathrm{hPa}$ (sombreado, em m) e VR em $500 \mathrm{hPa}$ (sombreado, em $10^{-5} \mathrm{~s}^{-1}$ ); (d) composições de imagens de satélites no infravermelho.

Figura 3.50: Dia 26/09/2000 às 12 UTC: (a) PNMM (linha contínua, em hPa) e VR em 1000 $\mathrm{hPa}$ (sombreado, em $10^{-5} \mathrm{~s}^{-1}$ ); (b) temperatura do ar a $2 \mathrm{~m}$ (sombreado, em ${ }^{\circ} \mathrm{C}$ ) e vento horizontal a $10 \mathrm{~m}$ (vetores, em m/s); (c) altura geopotencial em $500 \mathrm{hPa}$ (sombreado, em m) e VR em $500 \mathrm{hPa}$ (sombreado, em $10^{-5} \mathrm{~s}^{-1}$ ); (d) composições de imagens de satélites no infravermelho.

Figura 3.51: Dia 27/09/2000 às 12 UTC: (a) PNMM (linha contínua, em hPa) e VR em 1000 $\mathrm{hPa}$ (sombreado, em $10^{-5} \mathrm{~s}^{-1}$ ); (b) temperatura do ar a $2 \mathrm{~m}$ (sombreado, em ${ }^{\circ} \mathrm{C}$ ) e vento horizontal a $10 \mathrm{~m}$ (vetores, em m/s); (c) altura geopotencial em $500 \mathrm{hPa}$ (sombreado, em m) e VR em $500 \mathrm{hPa}$ (sombreado, em $10^{-5} \mathrm{~s}^{-1}$ ); (d) composições de imagens de satélites no infravermelho. 103

Figura 3.52: Composições defasadas das anomalias interanuais de PNMM (hPa) durante os eventos (a) ENGM e (b) EPGM no setor dos MBA, no lag $=-365$, lag $=-183$, lag $=0$ e lag $=+183$, no período de inverno austral (1989-2007) 107

Figura 3.53: Similar à Figura 3.52, mas para as anomalias interanuais de vento zonal a $10 \mathrm{~m}$ $(\mathrm{m} / \mathrm{s})$ 108

Figura 3.54: Similar à Figura 3.52, mas para as anomalias interanuais de vento meridional a $10 \mathrm{~m}(\mathrm{~m} / \mathrm{s})$..... 109

Figura 3.55: Similar à Figura 3.52, mas para as anomalias interanuais de temperatura do ar a $2 \mathrm{~m}\left({ }^{\circ} \mathrm{C}\right)$. 
Figura 3.56: Composições defasadas das anomalias interanuais de PNMM (hPa) durante os eventos (a) ENGM e (b) EPGM no setor do MW, no lag $=-365$, lag $=-183$, lag $=0$ e lag $=+183$, no período de inverno austral (1989-2007).

Figura 3.57: Similar à Figura 3.56, mas para as anomalias interanuais de vento zonal a $10 \mathrm{~m}$ $(\mathrm{m} / \mathrm{s})$.

Figura 3.58: Similar à Figura 3.56, mas para as anomalias interanuais de vento meridional a $10 \mathrm{~m}(\mathrm{~m} / \mathrm{s})$.

Figura 3.59: Similar à Figura 3.56, mas para as anomalias interanuais de temperatura do ar a $2 \mathrm{~m}\left({ }^{\circ} \mathrm{C}\right)$.

Figura 3.60: Composições defasadas das anomalias interanuais de PNMM (hPa) durante os eventos (a) ENGM e (b) EPGM no setor dos MBA, no lag $=-365$, lag $=-183$, lag $=0$ e lag $=+183$, no período de verão austral (1989-2007) 119

Figura 3.61: Similar à Figura 3.60, mas para as anomalias interanuais de vento zonal a $10 \mathrm{~m}$ $(\mathrm{m} / \mathrm{s})$

Figura 3.62: Similar à Figura 3.60, mas para as anomalias interanuais de vento meridional a $10 \mathrm{~m}(\mathrm{~m} / \mathrm{s})$

Figura 3.63: Similar à Figura 3.60, mas para as anomalias interanuais de temperatura do ar a $2 \mathrm{~m}\left({ }^{\circ} \mathrm{C}\right)$.

Figura 3.64: Composições defasadas das anomalias interanuais de PNMM (hPa) durante os eventos (a) ENGM e (b) EPGM no setor do MW, no período de verão (1989-2007), para (a) lag $=-365$, (b) lag $=-183$, (c) lag $=0$ e (d) lag $=+183$.

Figura 3.65: Similar à Figura 3.64, mas para as anomalias interanuais de vento zonal a $10 \mathrm{~m}$ $(\mathrm{m} / \mathrm{s})$.

Figura 3.66: Similar à Figura 3.64, mas para as anomalias interanuais de vento meridional a $10 \mathrm{~m}(\mathrm{~m} / \mathrm{s})$.

Figura 3.67: Similar à Figura 3.64, mas para as anomalias interanuais de temperatura do ar a $2 \mathrm{~m}\left({ }^{\circ} \mathrm{C}\right)$.

Figura 3.68: Composições de (a) densidade [número de sistemas por $10^{3}$ ( ${ }^{\circ}$ lat $)^{-2}$ ], (b) profundidade $(\mathrm{hPa})$ e (c) raio $\left({ }^{\circ}\right.$ lat) dos ciclones, entre os cinco meses com maiores anomalias interanuais negativas menos os cinco meses com maiores anomalias interanuais positivas de gelo marinho no setor dos MBA, nos meses de julho, agosto e setembro......

Figura 3.69: Composições de (a) densidade [número de sistemas por $10^{3}\left({ }^{\circ} \text { lat }\right)^{-2}$ ], (b) profundidade $(\mathrm{hPa})$ e (c) raio $\left({ }^{\circ}\right.$ lat) dos ciclones, entre os cinco meses com maiores anomalias interanuais negativas menos os cinco meses com maiores anomalias interanuais positivas de gelo marinho no setor do MW, nos meses de julho, agosto e setembro.

Figura 3.70: Composições de (a) densidade [número de sistemas por $10^{3}\left({ }^{\circ} \text { lat }\right)^{-2}$ ], (b) profundidade $(\mathrm{hPa})$ e (c) raio $\left({ }^{\circ}\right.$ lat) dos ciclones, entre os cinco meses com maiores anomalias interanuais negativas menos os cinco meses com maiores anomalias interanuais positivas de gelo marinho no setor dos MBA, nos meses de janeiro, fevereiro e março..

Figura 3.71: Composições de (a) densidade [número de sistemas por $10^{3}\left({ }^{\circ} \text { lat }\right)^{-2}$ ], (b) profundidade $(\mathrm{hPa})$ e (c) raio $\left({ }^{\circ}\right.$ lat) dos ciclones, entre os cinco meses com maiores anomalias interanuais negativas menos os cinco meses com maiores anomalias interanuais positivas de gelo marinho no setor do MW, nos meses de janeiro, fevereiro e março. 


\section{LISTA DE TABELAS}

Tabela 2.1 - ENGM e EPGM de alta frequência e interanual, nos setores dos MBA e do MW, nas estações de verão e inverno austral

Tabela 2.2 - Mês/anos utilizados para as composições de densidade, profundidade e raio dos ciclones entre as cinco maiores anomalias interanuais negativas menos as cinco maiores anomalias interanuais positivas de extensão de gelo marinho para o setor dos MBA.

Tabela 2.3 - Mês/anos utilizados para as composições de densidade, profundidade e raio dos ciclones entre as cinco maiores anomalias interanuais negativas menos as cinco maiores anomalias interanuais positivas de extensão de gelo marinho para o setor do MW

Tabela 2.4 - Casos selecionados para o estudo de casos no setor dos MBA em fases de El Niño, La Niña e Neutro em eventos ENGM e EPGM no mês de setembro. 


\section{LISTA DE ABREVIATURAS E SIGLAS}

\begin{tabular}{|c|c|}
\hline CPTEC & Centro de Previsão de Tempo e Estudos Climáticos \\
\hline DPA & Dipolo Antártico \\
\hline ECMWF & European Centre for Medium-Range Weather Forecasts \\
\hline ENGM & Extremos negativos de gelo marinho \\
\hline ENSO & El Niño Oscilação Sul \\
\hline EOF & Empirical Orthogonal Function \\
\hline EPGM & Extremos positivos de gelo marinho \\
\hline ESRL & Earth System Research Laboratory \\
\hline FFT & Fast Fourier Transform \\
\hline FPA & Frente Polar Antártica \\
\hline HS & Hemisfério Sul \\
\hline INPE & Instituto Nacional de Pesquisas Espaciais \\
\hline MBA & Mares de Bellingshausen-Amundsen \\
\hline MCGA & Modelo de Circulação Geral da Atmosfera \\
\hline MW & Mar de Weddell \\
\hline NOAA & National Oceanic and Atmospheric Administration \\
\hline NSIDC & National Snow and Ice Data Center \\
\hline OAR & Office of Oceanic and Atmospheric Research \\
\hline $\mathrm{PF}$ & Profundidade de ciclones \\
\hline PNMM & Pressão ao nível médio do mar \\
\hline PSA & Pacific-South American \\
\hline PSD & Physical Sciences Division \\
\hline $\mathrm{q} 25$ & Primeiro quartil \\
\hline $\mathrm{q} 75$ & Terceiro quartil \\
\hline
\end{tabular}


Raio de ciclones

SMMR

Scanning Multichannel Microwave Radiometer

SSEC Space Science and Engineering Center

SSM/I Special Sensor Microwave/Imager

TSM Temperatura da superfície do mar

VR Vorticidade relativa 


\section{SUMÁRIO}

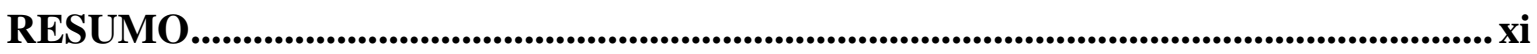

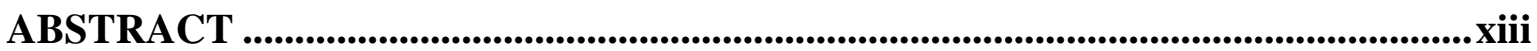

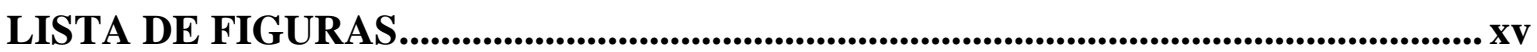

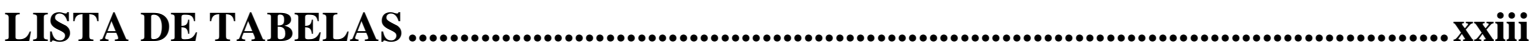

LISTA DE ABREVIATURAS E SIGLAS ............................................................

Capítulo 1: Introdução........................................................................................................................ 1

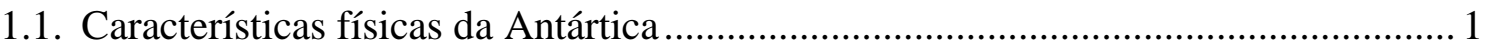

1.1.1 A influência da Antártica no sistema climático global .................................... 1

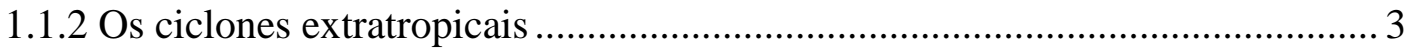

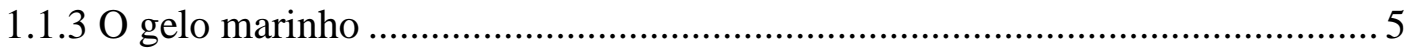

1.1.4 Interação entre os ciclones extratropicais e o gelo marinho antártico .............. 8

1.1.5 Modos de variabilidade climática ............................................................... 12

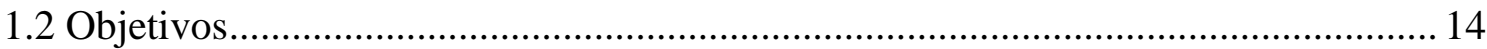

Capítulo 2: Dados e Metodologia ....................................................................................17

2.1 Dados

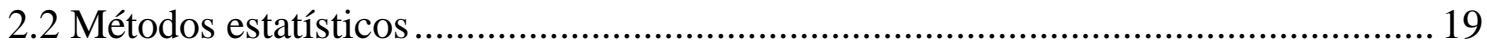

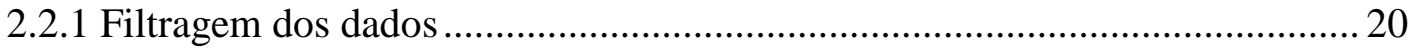

2.2.2 Análise de extremos e persistência ................................................................ 26

2.3 Algoritmo de identificação e rastreamento de ciclones ........................................... 32

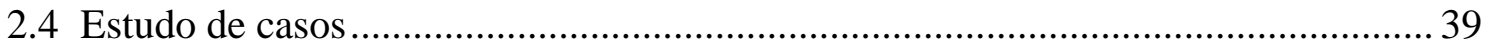

Capítulo 3: Resultados e discussão ............................................................................................. 41

3.1 Desvio padrão das anomalias de alta frequência ..................................................... 41

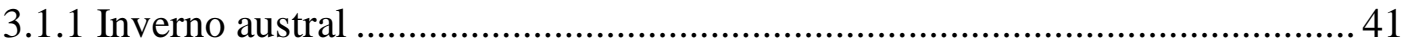

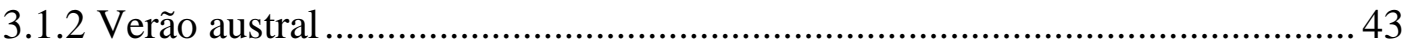


3.2 Extremos de gelo marinho associados à circulação atmosférica na escala de alta

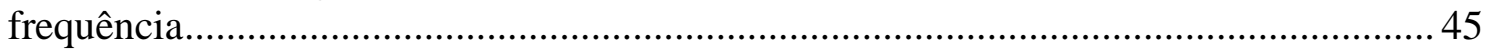

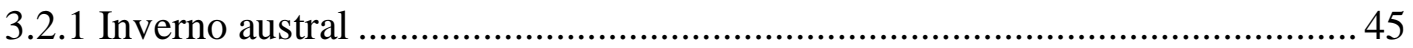

3.2.1.1 Setor dos Mares de Bellingshausen-Amundsen ............................... 45

3.2.1.2 Setor do Mar de Weddell ................................................................... 51

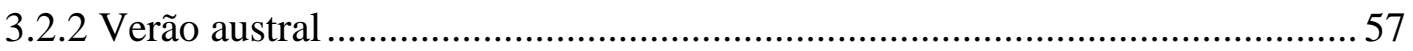

3.2.2.1 Setor dos Mares de Bellingshausen-Amundsen ................................57

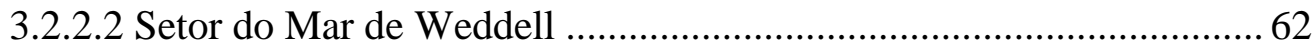

3.3 Análise sinótica dos eventos extremos de gelo marinho em fases distintas do fenômeno El Niño: estudo de casos no setor dos mares de Bellingshausen-Amundsen

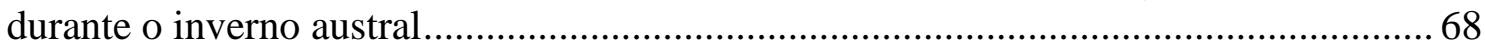

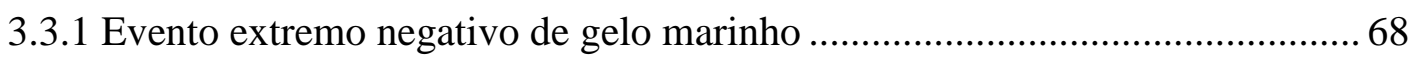

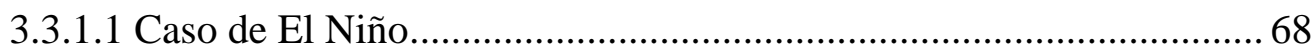

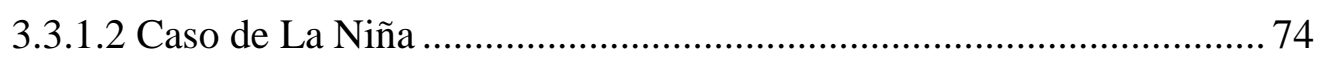

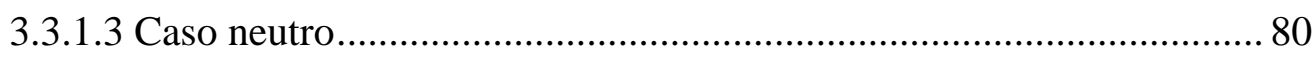

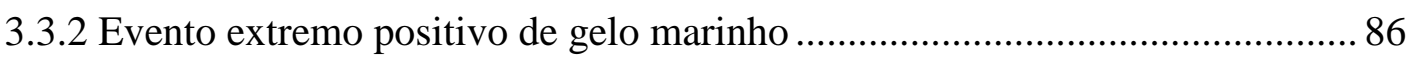

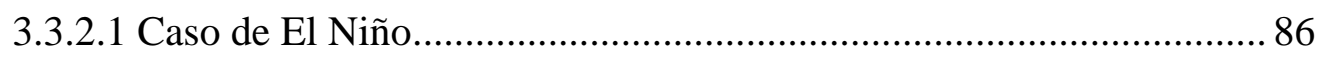

3.3.2.2 Caso de La Niña .................................................................... 92

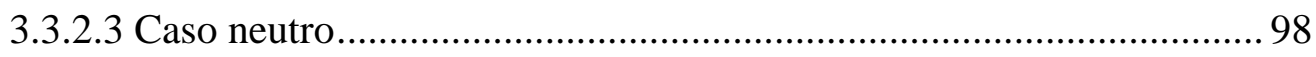

3.4 Extremos de gelo marinho associados à circulação atmosférica na escala

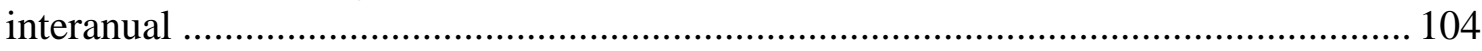

3.4.1 Inverno austral: Setor dos Mares de Bellingshausen-Amundsen ................. 104

3.4.2 Inverno austral: Setor do Mar de Weddell................................................. 111

3.4.3 Verão austral: Setor dos Mares de Bellingshausen-Amundsen .................... 117

3.4.4 Verão austral: Setor do Mar de Weddell .................................................... 123

3.5 Atividade ciclônica associada à variabilidade interanual da extensão do gelo

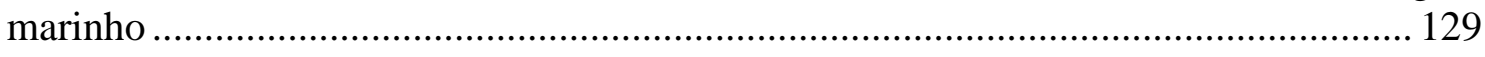

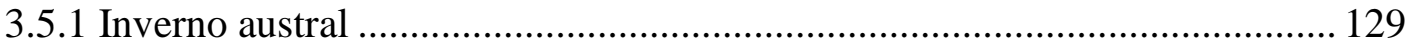

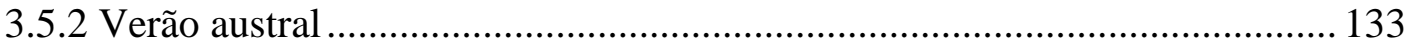

Capítulo 4: Conclusões...................................................................................................................... 139

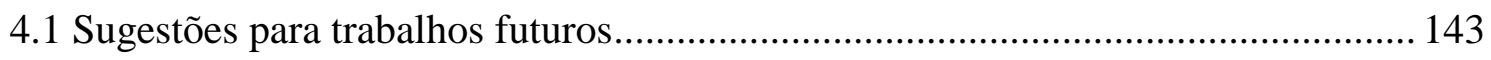

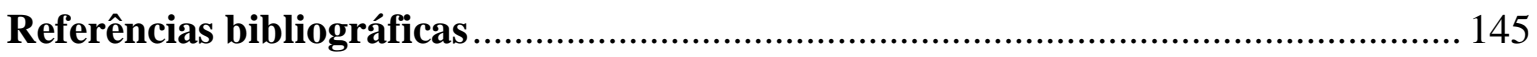




\section{Capítulo 1: Introdução}

\subsection{Características físicas da Antártica}

\subsubsection{A influência da Antártica no sistema climático global}

Embora a Antártica seja a região mais remota e inacessível do globo, o continente está fortemente relacionado com as condições climáticas, meteorológicas e oceanográficas principalmente do Hemisfério Sul (HS, KING; TURNER, 1997). A atmosfera da região antártica perde mais calor por resfriamento radiativo do que ganha por trocas de energia em superfície. Isso porque a presença de neve e gelo origina um feedback fortemente positivo, aumentando o resfriamento nas altas latitudes por refletir mais radiação solar (50-90\%) do que as superfícies com rocha exposta (4-15\%) e oceânicas (10\%) (KING; TURNER, 1997; WADHAMS, 2000). Esse déficit de energia tem que ser balanceado pelo transporte de calor oriundo das latitudes médias, o que é amplamente realizado pela circulação meridional média atmosférica e oceânica. Desta forma, a circulação de grande escala é fortemente forçada pelo balanço de energia (KING; TURNER, 1997).

A região antártica (Figura 1.1) possui características físico-geográficas peculiares. A Antártica possui $99,6 \%$ de sua área coberta por gelo, com um volume aproximado de $30 \times 10^{6} \mathrm{~km}^{3}$, o que corresponde a $90 \%$ do gelo do planeta. Assim, se todo o gelo da Antártica derretesse, o nível médio dos oceanos aumentaria em 65 m (KING; TURNER, 1997). A Antártica é também o continente mais elevado do globo, com uma altitude média de $2.500 \mathrm{~m}$, superando $4.000 \mathrm{~m}$ no platô antártico. Sua área é de $13,6 \times 10^{6} \mathrm{~km}^{2}$, equivalente a cerca de 1,6 vezes a área do Brasil, sendo rodeada pelo Oceano Austral, que é o principal meio pelo qual ocorrem as trocas de energia, calor e massa entre os oceanos Atlântico, Pacífico e Índico (SCAR, 2009). Além disso, o Oceano Austral desempenha um papel importante no ciclo de carbono global. A ressurgência de águas profundas ao sul da Frente Polar Antártica (FPA, cf. seção 1.1.2) traz para a superfície os nutrientes dissolvidos e o dióxido de carbono,

liberando esse gás para a atmosfera. Por outro lado, as massas de Água Intermediária submergem ao norte da FPA, retirando o dióxido de carbono da atmosfera. Estes processos 
fazem com que o Oceano Austral atue como uma fonte e um sumidouro de dióxido de carbono atmosférico (SABINE et al., 2004).

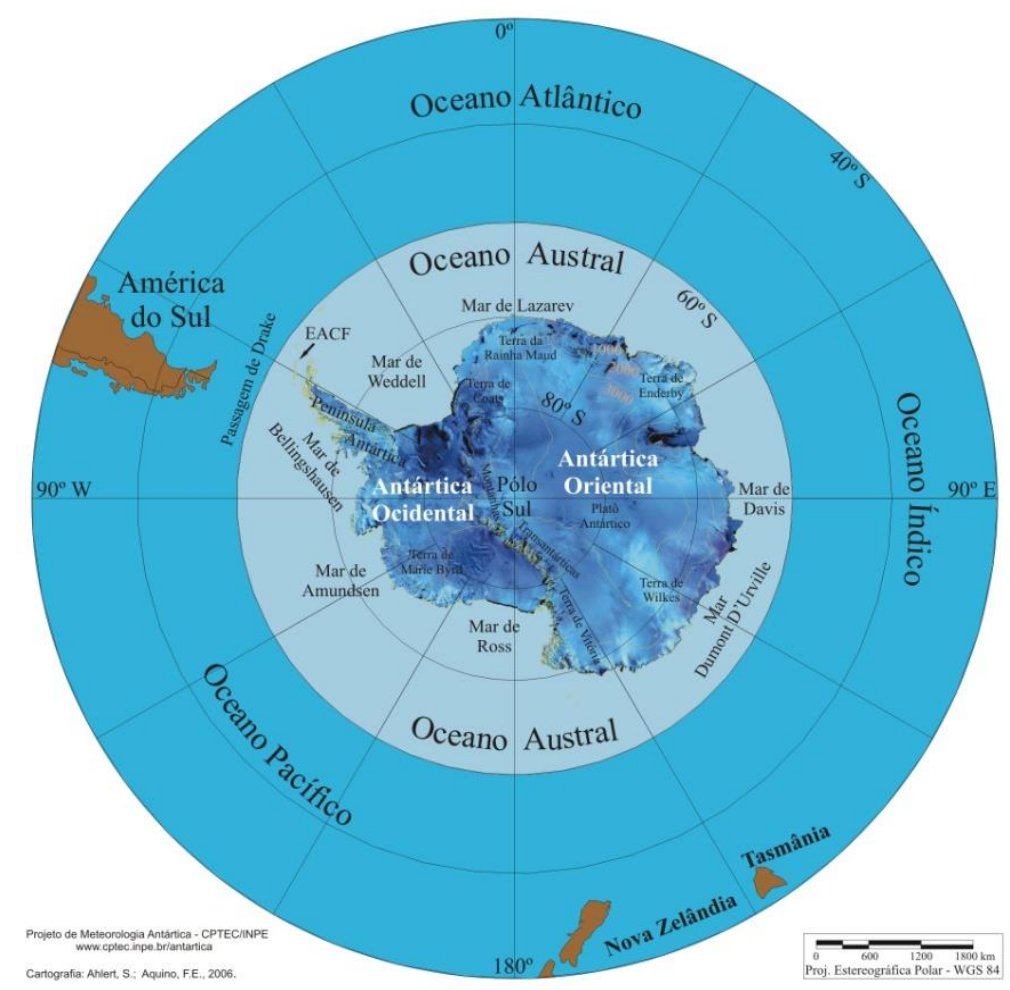

Figura 1.1: Mapa da Antártica enfatizando os mares que a circundam, suas principais regiões e sua posição centrada no polo sul geográfico da Terra (AHLERT; AQUINO, 2009).

Sobre toda a Antártica, um centro de alta pressão, formado pelo braço descendente da Célula Polar (Figura 1.2a), gera uma circulação na baixa atmosfera denominada de ventos catabáticos (Figura 1.2b). Os ventos catabáticos são observados em muitas regiões das latitudes médias, mas geralmente são considerados fenômenos da camada limite ou de mesoescala, tendo em vista que eles ocorrem à noite e sobre terrenos inclinados. Na Antártica, as extensas superfícies inclinadas e o resfriamento ininterrupto da superfície por muitos anos permitem o desenvolvimento da circulação catabática em grande escala. Os fluxos de massa de sul pelos ventos catabáticos é compensado pela subsidência na média troposfera que, por sua vez, implica em convergência horizontal em superfície. Assim, ar frio é exportado dos baixos níveis, enquanto ar aquecido é advectado das latitudes médias em direção a Antártica pelos altos níveis, havendo subsidência sobre o continente (KING; TURNER, 1997; RIFFENBURGH, 2007). A intensidade dos ventos catabáticos é proporcional à inclinação do terreno subjacente e, assim, os ventos mais intensos são encontrados próximos às regiões íngremes, como é o caso da Antártica Oriental. Estes ventos possuem velocidades variando 
entre 5 e $10 \mathrm{~m} \mathrm{~s}^{-1}$ no interior do continente e adquirem forte componente de leste próximo à costa devido à deflexão de Coriolis (KING; TURNER, 1997; BROMWICH; PARISH, 1998).

(a)

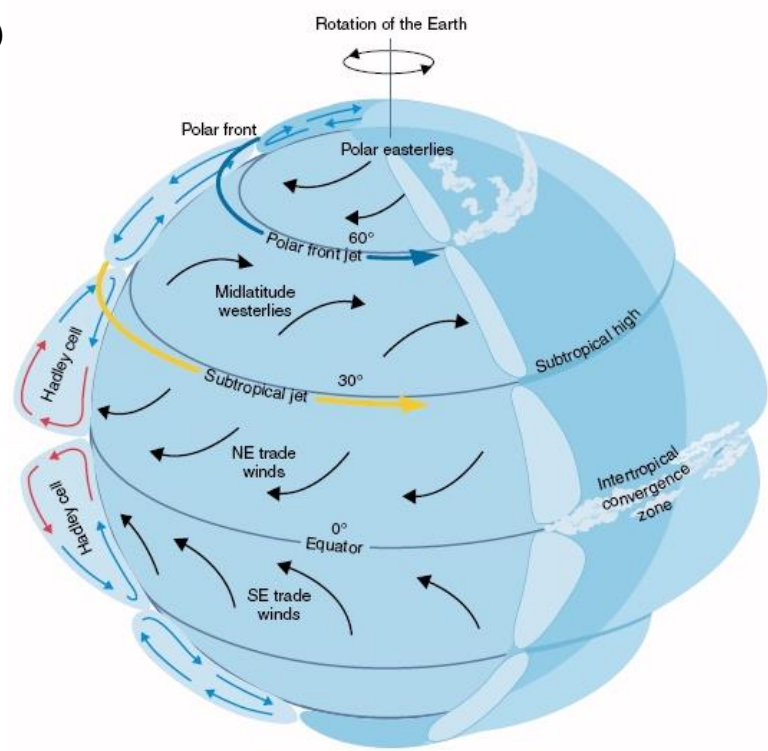

(b)

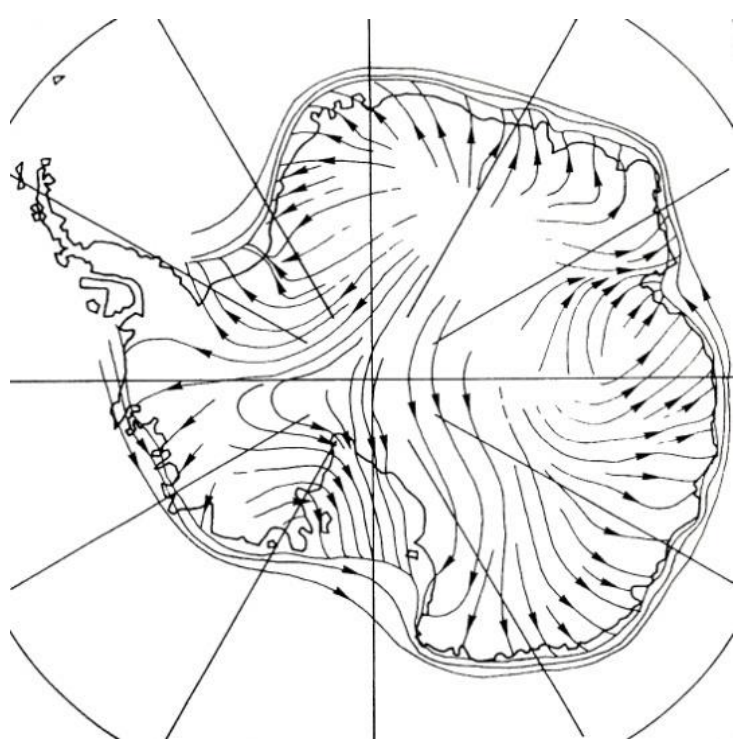

Figura 1.2: (a) Modelo de circulação geral da atmosfera, em que se destaca a célula de circulação polar sobre as altas latitudes (CIMSS, 2011); (b) Escoamento médio em superfície sobre a Antártica, em que se observam os ventos catabáticos, com forte componente de leste próximo à costa (KING; TURNER, 1997).

A orografia assimétrica do continente em relação ao polo sul geográfico propicia a formação de ondas de Rossby, as quais modificam a estrutura do escoamento em altos níveis, modulam as características dos sistemas sinóticos e, por consequência, afetam a circulação nas médias latitudes ao propagarem-se para norte. Esta ondulação origina-se em uma zona de contato entre o ar frio polar e o ar quente tropical, modulada pela corrente de jato polar, promovendo a troca de massas de ar subtropicais e polares a partir do transporte de ciclones e anticiclones extratropicais migratórios, que se formam nas latitudes médias ao redor do continente antártico no cinturão circumpolar de baixas pressões (KING; TURNER, 1997).

\subsubsection{Os ciclones extratropicais}

Os ciclones extratropicais são os principais sistemas atmosféricos de escala sinótica encontrados na região costeira da Antártica e sobre o Oceano Austral, possuindo papel importante na circulação geral da atmosfera e no sistema acoplado atmosfera-oceano-gelo nas altas latitudes (KING; TURNER, 1997). Além disso, são responsáveis por grande parte dos fluxos de umidade e de energia em direção ao polo através do transporte de calor latente e 
sensível, agindo para reduzir o gradiente de temperatura equador-polo, o qual é mantido por forçantes radiativas (RADOK; STRETEN; WELLER, 1975; PHYSICK, 1981; KING; TURNER, 1997). Os ciclones extratropicais possuem núcleo frio e são assimétricos, apresentando uma extensão na ordem de 1.000 a $6.000 \mathrm{~km}$ e um tempo de vida de um dia a uma semana na região antártica (BJERKNES; SOLBERG, 1922; KING; TURNER, 1997). A distância percorrida pelos ciclones mostra uma ampla distribuição e uma considerável fração de sistemas que deslocam-se a distâncias superiores a $5.000 \mathrm{~km}$. A trajetória média é de $2.315 \mathrm{~km}$ no inverno e de $1.946 \mathrm{~km}$ no verão (SIMMONDS; KEAY, 2000a). O deslocamento médio dos ciclones é predominantemente para leste nas altas latitudes, embora vários sistemas apresentem uma tendência de movimento em direção ao polo e alguns poucos exibem um movimento para o oeste, particularmente no lado sul da região de trajetórias de tempestades ou storm tracks (JONES; SIMMONDS, 1993), assim chamadas por serem os caminhos preferenciais de propagação de ondas baroclínicas (BERBERY; VERA, 1996).

No HS a maior mudança na temperatura troposférica meridional ocorre na FPA, separando as massas de ar tropicais e as massas de ar polares. A FPA é também uma zona de transição entre as correntes frias do Oceano Austral e as águas mais aquecidas vindas de norte (CCAMLR, 2008). Essa confluência é marcada por uma zona fortemente baroclínica, com fortes gradientes meridionais de temperatura do ar, de $3^{\circ}$ a $8^{\circ} \mathrm{C}$ no verão e de $1^{\circ}$ a $5^{\circ} \mathrm{C}$ no inverno. A posição da FPA possui variações em torno do globo entre as latitudes de $47^{\circ} \mathrm{e}$ $61^{\circ} \mathrm{S}$. Deste modo, a FPA é uma das principais regiões para o desenvolvimento de ciclones extratropicais do HS. Outra área de significativo contraste térmico é a região costeira da Antártica, onde o ar frio do interior do continente se encontra com a massa de ar marítima mais aquecida (BJERKNES, 1919; BERBERY; VERA, 1996; KING; TURNER, 1997).

Evidentemente as características dos ciclones em superfície estão intimamente associadas com a pressão ao nível médio do mar (PNMM). Sobre o Oceano Austral e adjacências os menores valores de PNMM estão concentrados ao sul de $60^{\circ} \mathrm{S}$ até a borda do continente antártico (Figura 1.3), que corresponde ao cinturão circumpolar de baixas pressões, região de intensa atividade ciclônica (JONES; SIMMONDS, 1993; SIMMONDS; KEAY, 2000a; SIMMONDS; KEAY; LIM, 2003). Climatologicamente, três centros de baixa pressão são observados durante todo o ano, localizados em cerca de $20^{\circ} \mathrm{E}, 90^{\circ} \mathrm{E}$ e $150^{\circ} \mathrm{W}$ (KING; TURNER, 1997). No verão os menores valores são observados na Antártica Ocidental e sobre os mares de Ross, Bellingshausen e Amundsen, com PNMM de 985 hPa (Figura 1.3a). No inverno, a PNMM mínima de 980 hPa é encontrada na região leste do mar de Ross e sobre os 
mares Dumont D`Urville e de Davis (Figura 1.3b). Assim, a PNMM ao redor da Antártica é predominantemente menor durante o inverno (SIMMONDS; KEAY; LIM, 2003).

a)

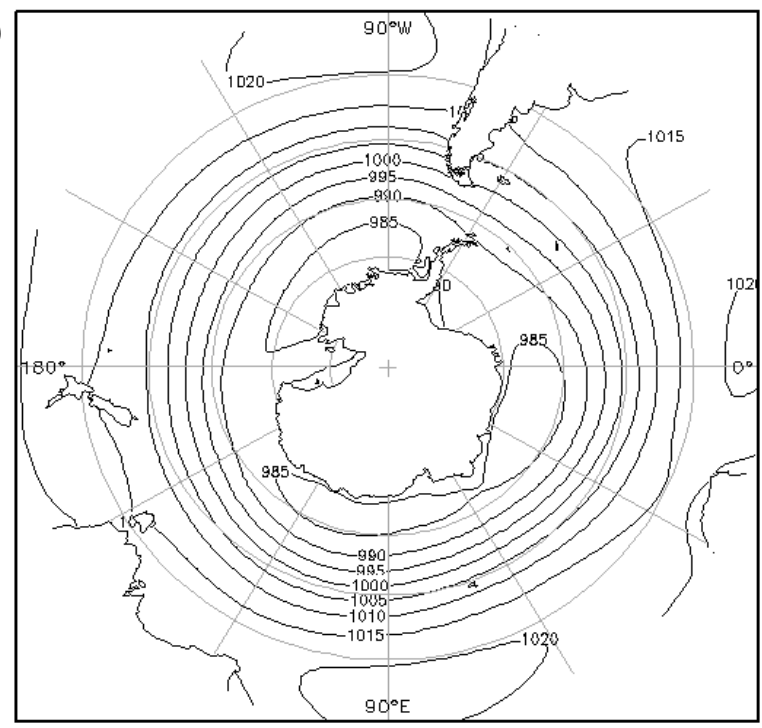

b)

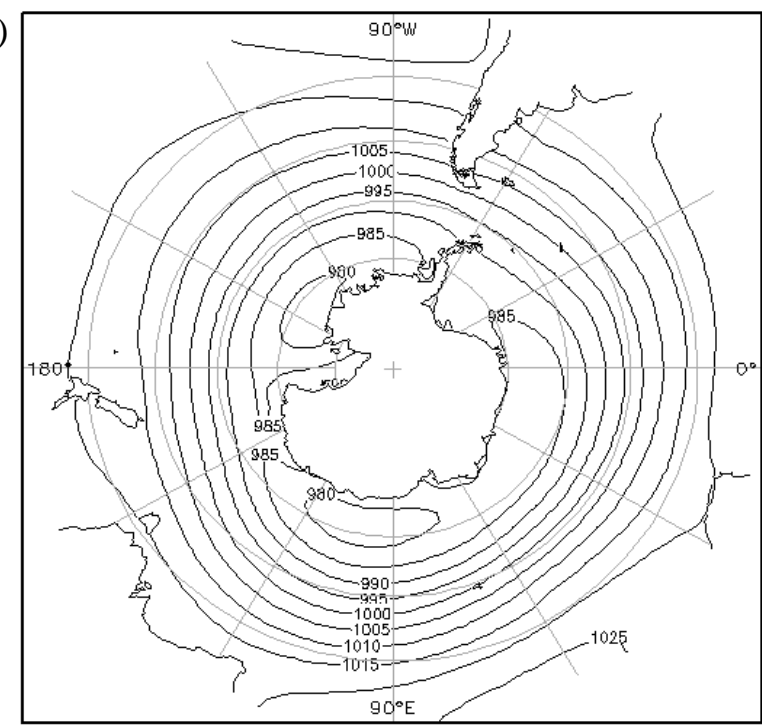

Figura 1.3: Climatologia da PNMM (hPa) das reanálises do ERA-Interim sobre o Oceano Austral e adjacências, para o período de (a) verão (JFM) e (b) inverno (JAS), entre 1989 e 2007.

\subsubsection{O gelo marinho}

Gelo marinho é qualquer forma de gelo formado pelo congelamento da água do mar (SIMÕES, 2004). É um dos parâmetros mais variáveis e sensíveis do sistema climático, ocupando grandes extensões oceânicas. A área máxima de oceanos coberta por gelo marinho representa cerca de $7 \%$ da superfície terrestre $\left(30 \times 10^{6} \mathrm{~km}^{2}\right)$, o que equivale a uma área maior do que a Europa e a América do Norte juntas (WADHAMS, 2000). Em relação à área oceânica, o gelo marinho ocupa cerca de 10\% no Hemisfério Norte e 13\% no HS (SQUIRE, 1984). Na Antártica, a cobertura de gelo marinho abrange uma área de $4 \%$ da superfície terrestre no seu máximo sazonal, o que corresponde a uma extensão média que varia de 15,5 a $19,1 \times 10^{6} \mathrm{~km}^{2}$ no mês de setembro (Figura 1.4b), superior à área de gelo continental $\left(14 \times 10^{6} \mathrm{~km}^{2}\right)$. Em fevereiro, mínimo sazonal, a extensão média varia de 3,4 a $4,3 \times 10^{6} \mathrm{~km}^{2}$ (Figura 1.4a, WADHAMS, 2000).

O gelo marinho antártico desempenha um papel importante no sistema climático global. Como as superfícies com neve ou gelo possuem um alto albedo (gelo nu de 50\% e gelo com neve de até 90\%), o gelo marinho absorve uma menor quantidade de energia solar, mantendo assim a superfície resfriada (KING; TURNER, 1997; NSIDC, 2010). O gelo marinho também influencia no balanço de energia em superfície devido a sua baixa condutividade térmica, inibindo as trocas de calor, massa e momento entre oceano e atmosfera 
(KING; TURNER, 1997). Nos meses de inverno, o gelo marinho é tão eficiente como isolante térmico que o fluxo de calor da atmosfera para o oceano aberto pode ser duas vezes maior do que sobre o gelo marinho (MAYKUT, 1978). Isto influencia a formação de nuvens, a estabilidade atmosférica e, portanto, a precipitação (KING; TURNER, 1997).

a)

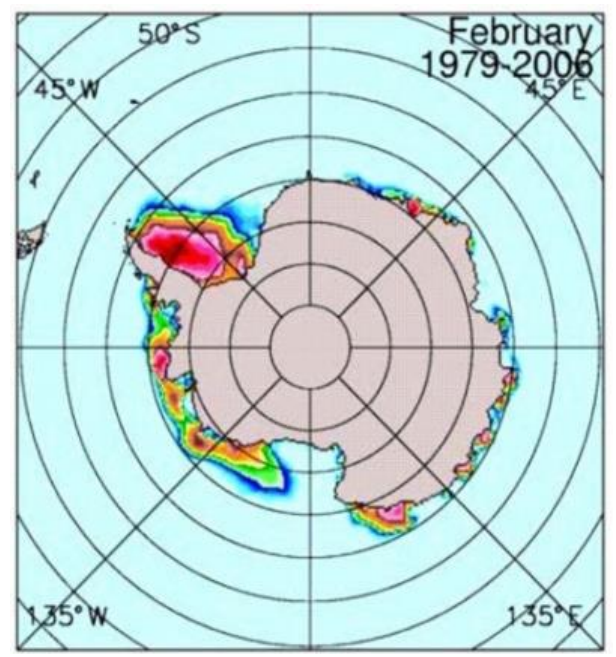

b)

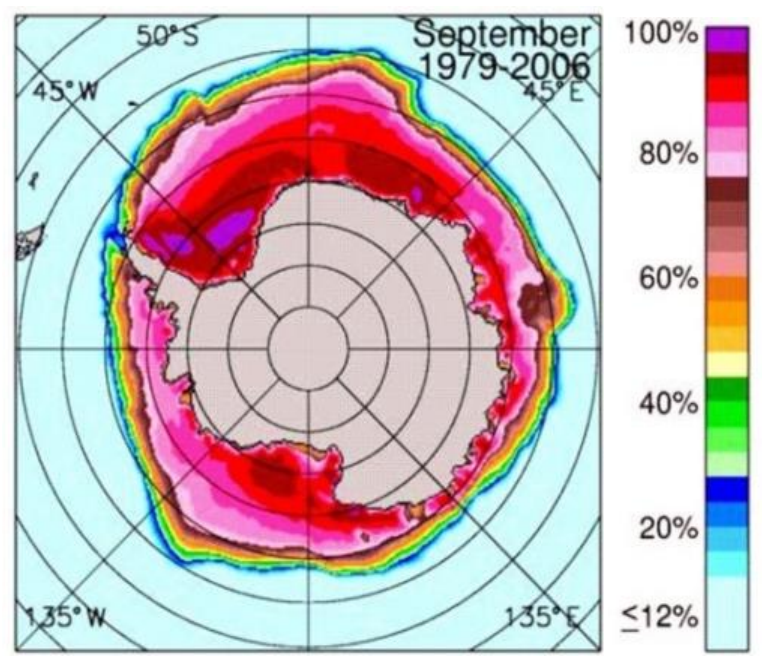

Figura 1.4: Concentração média do gelo marinho antártico para os meses de (a) fevereiro e (b) setembro, entre 1979 e 2006 (CAVALIERI; PARKINSON, 2008).

O derretimento e congelamento do gelo marinho influenciam a estabilidade do oceano superior devido às mudanças de salinidade. Este mecanismo afeta diretamente o processo de formação das massas de água, em especial a Água de Fundo Antártica, que por sua vez influenciam a circulação termohalina global (KING; TURNER, 1997). Além disso, a interface entre a borda do gelo marinho e o oceano aberto possui forte gradiente meridional de temperatura do ar que, juntamente com a advecção fria de sul, são fatores importantes para a ciclogênese (YUAN; MARTINSON; LIU, 1998).

O gelo marinho também tem um papel importante na formação das massas de ar nas altas latitudes do HS. No verão, devido à máxima retração sazonal do gelo marinho, a massa de ar formada sobre o Oceano Austral, entre a Convergência Subtropical e a borda do gelo marinho, é chamada de marítima polar. Contudo, no inverno, o limite sul da região de origem da massa de ar marítima polar está ao norte da borda do gelo marinho, e sobre a região do Oceano Austral com gelo marinho é formada uma massa de ar mais fria, a marítima antártica (TALJAARD, 1972). Essas massas de ar afetam significativamente o tempo na América do Sul, a qual possui uma economia altamente dependente da agricultura. A estreita ligação entre a produção agrícola e as condições de tempo faz com que frentes frias severas e precipitação de neve nas regiões produtoras tenham efeitos altamente danosos (HAMILTON; TARIFA, 
1978; MARENGO et al., 1997; VERA; VIGLIAROLO, 2000; GARREAUD, 2000). Estes efeitos se traduzem muitas vezes em perdas quase totais da produção de uma determinada região. Portanto, uma melhor compreensão da variabilidade de alta frequência nas altas latitudes é importante para melhorar o monitoramento e previsão de tempo na América do Sul.

Devido a sua espessura, que varia até poucos metros, o gelo marinho que flutua sobre as águas profundas está sujeito à ação dos ventos e das correntes oceânicas, as quais movem o gelo marinho à deriva. A força exercida pelo vento sobre a superfície é proporcional ao quadrado da velocidade relativa do vento em relação à superfície. A tensão do vento depende também das características da superfície do gelo marinho. Assim, o vento que sopra sobre a superfície do gelo marinho resulta em uma força de arrasto e faz com que este se movimente, em uma escala de tempo de dias a semanas. O movimento do gelo marinho em escala sinótica responde rapidamente a mudanças nos ventos em escalas de tempo de 12 horas ou menos, variando conforme a proximidade com a linha de costa (DRINKWATER, 1998). O gelo marinho livre se movimenta com $2 \%$ da velocidade do vento, sendo que o vento explica até $70 \%$ do seu movimento. Porções maiores de gelo marinho movimentam-se sobre uma faixa maior, de $20^{\circ}$ a $40^{\circ}$ para a esquerda da direção do vento no HS (NSIDC, 2010). No geral, o movimento do gelo marinho em grande escala pode ser mais ou menos alinhado com o vento geostrófico e os vetores de movimento do gelo marinho são aproximadamente paralelos às isóbaras da pressão em superfície (DRINKWATER; LIU, 1999).

A força exercida pelo movimento relativo da água sobre o gelo marinho atua em uma escala de tempo de mês a ano. A corrente Circumpolar Antártica, que possui deslocamento no sentido horário em cerca de $60^{\circ} \mathrm{S}$, juntamente com a corrente Costeira Antártica, com sentido anti-horário ao redor do continente junto à costa, são as principais responsáveis pela redistribuição de gelo marinho entre os diferentes setores do Oceano Austral (ZWALLY et al., 2002). Lembrando que os ventos de oeste dominam o escoamento básico nas latitudes médias do HS, enquanto que do continente antártico sopram ventos de sudeste, quando o efeito da circulação atmosférica e oceânica é combinado, observa-se que a circulação de grande escala do gelo marinho é preferencialmente no sentido horário em cerca de $60^{\circ} \mathrm{S}$, enquanto que junto ao continente o deslocamento é no sentido anti-horário (Figura 1.5). Existe uma componente média para norte devido à deflexão de Coriolis. Então o gelo marinho gradualmente se move para norte da sua borda após se formar (NSIDC, 2010). 


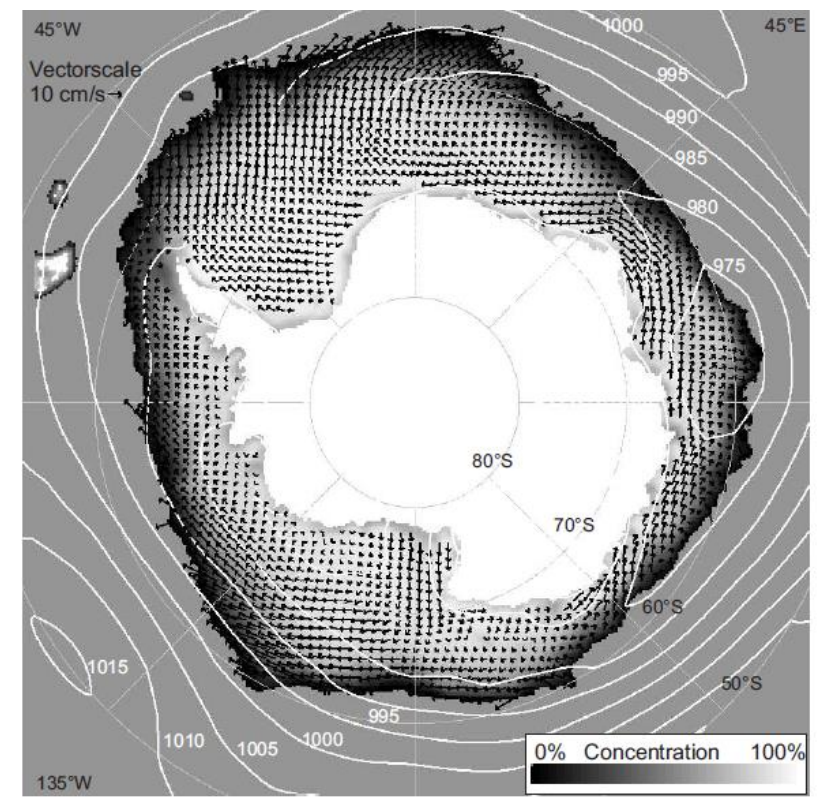

Figura 1.5: Movimento médio do gelo marinho antártico em julho de 1979 a 1997. Os vetores mostram a deriva do gelo marinho (velocidade e direção), sobrepostos aos campos de concentração de gelo marinho e de PNMM (SCHMITT, 2006).

1.1.4 Interação entre os ciclones extratropicais e o gelo marinho antártico

O sistema atmosfera-gelo marinho é complexo e fortemente acoplado. Em uma região de transição entre a cobertura de gelo marinho e o mar aberto a interação entre esse sistema é particularmente intensa, sendo significativa o suficiente para influenciar a circulação atmosférica de grande escala e a cobertura de gelo marinho (YUAN; MARTINSON; LIU, 1998). Supõe-se que a distribuição das anomalias de gelo marinho pode afetar e ser afetada por perturbações sinóticas, como por exemplo, através de modificações no transporte de calor pelos sistemas ciclônicos em direção ao polo ou através de modificações na intensidade de ar frio oriundo da Antártica. Além disso, um único evento sinótico pode sozinho mudar drasticamente a cobertura de gelo marinho sobre uma região (ACKLEY; KELHIER 1976). Estes autores observaram uma retração do gelo marinho sobre o mar de Bellingshausen durante a passagem de uma tempestade de inverno. A perturbação inicial foi preservada durante toda a estação devido aos processos de feedback entre o oceano e a atmosfera (ACKLEY; KELHIER 1976).

A instabilidade baroclínica causada pelos fortes gradientes horizontais de temperatura do ar, devido ao contraste térmico entre gelo marinho-oceano e continenteoceano, é um importante mecanismo na formação de tempestades polares (ACKLEY, 1981; YUAN; MARTINSON; LIU, 1998). A variação na cobertura de gelo marinho pode modificar a posição e a intensidade das regiões baroclínicas (ROSS; WALSH, 1986; MENÉNDEZ; 
SERAFINI; TREUT, 1999a). A máxima extensão de gelo marinho pode aumentar regionalmente o gradiente meridional de pressão em superfície e, portanto, reforçar os ventos de oeste ao norte da borda da banquisa ${ }^{1}$. Os ventos de oeste mais intensos são observados próximos aos três máximos de gelo marinho. Três razões poderiam explicar tal distribuição: (1) a máxima extensão do gelo marinho está invadindo o jato principal dos ventos de oeste, localizado em cerca de $50^{\circ} \mathrm{S}$; (2) o cinturão de baixas pressões sobre a banquisa é deslocado para norte pela máxima extensão do gelo marinho, resultando em intensos ventos de oeste; (3) a frequência das tempestades na zona de gelo marginal, inicializadas ao norte e nordeste da máxima extensão do gelo marinho, reforça os campos de ventos médios próximos à região de máxima extensão de gelo marinho. Por outro lado, fortes ventos de sul ocorrem com maior frequência a leste dos três máximos de gelo marinho, onde a sua extensão diminui para leste. A diminuição na extensão do gelo marinho a leste das máximas extensões da banquisa cria localmente um gradiente térmico zonal que intensifica os ventos de sul local. Quando a temperatura da superfície do mar (TSM) é mais quente fora da borda do gelo marinho e os ventos de sul são mais intensos, o potencial de ciclogênese é mais provável (YUAN; MARTINSON; LIU, 1998).

Simmonds e Budd (1991) testaram a sensibilidade da atmosfera às mudanças na fração de água e gelo sobre a cobertura de gelo marinho no HS, usando o Modelo de Circulação Geral da Atmosfera (MCGA) R21. Eles observaram que existe um substancial aquecimento próximo à superfície da banquisa quando a fração de água aberta aumenta, devido a um aumento nos fluxos de calor em superfície, em especial o calor sensível. Cunningham e Bonatti (2009) fizeram experimentos com o MCGA do Centro de Previsão de Tempo e Estudos Climáticos do Instituto Nacional de Pesquisas Espaciais (CPTEC - INPE) para entender o papel da extensão do gelo marinho como forçante da circulação atmosférica durante a primavera austral. Os resultados mostram que onde a cobertura do gelo marinho nos mares de Ross e Amundsen foi excessiva (deficiente), os fluxos de calor latente e sensível através do oceano foram atenuados (acentuados), levando a fortes anomalias negativas (positivas) de fluxos de superfície ascendentes. Em geral, as anomalias de fluxo de calor sensível apresentaram maiores valores que as anomalias de fluxo de calor latente. Os fluxos anômalos induzem a anomalias na temperatura do ar próximas à superfície, de modo que quando a borda do gelo marinho está anomalamente avançando (retrocedendo) para o norte

\footnotetext{
${ }^{1}$ Qualquer área de gelo marinho, com exceção do gelo fixo, não importando a forma ou a disposição (SIMÕES, 2004).
} 
(para o sul), as anomalias de fluxos são negativas (positivas) (CUNNINGHAM; BONATTI, 2009; CUNNINGHAM, 2011).

O transporte de calor e momento pelos transientes atmosféricos estão sujeitos a modificações devido a mudanças na extensão/concentração de gelo marinho e por outros efeitos de feedback. Por exemplo, uma redução ou remoção na cobertura de gelo marinho poderia implicar em uma redução no gradiente meridional de temperatura do ar e um predomínio de aumento da pressão em superfície em direção ao equador a partir da borda do gelo marinho. Assim haveria um enfraquecimento das storm tracks sobre grande parte do Oceano Austral, reduzindo ainda mais os fluxos de calor para o polo e deixando menos calor para ser absorvido pelo Oceano Austral. Isso diminuiria a temperatura do ar em superfície, contribuiria para a formação de gelo marinho em um feedback negativo e poderia afetar significativamente a propagação de sistemas frontais, impactando a precipitação nas latitudes médias sobre os continentes do HS. Por outro lado, as flutuações de escala sinótica são reforçadas na saída do jato subtropical, em cerca de $40^{\circ} \mathrm{S}$, e na região costeira da Antártica, principalmente no setor do Oceano Pacífico, apresentando anomalias predominantemente negativas de pressão em superfície (SIMMONDS; WU, 1993; MENÉNDEZ; SERAFINI; LE TREUT, 1999a; MENÉNDEZ; SERAFINI; LE TREUT, 1999b). Pezza et al. (2008) fizeram composições de densidade e profundidade de sistemas ciclônicos para anomalias positivas e negativas de extensão de gelo marinho antártico, usando o critério dos cinco maiores e cinco menores anos anômalos para cada setor do Oceano Austral. Os resultados sugerem que um aumento na frequência nem sempre está associado com um aumento na intensidade dos ciclones e vice-versa. A presença da máxima extensão de gelo marinho pode interagir com as trajetórias dos ciclones através de alterações na temperatura do ar em superfície e, consequentemente, no gradiente de pressão, que tende a ser intensificado sobre o limite entre o gelo marinho e o mar aberto (PEZZA et al., 2008).

No cinturão de baixas pressões, a atividade sinótica influencia a distribuição e formação do gelo marinho. A extensão do gelo marinho depende das condições dinâmicas e termodinâmicas da atmosfera. Normalmente os sistemas de baixa pressão se deslocam para leste no cinturão de baixas pressões. A rotação dos ciclones no sentido horário leva a um predomínio de ventos de oeste no seu lado norte e ventos de leste no seu lado sul. Levando em consideração o transporte de Ekman próximo à superfície, o transporte de gelo marinho resultante é para nordeste (no lado norte do ciclone) e para sudoeste (no lado sul do ciclone). Dependendo da localização do centro do ciclone em relação à borda da banquisa, isso leva a uma convergência ou divergência de gelo marinho (ENOMOTO; OHMURA, 1990). A 
convergência geralmente leva a altas concentrações de gelo marinho e menor extensão, já a divergência pode levar a baixas e altas extensões/concentrações de gelo marinho, dependendo da temperatura do ar dominante. No inverno ou em regiões costeiras a divergência pode levar a um aumento na produção de gelo novo e, assim, a um aumento na extensão de gelo marinho. Por outro lado, na primavera/verão e em regiões marginais a divergência pode acelerar o derretimento do gelo marinho, reduzindo a sua extensão e concentração. A influência de forçantes de escala sinótica sobre o movimento do gelo marinho em relação às forçantes oceânicas também dependem da região geográfica (HEIL et al., 2009).

Cavalieri e Parkinson (1981) analisaram a interação entre a atmosfera e o gelo marinho na Antártica em 1974. Os autores encontraram um forte fluxo circumpolar próximo à borda da banquisa nos meses de setembro, resultando em grandes mudanças no seu limite associada com a circulação de oeste climatológica, enquanto as respostas mais fracas ocorreram durante o período de derretimento do gelo marinho. Stammerjohn et al. (2003) analisaram a evolução sazonal da extensão, concentração e movimento do gelo marinho, juntamente com a variabilidade sinótica atmosférica na região oeste da Península Antártica, para o período de inverno austral de 1992, em que o avanço e retração do gelo marinho ocorreram anomalamente cedo. Quando fortes ventos de norte ocorreram, o impacto foi sentido em toda a região oeste da Península Antártica, com compactação da cobertura de gelo marinho contra a costa da Península Antártica, coincidentes com grandes reduções na extensão do gelo marinho. A persistência e intensidade das anomalias de vento meridional determinaram a duração e magnitude do ciclo anual no avanço e retração do gelo marinho, afetado pela dinâmica do seu movimento (STAMMERJOHN et al., 2003).

Contudo, alguns trabalhos mostram pouca ou nenhuma relação entre o gelo marinho antártico e os ciclones extratropicais. Por exemplo, Godfred-Spenning e Simmonds (1996) investigaram a relação entre o gelo marinho antártico e os ciclones extratropicais no HS, na escala sazonal, mas nenhuma relação foi encontrada. A influência da circulação atmosférica sobre o gelo marinho aparentemente foi maior do que vice-versa. Contudo, os autores afirmaram que a ciclogênese de inverno esteve mais fortemente associada com o gelo marinho local. A influência dos ventos do ciclone pode ser menos importante do que a incursão de ar frio ou quente para forçar o crescimento/derretimento do gelo marinho em grande escala. 


\subsubsection{Modos de variabilidade climática}

Modos de variabilidade climática local, regional e remota influenciam o gelo marinho em diferentes escalas de tempo. Vários estudos sugerem uma forte associação entre a variabilidade do gelo marinho antártico e o fenômeno tropical El Niño Oscilação Sul (ENSO) (e.g., CARLETON 1989; SIMMONDS; JACKA, 1995; WHITE; PETERSON, 1996; YUAN; CANE; MARTINSON, 1996; YUAN; MARTINSON, 2000; YUAN; MARTINSON, 2001; HARANGOZO, 2000; YUAN, 2004). Hoskins e Karoly (1981) analisaram através de modelos barotrópicos e baroclínicos, que uma convecção anômala na região tropical, através da vorticidade gerada por aquecimento diabático, é uma forçante para originar ondas de Rossby. Essas ondas se propagam em direção aos polos e geram configurações de teleconexões entre os trópicos e os extratrópicos.

O Pacífico-América do Sul (Pacific-South American - PSA) é o modo dominante da variabilidade climática de baixa frequência entre a região tropical do Pacífico/Indonésia e a América do Sul. Sugere-se que esse padrão é parte do trem de ondas de Rossby estacionário (MO; HIGGINS, 1998). Alguns estudos atribuíram às ondas de Rossby a propagação do sinal do ENSO para as altas latitudes do HS (KAROLY, 1989; MO; HIGGINS, 1998; GARREAUD; BATTISTI, 1999). Yuan e Li (2008) estudaram as principais características dos modos de variabilidade do HS e seus impactos sobre o gelo marinho antártico, entre 1978 e 2002. Os autores observaram que o PSA, padrão mais diretamente relacionado à variabilidade do ENSO, tem a maior influência sobre o gelo marinho na região do Dipolo Antártico (DPA) no Hemisfério Ocidental, na escala de tempo interanual, que é a região de estudo deste trabalho.

Entre as muitas respostas do ENSO conhecidas na atmosfera do HS, uma relaciona a influência da variabilidade do gelo marinho na região do DPA. O DPA é a mais forte teleconexão circumpolar, refletindo uma relação fora de fase entre os setores da Antártica localizados no centro e leste do Oceano Pacífico Sul e Atlântico Sul, onde a extensão do gelo marinho é mais sensível à variabilidade climática extrapolar. Este modo é observado fortemente na temperatura do ar em superfície e na cobertura de gelo marinho (YUAN; MARTINSON, 2000; YUAN; MARTINSON, 2001). A forçante tropical pode engatilhar dois diferentes processos atmosféricos: um alterando a circulação meridional média no Pacífico Sul e Atlântico Sul; e outro iniciando a onda de Rossby estacionária. Ambos contribuem para gerar anomalias no DPA nas altas latitudes. As contribuições destes dois processos estão em 
fase, resultando em anomalias persistentes do ENSO no sistema acoplado ar-gelo marinho no Hemisfério Ocidental da Antártica.

Para ilustrar o acoplamento entre o sistema ar-gelo marinho, Yuan (2004) fez composições mensais de anomalias de diversos campos atmosféricos em superfície e de cobertura de gelo marinho para eventos quentes e frios de ENSO. As maiores anomalias apareceram na região do DPA, sendo que o principal impacto do ENSO sobre o gelo marinho ocorreu próximo à sua borda. Para eventos quentes de ENSO (Figura 1.6a) foram observadas anomalias positivas de temperatura do ar em superfície e negativas de gelo marinho no Pacífico Sul do DPA, enquanto que anomalias negativas de temperatura do ar em superfície e positivas de gelo marinho ocorreram simultaneamente no Atlântico Sul do DPA. Um centro de alta pressão em superfície persistente foi observado no mar de Bellingshausen, trazendo ar quente das baixas latitudes para a região polar a leste do mar de Ross e de Amundsen, e ar frio do continente Antártico para o oceano aberto no mar de Weddell, criando simultaneamente um dipolo de anomalias nestas duas regiões para eventos quentes (YUAN, 2004).

Uma característica climática distinta no Pacífico Sul é a presença de uma corrente de jato dividida durante o inverno austral. A corrente de jato no escoamento de altos níveis, próximo a Austrália e Nova Zelândia, divide-se em jato subtropical, centrado em cerca de $25^{\circ} \mathrm{S}$, e em jato polar, centrado em torno de $60^{\circ} \mathrm{S}$. Embora a localização destes jatos não varie muito, a suas intensidades variam em resposta aos ciclos do ENSO (KAROLY, 1989; CHEN; SMITH; BROMWICH, 1996). Durante a fase quente do ENSO (Figura 1.6a) o jato subtropical é intensificado, centrado em cerca de $25^{\circ} \mathrm{S}$ entre $160^{\circ} \mathrm{E}$ e $120^{\circ} \mathrm{W}$, estendendo-se do Pacífico Sul para a América do Sul. Concomitantemente o jato polar é enfraquecido no Pacífico Sul. Além disso, o fluxo de calor para o polo devido à circulação meridional regional média é reforçada no Pacífico Sul, mas enfraquecida sobre o Atlântico Sul (YUAN, 2004). As anomalias no DPA e o padrão de circulação atmosférica associado em eventos frios de ENSO (Figura 1.6b) são opostos aos eventos quentes.

O aquecimento tropical (Figura 1.6a) desloca a circulação zonal para leste, de forma que o seu ramo descendente ocorre no Atlântico tropical, o qual atenua e expande a Célula de Hadley nessa região. Consequentemente, a storm track desloca-se em direção ao polo no Atlântico Sul. As mudanças nas correntes de jato e na Célula de Hadley regional aparentemente resultam em um reforço da Célula de Ferrel no Pacífico Sul e em um enfraquecimento no Atlântico Sul. Consequentemente, mais (menos) calor é transportado para a região polar no Pacífico Sul (Atlântico Sul) nos baixos níveis atmosféricos. Assim, a 
variação do transporte de calor em direção ao polo devido à circulação meridional média regional contribui diretamente para a formação de anomalias de temperatura do ar fora de fase no Pacífico Sul e Atlântico Sul (RIND et al., 2001; LIU et al., 2002; YUAN, 2004).

a)

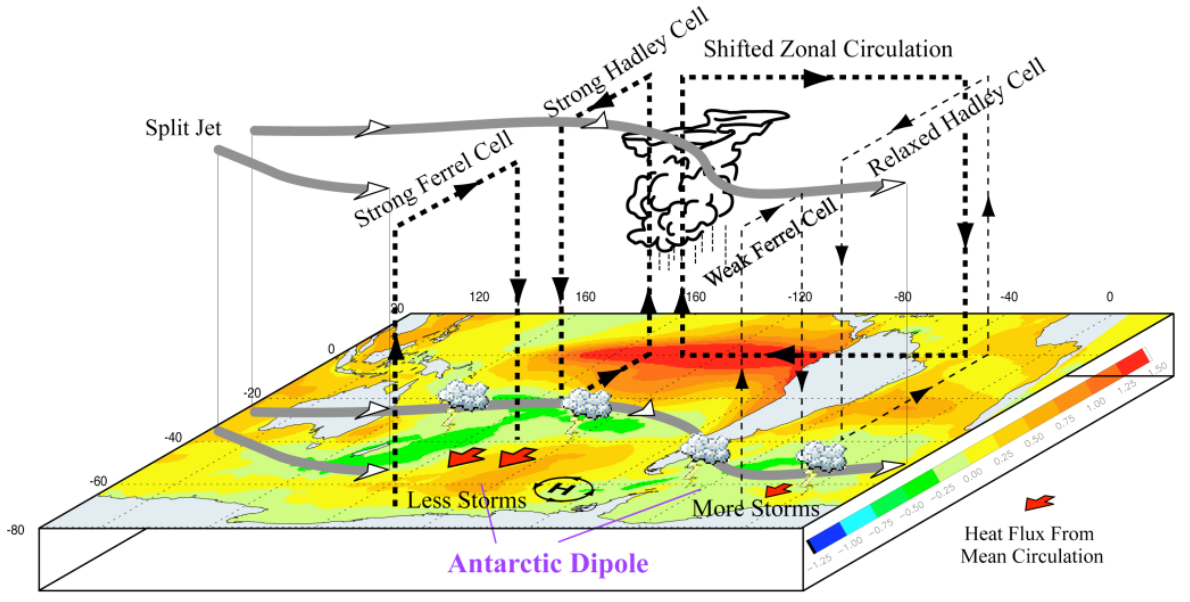

b)

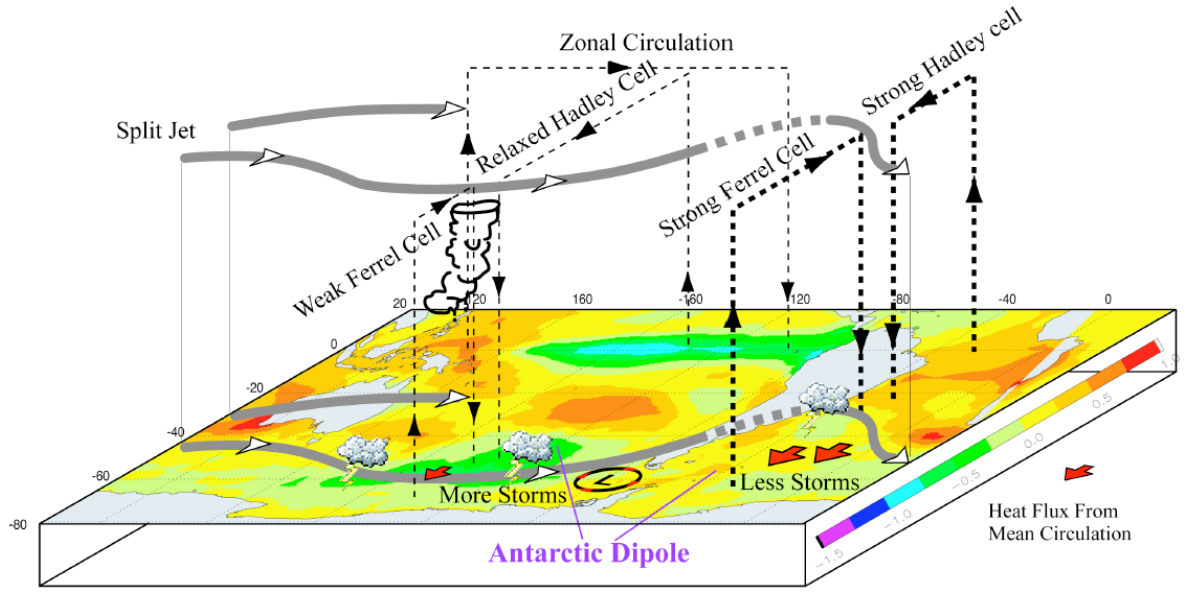

Figura 1.6: Padrão de circulação atmosférica em resposta a eventos (a) quentes e (b) frios de ENSO sobreposto à composição de TSM em evento de El Niño e La Niña, respectivamente (YUAN, 2004).

\subsection{Objetivos}

O objetivo principal deste trabalho foi analisar as interações entre os ciclones extratropicais e a variabilidade extrema do gelo marinho nos setores dos mares de Bellingshausen-Amundsen e do mar de Weddell, nos períodos de verão e inverno austral entre 1989 e 2007. Nesse sentido, o presente estudo tentou responder às seguintes questões:

1) Quais os padrões de circulação atmosférica de alta frequência no HS em eventos extremos de gelo marinho na mesma escala de tempo? Como esta circulação pode influenciar na variabilidade extrema do gelo marinho nesta escala temporal? 
2) Conhecendo os padrões atmosféricos associados aos extremos de gelo marinho de alta frequência, qual o comportamento sinótico de casos específicos em fases distintas de El Niño, sabendo-se da existência de teleconexão entre este fenômeno e o gelo marinho antártico?

3) Qual a influência da circulação atmosférica de grande escala, na escala interanual, na variabilidade extrema do gelo marinho antártico na mesma escala de tempo?

4) Quais as características dos ciclones extratropicais, em termos de densidade, profundidade e raio, em extremos de anomalias negativas e positivas de gelo marinho na escala interanual? 


\section{Capítulo 2: Dados e Metodologia}

Neste capítulo serão apresentados os métodos empregados, bem como o conjunto de dados utilizados para as análises. As características da circulação atmosférica de alta frequência e interanual associadas aos eventos extremos de gelo marinho, na mesma escala de tempo, foram obtidas através de composições defasadas das anomalias dos campos atmosféricos, utilizando-se as reanálises do ERA-Interim e a extensão de gelo marinho do NSIDC, da Universidade do Colorado. Posteriormente, para a análise sinótica de estudo de casos em relação aos eventos extremos de alta frequência de gelo marinho em fases distintas do fenômeno El Niño, também foram utilizados o conjunto de dados do ERA-Interim, além de composições de imagens de satélite do SSEC e o Índice de Niño Oceânico do CPC/NOAA. A estatística de ciclones do Automatic Cyclone Tracking, da Universidade de Melbourne, foi empregada para analisar a ocorrência de ciclones associados aos períodos de mínima e máxima extensão de gelo marinho na escala interanual. Para isso, a densidade, profundidade e raio dos sistemas foram calculados a partir das reanálises do NCEP-2.

\subsection{Dados}

Foram utilizados campos de 6 em 6 horas (00, 06, 12 e 18 UTC) de PNMM, vorticidade relativa (VR) em $1000 \mathrm{hPa}$, componentes zonal e meridional do vento a $10 \mathrm{~m}$, temperatura do ar a $2 \mathrm{~m}$, altura geopotencial e VR em $500 \mathrm{hPa}$, altura geopotencial e vento zonal em $200 \mathrm{hPa}$ oriundos das reanálises do ERA-Interim, obtidos do European Centre for Medium-Range Weather Forecasts (ECMWF) Data Server (http://www.ecmwf.int). ERAInterim é a reanálise atmosférica global mais recente produzida pelo ECMWF, cobrindo originalmente o período de 01 de janeiro de 1989 até 31 de dezembro de 2011, embora tenha sido incluído recentemente mais uma década de dados (1979-1988). A assimilação de dados produz parâmetros em superfície e em 37 níveis de pressão, sendo o nível superior em $0,1 \mathrm{hPa}$ (BERRISFORD et al., 2009). O espaçamento horizontal é de $1,5^{\circ}$ de latitude/longitude. As 
configurações e o desempenho do sistema de assimilação de dados podem ser vistos com maior detalhe em Dee et al. (2011).

Também foi utilizado o campo de PNMM das reanálises do NCEP-2 oriundo da National Oceanic and Atmospheric Administration/Office of Oceanic and Atmospheric Research/Earth System Research Laboratory (NOAA/OAR/ESRL) Physical Sciences Division (PSD), Boulder, Colorado (http://www.esrl.noaa.gov/psd/). O NCEP-2 é uma versão melhorada das reanálises do NCEP-NCAR (KALNAY et al., 1996), corrigindo os erros de processamento e utilizando um sistema de assimilação de dados e um modelo de previsão melhorados. As reanálises do NCEP-2 possuem quatro análises diárias, de 01 de janeiro de 1979 até o presente, distribuídos em uma grade global com espaçamento horizontal de $2,5^{\circ}$ de latitude/longitude e em 17 níveis de pressão, até 10 hPa (KANAMITSU et al., 2002).

Os dados de extensão de gelo marinho ${ }^{2}$ foram obtidos do National Snow and Ice Data Center (NSIDC), da Universidade do Colorado, Boulder (CAVALIERI et al., 1996), disponíveis em ftp://sidads.colorado.edu/DATASETS/seaice/polar-stereo/trends-climatologies /ice-extent. A extensão de gelo marinho é definida como a área total coberta por gelo marinho com concentração média superior a $15 \%$, ou seja, é o número de pixels com concentração maior do que $15 \%$ vezes a área do pixel, medida $\mathrm{em}^{\mathrm{km}}{ }^{2}$. A concentração de gelo marinho, medida em percentual (\%), representa uma estimativa média da cobertura de gelo marinho, devendo ser superior a $15 \%$ para cada grade de $25 \times 25 \mathrm{~km}$, que é a resolução espacial do dado, em projeção polar estereográfica (NSIDC, 2011).

A concentração de gelo marinho é derivada dos sensores Scanning Multichannel Microwave Radiometer (SMMR), a bordo do satélite Nimbus-7, e do Special Sensor Microwave/Imager (SSM/I), a bordo do Defense Meteorological Satellite Program F8, F11 e F13. O SMMR e o SSM/I são radiômetros de microondas de multi-frequências e bipolarizados. Essa radiação é afetada pelas condições de superfície, subsuperfície e atmosféricas, fornecendo uma gama de informações geofísicas (NSIDC, 2011). As séries temporais de concentração de gelo marinho do SMMR e SSM/I são produzidas a partir da temperatura de brilho, a qual é convertida para concentração de gelo marinho através dos algoritmos NASA Team ou Bootstrap. Neste estudo foi utilizado o algoritmo NASA Team. O seu desempenho pode ser verificado em Cavalieri et al. (1992) e Steffen et al. (1992). Os dados do SMMR estão disponíveis a cada dois dias, para o período entre 01/novembro/1978 e

\footnotetext{
${ }^{2}$ Extensão de gelo marinho: área total coberta por alguma quantidade de gelo marinho, incluindo águas abertas entre os blocos de gelo flutuantes. Este parâmetro indica onde se encontra a borda do gelo marinho (NSIDC, 2010).
} 
20/agosto/1987. Os dados do SSM/I são diários, para o período de 9/julho/1987 a 31/dezembro/1991 (satélite F8), de 3/dezembro/1991 a 30/setembro/1995 (satélite F11) e de 3/maio/1995 a dezembro/2007 (satélite F13). São disponibilizadas médias de extensão de gelo marinho para todo o Oceano Austral e separadamente para cada setor: setor do mar de Weddel (MW), setor do Oceano Índico, setor do Oceano Pacífico Oeste, setor do mar de Ross e setor dos mares de Bellingshausen-Amundsen (MBA) (Figura 2.1). No presente estudo foram utilizados os dados diários, entre 01/janeiro/1989 a 31/dezembro/2007, obtidos para o setor dos $\mathrm{MBA}\left(130^{\circ} \mathrm{W}\right.$ a $\left.60^{\circ} \mathrm{W}\right)$ e para o setor do $\mathrm{MW}\left(60^{\circ} \mathrm{W}\right.$ a $\left.20^{\circ} \mathrm{E}\right)$.

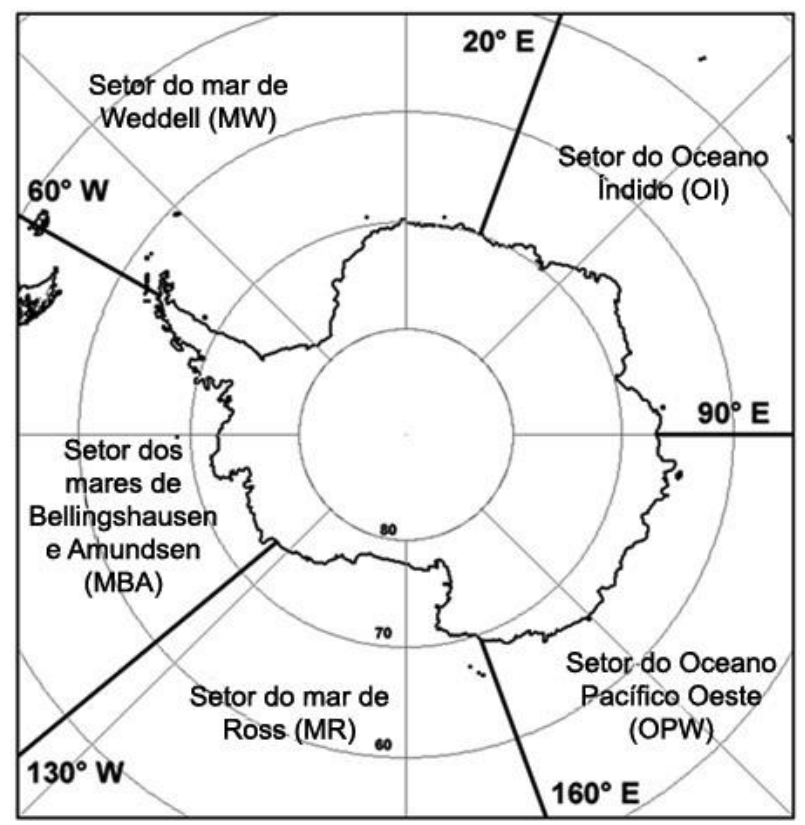

Figura 2.1: Setores do Oceano Austral (modificado de Cavalieri e Parkinson, 2008).

A composição de imagens de satélite do canal infravermelho foram obtidos do Space Science and Engineering Center (SSEC), Universidade de Wisconsin-Madison (amrc.ssec.wisc.edu). As imagens são construídas com intervalos de 3 horas, através das imagens de satélites polares (NOAA) e geoestacionários (GOES, Meteosat, FY-2, MTSAT, Aqua/Terra, Kalpana) (LAZZARA et al., 2003).

\subsection{Métodos estatísticos}

Uma série temporal é um conjunto de dados que consiste em medidas consecutivas de variáveis atmosféricas e pode ser representada em função de contribuições feitas por fenômenos em diferentes escalas de tempo (WILKS, 2006). As séries temporais podem ser 
decompostas em componentes que representam a tendência (linear ou não linear), a variação sazonal, as variações cíclicas e as variações irregulares (CHATFIELD, 2004). Para descrever as variações observadas na variável de interesse, cada componente é analisada separadamente através da remoção sistemática de cada componente dos dados, a começar pela tendência. A tendência é uma mudança de longo período na série de dados e pode ser obtida através da equação de mínimos quadrados (linear ou não linear). A variação sazonal, também denominada de ciclo sazonal ou ciclo anual, varia na escala de um ano, ou seja, está associada com as estações do ano. Nos estudos climatológicos é importante remover o ciclo anual da série temporal, tendo em vista que ele é muito marcado, sobretudo nas regiões extratropicais, o que acaba mascarando as outras componentes da série. As variações cíclicas apresentam certo grau de regularidade, contudo com período diferente de um ano. Por fim, as variações irregulares são variações aleatórias sem regularidade.

\subsubsection{Filtragem dos dados}

Para analisar os padrões de circulação atmosférica de alta e baixa frequência em eventos extremos de gelo marinho, na mesma escala de tempo, as séries temporais foram filtradas utilizando a transformada rápida de Fourier (Fast Fourier Transform - FFT). A FFT é um algoritmo para computar a transformada de Fourier discreta para uma série temporal em todas as frequências de Fourier, usando relativamente poucas operações aritméticas (BLOOMFIELD, 1976). Antes de calcular a FFT é necessário remover das séries temporais a tendência linear e o ciclo anual. O ciclo anual será removido somente da série temporal que será filtrada na escala de tempo de alta frequência. No caso da tendência linear, a reta de tendência (Equação 2.1) é baseada nos coeficientes linear da reta $a$ (Equação 2.2) e angular da reta $b$ (Equação 2.3), no tempo $(t)$, para o valor preditado da série temporal $y(t)$. O coeficiente angular está associado à taxa de variação linear da variável analisada (tendências lineares).

$$
\begin{gathered}
y(t)=a+b t \\
a=\frac{\sum y-b \sum t}{n} \\
b=\frac{n \sum t y-\sum t \sum y}{n \sum t^{2}-\left(\sum t\right)^{2}}
\end{gathered}
$$


O problema geral de mínimos quadrados (Figura 2.2) é encontrar entre todas as curvas que se aproximam de determinado conjunto de pontos, a curva que possui a propriedade $d_{1}^{2}+d_{2}^{2}+\ldots+d_{n}^{2}=$ mínimo, a qual será a melhor curva ajustadora.

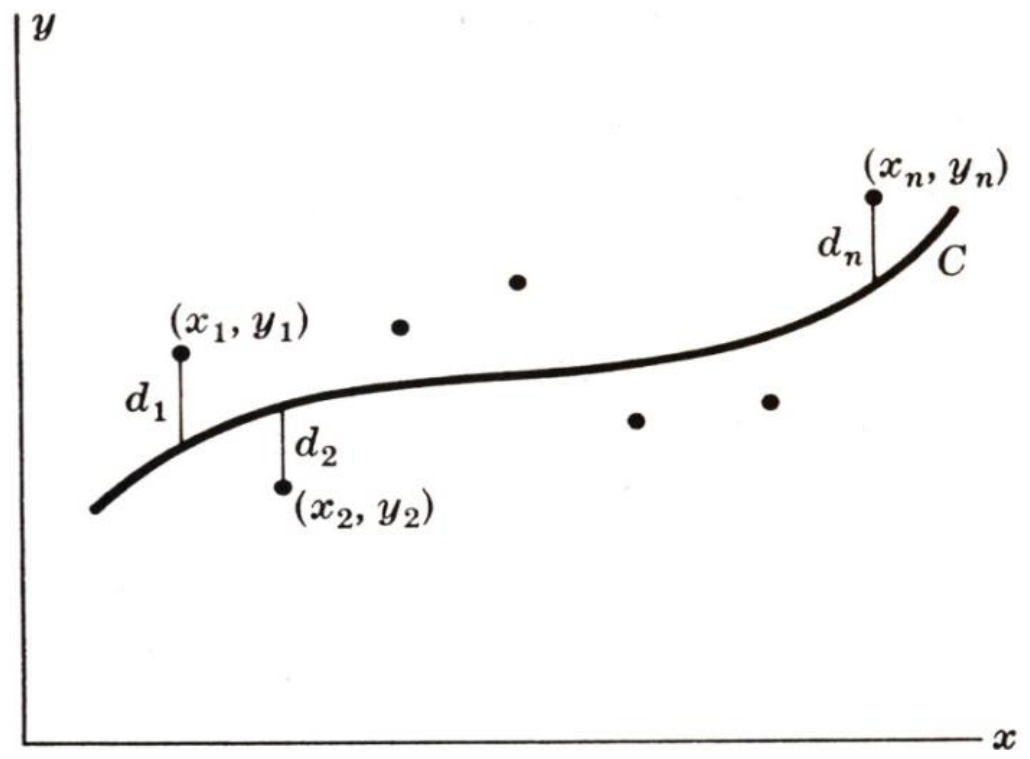

Figura 2.2: Curva de regressão de $y$ sobre $x$, em que os pontos dados são $\left(x_{1}, y_{1}\right), \ldots,\left(x_{n}, y_{n}\right)$. Para determinado valor de $x_{n}$ haverá uma diferença entre o valor $y_{n}$ e o correspondente valor "ajustado", determinado pela curva $C$. Denotamos tal diferença por $d_{n}$, chamada de desvio, erro ou resíduo (SPIEGEL, 1977, p. 371).

Existem diversos métodos para a remoção do ciclo anual: método trigonométrico de três termos, subtração das normais climatológicas, média móvel centrada em 12 meses, funções harmônicas, entre outros. No presente trabalho, serão utilizadas as funções harmônicas para a série de extensão de gelo marinho e a média móvel para as séries dos campos atmosféricos. Para as funções harmônicas, inicialmente foi calculada a média diária (Equação 2.4) da extensão do gelo marinho nos setores dos MBA e MW, entre 01/janeiro/1989 a 31/dezembro/2007.

$$
\bar{X}_{t}=\sum_{y=1}^{a} x_{t, y}
$$

onde $\mathrm{x}_{\mathrm{t}, \mathrm{y}}$ é a série temporal no tempo $\mathrm{t}=[1,365]$ dias e $\mathrm{y}=[1, \mathrm{a}]$, a é o número de anos da série temporal. Em anos bissextos foi feita a média entre os dias 28 e 29 de fevereiro, considerando-se assim 28 dias. Desta forma, obteve-se uma série temporal com 365 valores (Figura 2.3, linha vermelha). Com esse procedimento, a série temporal média provavelmente apresentará pequenas oscilações devido ao reduzido número de anos, as quais são resultado de variabilidades interanuais. Pode-se observar que a média diária de extensão de gelo marinho é pouco ruidosa, pois o ciclo anual é visível mesmo na ausência da aplicação da técnica de 
filtragem (Figura 2.3, linha vermelha). Isso porque o ciclo sazonal do gelo marinho antártico é bastante destacado, variando a sua extensão média climatológica entre 3,4 e 4,3 $\times 10^{6} \mathrm{~km}^{2}$ (fevereiro) a 15,5 e 19,1 × $10^{6} \mathrm{~km}^{2}$ (setembro) (WADHAMS, 2000).
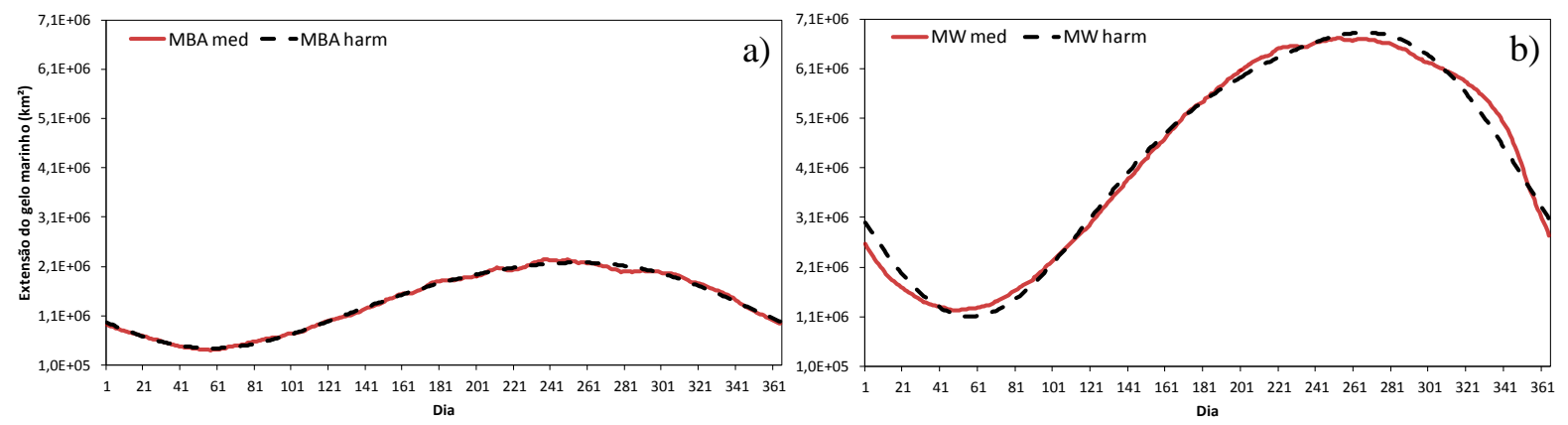

Figura 2.3: Ciclo anual obtido a partir da média diária (linha vermelha) e ajustado pelo primeiro e segundo harmônico (tracejado preto) para os setores (a) dos MBA e (b) do MW, de 1989 a 2007.

A partir do ciclo anual obtido com as médias diárias (de 1989 a 2007), foram calculados o primeiro e segundo harmônicos. Uma análise no domínio da frequência consiste em representar séries de dados em termos de contribuições feitas em diferentes escalas de tempo. Neste sentido, a análise harmônica consiste em representar as flutuações ou variações em uma série temporal proveniente da adição de uma série de funções seno e cosseno. Estas funções trigonométricas são harmônicos, os quais são escolhidos por ter frequências múltiplas da frequência fundamental, determinada pelo tamanho da amostra da série de dados (WILKS, 2006).

Qualquer série temporal consistindo de $n$ pontos pode ser representada exatamente, o que significa que é possível encontrar uma função harmônica que passa por cada um dos pontos, somando uma série de $n / 2$ funções harmônicas (Equação 2.5).

$$
\begin{aligned}
y_{t} & =\bar{y}+\sum_{k=1}^{n / 2}\left\{C_{k} \cos \left[\frac{2 \pi k t}{n}-\phi_{k}\right]\right\} \\
& =\bar{y}+\sum_{k=1}^{n / 2}\left\{A_{k} \cos \left[\frac{2 \pi k t}{n}\right]+B_{k} \operatorname{sen}\left[\frac{2 \pi k t}{n}\right]\right\}
\end{aligned}
$$

onde k é um inteiro qualquer, $\phi_{k}$ é a fase ou o ângulo de fase e os coeficientes $A_{k}, B_{k}$ e $C_{k}$ são as amplitudes de uma onda senoidal. A onda cosseno obtida para $\mathrm{k}=1$, na Equação 2.5, é o primeiro harmônico e os outros $(n / 2)-1$ termos da somatória na Equação 2.5 são harmônicos de ordem maior ou ondas cosseno com frequências:

$$
\omega_{k}=\frac{2 \pi k}{n}
$$


que são múltiplos inteiros da frequência fundamental $\omega_{1}$. Para as séries temporais igualmente espaçadas no tempo (sem valores faltantes) os coeficientes $A_{k}$ e $B_{k}$ podem ser encontrados através de:

$\mathrm{e}$

$$
\begin{aligned}
& A_{k}=\frac{2}{n} \sum_{t=1}^{n} y_{d} \cos \left(\frac{2 \pi k t}{n}\right) \\
& B_{k}=\frac{2}{n} \sum_{t=1}^{n} y_{d} \operatorname{sen}\left(\frac{2 \pi k t}{n}\right)
\end{aligned}
$$

Uma vez calculados os coeficientes $A_{k}$ e $B_{k}$, temos então que obter a fase e a amplitude dos harmônicos:

$$
C_{k}=\sqrt{A_{k}^{2}+B_{k}^{2}}
$$

Quanto à fase, deve-se primeiro testar o coeficiente $A_{k}$ e resolver:

$$
\phi_{k}= \begin{cases}\tan ^{-1} \frac{B_{k}}{A_{k}} & \mathrm{~A}_{\mathrm{k}}>0 \\ \tan ^{1} \frac{B_{k}}{A_{k}} \pm \pi & \mathrm{A}_{\mathrm{k}}<0 \\ \frac{\pi}{2}, \text { ou } 90^{\circ} & \mathrm{A}_{\mathrm{k}}=0\end{cases}
$$

Pode-se usar todos os $n / 2$ harmônicos se o objetivo é obter uma função que represente exatamente através de todos os pontos da série. Entretanto, se a finalidade é representar o ciclo anual de uma quantidade climatológica, os primeiros poucos harmônicos podem fornecer uma representação adequada. A função obtida no presente estudo, através do primeiro e segundo harmônico, pode ser visualizada na Figura 2.3 (linha tracejada). A curva obtida através do primeiro e segundo harmônico se apresenta quase superposta à curva obtida através da média diária (Figura 2.3, linha contínua). No ciclo anual do gelo marinho no setor dos MBA, obtido através da média diária (dos harmônicos), a mínima extensão do gelo marinho é observada no dia 26/fev (27/fev) e a máxima extensão em 26/ago (13/set). Já no setor do MW a mínima extensão do gelo marinho é observada em 17/fev (26/fev) e a máxima extensão em 11/set (24/set). A formação/expansão de gelo marinho se dá no outono, quando há redução na energia solar incidente e a temperatura do ar cai abaixo do ponto de congelamento, e no inverno, quando o gelo marinho se torna mais espesso com a transferência contínua de calor do oceano relativamente quente para a atmosfera fria. O derretimento do gelo marinho ocorre durante a primavera e o verão, período em que o Sol está mais a zênite, aumentando a radiação solar e as temperaturas do ar (NSIDC, 2010). 
Da definição da Equação 2.5, uma série temporal $y_{t}$ de comprimento $n$ pode ser totalmente especificada em termos dos $n$ parâmetros, usando-se $n / 2$ funções harmônicas. Isto é equivalente a transformar a série de dados $y_{t}$ em novos conjuntos de quantidades $A_{k}$ e $B_{k}$ de acordo com as Equações 2.7 e 2.8. Por esta razão, as equações citadas são chamadas de transformadas de Fourier discretas. A descrição completa sobre análise de harmônicos pode ser obtida em Wilks (2006).

Outra forma de se obter o ciclo anual é através do método da média móvel. Através de um filtro linear, uma série temporal $X_{t}$ é convertida em outra $Y_{t}$ por meio da operação linear (CHATFIELD, 2004):

$$
Y_{t}=\sum_{r=-q}^{+s} a_{r} x_{t+r}
$$

onde $\mathrm{a}_{\mathrm{r}}$ é o conjunto de pesos. Para alisar flutuações locais e estimar a média local, deve-se escolher pesos tais que $\sum a_{r}=1$. Essa operação é geralmente referida como média móvel. Comumente as médias móveis são simétricas, com $s=q$ e $a_{j}=a_{-j}$. O filtro 1-2-1 considera uma média móvel de três elementos, com pesos $a_{r}$ iguais a 0,25, 0,5 e 0,25. Assim, da Equação 2.11 obtém-se:

$$
Y_{t}=0,25 \cdot x_{t-1}+0,5 \cdot x_{t}+0,25 \cdot x_{t+1}
$$

É recomendado que o filtro seja passado 300 vezes na série (HARTMANN; MICHELSEN, 1989), embora o número correto de vezes que se deve passar o filtro é decidido investigandose o comportamento da série alisada.

Considerando a série temporal $X(t)$ sem a tendência linear e o ciclo anual (daqui por diante denominada de série de anomalias totais), aplica-se então a FFT na série $X(t)$, que resulta em uma nova série $H(f)$, transformada para o domínio da frequência (Equação 2.13).

$$
H(f)=\int_{-\infty}^{\infty} X(t) \exp (2 \pi i f t) d t
$$

Calcula-se a convolução entre $R(f)$ (Equação 2.14) e $H(f)$, que resulta em uma nova função $H^{\prime}(f)$ (Equação 2.15), onde as amplitudes das frequências a serem retidas são preservadas e as demais amplitudes são removidas ou atenuadas. $R(f)$ da Equação 2.15 é definida pela razão entre a amplitude das ondas que compõem a série temporal filtrada $C^{\prime}(f)$ e a amplitude das ondas que compõem a série temporal original $C(f)$. No presente caso construiu-se um filtro passa-banda, no período de 2 a 10 dias (alta frequência), e um filtro passa baixa, no período maior que 370 dias (escala interanual). Por fim, calcula-se a inversa da FFT em $H^{\prime}(f)$ com o objetivo de retornar ao domínio do tempo, gerando a série temporal 
filtrada $Y(t)$ (Equação 2.16). Daqui por diante, $Y(t)$ será referida como série de anomalias de alta frequência ou anomalias de baixa frequência (interanuais).

$$
\begin{gathered}
R(f)=\frac{C^{\prime}(f)}{C(f)} \\
H^{\prime}(f)=\int_{-\infty}^{\infty} R(\tau) H(t-\tau) d \tau \\
Y(t)=\int_{-\infty}^{\infty} H^{\prime}(f) \exp (-2 \pi i f t) d f
\end{gathered}
$$

As séries de anomalias totais, de alta frequência e interanuais de extensão de gelo marinho nos setores dos MBA e MW, entre janeiro de 1989 a dezembro de 2007, podem ser visualizadas na Figura 2.4. No setor dos MBA as anomalias de alta frequência apresentaram desvio padrão de 9,0\% do desvio padrão das anomalias totais, enquanto que no MW foi de $5,9 \%$. No verão austral, o desvio padrão das anomalias de alta frequência nos MBA foi de 9,8\% do desvio padrão das anomalias totais (Figura 2.4a), enquanto que no MW foi 4,3\% do desvio padrão (Figura 2.4b). No inverno, o desvio padrão das anomalias de alta frequência no setor dos MBA corresponde a 10,3\% do desvio padrão das anomalias totais e no setor do MW corresponde a 8,0\%. Assim, observou-se que nos setores dos MBA e do MW existe uma maior contribuição das anomalias de alta frequência nas anomalias totais durante o período de inverno, possivelmente associado à maior atividade ciclônica nesta época do ano no Oceano Austral (JONES; SIMMONDS, 1993; SIMMONDS; KEAY, 2000a; HOSKINS; HODGES, 2005). Além disso, nos MBA a contribuição das anomalias de alta frequência nas anomalias totais durante o verão e inverno é maior em relação ao MW. Isso porque no setor do $\mathrm{MW}$ há uma menor atividade ciclônica durante o verão e inverno austral em relação aos outros setores do Oceano Austral (JONES; SIMMONDS, 1993). Verifica-se uma maior amplitude nas anomalias interanuais de extensão de gelo marinho no setor do MW (Figura 2.4b) em relação aos MBA (Figura 2.4a). Destaca-se uma assimetria nas anomalias interanuais de gelo marinho nos MBA, com uma distribuição mais frequente para os valores positivos, enquanto que as anomalias interanuais no setor do MW apresentaram uma distribuição mais frequente para os valores negativos de extensão. 
a)

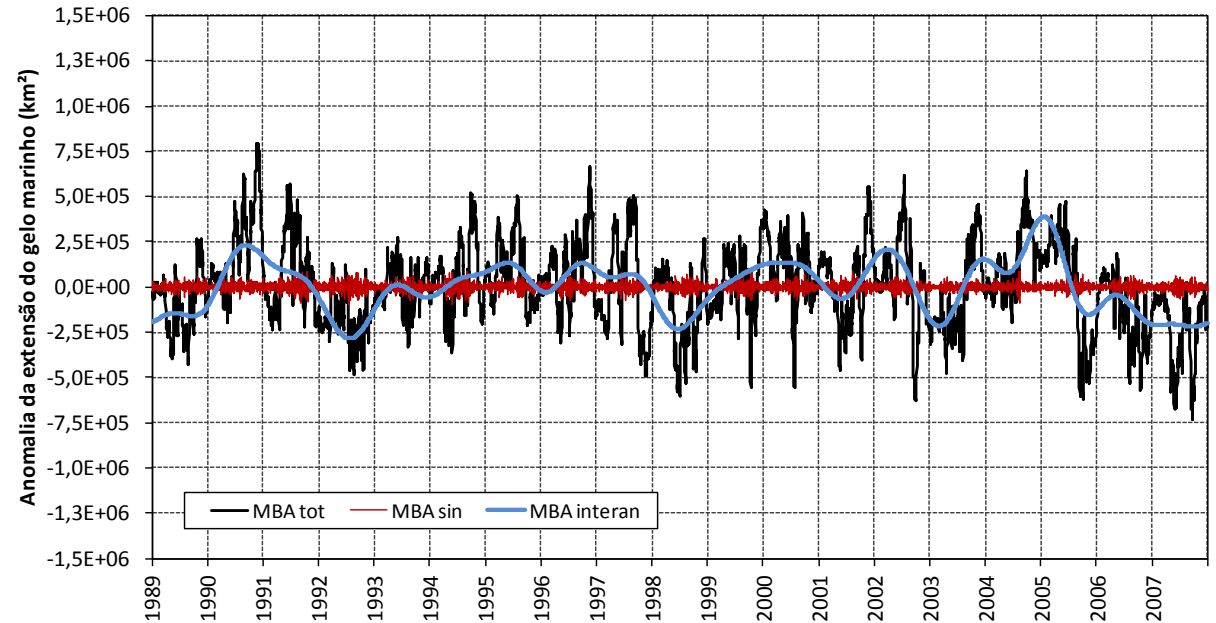

b)

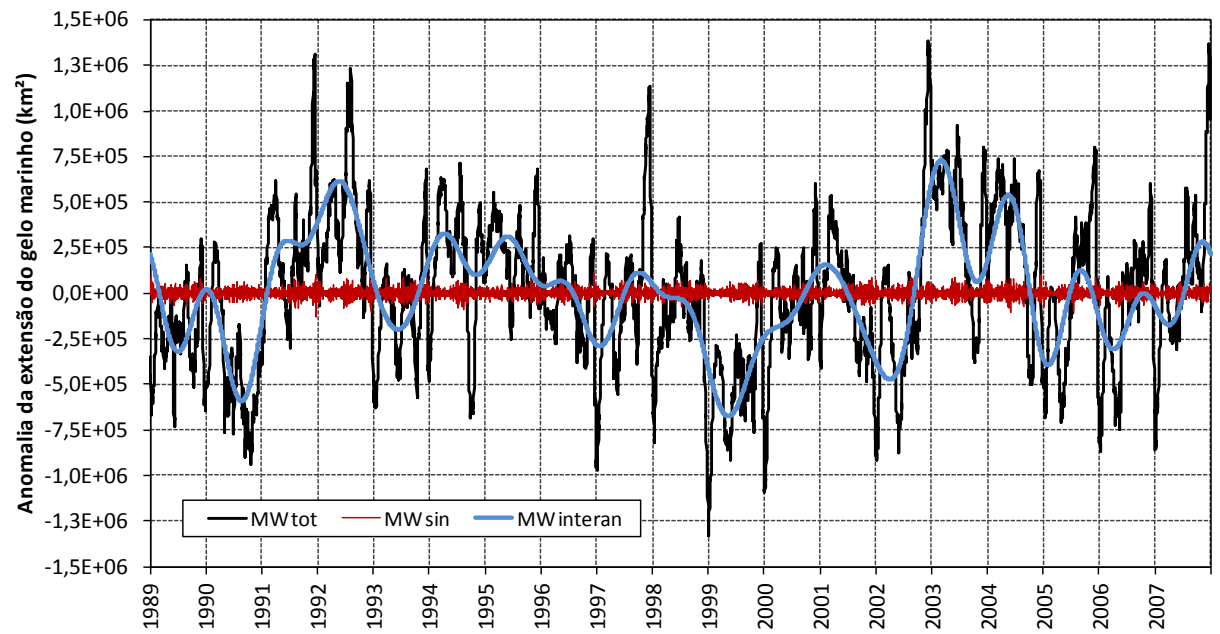

Figura 2.4: (a) Anomalias totais (linha preta), de alta frequência (linha vermelha) e interanuais (linha azul) de gelo marinho no setor (a) dos MBA e (b) do MW, entre janeiro de 1989 e dezembro de 2007.

\subsubsection{Análise de extremos e persistência}

Os eventos extremos de cobertura de gelo marinho foram obtidos a partir da técnica de quantil. Ordenando um conjunto de dados em ordem de grandeza, o valor central que divide a série temporal em duas partes iguais é a mediana. Assim, 50\% das observações ordenadas estarão abaixo da mediana. Da mesma forma, os valores que dividem o conjunto de dados em quatro partes iguais denominam-se primeiro, segundo e terceiro quartil. Deste modo, o primeiro quartil terá $25 \%$ dos valores ordenados abaixo dele, o segundo quartil (que é igual à mediana) terá $50 \%$ abaixo e o terceiro quartil terá $75 \%$ abaixo. Os valores que dividem os dados em dez partes iguais denominam-se decis, enquanto os valores que dividem os dados em cem partes iguais chamam-se percentis (SPIEGEL, 1985). Portanto, as medianas, os quartis, os decis, os percentis e outros valores obtidos através da subdivisão dos dados em partes iguais são denominados quantis. A técnica dos quantis para estudos de eventos 
extremos é adequada por não ser contaminada por valores extremos, como é o caso da média e do desvio padrão (XAVIER et al., 2002).

Os extremos foram definidos utilizando como critério o primeiro (q25) e terceiro (q75) quartil da distribuição de anomalias de alta frequência e interanuais da extensão do gelo marinho para os setores dos MBA e do MW. Abaixo do q25 são considerados os extremos negativos de anomalias de alta frequência ou interanuais de gelo marinho (ENGM), indicando retrações de gelo marinho de alta frequência ou interanual, e acima do q75 os extremos positivos (EPGM), i.e., expansões de gelo marinho de alta frequência ou interanual. Os limiares q25 e q75 foram obtidos para os períodos de verão (janeiro, fevereiro e março) e inverno (julho, agosto e setembro) (ZWALLY et al., 2002) e são apresentados na Tabela 2.1. Os ENGM e EPGM das anomalias de alta frequência e interanuais, nas estações de verão e inverno, foram mais intensos no setor do MW, provavelmente por ser o setor que apresenta a maior cobertura e variabilidade de gelo marinho (CAVALIERI; PARKINSON, 2008).

Tabela 2.1 - ENGM e EPGM de alta frequência e interanual, nos setores dos MBA e do MW, nas estações de verão e inverno austral.

\begin{tabular}{clcccc}
\hline & & $\begin{array}{c}\text { MBA } \\
\text { verão }\end{array}$ & inverno & $\begin{array}{c}\text { MW } \\
\text { verão }\end{array}$ & inverno \\
\hline \multirow{2}{*}{$\begin{array}{c}\text { Alta } \\
\text { frequência }\end{array}$} & ENGM $\left(\mathbf{k m}^{2}\right)$ & $-7.686,1$ & $-17.555,8$ & $-11.040,8$ & $-18.484,2$ \\
& EPGM $\left(\mathbf{k m}^{2}\right)$ & $+7.592,9$ & $+17.549,4$ & $+9.808,4$ & $+18.703,9$ \\
\hline \multirow{2}{*}{ Interanual } & ENGM $\left(\mathbf{k m}^{2}\right)$ & $-104.236,8$ & $-104.101,9$ & $-225.935,8$ & $-125.583,0$ \\
& $\mathbf{E P G M}\left(\mathbf{k m}^{2}\right)$ & $+114.534,8$ & $+94.705,5$ & $+186.470,4$ & $+185.305,6$ \\
\hline
\end{tabular}

A persistência dos extremos foi definida como a ocorrência consecutiva de dias que satisfazem as condições de ENGM e EPGM. Todas as ocorrências de extremos que foram separadas por dois ou mais dias, foram consideradas como eventos independentes (BOIASKI, 2007). No setor dos MBA, predominaram eventos EPGM no período de verão (226 eventos), enquanto que o total de eventos ENGM foi de 217, ambos com persistência dominante de 01 dia (92 e 88 eventos, respectivamente), chegando a eventos com 05 dias (Figura 2.5a). Destaca-se que no ano de 1993 e 2002 (2005 e 2002) foi observado o número máximo de eventos EPGM (ENGM), totalizando 15 eventos (Figura 2.5b). No período de inverno predominou evento ENGM (total de 191 eventos), com persistência dominante de 02 dias (65 eventos), chegando a eventos com 05 dias (Figura 2.6a). O número de eventos EPGM foi de 187, apresentando persistência dominante de 02 dias. O ano de 1993 apresentou o número máximo de eventos ENGM, com um total de 15 eventos, seguido de 1998 com 13 eventos 
(Figura 2.6b). Já o número máximo de eventos EPGM em um ano foi de 12 eventos, os quais foram observados em 1992, 1999 e 2006.

a)

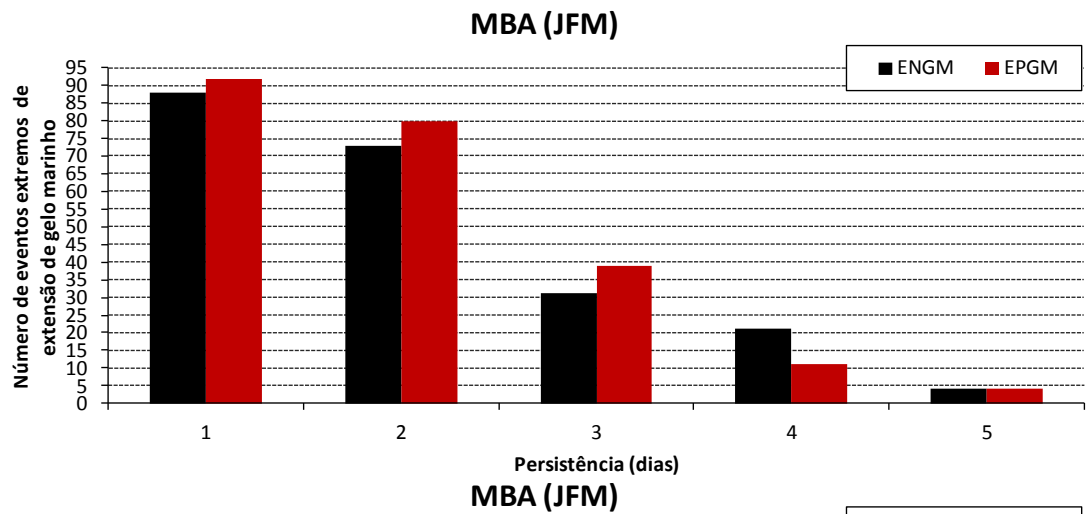

b)

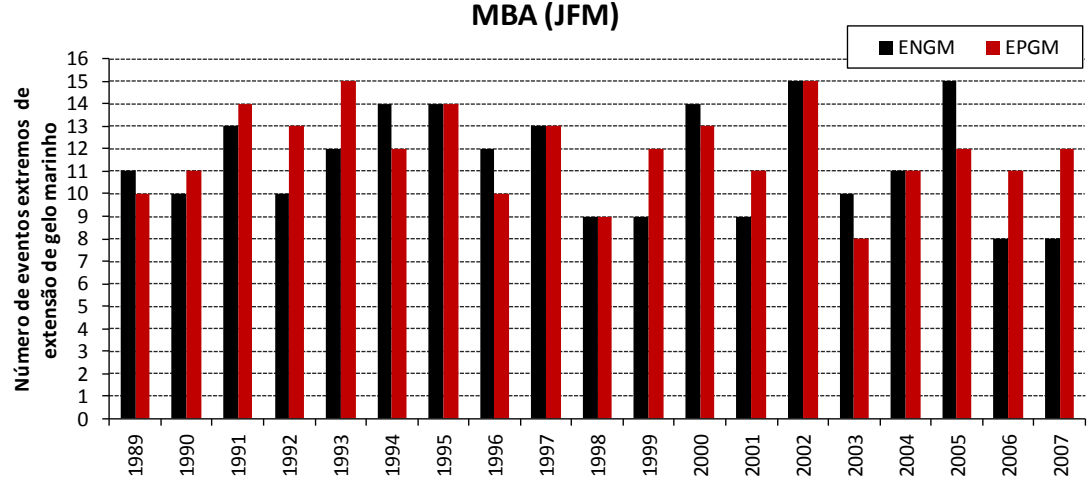

Figura 2.5: (a) Persistência dos eventos ENGM (barra preta) e EPGM (barra vermelha) e (b) número de eventos ENGM (barra preta) e EPGM (barra vermelha) de alta frequência, no setor dos MBA, durante o verão de 1989 a 2007.

a)

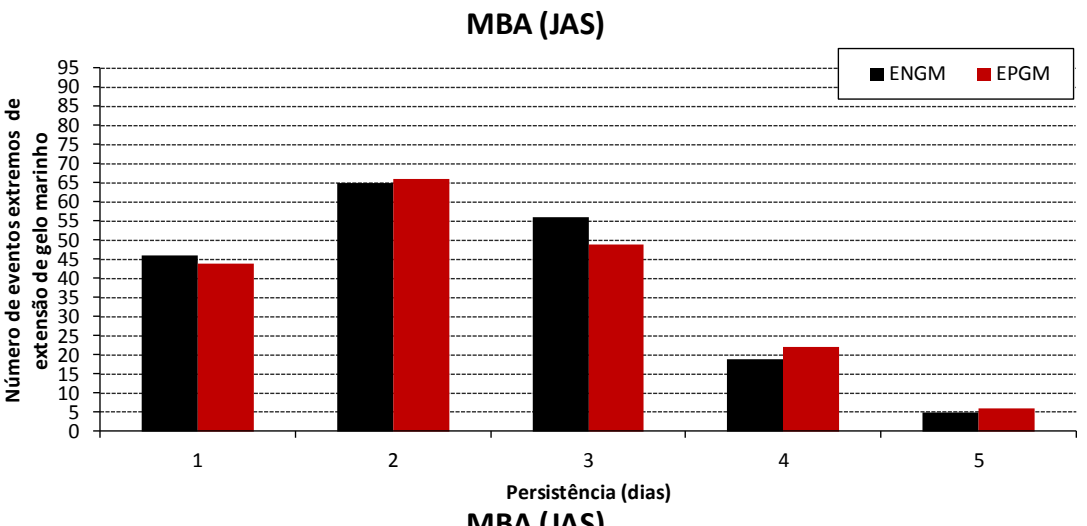

b)

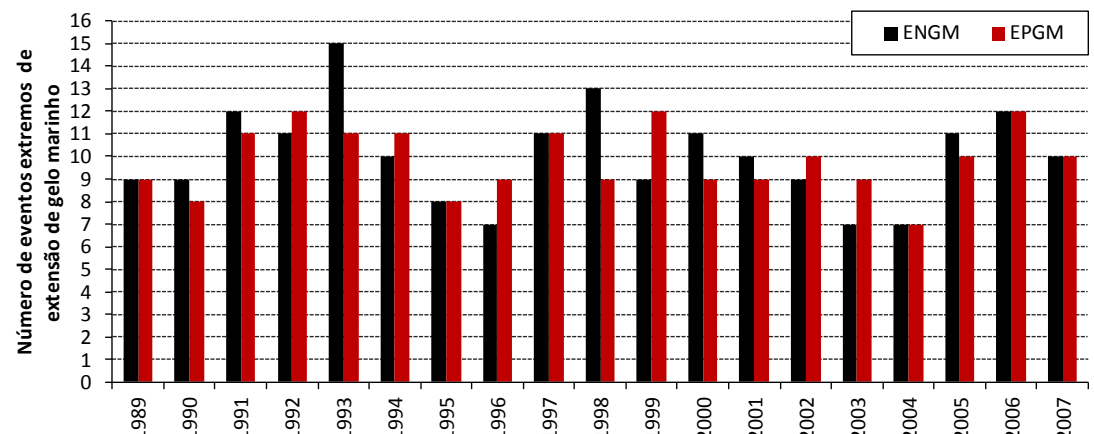

Figura 2.6: (a) Persistência dos eventos ENGM (barra preta) e EPGM (barra vermelha) e (b) número de eventos ENGM (barra preta) e EPGM (barra vermelha) de alta frequência, no setor dos MBA, durante o inverno de 1989 a 2007. 
No setor do MW predominaram eventos EPGM (199 eventos) contra 194 eventos ENGM durante o verão (Figura 2.7a). Em ambos os eventos a persistência dominante foi de 02 dias (78 e 82 eventos, respectivamente), chegando a uma persistência de 06 dias. Verificou-se que no ano de 2002 ocorreu o mesmo número de eventos ENGM e EPGM, com um total de 15 eventos (Figura 2.7b). Também foram observados 15 eventos EPGM (ENGM) nos anos de 1993 (2005). No inverno o número de eventos ENGM foi de 207, enquanto que o número de eventos EPGM foi de 201, dominando eventos com persistência de 02 dias (78 e 73 eventos, respectivamente), chegando a persistência com 05 dias (Figura 2.8a). Os anos que apresentaram o maior número de eventos ENGM foram 1991 (14 eventos), 1996 e 2004 (ambos com 13 eventos). Já os anos que apresentaram o maior número de eventos EPGM foram 1992 (13 eventos), 1994, 1996 e 2006 (todos com 12 eventos) (Figura 2.8b).

a)

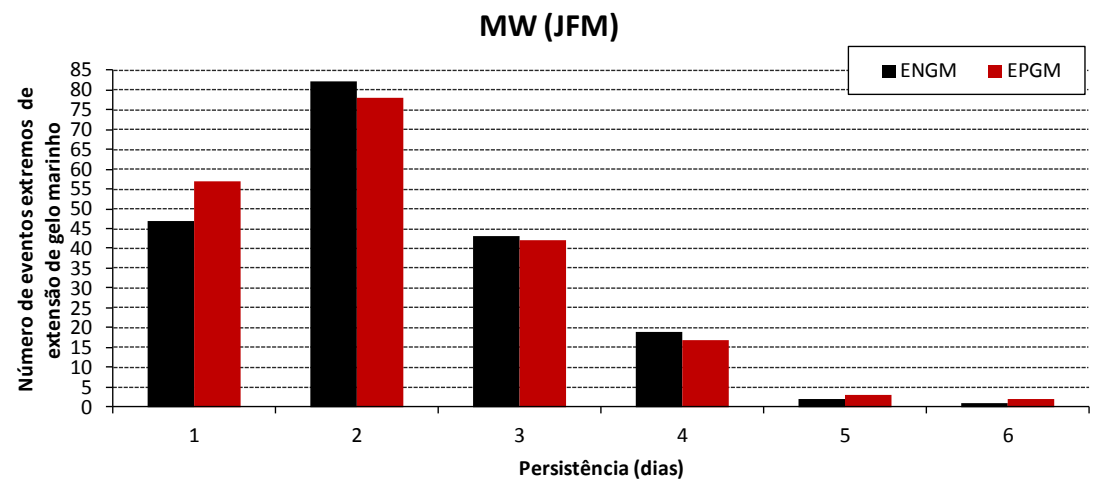

b)

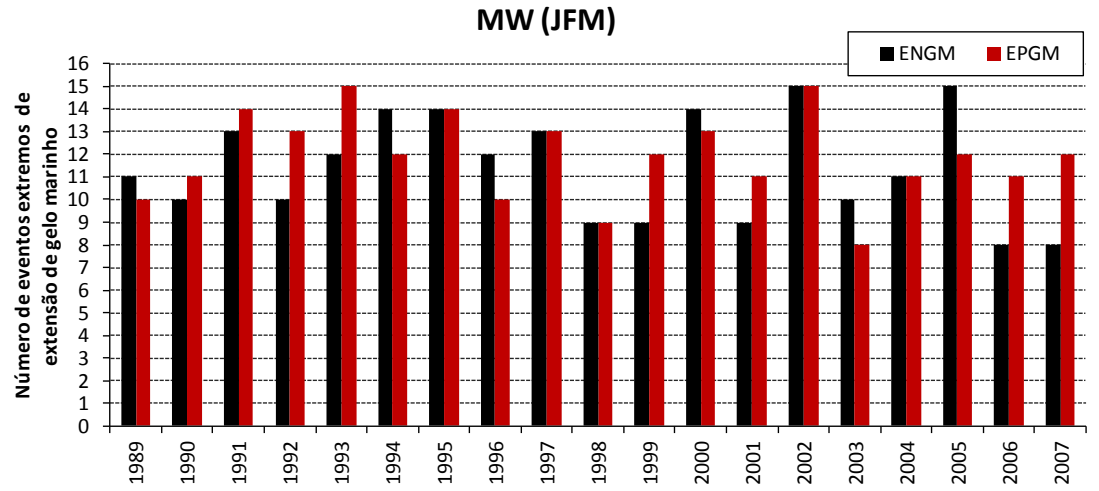

Figura 2.7: (a) Persistência dos eventos ENGM (barra preta) e EPGM (barra vermelha) e (b) número de eventos ENGM (barra preta) e EPGM (barra vermelha) de alta frequência, no setor do MW, durante o verão de 1989 a 2007. 
a)

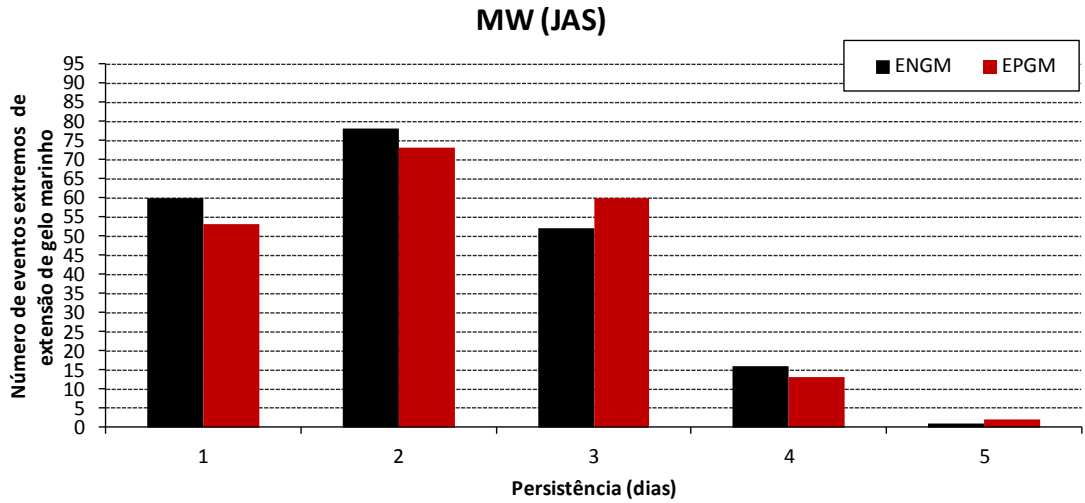

b)

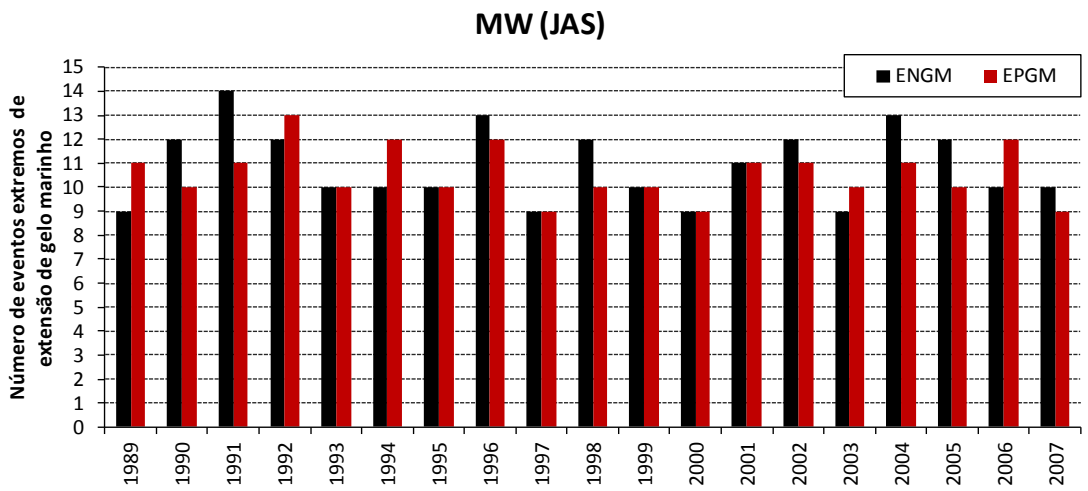

Figura 2.8: (a) Persistência dos eventos ENGM (barra preta) e EPGM (barra vermelha) e (b) número de eventos ENGM (barra preta) e EPGM (barra vermelha) de alta frequência, no setor do MW, durante o inverno de 1989 a 2007.

A persistência dos eventos ENGM/EPGM na escala interanual, durante o verão e inverno austral para os MBA, é apresentada na Figura 2.9. No verão (Figura 2.9a), foram observados 03 eventos ENGM (em 1989, 2003 e 2007) e 03 eventos EPGM (em 2000, 2002 e 2005) no setor dos MBA, com persistência de 90 dias, ou seja, eventos que persistiram por todo o período de verão. No total, foram observados 07 eventos ENGM e 06 eventos EPGM nos MBA. Durante o inverno (Figura 2.9b), predominaram eventos ENGM na escala interanual com persistência de 92 dias, totalizando 04 eventos nos anos de 1989, 1992, 1998 e 2007. Predominaram eventos EPGM (03 eventos) com persistência de 92 dias, ocorridos em 1990, 2000 e 2004. No total, foram observados 06 eventos ENGM e EPGM. No setor do MW, foram observados no período de verão (Figura 2.10a) 03 eventos ENGM (1999, 2002 e 2005) e 03 eventos EPGM (1992, 1994 e 2003) na escala interanual com persistência de 90 dias. O número total foi de 06 eventos ENGM e 07 eventos EPGM. Já no inverno (Figura 2.10b) ocorreram 03 eventos ENGM e 02 EPGM com persistência de 92 dias. O total foi de 09 eventos ENGM e 07 eventos EPGM. 
a)

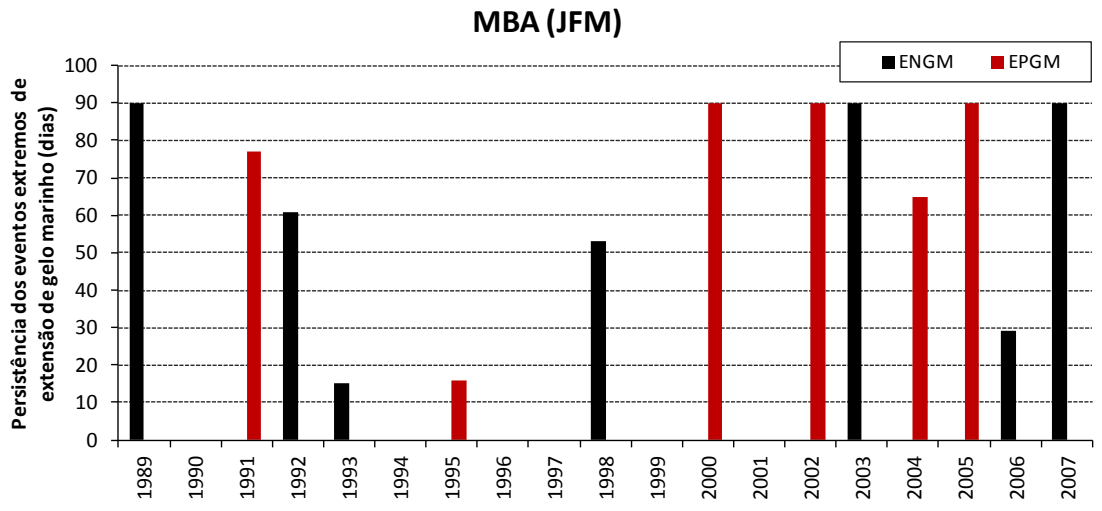

b)

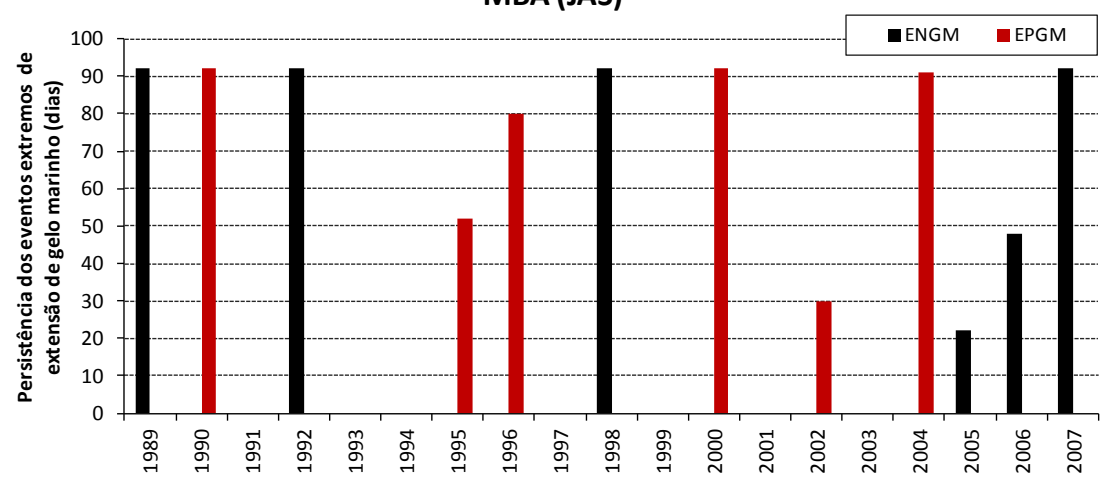

Figura 2.9: Persistência dos eventos ENGM (barra preta) e EPGM (barra vermelha) na escala interanual no setor dos MBA, durante o (a) verão e (b) inverno austral, de 1989 a 2007. Cada barra corresponde a um evento.

a)

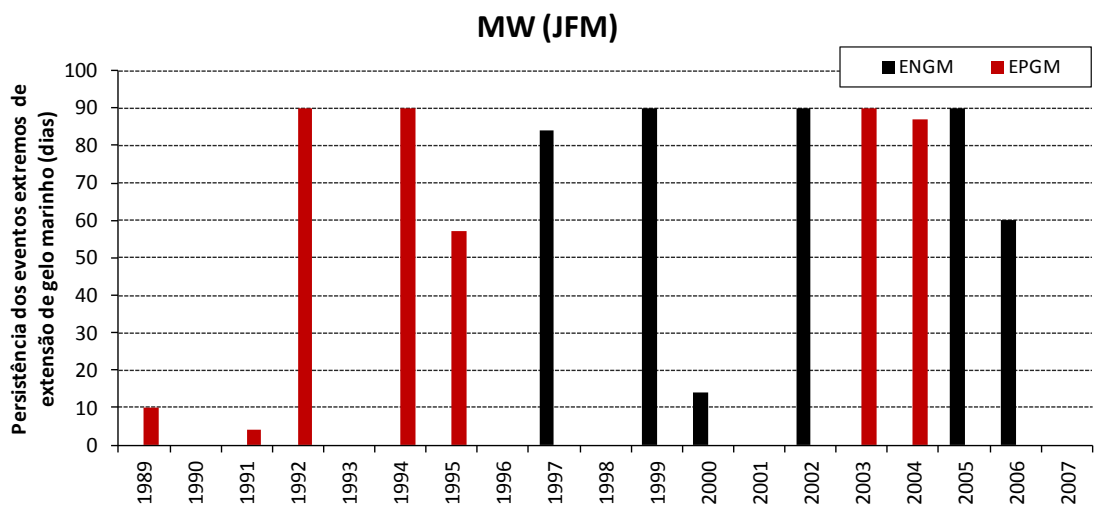

b)

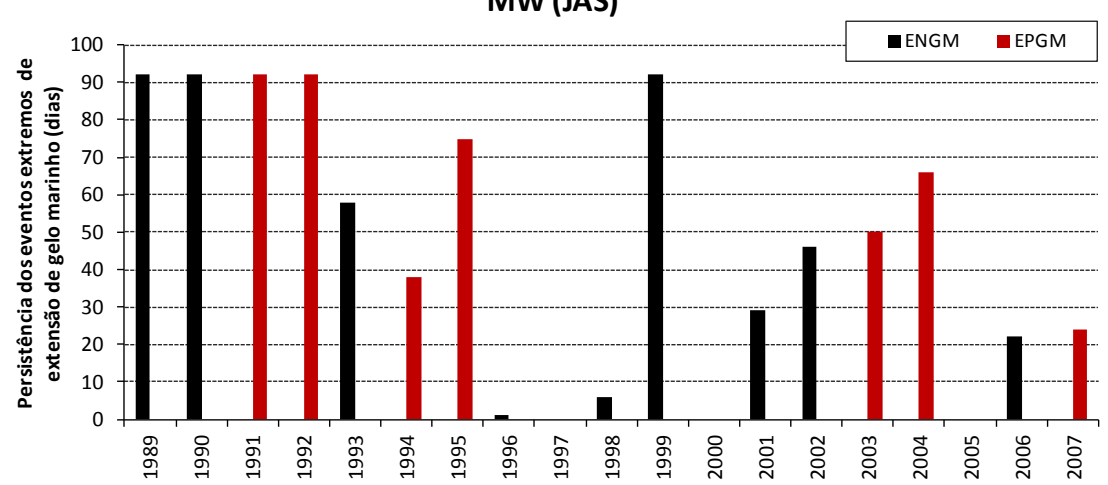

Figura 2.10: Persistência dos eventos ENGM (barra preta) e EPGM (barra vermelha) na escala interanual no setor do MW, durante o (a) verão e (b) inverno austral, de 1989 a 2007. Cada barra corresponde a um evento. 
Para analisar os padrões de circulação atmosférica nos períodos anteriores, durante e posteriores aos eventos ENGM e EPGM no setor dos MBA e do MW, foram feitas composições defasadas no tempo para as anomalias de alta frequência dos campos atmosféricos, considerando 25 dias anteriores aos eventos ENGM e EPGM (lag = -25) e 25 dias posteriores ao seu início $(\mathrm{lag}=+25)$. Dentro deste intervalo será apresentado o período em que o trem de ondas foi bem identificado e com valores de anomalias de alta frequência estatisticamente significativas ao nível de 95\% (lag $=-6$, lag $=-3$, lag $=0$ e lag $=+3$ ). A significância estatística das anomalias foi obtida com o teste t-Student, ao nível de $95 \%$.

Nas composições defasadas no tempo para as anomalias interanuais dos campos atmosféricos, foram considerados 730 dias ( 2 anos) anteriores aos eventos ENGM e EPGM $($ lag $=-730)$ e 730 dias posteriores ao seu início $(\mathrm{lag}=+730)$. Dentro deste intervalo será apresentado o período entre os lag $=-365$, lag $=-183$, lag $=0$ e lag $=+183$. Devido ao reduzido número de eventos independentes, a significância estatística das composições das anomalias interanuais não pode ser calculada. Assim, foram analisadas as composições das anomalias dos campos atmosféricos.

\subsection{Algoritmo de identificação e rastreamento de ciclones}

Para analisar a ocorrência de ciclones associados aos períodos de mínima e máxima extensão de gelo marinho na escala interanual, foi utilizada a estatística de ciclones do Automatic Cyclone Tracking, da Universidade de Melbourne (MURRAY; SIMMONDS, 1991a; MURRAY; SIMMONDS, 1991b; SIMMONDS; MURRAY; LEIGHTON, 1999; SIMMONDS; MURRAY, 1999; SIMMONDS; KEAY; LIM, 2003; LIM; SIMMONDS, 2007), obtida em http://www.earthsci.unimelb.edu.au/tracks/cychome.htm. Foram avaliadas a densidade, profundidade e raio dos sistemas através da PNMM das reanálises do NCEP-2. Basicamente, o processo de identificação da pressão mínima é feito pelo método do vizinho mais próximo, comparando a pressão de cada ponto de grade com seus arredores. Assim, o centro do sistema será o ponto de grade em que o Laplaciano da pressão é maior que o laplaciano em oito pontos de grade ao seu redor e maior também que um valor positivo previamente definido ao longo de um raio específico do centro do ciclone. Para depressões abertas, em que nenhum ponto de pressão mínima existe, o método encontra o ponto de mínimo gradiente de pressão. O sistema é rastreado desde sua formação até a sua dissipação. Para determinar a trajetória do ciclone, o método estima a nova posição e, em seguida, calcula 
a probabilidade de associação entre as posições previstas e realizadas. Vários parâmetros compõem o esquema de identificação e rastreamento de ciclones, mas não serão discutidos.

Composições de densidade, profundidade e raio dos ciclones foram calculadas para anos com as cinco maiores anomalias interanuais negativas menos anos com as cinco maiores anomalias interanuais positivas de extensão de gelo marinho para os setores dos MBA e MW, conforme a metodologia descrita por Pezza, Durrant e Simmonds (2008). Os autores mostram que dado o tamanho e distribuição da amostra de anomalias, este critério é aproximadamente equivalente a encontrar casos anômalos longe da média de 1,5 desvios padrões. Assim, para garantir o mesmo número de meses/anos para cada composição utilizou-se essa metodologia ao invés de utilizar um limite absoluto baseado em desvios padrões. Como a resposta dos ciclones é relativamente linear entre casos extremos e, com a finalidade de maximizar os padrões físicos aqui discutidos, serão apresentadas as diferenças entre os cinco meses com maiores anomalias interanuais negativas e positivas de gelo marinho (PEZZA; DURRANT; SIMMONDS, 2008). Nas Tabelas 2.2 e 2.3 pode-se visualizar os anos utilizados para o cálculo das composições.

Tabela 2.2 - Mês/anos utilizados para as composições de densidade, profundidade e raio dos ciclones entre as cinco maiores anomalias interanuais negativas menos as cinco maiores anomalias interanuais positivas de extensão de gelo marinho para o setor dos MBA.

\begin{tabular}{|cccc|}
\hline & Anomalia negativa nos MBA & menos & Anomalia positiva nos MBA \\
\hline Janeiro & $1989,1993,2003,2006$ e 2007 & $1991,2000,2002,2004$ e 2005 \\
Fevereiro & $1989,1992,1998,2003$ e 2007 & $1991,2000,2002,2004$ e 2005 \\
Março & $1989,1992,1998,2003$ e 2007 & $1991,1995,2000,2002$ e 2005 \\
Julho & $1989,1992,1998,2006$ e 2007 & $1990,1995,2000,2002$ e 2004 \\
Agosto & $1989,1992,1998,2006$ e 2007 & $1990,1995,1996,2000$ e 2004 \\
Setembro & $1989,1992,1998,2006$ e 2007 & $1990,1996,1999,2000$ e 2004 \\
\hline
\end{tabular}

Tabela 2.3 - Mês/anos utilizados para as composições de densidade, profundidade e raio dos ciclones entre as cinco maiores anomalias interanuais negativas menos as cinco maiores anomalias interanuais positivas de extensão de gelo marinho para o setor do MW.

\begin{tabular}{|c|c|c|c|}
\hline & Anomalia negativa no MW & menos & Anomalia positiva no MW \\
\hline Janeiro & $1997,1999,2000,2002$ e 2005 & & $1989,1992,1994,2003$ e 2004 \\
\hline Fevereiro & $1997,1999,2002,2005$ e 2006 & & $1992,1994,1995,2003$ e 2004 \\
\hline Março & 1997, 1999, 2002, 2005 e 2006 & & $1992,1994,1995,2003$ e 2004 \\
\hline Julho & 1989, 1990, 1999, 2002 e 2006 & & $1991,1992,1995,2003$ e 2004 \\
\hline Agosto & 1989, 1990, 1993, 1999 e 2002 & & $1991,1992,1995,2003$ e 2004 \\
\hline Setembro & $1989,1990,1998,1999$ e 2001 & & $1991,1992,1994,1995$ e 2007 \\
\hline
\end{tabular}


A densidade de ciclone refere-se ao número médio de sistemas dentro de uma área de referência de $10^{3}$ (graus latitude) $^{2}$ de área por análise (SIMMONDS; KEAY, 2000b). No HS as maiores densidades são encontradas próximas ou ao sul de $60^{\circ} \mathrm{S}$ (JONES; SIMMONDS, 1993; SIMMONDS; KEAY, 2000a; SIMMONDS; KEAY; LIM, 2003), com picos nos setores do mar de Ross, Oceano Pacífico Oeste e Oceano Índico (Figura 2.11). A máxima densidade sobre a região costeira da Antártida Oriental provavelmente é em consequência da maior baroclinia e de uma storm track mais restrita nesta região (VAN LOON; KIDSON, 1993). No mar de Ross, a máxima densidade ocorre por ser uma região de frequente decaimento e estagnação de sistemas, os quais, combinados com a confluência de sistemas oriundos da região sudeste da Austrália e Pacífico Sul, resultam em um aumento local na densidade de ciclones. No Pacífico Sul, a região de maior densidade coincide com o aumento da atividade ciclogenética, localizada sob uma região de grande nebulosidade, associada com a Zona de Convergência do Pacífico Sul semi-permanente (JONES; SIMMONDS, 1993).

No verão austral, a menor densidade de sistemas é observada no mês de janeiro (Figura 2.11a), enquanto que em março há um significativo aumento de densidade junto à região costeira antártica (Figura 2.11c). Já no inverno austral há densidade de ciclones até cerca de $30^{\circ} \mathrm{S}$, com destaque para os setores do mar de Ross e oeste dos MBA (Figuras 2.11d, 2.11e, 2.11f). No inverno e nas estações intermediárias, duas ramificações tem sido observadas em duas bandas de latitude médias, visível na densidade de ciclones. A mais notável das duas bandas de maior densidade é encontrada originária na região sudeste da Austrália, em direção ao polo, fundindo-se com o cinturão de baixas pressões nas proximidades da Passagem de Drake. A segunda banda, menos bem definida, tem origem na região da América do Sul, estendendo-se do sudeste do Atlântico Sul, e fundindo-se com o cinturão de baixas pressões no sul da África. Ambas as bandas são originárias de regiões de ciclogênese de latitudes médias, e fundem-se com o cinturão de baixas pressões nas altas latitudes (JONES; SIMMONDS, 1993). No inverno a densidade de sistemas é maior que no verão (SIMMONDS; KEAY, 2000a; SIMMONDS; KEAY; LIM, 2003), possivelmente por ser uma estação de maior formação de ciclones (JONES; SIMMONDS, 1993). 
a)

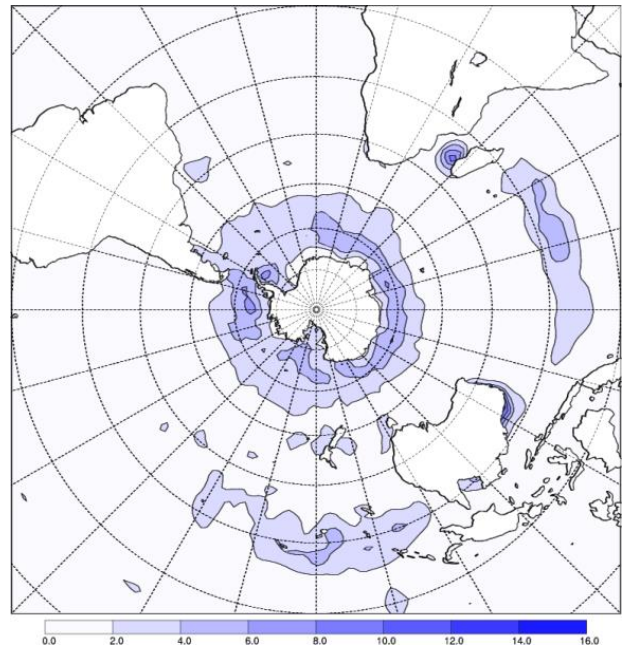

b)

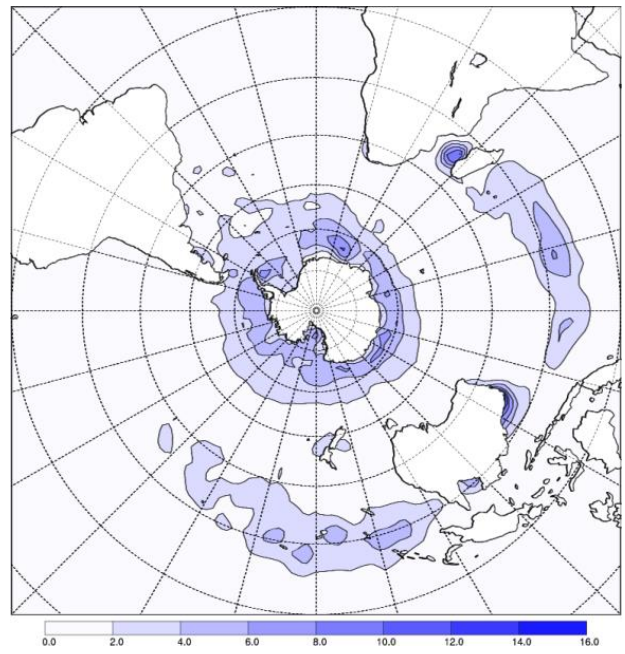

c)

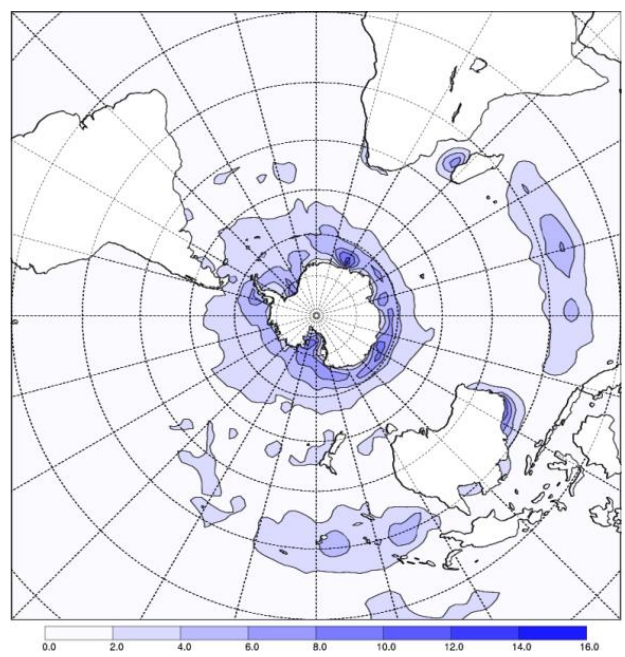

d)

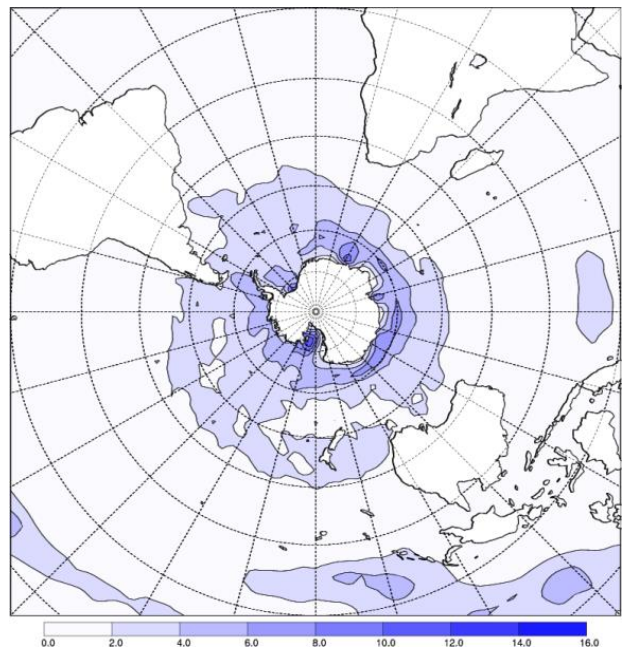

e)

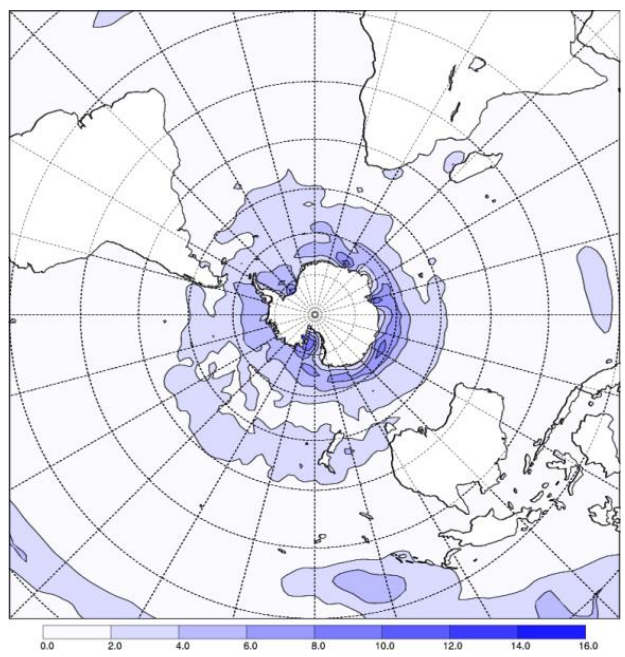

f)

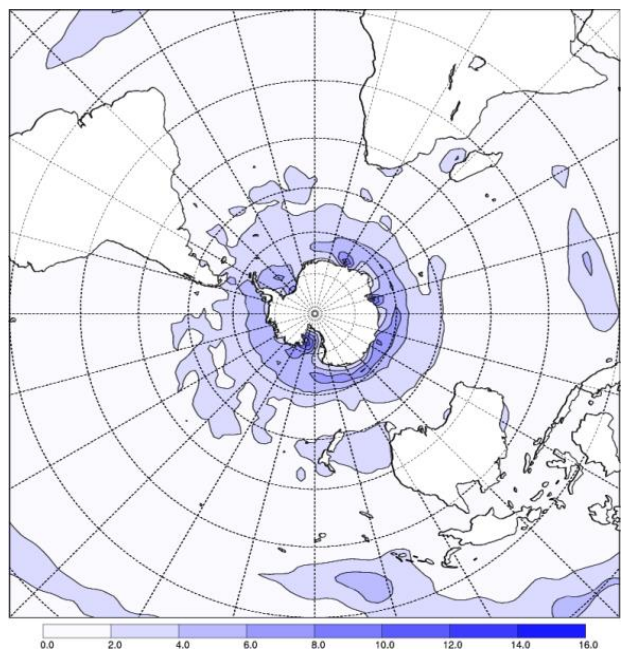

Figura 2.11: Densidade de ciclones [número de sistemas por $10^{3}\left({ }^{\circ} \text { lat }\right)^{-2}$ ] no HS, no período de verão austral: (a) janeiro, (b) fevereiro e (c) março; e de inverno austral: (d) julho, (e) agosto e (f) setembro, entre 1989 e 2007. 
A profundidade (PF) é a diferença de pressão entre o centro e a borda do ciclone, medida em hPa (SIMMONDS; KEAY; LIM, 2003; LIM; SIMMONDS, 2007). Os valores de grade da profundidade referem-se a média de profundidade de todos os sistemas que passaram próximo ao ponto da grade durante o período analisado. $\mathrm{O}$ raio $(\mathrm{R})$ e a profundidade estão relacionados através da Equação 2.17. Assim, a profundida é proporcional ao Laplaciano da PNMM e não deve ser confundida com a pressão central de um ciclone. Esta definição de profundidade com base no Laplaciano da PNMM tem a vantagem de ser relativamente insensível às tendências artificiais na PNMM, que possam existir na reanálise (PEZZA; SIMMONDS; RENWICK, 2007).

$$
P F=0,25 R^{2}\left[\nabla^{2}(P N M M)\right]
$$

O raio médio dos sistemas é apresentado na Figura 2.12. No verão austral, os maiores sistemas são encontrados em $60^{\circ} \mathrm{S}$ nos setores do Oceano Índico, Oceano Pacífico Oeste, leste dos MBA e leste do MW (Figuras 2.12a, 2.12b, 2.12c). Da mesma forma, no inverno os maiores valores de raio são encontrados nestes setores, embora menores e atingindo latitudes mais baixas (cerca de $30^{\circ} \mathrm{S}$ ), especialmente no setor do mar de Ross (Figuras 2.12d, 2.12e, 2.12f). Em ambas as estações do ano, os menores sistemas são encontrados próximos ao continente antártico e sobre a banquisa. A profundidade média dos ciclones no verão apresenta maiores valores ao sul de $60^{\circ} \mathrm{S}$, com gradual diminuição ao norte desta latitude (Figuras 2.13a, 2.13b, 2.13c). O mês de janeiro é o que apresenta as menores profundidades, destacando-se o setor do mar de Ross, enquanto que no mês de março há as maiores profundidades, com valores de até $14 \mathrm{hPa}$ nos setores do Oceano Pacífico Oeste, leste do Oceano Índico e leste do MW. Da mesma forma que no verão, no inverno as maiores profundidades são observadas ao sul de $60^{\circ} \mathrm{S}$, nos mesmos setores (Figuras 2.13d, 2.13e, 2.13f). No geral, a profundidade média dos ciclones é maior durante o inverno, com exceção do mês de março. Os resultados apresentados estão de acordo com Simmonds e Keay (2000) e Simmonds, Keay e Lim (2002). 
a)

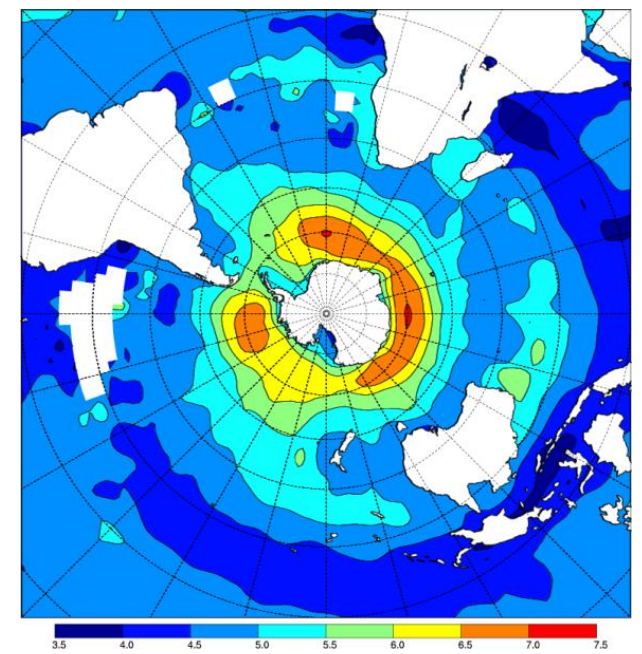

b)

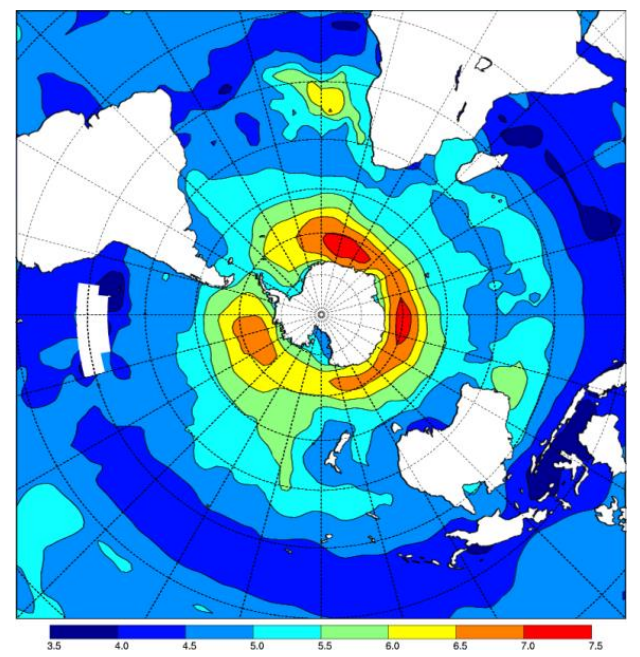

c)

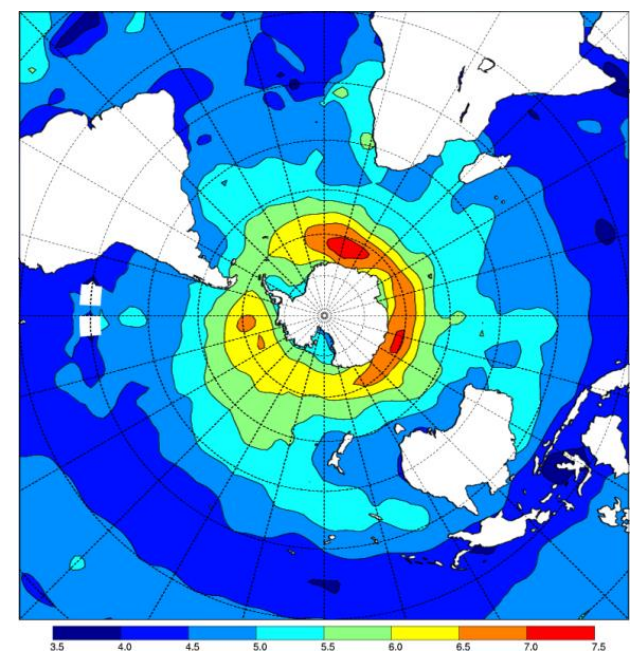

d)

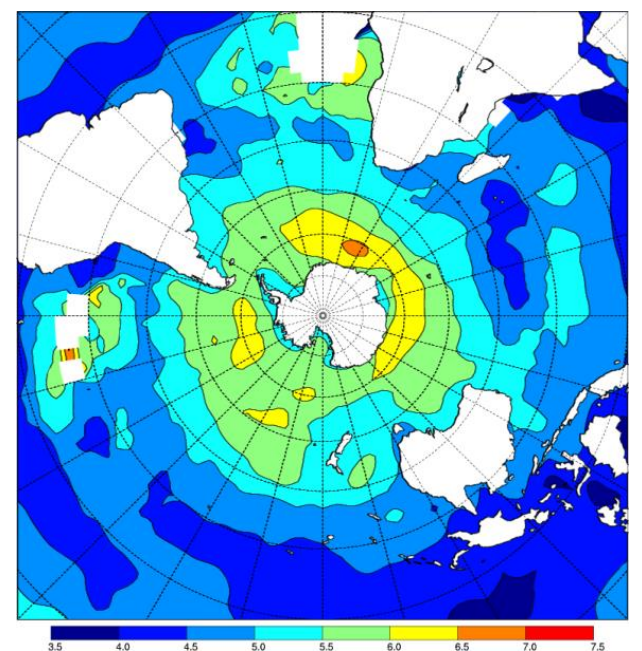

e)

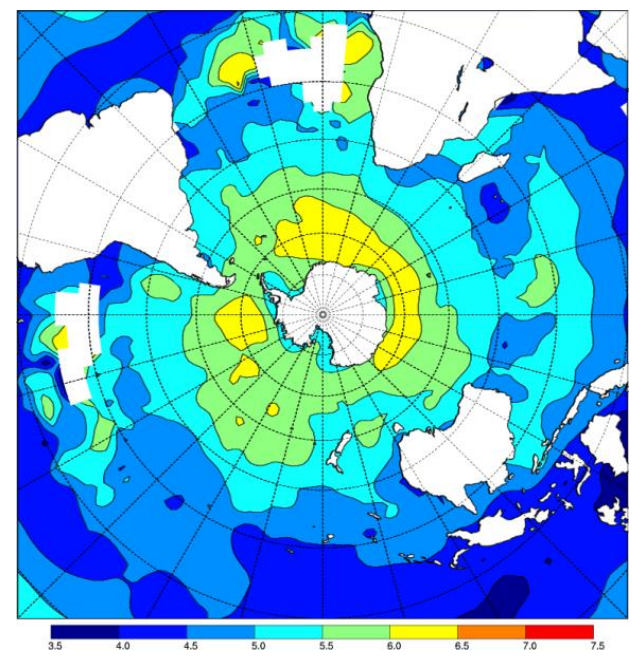

f)

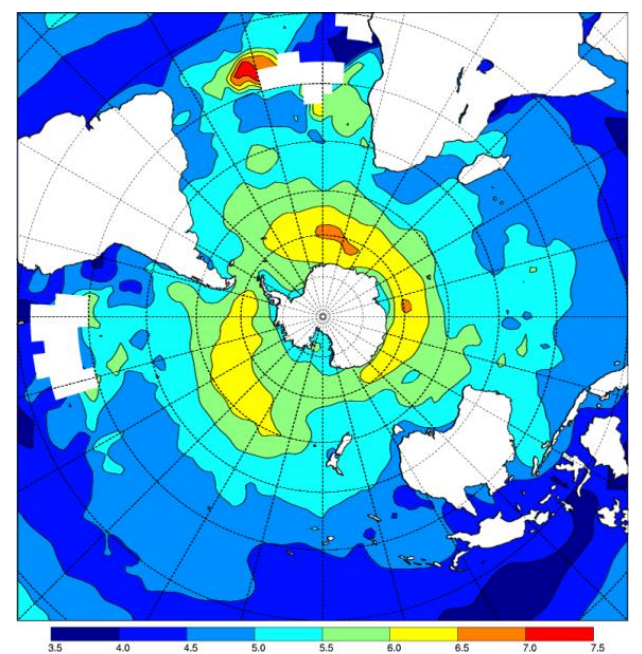

Figura 2.12: Raio dos ciclones $\left({ }^{\circ}\right.$ lat) no HS, no período de verão austral: (a) janeiro, (b) fevereiro e (c) março; e de inverno austral: (d) julho, (e) agosto e (f) setembro, entre 1989 e 2007. 
a)

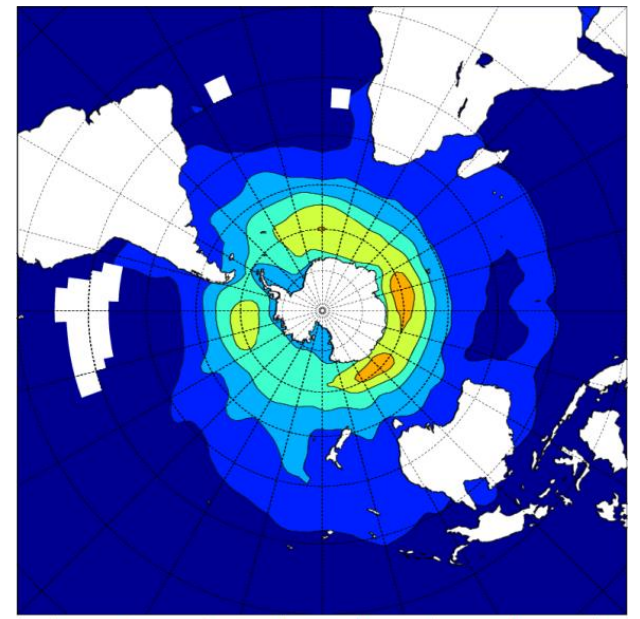

b)

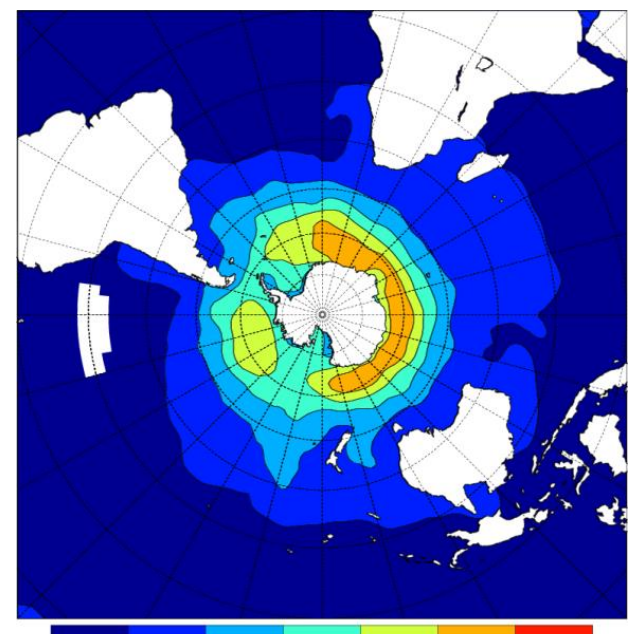

c)

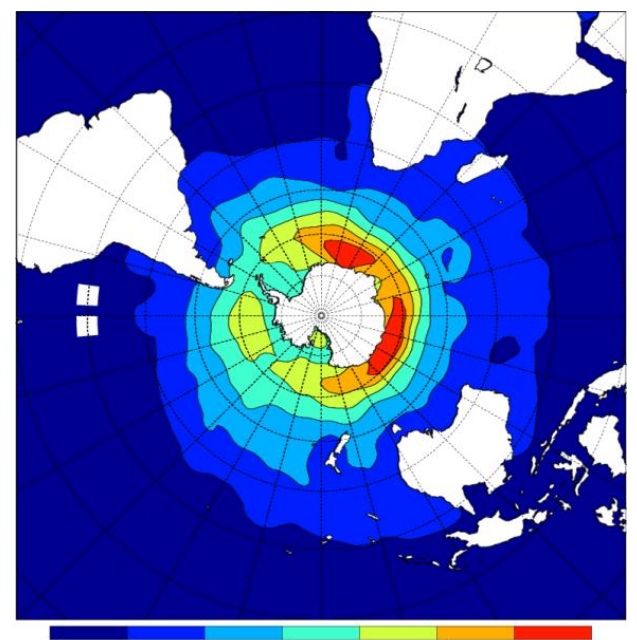

d)

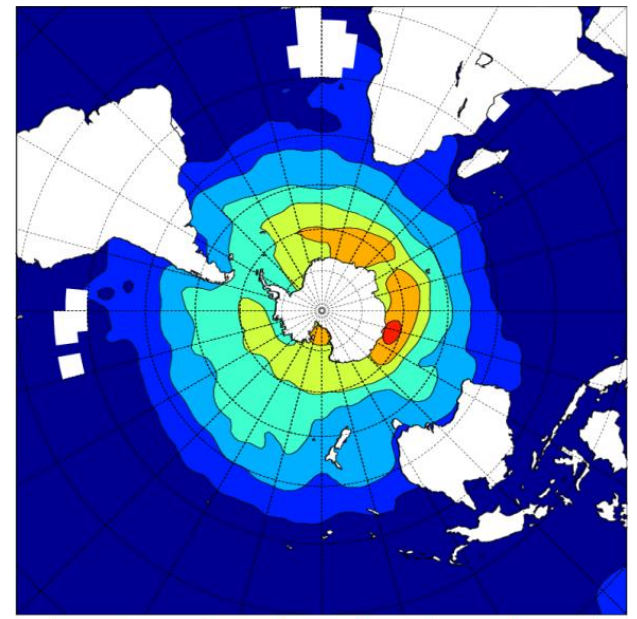

e)

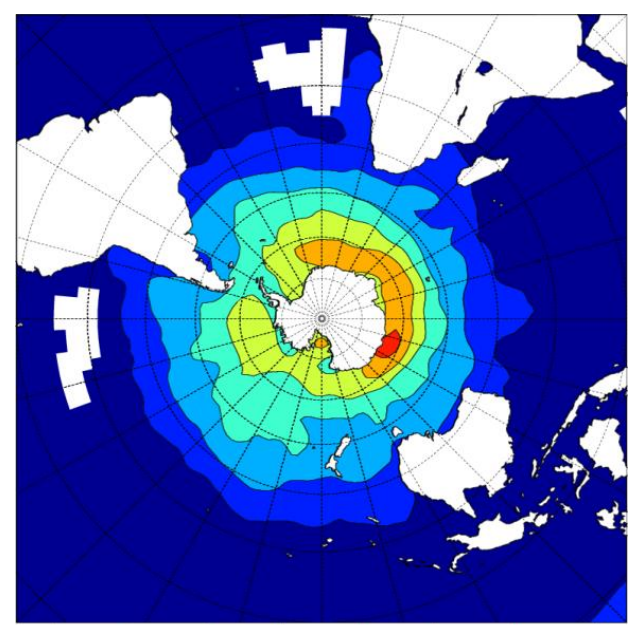

f)

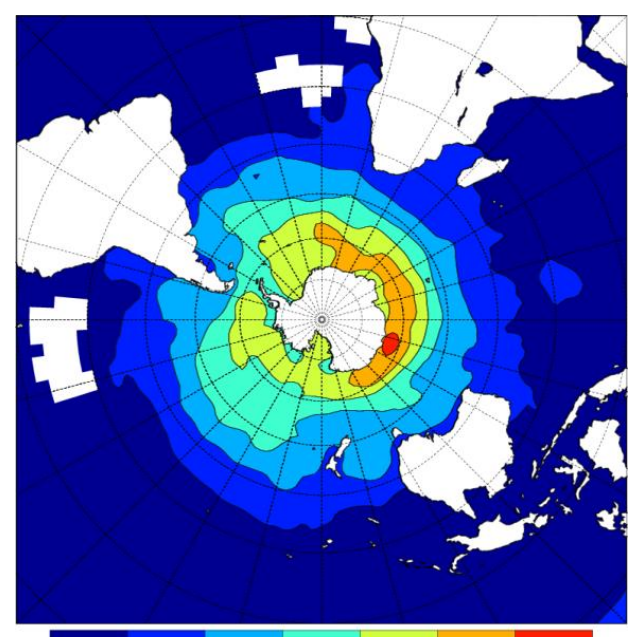

Figura 2.13: Profundidade dos ciclones (hPa) no HS, no período de verão austral: (a) janeiro, (b) fevereiro e (c) março; e de inverno austral: (d) julho, (e) agosto e (f) setembro, entre 1989 e 2007. 


\subsection{Estudo de casos}

Com o objetivo de evidenciar e exemplificar os padrões encontrados nas composições das anomalias de alta frequência dos campos atmosféricos associados aos eventos ENGM e EPGM, na mesma escala de tempo, foram feitos estudo de casos para o setor dos MBA (por apresentar maior atividade ciclônica em relação ao setor do MW) no mês de setembro (por ser o mês de maior extensão do gelo marinho antártico). Além disso, os casos foram separados em fases distintas do fenômeno El Niño (El Niño, La Niña e Neutra), tendo em vista que quando há um aquecimento na região tropical, a circulação zonal é deslocada para leste e, assim, o seu ramo ascendente ocorre no Pacífico tropical, intensificando e contraindo a Célula de Hadley nessa região. Portanto, a storm track deslocase em direção ao equador no Pacífico Sul, resultando em menor atividade ciclônica na região do setor dos MBA. Já em evento de La Niña o efeito é contrário em relação ao El Niño e, portanto, há uma maior atividade ciclônica sobre os MBA (RIND et al., 2001; LIU et al., 2002; YUAN, 2004). Desta forma, eventos ENGM e EPGM nos MBA provavelmente estarão associados a campos sinóticos distintos nas diferentes fases do El Niño.

Foram selecionados qualitativamente seis casos (Tabela 2.4), seguindo os seguintes critérios: eventos ENGM e EPGM com maior persistência e que ocorreram a partir do período com composições de imagens de satélites disponíveis; trajetória dos ciclones próxima à posição média climatológica da extensão do gelo marinho em setembro (cerca de $65^{\circ} \mathrm{S}$ nos MBA). Devido ao grande número de campos, serão apresentados somente os campos referentes às 12 UTC e para o período que corresponde a 3 dias anteriores aos eventos ENGM/EPGM até o primeiro dia do evento. Cada caso corresponde a uma fase do fenômeno El Niño: El Niño, La Niña e Neutra. O Índice de Niño Oceânico foi obtido do Climate Prediction Center da NOAA (http://www.cpc.ncep.noaa.gov/products/analysis_monitoring/ ensostuff/ensoyears.shtml), em que os episódios quentes e frios são baseados em um limiar de $\pm 0,5^{\circ} \mathrm{C}$ para o Índice de Niño Oceânico, na região do Niño $3.4\left(5^{\circ} \mathrm{N}-5^{\circ} \mathrm{S}, 120^{\circ}-170^{\circ} \mathrm{W}\right)$, com base no período de 1971-2000. Episódios quentes e frios são definidos quando o limiar for atendido por um período mínimo de cinco estações consecutivas.

Inicialmente foram analisadas as anomalias de alta frequência de temperatura do ar a $2 \mathrm{~m}$, vento zonal e meridional a 10 m, PNMM, altura geopotencial em 500 e $200 \mathrm{hPa}$ e vento zonal em $200 \mathrm{hPa}$. Por fim, foi feita a análise sinótica dos casos a partir dos campos de PNMM e vorticidade relativa (VR) em $1000 \mathrm{hPa}$; temperatura do ar a $2 \mathrm{~m}$ e vento horizontal a 
$10 \mathrm{~m}$; altura geopotencial e VR em $500 \mathrm{hPa}$; composição de imagens de satélite do canal infravermelho.

Tabela 2.4 - Casos selecionados para o estudo de casos no setor dos MBA em fases de El Niño, La Niña e Neutro em eventos ENGM e EPGM no mês de setembro.

\begin{tabular}{|ccc|}
\hline & Evento ENGM & Evento EPGM \\
\hline El Niño & $11-12 / 09 / 2004$ & $20-21 / 09 / 1997$ \\
La Niña & $14-15 / 09 / 1999$ & $17-21 / 09 / 1999$ \\
Neutro & $23-26 / 09 / 2005$ & $27-29 / 09 / 2000$ \\
\hline
\end{tabular}




\section{Capítulo 3: Resultados e discussão}

Neste capítulo serão apresentados primeiramente os resultados referentes à como a circulação atmosférica de alta frequência pode influenciar na variabilidade extrema do gelo marinho nos setores dos MBA e do MW, na mesma escala de tempo. Para isso, inicialmente será apresentada a variabilidade espacial de alta frequência das variáveis atmosféricas analisadas. A seguir serão mostradas as composições defasadas das anomalias dos campos atmosféricos associadas aos eventos ENGM e EPGM. Por fim, para evidenciar e exemplificar os padrões encontrados nas composições apresenta-se uma análise sinótica de estudo de casos para o setor dos MBA durante o inverno austral, em eventos ENGM e EPGM, separando os casos em fases distintas do fenômeno tropical El Niño. Na segunda parte serão apresentadas as características da circulação atmosférica na escala interanual associadas aos eventos ENGM e EPGM nos MBA e MW, na mesma escala de tempo, obtidas através de composições defasadas das anomalias dos campos atmosféricos. Por fim, para analisar a ocorrência de ciclones associados aos períodos de mínima e máxima extensão de gelo marinho na escala interanual serão apresentados campos de diferenças das composições de densidade, profundidade e raio dos sistemas.

\subsection{Desvio padrão das anomalias de alta frequência}

\subsubsection{Inverno austral}

Analisando o desvio padrão das composições das anomalias de alta frequência em relação aos eventos ENGM/EPGM no setor dos MBA, durante o inverno austral, destaca-se a grande variabilidade dos campos de PNMM (de até $\pm 10,0 \mathrm{hPa}$ ) e de vento meridional a $10 \mathrm{~m}$ (de até $\pm 6,0 \mathrm{~m} \mathrm{~s}^{-1}$ ) (Figuras 3.1,3.2). Observa-se uma máxima variabilidade das anomalias de PNMM no sul do Atlântico Sul e no Hemisfério Oriental, entre as latitudes de $35^{\circ}$ e $75^{\circ} \mathrm{S}$ (Figura 3.1). Já a máxima variabilidade das anomalias do vento meridional encontra-se entre as latitudes de $30^{\circ}$ e $70^{\circ} \mathrm{S}$, com um pico no sudeste do continente africano (Figura 3.2). Provavelmente essa grande variabilidade das anomalias de alta frequência de PNMM e vento 
meridional esteja associada com as storm tracks, que são regiões preferenciais em que os distúrbios de alta frequência apresentam maior energia cinética nas latitudes médias do Hemisfério Oriental no HS. Estas são regiões onde a variância das variáveis, como o geopotencial e o vento meridional, é máxima na escala de tempo menor do que 10 dias (HOSKINS, 1983; TRENBERTH, 1991; BERBERY; VERA, 1996; CAVALCANTI; KAYANO, 2000; HOSKINS; HODGES, 2005). Em relação aos eventos ENGM/EPGM no setor do MW (figuras não apresentadas), os padrões e intensidade do desvio padrão das anomalias de alta frequência de PNMM e vento meridional foram muito parecidos com os encontrados no setor dos MBA.

Climatologicamente, a storm track de inverno se distribui por uma faixa mais ampla em relação ao verão, entre aproximadamente $35^{\circ}$ e $75^{\circ} \mathrm{S}$ (SILVA, 2010), apresentando uma marcada assimetria zonal, determinada por um trem de ondas de Rossby estacionário na alta troposfera, forçado pela convecção tropical assimétrica. Já na baixa troposfera, a storm track é determinada pelo comportamento do gradiente de TSM nas latitudes médias (INATSU; HOSKINS, 2004; HOSKINS; HODGES, 2005). Durante o inverno as frentes frias atingem latitudes menores e o jato polar acompanha o deslocamento desses sistemas (ESCOBAR, 2009). Como o jato polar determina a posição média da região de máxima baroclinia, pressupõe-se que ele forneça importante suporte dinâmico aos sistemas ciclônicos, sendo determinante para a distribuição das storm tracks na região (TRENBERTH, 1991).

a)

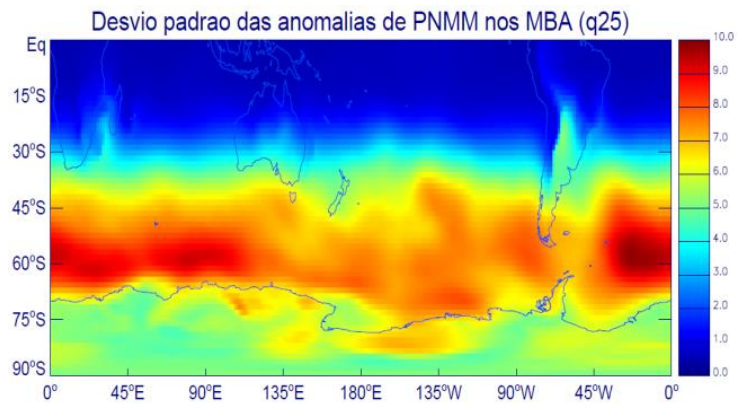

b)

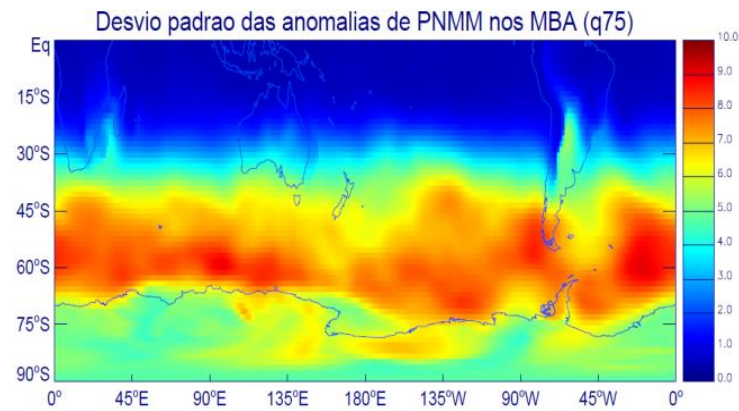

Figura 3.1: Composição do desvio padrão de PNMM no lag = 0 em eventos (a) ENGM e (b) EPGM no setor dos MBA durante o inverno austral (1989-2007).

a)

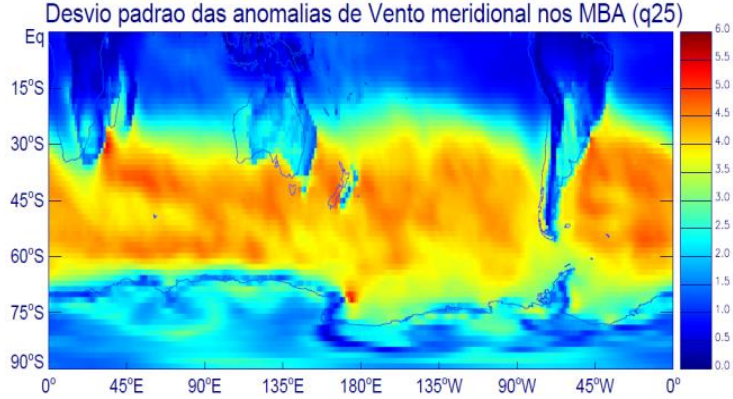

b)

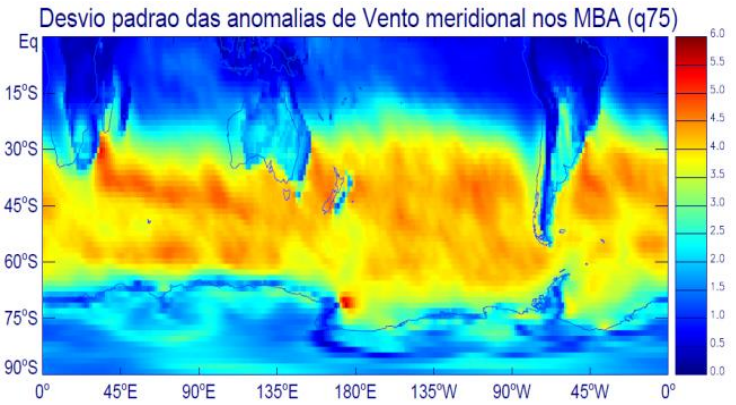

Figura 3.2: Composição do desvio padrão de vento meridional a $10 \mathrm{~m}$ no lag $=0$ em eventos (a) ENGM e (b) EPGM no setor dos MBA durante o inverno austral (1989-2007). 
A maior variabilidade das anomalias de alta frequência de vento zonal a $10 \mathrm{~m}$ foi observada na borda do continente antártico, com valores de até $\pm 6,0 \mathrm{~m} \mathrm{~s}^{-1}$ (figuras não apresentadas), provavelmente devido à variação dos ventos catabáticos, os quais possuem uma resultante de leste, coerente com a deflexão de Coriolis (KING; TURNER, 1997; BROMWICH; PARISH, 1998). Já a maior variabilidade das anomalias de alta frequência de temperatura do ar em relação aos eventos ENGM e EPGM nos MBA foi observada sobre a região do Oceano Austral coberta por gelo marinho, com maiores valores entre as latitudes de $60^{\circ}$ e $65^{\circ} \mathrm{S}$, de até $\pm 5,0^{\circ} \mathrm{C}$ (Figura 3.3). Esta região está localizada próximo à borda do gelo marinho durante o inverno austral, em que ocorrem os processos de derretimento / congelamento e o transporte de gelo marinho para norte/sul pela ação mecânica dos ventos. Portanto, esta é a região de maior variação da extensão do gelo marinho, a qual contribui nas mudanças da temperatura do ar próxima à superfície. Isso porque com o resfriamento (aquecimento) da atmosfera adjacente à cobertura de gelo marinho existe um congelamento (derretimento) do gelo, dificultando (facilitando) a absorção de radiação solar e reforçando o resfriamento (aquecimento) inicial. Este mecanismo dinâmico, conhecido como feedback positivo (negativo), é mais efetivo no inverno, e uma pequena variação na extensão de gelo marinho pode resultar em um grande impacto nas temperaturas do ar na baixa troposfera, com maiores (menores) valores de temperatura do ar associados com menor (maior) extensão de gelo marinho (TURNER et al., 2005; WALLACE; HOBBS, 2006; JUSTINO et al., 2007). Da mesma forma, em relação aos eventos ENGM e EPGM no MW (figuras não apresentadas), o desvio padrão das anomalias de alta frequência de temperatura do ar apresentou o mesmo comportamento que nos MBA.
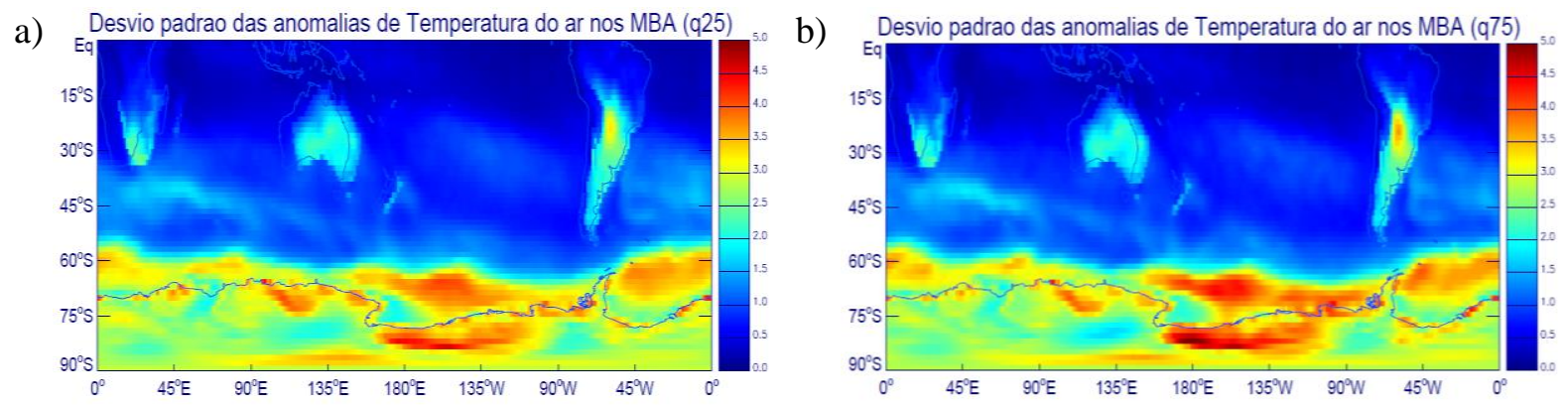

Figura 3.3: Composição do desvio padrão de temperatura do ar a $2 \mathrm{~m}$ no lag $=0$ em eventos (a) ENGM e (b) EPGM no setor dos MBA durante o inverno austral (1989-2007).

\subsubsection{Verão austral}

A região de maior variabilidade das anomalias de alta frequência de PNMM no verão, em relação aos eventos ENGM e EPGM nos MBA, foi observada em uma faixa mais 
estreita de latitudes em relação ao inverno, entre $45^{\circ}$ e $70^{\circ} \mathrm{S}$ (como também observado por Silva, 2010), com valores de até $\pm 10,0 \mathrm{hPa}$ (Figura 3.4). O vento meridional a $10 \mathrm{~m}$ apresentou maior variabilidade entre $35^{\circ}$ e $70^{\circ} \mathrm{S}$ (Figura 3.5), com desvio padrão de até $\pm 5,4 \mathrm{~m} \mathrm{~s}^{-1}$ em evento EPGM (Figura 3.5b). Destaca-se que sobre a região dos MBA e MW (figura não apresentada) em relação aos eventos EPGM há uma maior variabilidade das anomalias de alta frequência. No verão austral, a storm track apresenta uma menor assimetria zonal em relação ao inverno (INATSU; HOSKINS, 2004). Por sua vez, o jato polar apresenta maior simetria que no inverno, ficando restrito a latitudes mais altas, acompanhando o caminho das frentes frias, e apresentando sua posição mais ao norte próximo dos $35^{\circ} \mathrm{S}$ (TRENBERTH, 1991; ESCOBAR, 2009). Nos eventos ENGM/EPGM no MW (figuras não apresentadas) os padrões e intensidade do desvio padrão das anomalias de alta frequência de PNMM e vento meridional foram muito semelhantes ao observado nos eventos ENGM/EPGM nos MBA.

a)

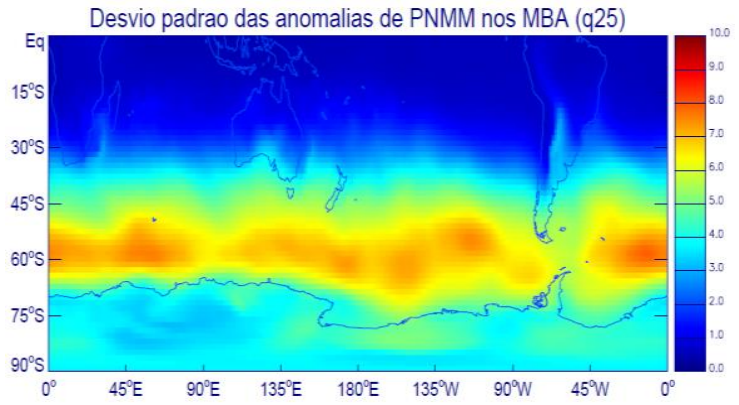

b)

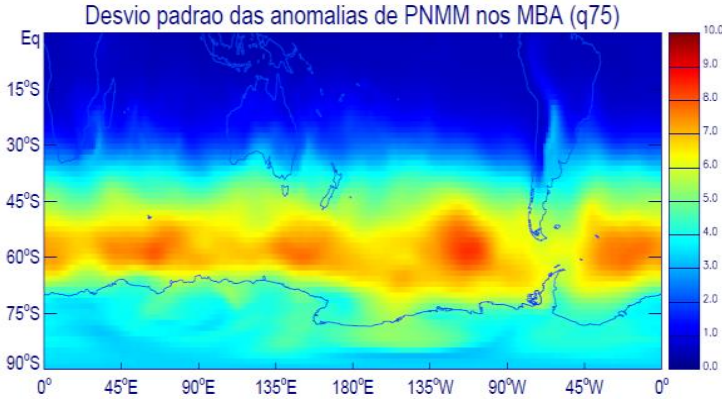

Figura 3.4: Composição do desvio padrão de PNMM no lag = 0 em eventos (a) ENGM e (b) EPGM no setor dos MBA durante o verão austral (1989-2007).

a)

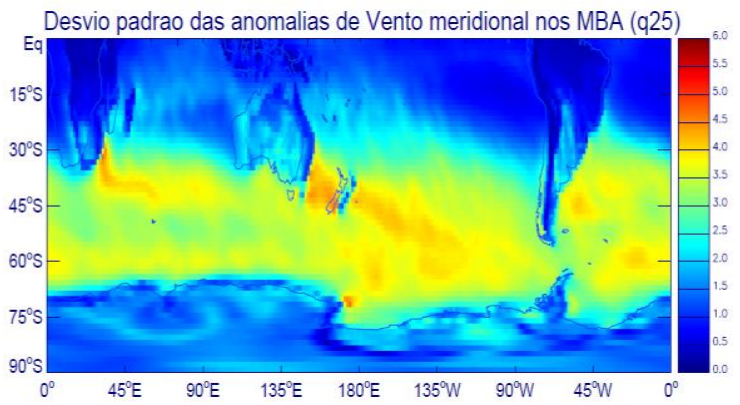

b)

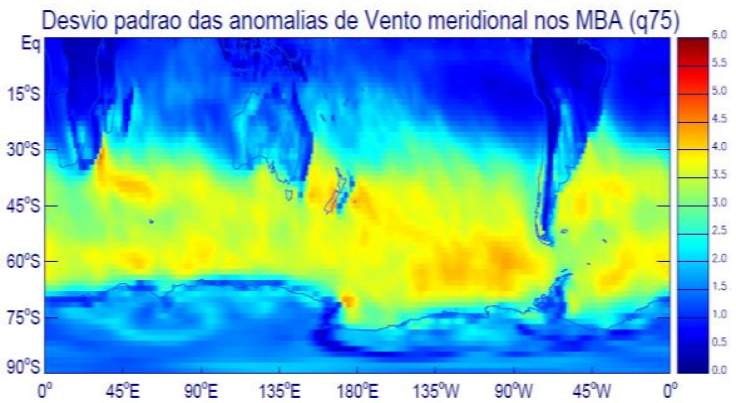

Figura 3.5: Composição do desvio padrão de vento meridional a $10 \mathrm{~m}$ no lag $=0$ em eventos (a) ENGM e (b) EPGM no setor dos MBA durante o verão austral (1989-2007).

A variabilidade das anomalias de vento zonal a $10 \mathrm{~m}$ em eventos ENGM/EPGM nos MBA e MW foi menor quando comparada ao período de inverno, apresentando maiores valores na borda do continente antártico, assim como observado no inverno, de até $\pm 5,4 \mathrm{~m} \mathrm{~s}^{-1}$ nos MBA em evento EPGM (figuras não apresentadas). Da mesma forma que as anomalias de 
vento zonal, as anomalias de temperatura do ar apresentaram menor variabilidade no verão, com valores de até $\pm 3,4^{\circ} \mathrm{C}$ nos MBA em evento EPGM (figuras não apresentadas).

\subsection{Extremos de gelo marinho associados à circulação atmosférica na escala de alta frequência}

\subsubsection{Inverno austral}

\subsubsection{Setor dos Mares de Bellingshausen-Amundsen}

Os distúrbios de alta frequência observados através das composições dos campos de anomalia de PNMM (Figura 3.6), durante os eventos ENGM e EPGM no inverno austral, descrevem um padrão de trem de ondas número 4 entre as latitudes médias e altas ao redor do HS. Destaca-se que as anomalias mais significativas estão localizadas principalmente no Hemisfério Ocidental. Cavalcanti e Kayano (1999) analisaram a variabilidade de alta frequência no HS, entre 1990 e 1994, através da análise de EOF (Empirical Orthogonal Function) do campo de altura geopotencial em $500 \mathrm{hPa}$ do NCEP/NCAR. No domínio entre $30^{\circ}$ e $70^{\circ} \mathrm{S}$, no período de inverno (maio-setembro), o primeiro autovetor da altura geopotencial em $500 \mathrm{hPa}$ mostra um padrão de trem de ondas zonal número 4 ao redor das latitudes médias do HS, com os maiores valores no Hemisfério Oriental, geralmente centrados ao sul de $45^{\circ} \mathrm{S}$.

A anomalia de alta frequência de PNMM no lag = -6, em relação aos eventos ENGM, foi positiva (anticiclônica) no oeste e centro dos MBA (Figura 3.6a), associada com a anomalia de vento zonal a $10 \mathrm{~m}$ negativa (de leste) no norte e positiva (de oeste) no sul (Figura 3.7a). Já no leste dos MBA, sobre a Península Antártica e ao sul da América do Sul a anomalia de PNMM foi negativa (ciclônica), associada com a anomalia de ventos de oeste no norte e de ventos de leste no sul. Essa configuração anômala da circulação gera anomalias de vento meridional a $10 \mathrm{~m}$ positivas, com uma intensificação dos ventos de sul ou desintensificação dos ventos de norte sobre o setor dos MBA (Figuras 3.8a), e uma consequente anomalia negativa de temperatura do ar a 2 m (Figura 3.9a).

Esse padrão de alta frequência propaga-se para leste e no lag $=-3$ uma anomalia anticiclônica no leste dos MBA, sobre a Península Antártica e ao sul da América do Sul (Figura 3.6a) está associada com anomalias de ventos de leste no norte e de ventos de oeste no sul (Figura 3.7a). No oeste do setor é observada uma anomalia de ventos de oeste no norte e de vento de leste no sul da anomalia ciclônica. Esse padrão de circulação anômalo promove a 
incursão de ar relativamente aquecido sobre o centro e leste dos MBA, através da anomalia de ventos de norte (Figura 3.8a). Portanto, há uma desintensificação e/ou inversão na direção dos ventos de sul na borda do continente antártico e uma intensificação dos ventos de norte oriundos das latitudes menores. Estes ventos são provenientes do Oceano Austral e adjacências, em que o ar é relativamente mais aquecido do que a região sobre o gelo marinho. Assim, observa-se uma anomalia positiva de temperatura do ar sobre o setor (Figura 3.9a).

No dia do evento ENGM (lag=0) observa-se uma anomalia ciclônica sobre todo o setor dos MBA (Figura 3.6a), com anomalias de ventos de oeste no norte e de ventos de leste no sul (Figura 3.7a). Assim, sobre o oeste dos MBA as anomalias foram de ventos de sul (Figura 3.8a), associadas com anomalias negativas de temperatura do ar (Figura 3.9a), e anomalias de ventos de norte no leste e sobre a Península Antártica, relacionadas com anomalias positivas de temperatura do ar. Destaca-se uma anomalia anticiclônica que atinge as latitudes de cerca de $30^{\circ} \mathrm{S}$ na América do Sul, com anomalias de ventos de sul na vanguarda e de ventos de norte na retaguarda da circulação anômala. Três dias após o evento, há uma mudança de fase das anomalias em relação ao lag $=0$, indicando que houve uma propagação para leste dos distúrbios de alta frequência. $O$ trem de ondas se desintensifica gradativamente até desaparecer completamente no lag $=+21$ (figura não apresentada).

As anomalias de alta frequência dos campos atmosféricos analisados nos eventos EPGM apresentaram um comportamento similar aos eventos ENGM, porém em fases opostas (Figuras 3.6b, 3.7b, 3.8b, 3.9b). O trem de ondas enfraquece, desaparecendo completamente no lag $=+19$ no campo de anomalia de PNMM (figura não apresentada).

Destaca-se que o trem de ondas associado ao evento EPGM nos MBA afeta a América do Sul tropical e subtropical, como pode ser visto através das composições de anomalias de alta frequência a partir do lag $=-3$, em que a anomalia de ventos de norte e anomalias positivas de temperatura do ar no sul da América do Sul estão associadas com a anomalia ciclônica no leste dos MBA e sobre a Península Antártica e a anomalia anticiclônica sobre o sudoeste do Atlântico Sul. Já relacionada à anomalia anticiclônica sobre a região sudoeste do Atlântico Sul e a anomalia ciclônica sobre o Atlântico Sul central, verifica-se uma anomalia de ventos de sul e anomalias negativas de temperatura do ar localizadas sobre o Brasil, entre as latitudes de $15^{\circ}$ e $30^{\circ} \mathrm{S}$. No lag $=0$ observa-se uma inversão de fase das anomalias de alta frequência atingindo a América do Sul. Por fim, no lag $=+3$ a propagação do trem de ondas atinge inclusive a região equatorial, apresentando anomalias de ventos de norte e anomalias positivas de temperatura do ar. Já entre as latitudes de $15^{\circ}$ e $30^{\circ} \mathrm{S}$ a anomalia é de ventos de sul, associada a anomalias negativas de temperatura do ar. 
a) ENGM
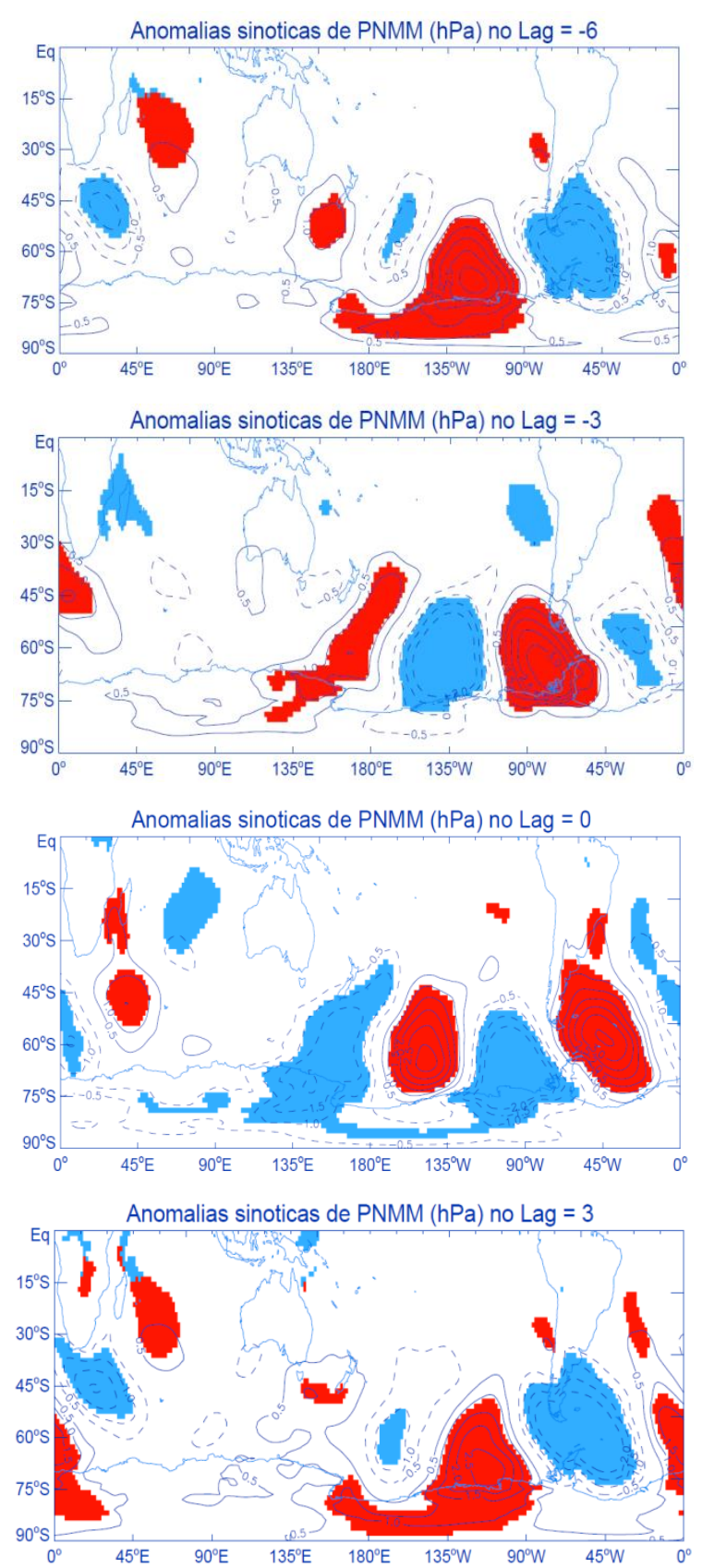

b) EPGM
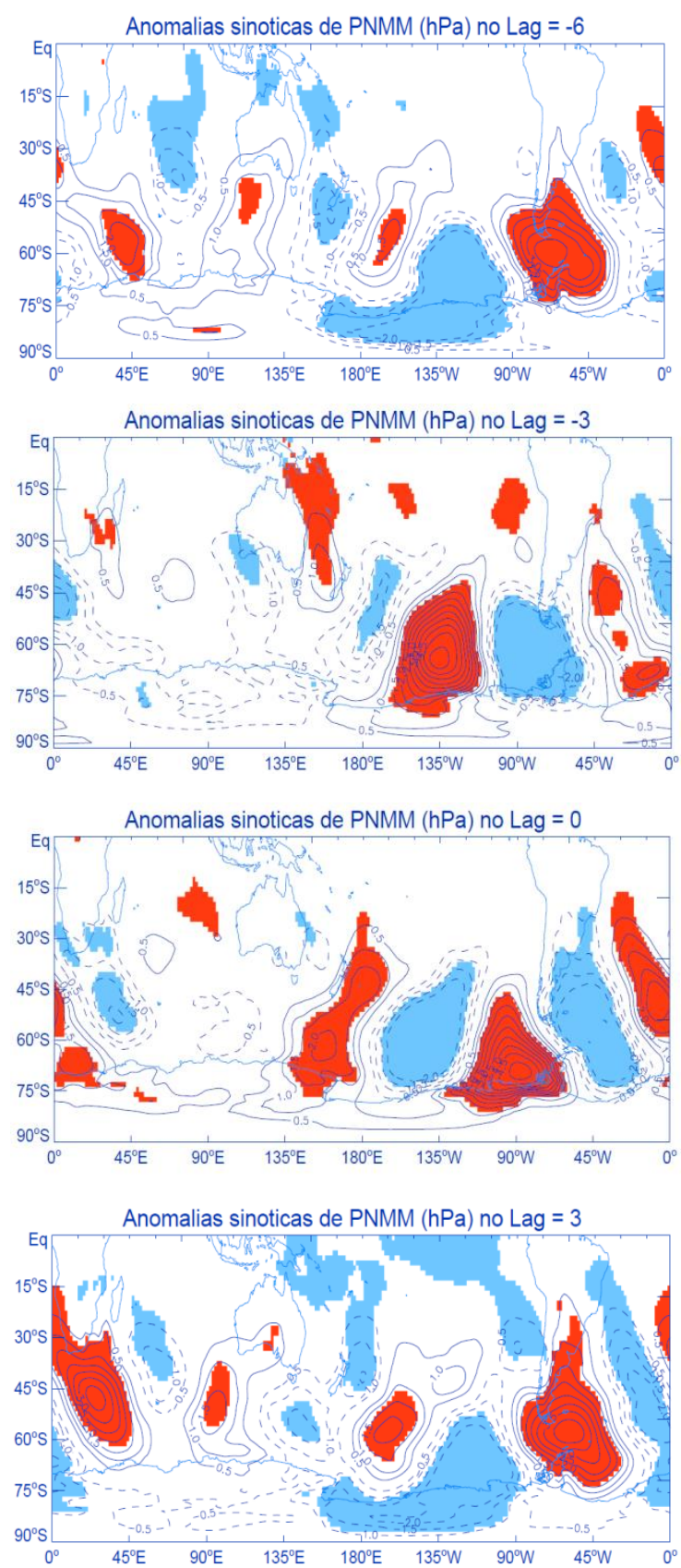

Figura 3.6: Composições defasadas das anomalias de alta frequência de PNMM (hPa) durante os eventos (a) ENGM e (b) EPGM no setor dos MBA, no lag = -6, lag $=-3$, lag $=0$ e lag $=+3$, período de inverno austral (1989-2007). Linhas contínuas (tracejadas) indicam valores positivos (negativos) de anomalias. Áreas coloridas são significativas ao nível de 95\%. 
a) ENGM
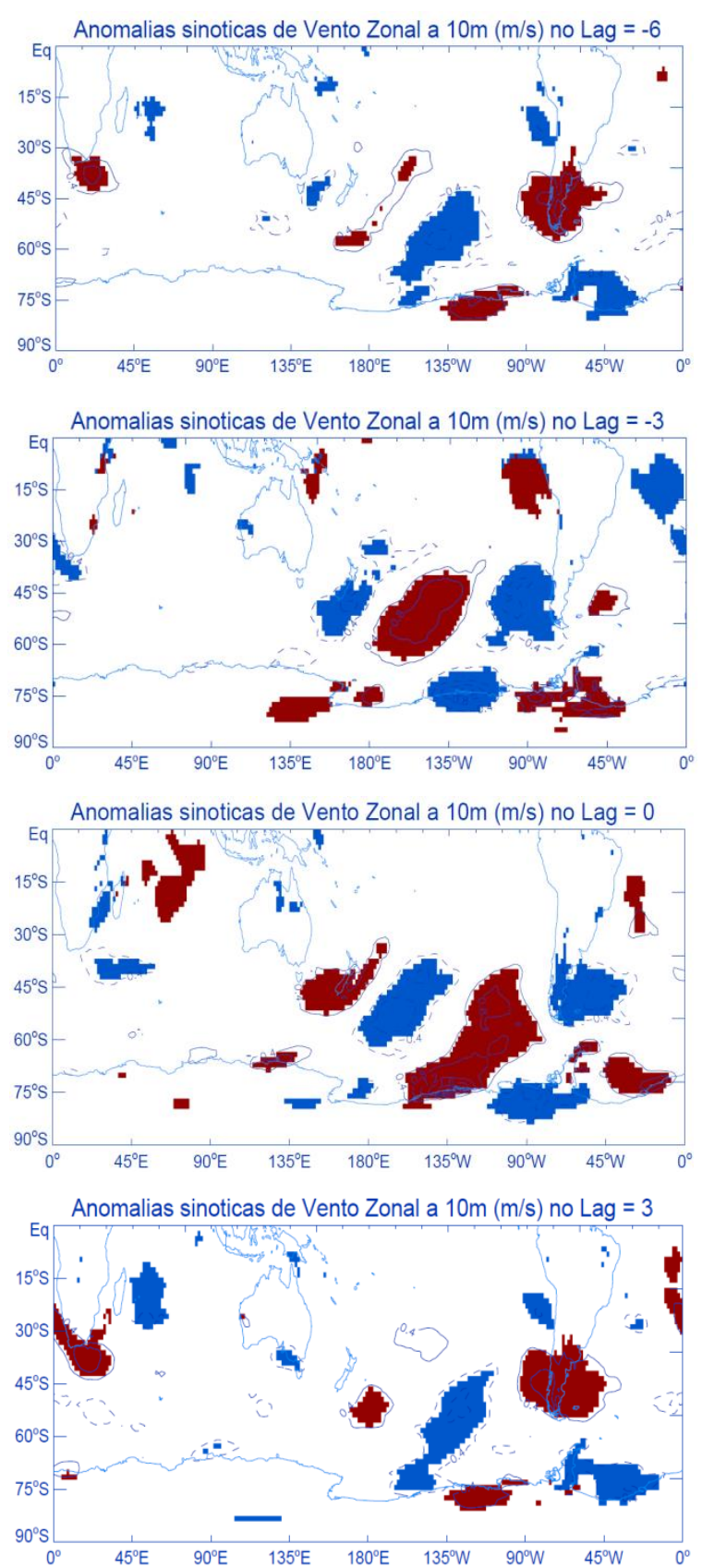

b) EPGM
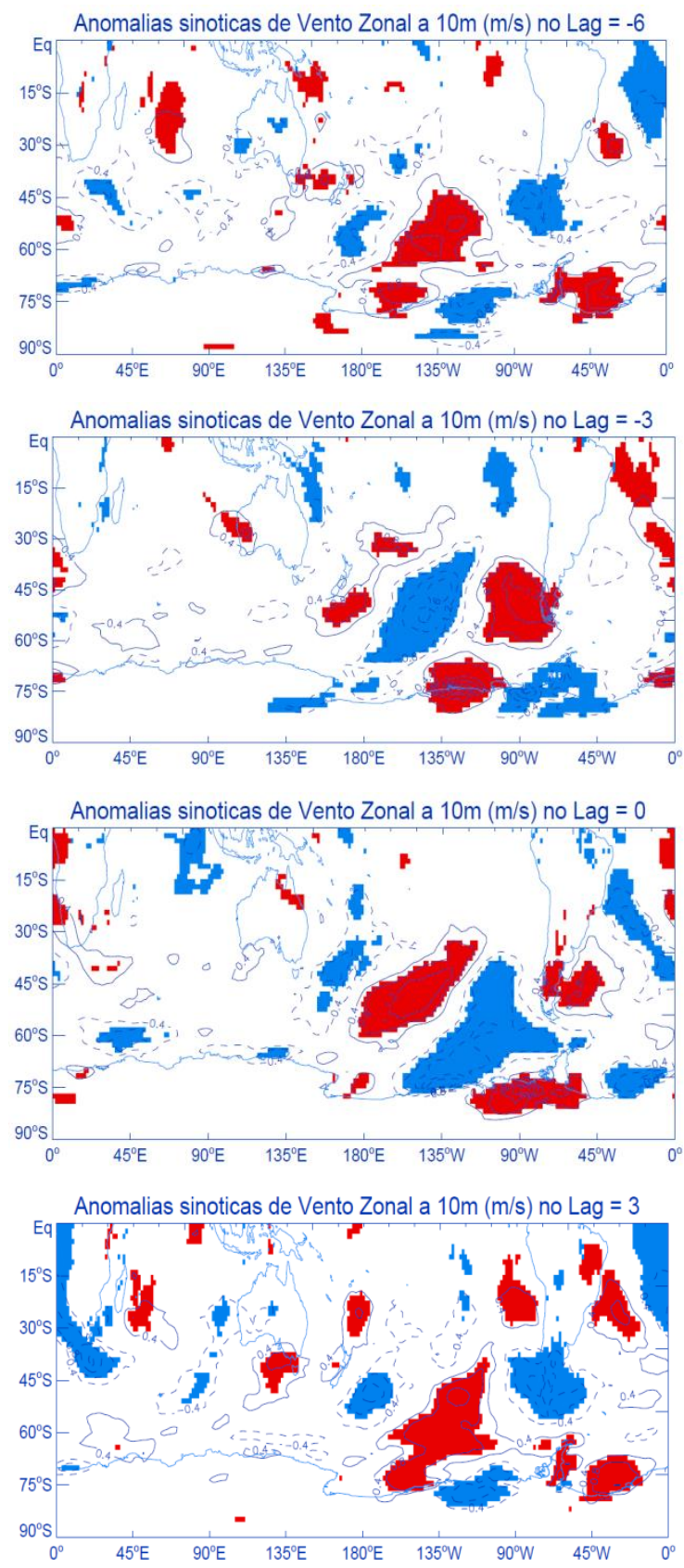

Figura 3.7: Similar à Figura 3.6, mas para as anomalias de alta frequência de vento zonal a $10 \mathrm{~m}$ $(\mathrm{m} / \mathrm{s})$. 
a) ENGM
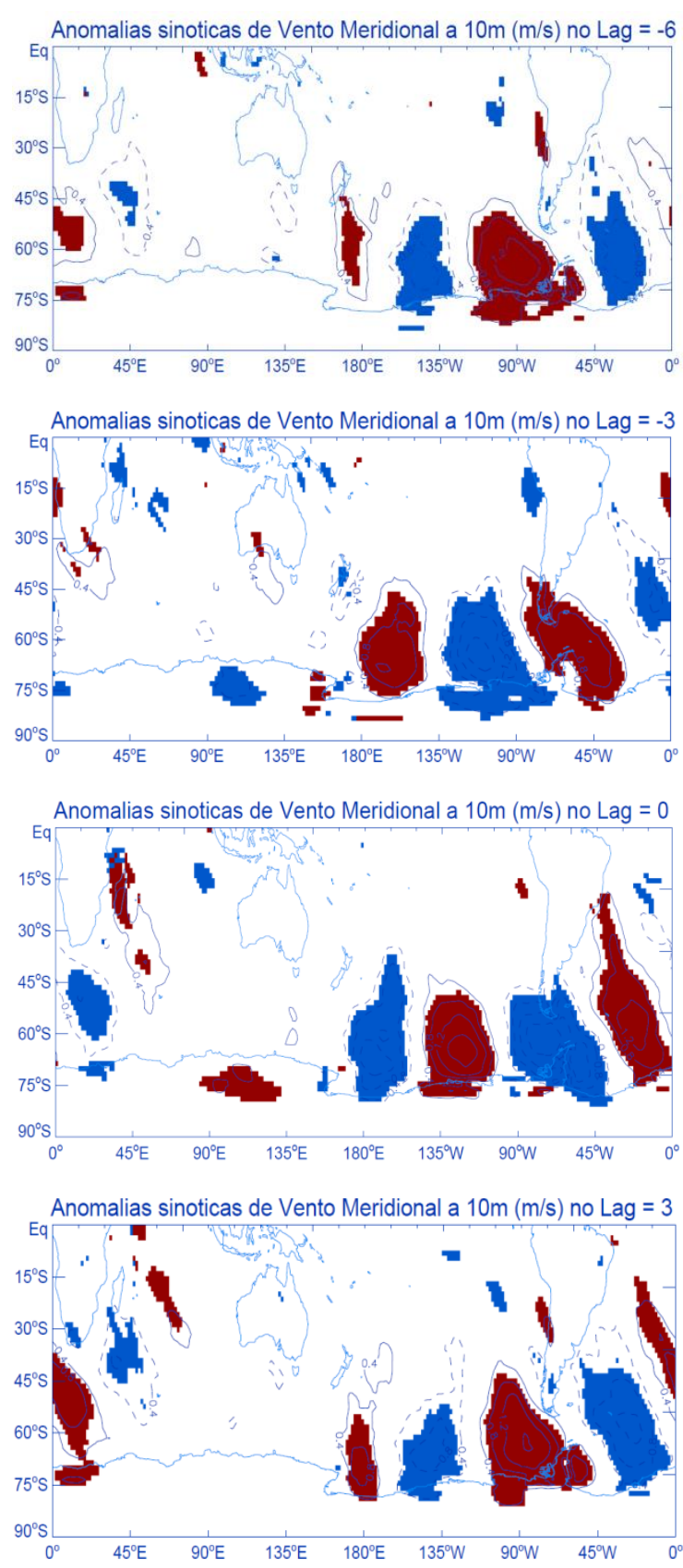

b) EPGM
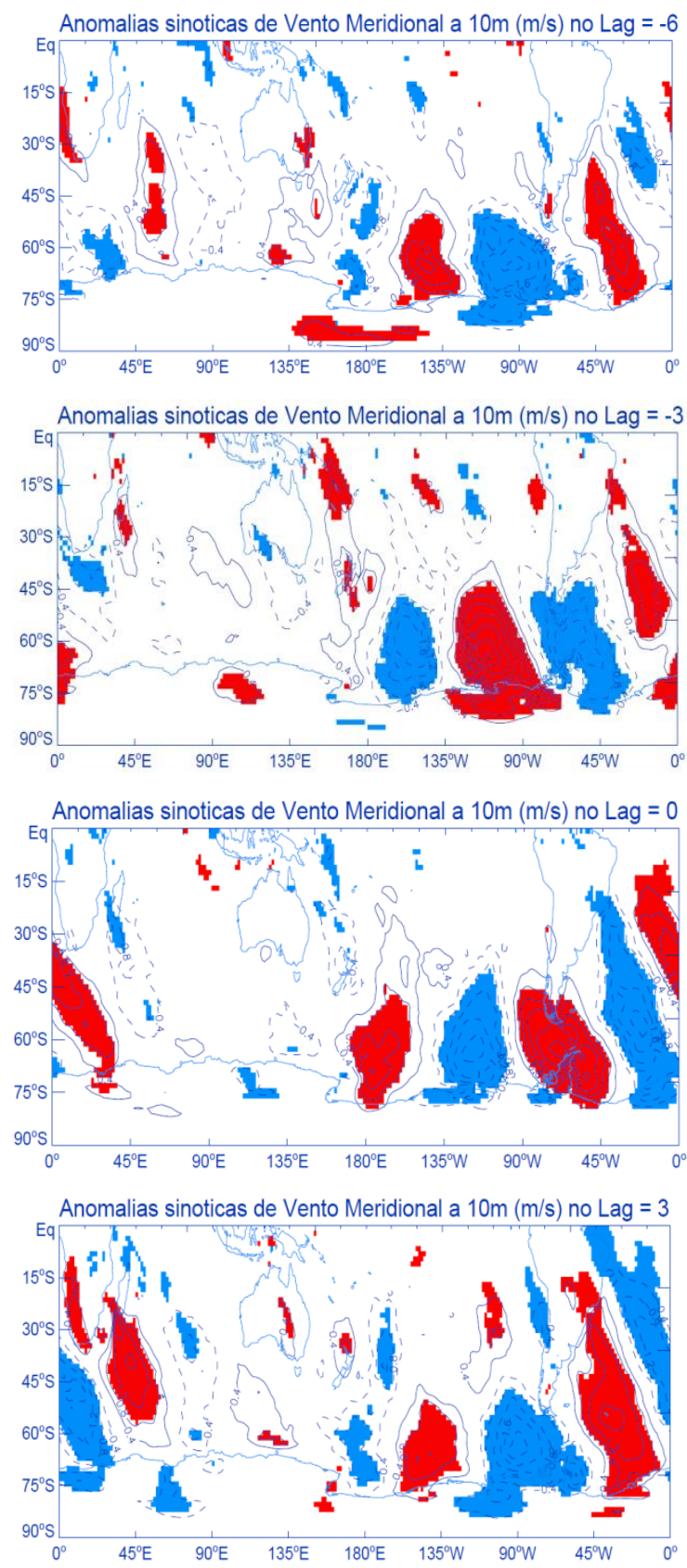

Figura 3.8: Similar à Figura 3.6, mas para as anomalias de alta frequência de vento meridional a $10 \mathrm{~m}$ $(\mathrm{m} / \mathrm{s})$. 
a) ENGM
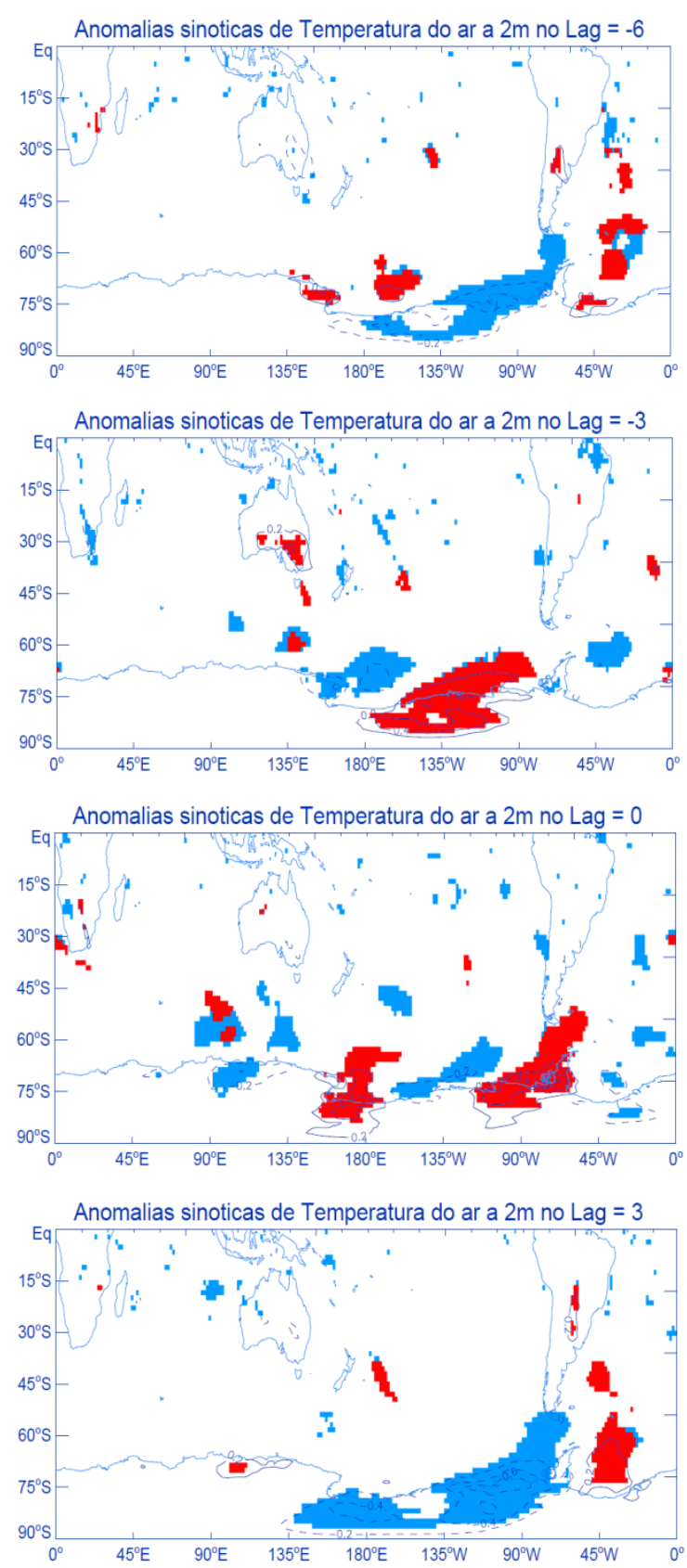

b) EPGM
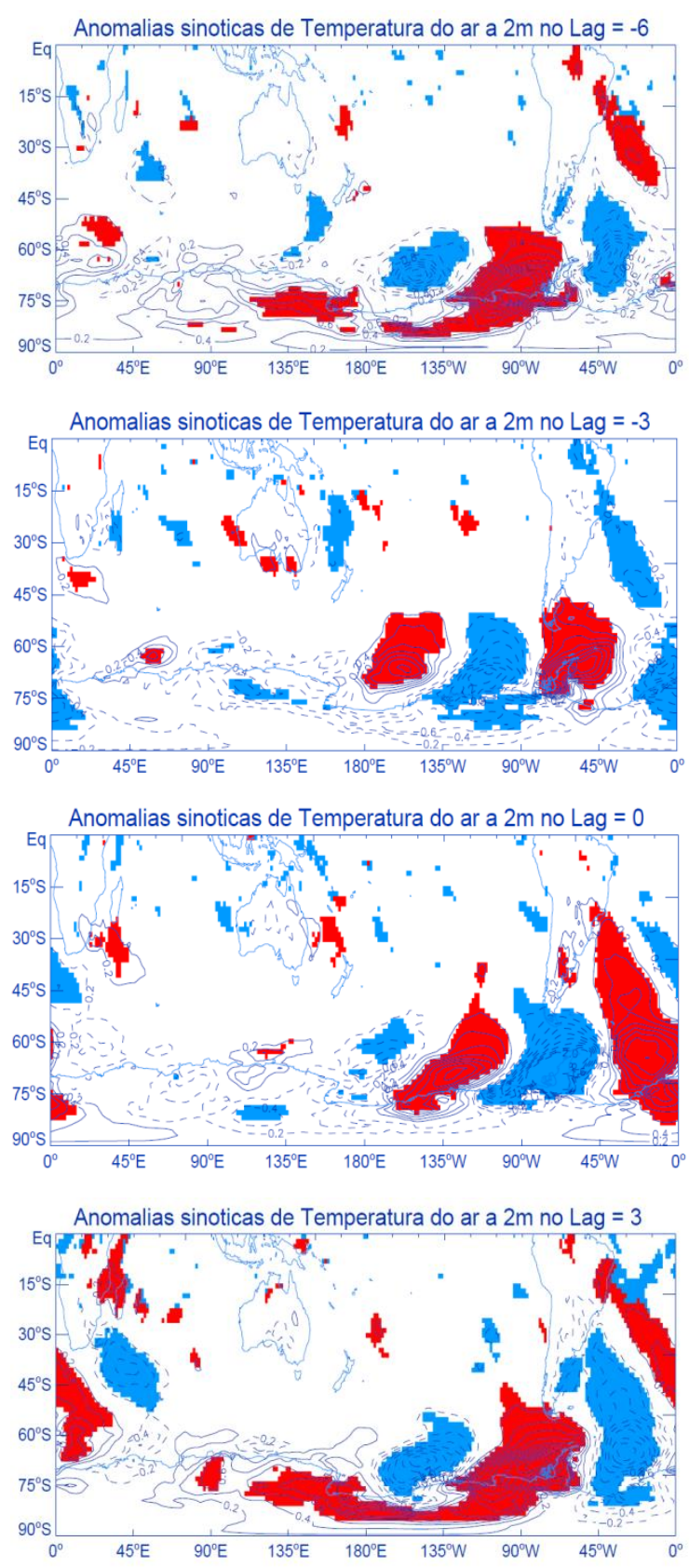

Figura 3.9: Similar à Figura 3.6, mas para as anomalias de alta frequência de temperatura do ar a $2 \mathrm{~m}$ $\left({ }^{\circ} \mathrm{C}\right)$. 


\subsubsection{Setor do Mar de Weddell}

A configuração de distúrbios de alta frequência observada a partir das composições de anomalia de PNMM nos eventos ENGM e EPGM no MW, durante o inverno austral, indica uma estrutura de trem de ondas número 4, assim como nos MBA, com anomalias mais significativas entre $90^{\circ} \mathrm{W}-0^{\circ}$ e $0^{\circ}-135^{\circ} \mathrm{E}$ (Figura 3.10). Seis dias anteriores ao evento ENGM foi observada uma anomalia anticiclônica no oeste do MW, associada com anomalias de ventos de leste no norte e de ventos de oeste no sul (Figura 3.11a). No leste do MW foi observada uma anomalia ciclônica, associada com anomalias de ventos de oeste no norte e de ventos de leste no sul. Essa configuração induz anomalias de ventos de norte sobre a Península Antártica e no oeste do MW (Figura 3.12a), onde foram encontradas anomalias positivas de temperatura do ar a 2 m (Figura 3.13a). Já no leste do setor, na vanguarda da anomalia anticiclônica há anomalias de ventos de sul, associadas com as anomalias negativas de temperatura do ar. Com a propagação para leste do trem de ondas, no lag = - 3 a anomalia ciclônica no oeste do MW (Figura 3.10a), associada com a anomalia de ventos de oeste no norte e de ventos de leste no sul (Figura 3.11a), e a anomalia anticiclônica no leste do setor, associada com a anomalia de ventos de leste no norte e de ventos de oeste no sul, induzem a uma anomalia de ventos de norte (Figura 3.12a) e, assim, a uma anomalia positiva de temperatura do ar (Figura 3.13a) sobre grande parte do MW, contribuindo assim para o evento ENGM três dias posteriores.

Já no dia do evento ENGM (lag = 0) é observada uma anomalia de ventos de leste no norte e de ventos de oeste no sul (Figuras 3.11a), associada com o giro anticiclônico anômalo sobre a Península Antártica e o oeste do MW (Figura 3.10a). Relacionadas com o giro ciclônico anômalo no leste do MW, observa-se uma anomalia de ventos de oeste no norte e de ventos de leste no sul. Assim, as anomalias de vento meridional foram de norte no oeste do MW (Figura 3.12a), acompanhadas por anomalias positivas de temperatura do ar (Figura 3.13a), e de ventos de sul no leste do setor, com anomalias negativas de temperatura do ar. No lag $=+3$ as anomalias sinóticas estão em fase oposta ao lag $=0$. Há uma desintensificação dos distúrbios de alta frequência, os quais desaparecem completamente no lag $=+8$ no campo de anomalias de PNMM (figura não apresentada).

As anomalias sinóticas dos campos atmosféricos em todos os casos (composições defasadas) de eventos EPGM apresentam fases opostas em relação aos eventos ENGM (Figuras 3.10b, 3.11b, 3.12b, 3.13b). O trem de ondas se desintensifica gradativamente até desaparecer no lag $=+12$ no campo de PNMM (figura não apresentada). 
Destaca-se que no lag $=+3$ o trem de ondas associado ao evento EPGM no MW afeta a região da costa leste da América do Sul, entre as latitudes de $15^{\circ}$ e $45^{\circ} \mathrm{S}$, através das anomalias de ventos de norte e anomalias positivas de temperatura do ar, associadas à anomalia ciclônica sobre sudoeste do Atlântico Sul e à anomalia anticiclônica centrada em cerca de $30^{\circ} \mathrm{S}$ sobre o Atlântico Sul.

\section{a) ENGM}
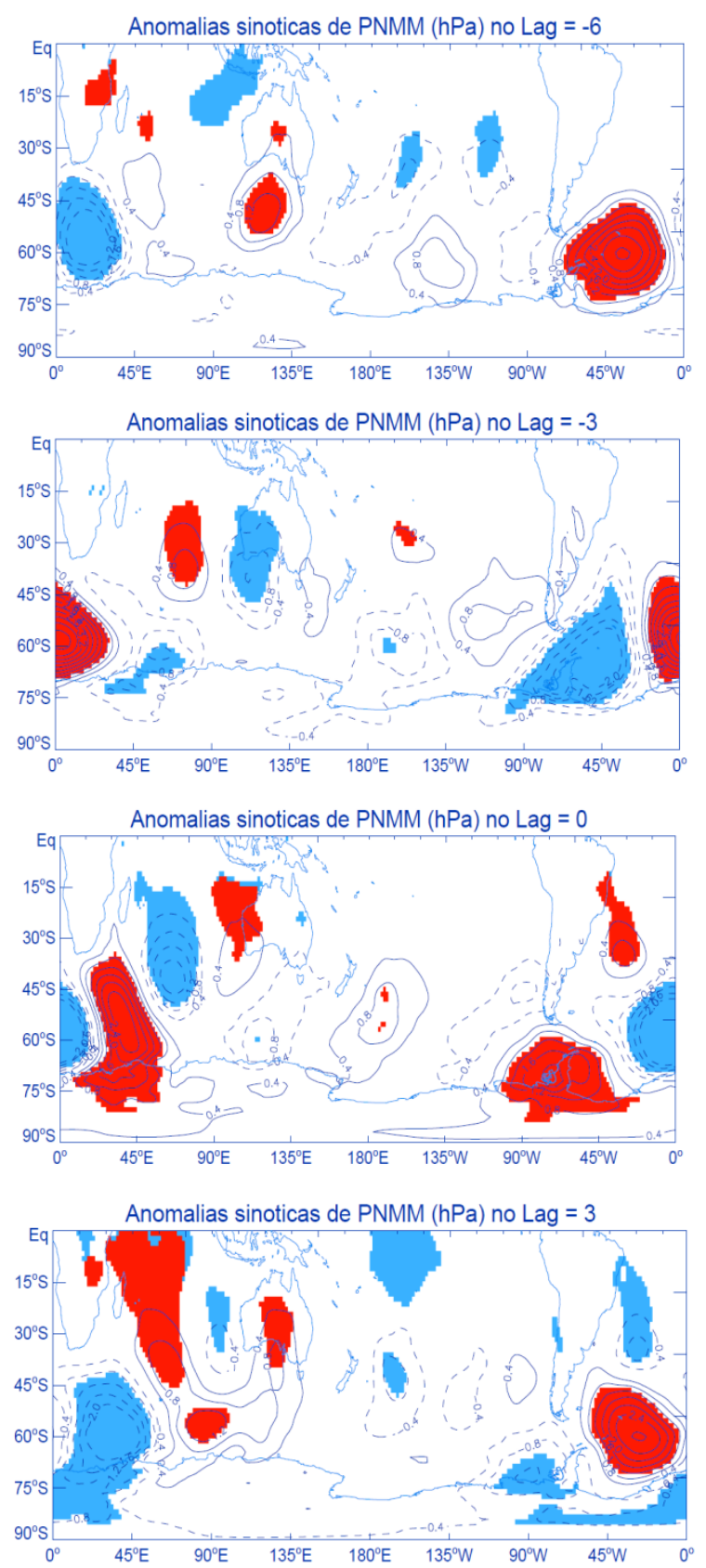

b) EPGM
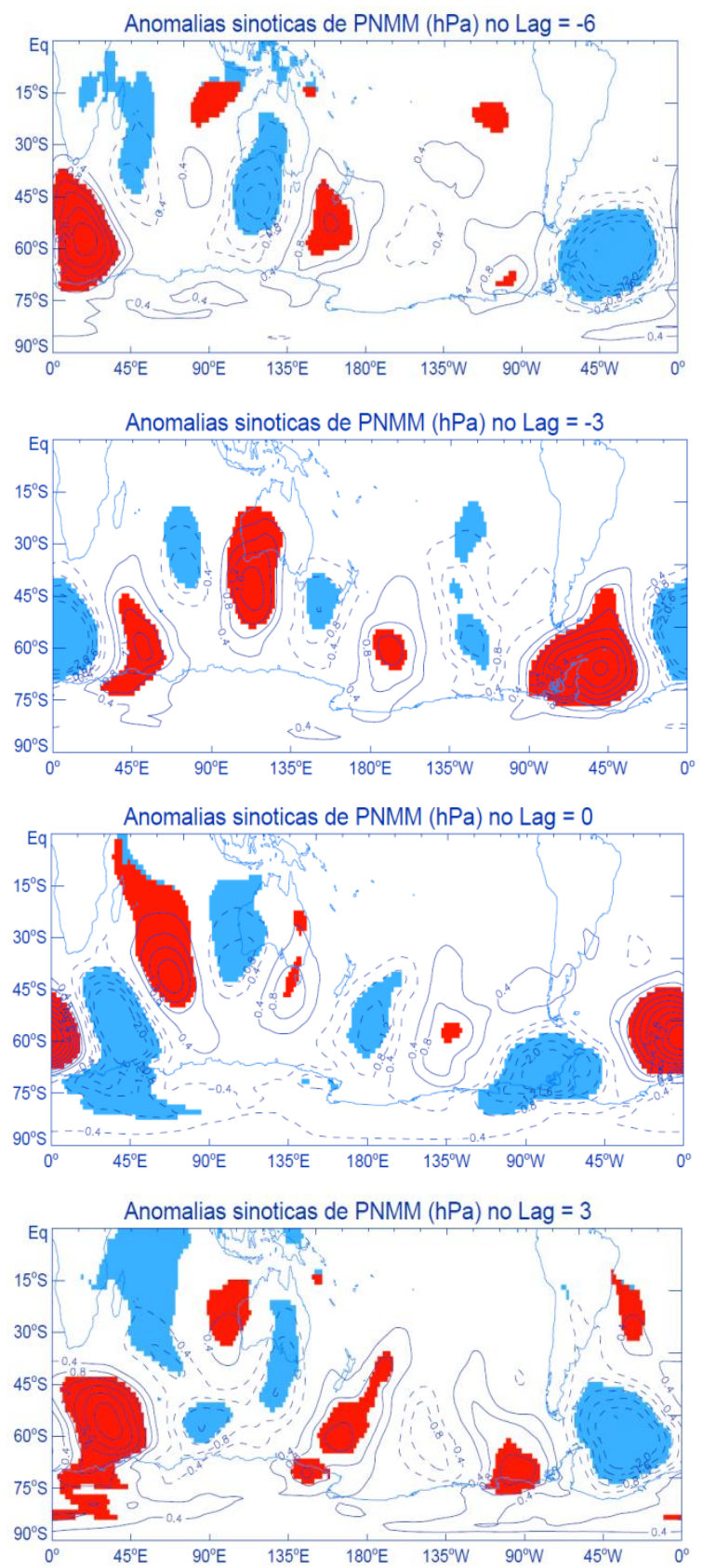

Figura 3.10: Composições defasadas das anomalias de alta frequência de PNMM ( $\mathrm{hPa}$ ) durante os eventos (a) ENGM e (b) EPGM no setor do MW, no lag $=-6$, lag $=-3$, lag $=0$ e lag $=+3$, no período de inverno austral (1989-2007). Linhas contínuas (tracejadas) indicam valores positivos (negativos) de anomalias. Áreas coloridas são significativas ao nível de 95\%. 
a) ENGM
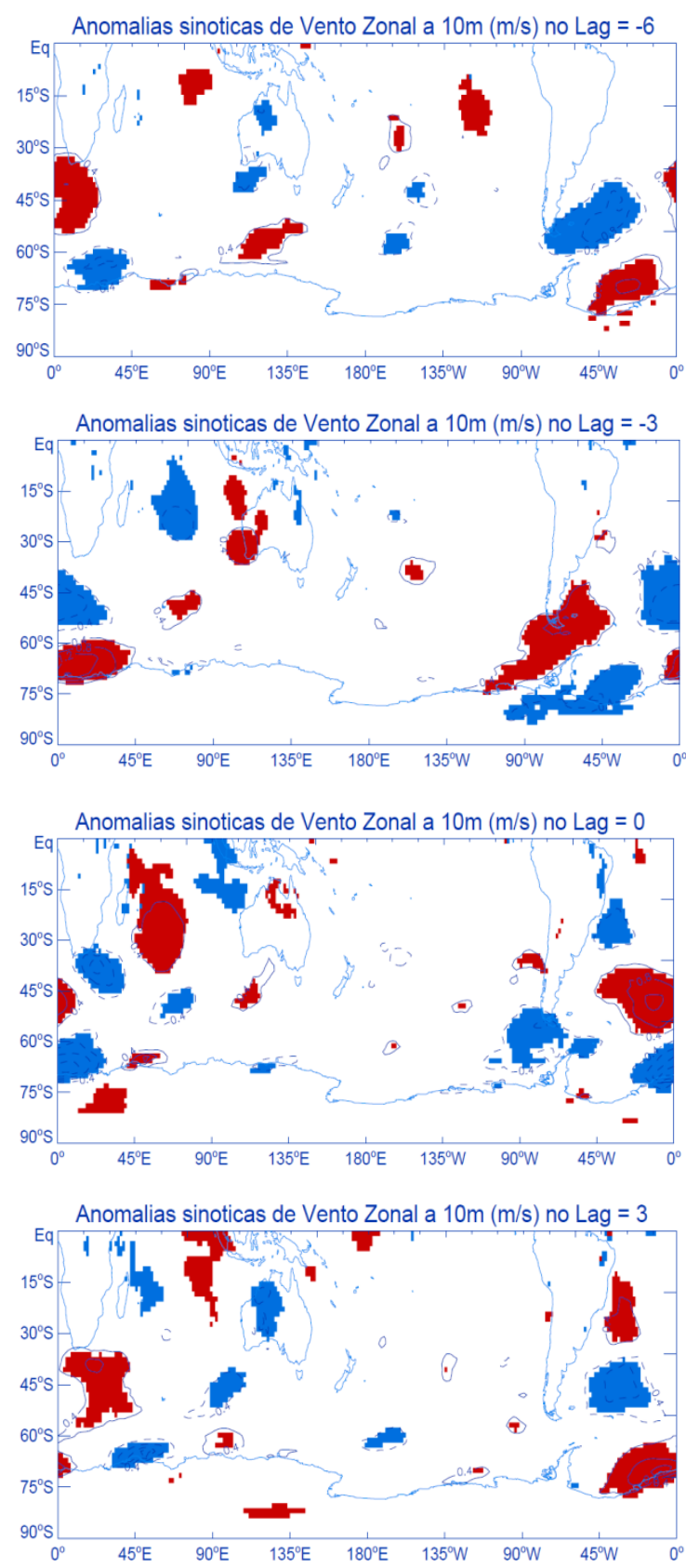

b) EPGM
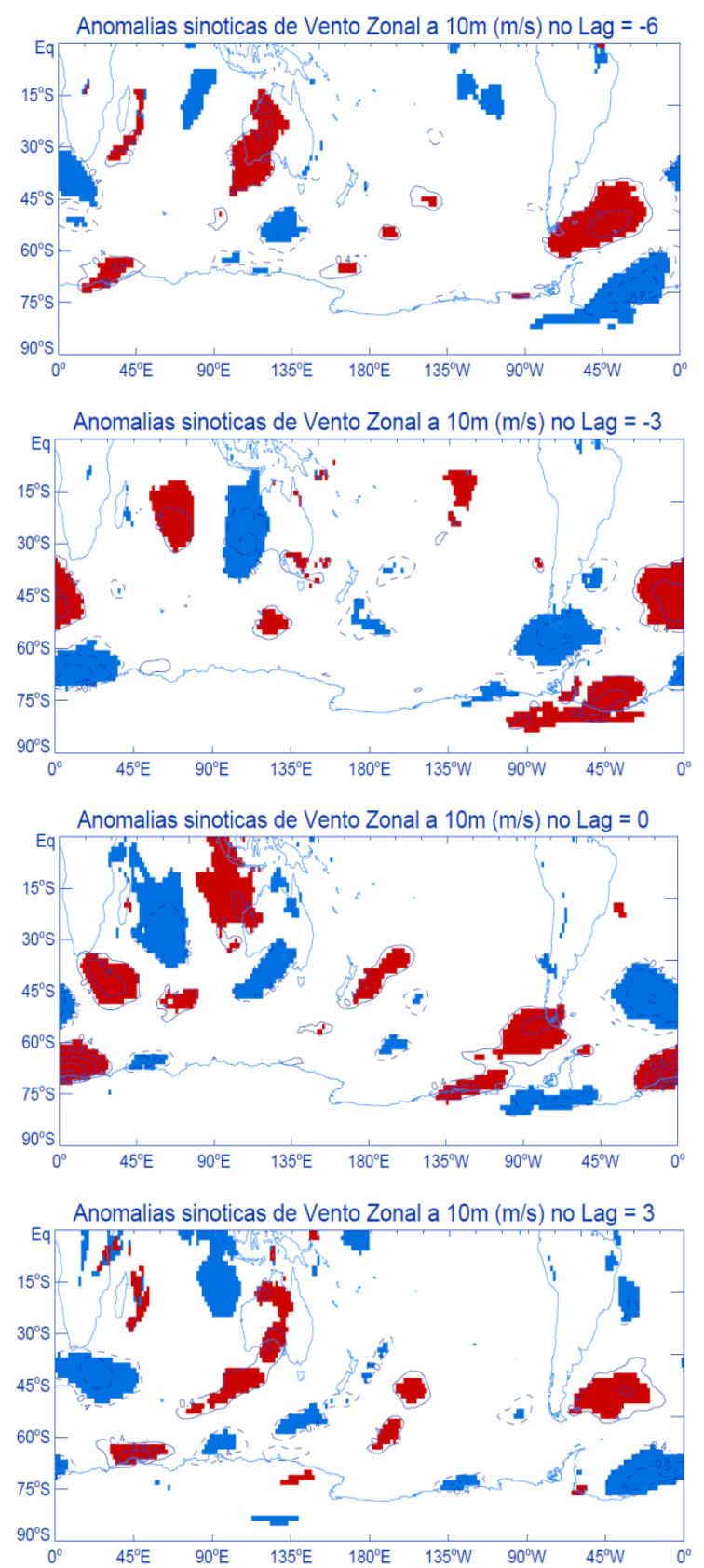

Figura 3.11: Similar à Figura 3.10, mas para as anomalias de alta frequência de vento zonal a $10 \mathrm{~m}$ $(\mathrm{m} / \mathrm{s})$. 
a) ENGM
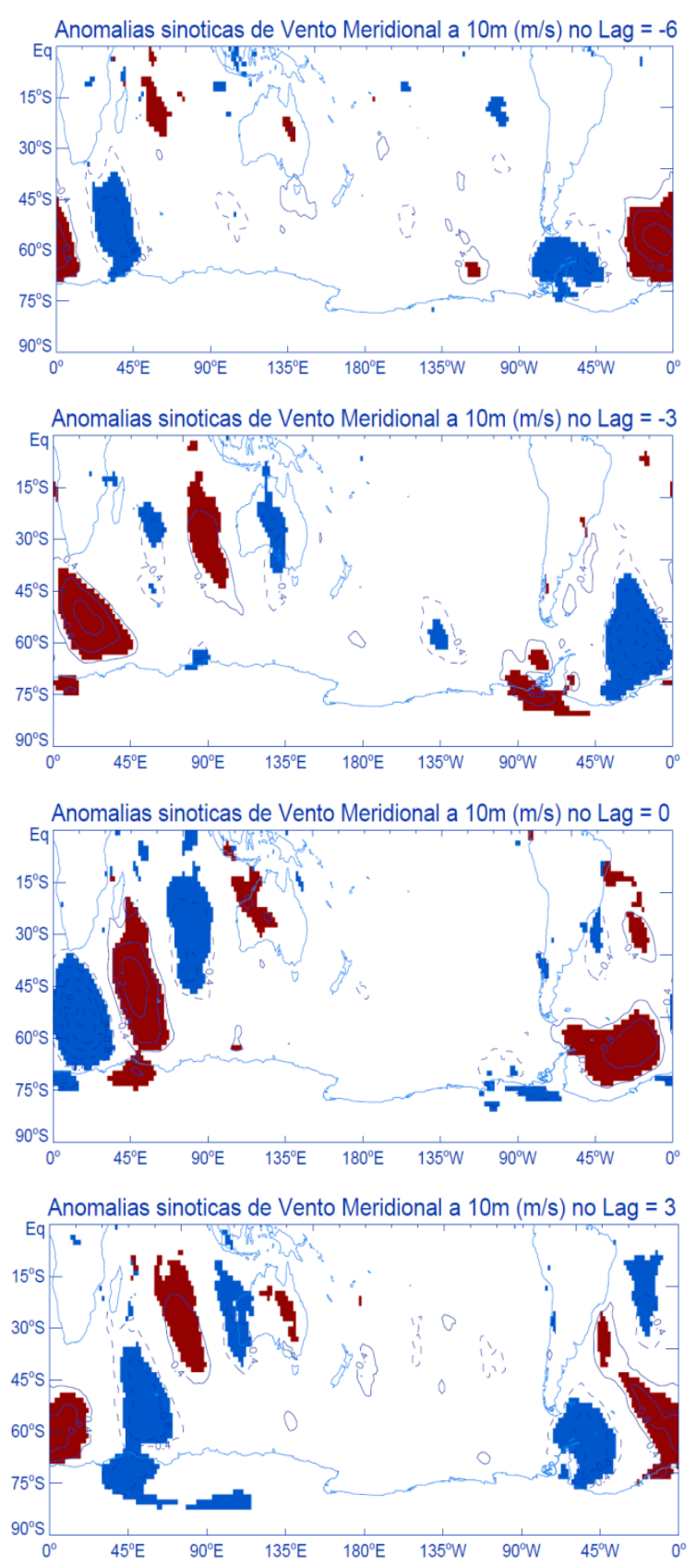

b) EPGM
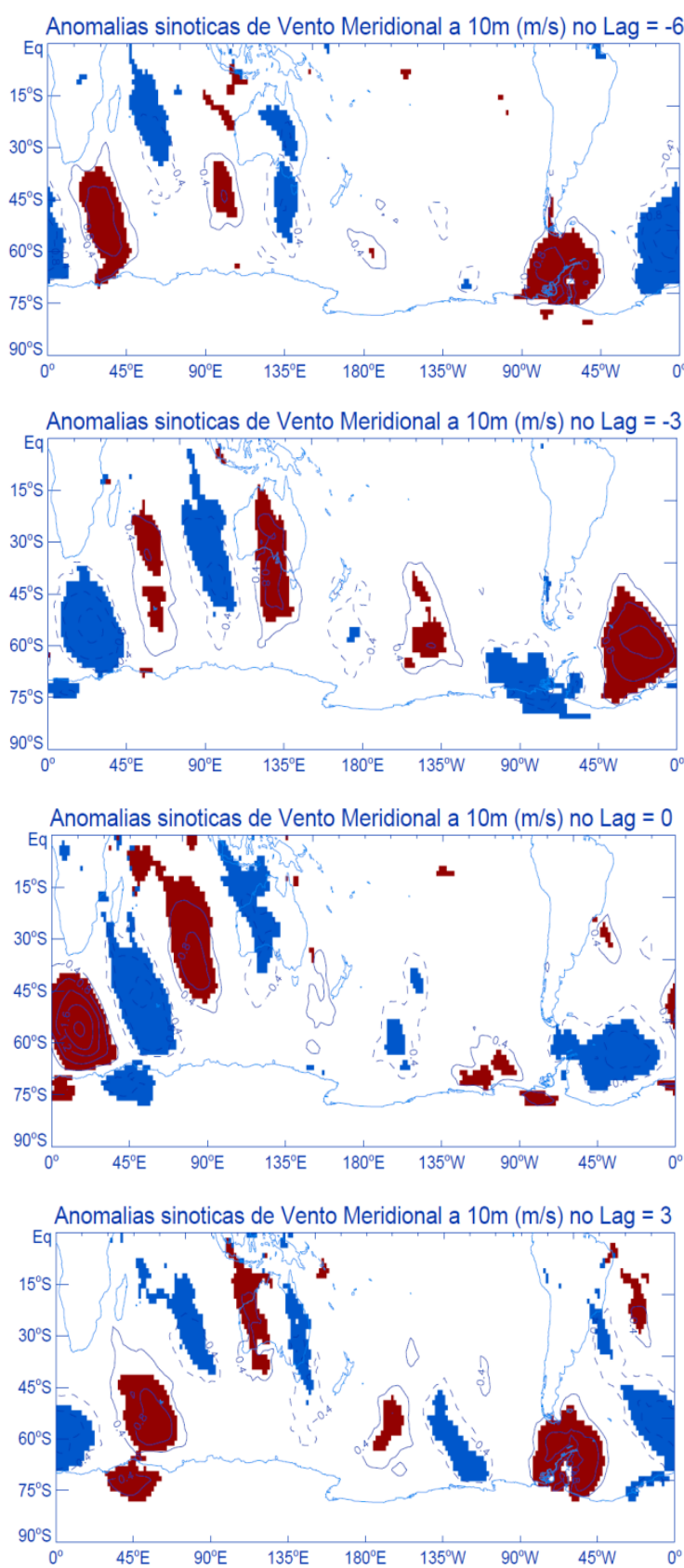

Figura 3.12: Similar à Figura 3.10, mas para as anomalias de alta frequência de vento meridional a $10 \mathrm{~m}(\mathrm{~m} / \mathrm{s})$. 
a) ENGM
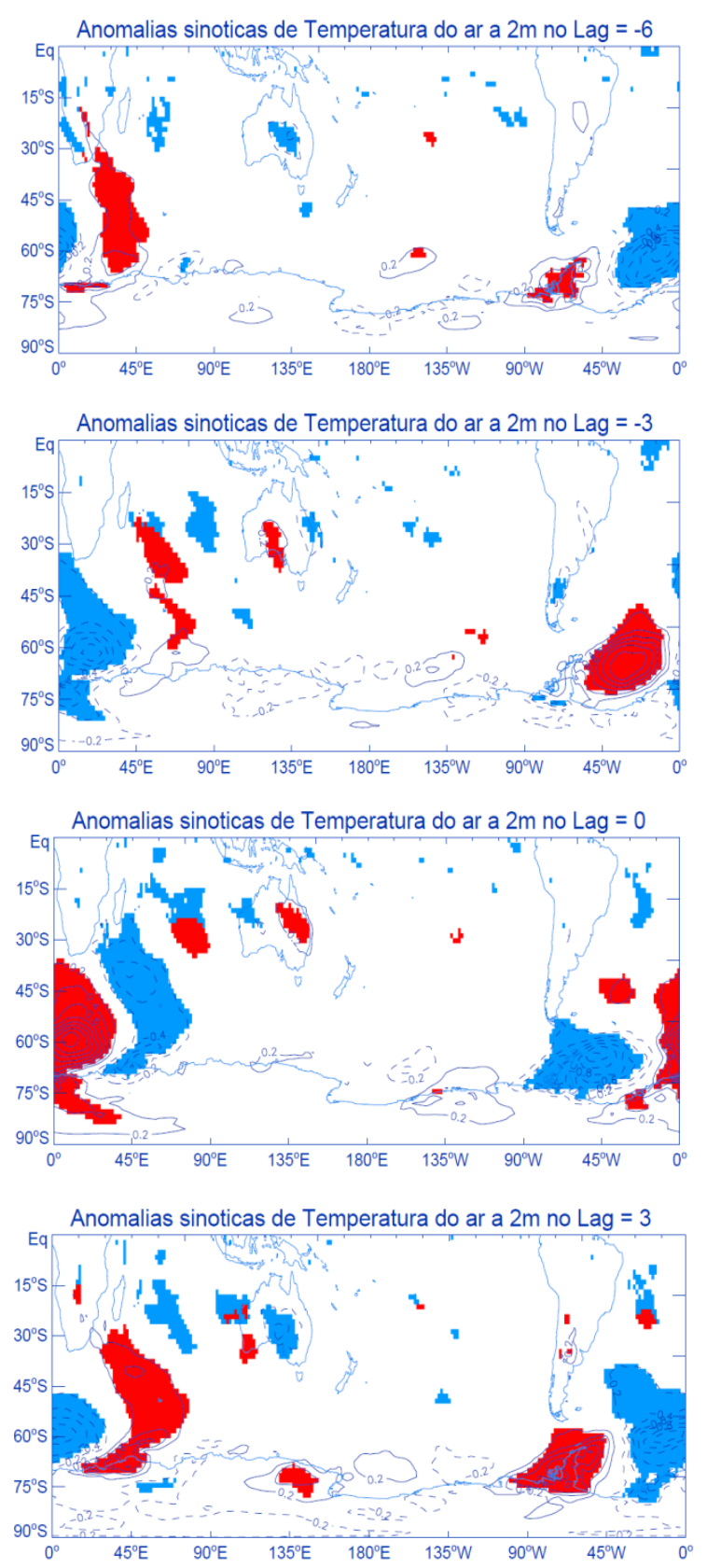

b) EPGM
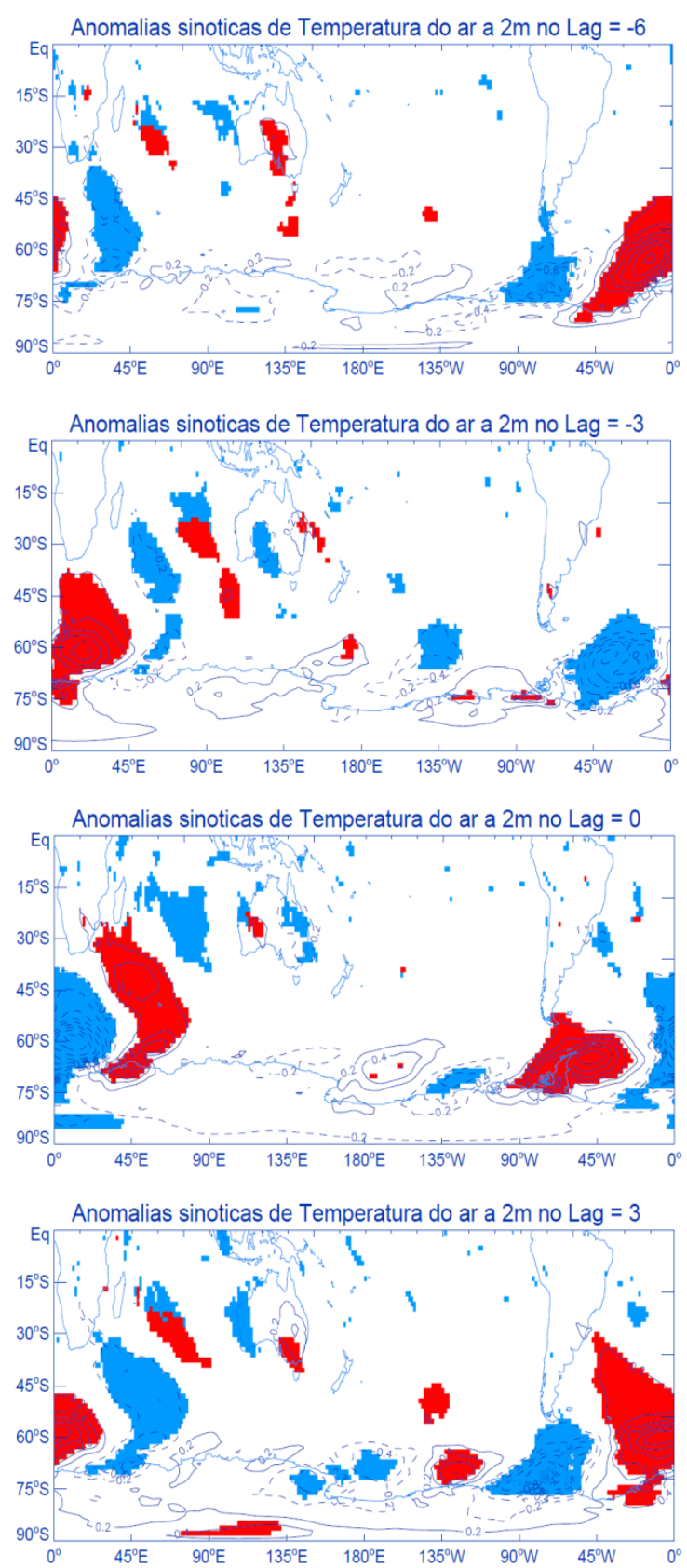

Figura 3.13: Similar à Figura 3.10, mas para as anomalias de alta frequência de temperatura do ar a $2 \mathrm{~m}\left({ }^{\circ} \mathrm{C}\right)$. 
Portanto, eventos ENGM e EPGM de alta frequência no setor dos MBA e do MW estão associados com as anomalias dos campos atmosféricos, na mesma escala de tempo, ocorridos a partir de três dias anteriores ao evento extremo. Esses distúrbios de alta frequência aparecem como um padrão de trem de ondas número 4 entre as latitudes médias e extratropicais ao redor do HS. A anomalia ciclônica no oeste do setor, associada com as anomalias de ventos de oeste no norte e de ventos de leste no sul, e a anomalia anticiclônica no leste, associada com as anomalias de ventos de leste no norte e de ventos de oeste no sul, resultam em uma anomalia de ventos de norte e, consequentemente, a anomalias positivas de temperatura do ar. Essa configuração anômala contribui para os eventos ENGM através do derretimento do gelo marinho e, principalmente, do seu próprio transporte em direção às altas latitudes pelos ventos de norte anômalos. O transporte de gelo marinho pelos ventos mostrouse fundamental para determinar a variabilidade do gelo marinho, como também observado por Lima (2007) na escala intrasazonal. Stammerjohn et al. (2003) observaram que quando fortes ventos de norte ocorreram, houve compactação da cobertura de gelo marinho contra a costa da Península Antártica, coincidentes com grandes reduções na extensão do gelo marinho. Destaca-se que o vento é o principal responsável pela dinâmica do gelo marinho, particularmente no período de dias ou semanas, explicando até $70 \%$ do seu movimento (NSIDC, 2010). As anomalias de alta frequência dos campos atmosféricos em todos os casos (composições defasadas) de eventos EPGM apresentam fases opostas em relação aos eventos ENGM. Portanto, fases distintas do trem de ondas induzem na modulação de extremos de gelo marinho opostos.

Destaca-se que o trem de ondas associado aos eventos EPGM afetam a América do Sul tropical e extratropical, especialmente em relação à variabilidade do gelo marinho nos MBA, através das anomalias de temperatura do ar. Durante os eventos ENGM não é observada tal associação. Assim, evidencia-se uma possível relação entre a variabilidade de alta frequência do gelo marinho antártico e a modulação de eventos frios/quentes nas latitudes médias e baixas da América do Sul através da propagação de distúrbios de alta frequência, tais como ciclones e anticiclones associados a sistemas frontais. 


\subsubsection{Verão austral}

\subsubsection{Setor dos Mares de Bellingshausen-Amundsen}

Durante o evento ENGM e EPGM nos MBA no período de verão austral, observa-se que o trem de ondas não está muito bem configurado, apresentando anomalias de alta frequência significativas principalmente no Hemisfério Ocidental (Figura 3.14). Durante o evento ENGM no lag = -6, as anomalias foram predominantemente sem significância estatística sobre os MBA. A anomalia anticiclônica nos MBA (Figura 3.14a), associada com a anomalia de ventos de oeste no sul (Figura 3.15a), induziu a uma anomalia de ventos de sul no leste dos MBA (Figura 3.16a) e a uma anomalia de temperatura do ar negativa sobre todo o setor (Figura 3.17a).

Três dias anteriores ao evento ENGM, no oeste dos MBA a anomalia ciclônica (Figura 3.14a) está associada com uma anomalia de ventos de oeste no norte e de ventos de leste no sul (Figura 3.15a). No leste dos MBA a anomalia é anticiclônica, com anomalia de ventos de leste no norte e de ventos de oeste no sul. Esse padrão induz a uma anomalia de ventos de norte sobre os MBA (Figura 3.16a) e, consequentemente, a uma anomalia positiva de temperatura do ar (Figura 3.17a). Essa configuração contribuiu para o evento ENGM três dias posteriores.

No dia do evento (lag $=0$ ), a fase das anomalias de alta frequência foi inversa ao lag $=-3$, embora menos abrangentes e com menor significância estatística. No lag $=+3$ a significância estatística das anomalias foi ainda menor. A anomalia anticiclônica na região dos MBA (Figura 3.14a) está associada com anomalias de ventos de oeste no sul (Figura 3.15a). No oeste do setor a anomalia foi de ventos de norte e no leste dos MBA a anomalia foi de ventos de sul (Figura 3.16a). Já a anomalia de temperatura do ar foi negativa sobre toda a região (Figura 3.17a). Gradativamente o trem de ondas se desintensifica, desaparecendo completamente no lag $=+7$ nos campos de PNMM (figura não apresentada).

As anomalias de alta frequência dos campos atmosféricos nos eventos EPGM apresentaram um comportamento similar aos eventos ENGM, porém em fases opostas (Figuras 3.14b, 3.15b, 3.16b, 3.17b). O padrão de alta frequência desintensifica, até desaparecer completamente no campo de PNMM no lag = +8 (figura não apresentada). 
a) ENGM
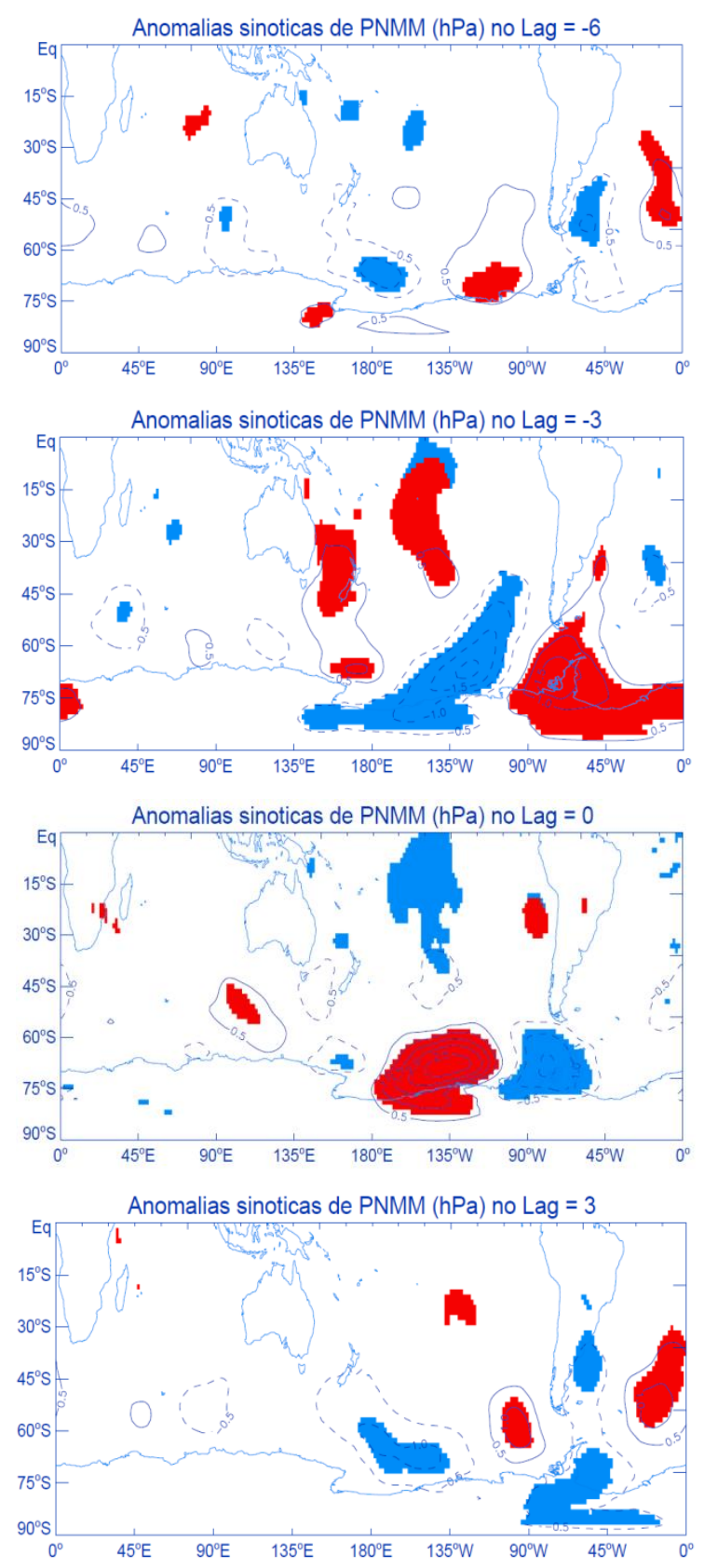

b) EPGM
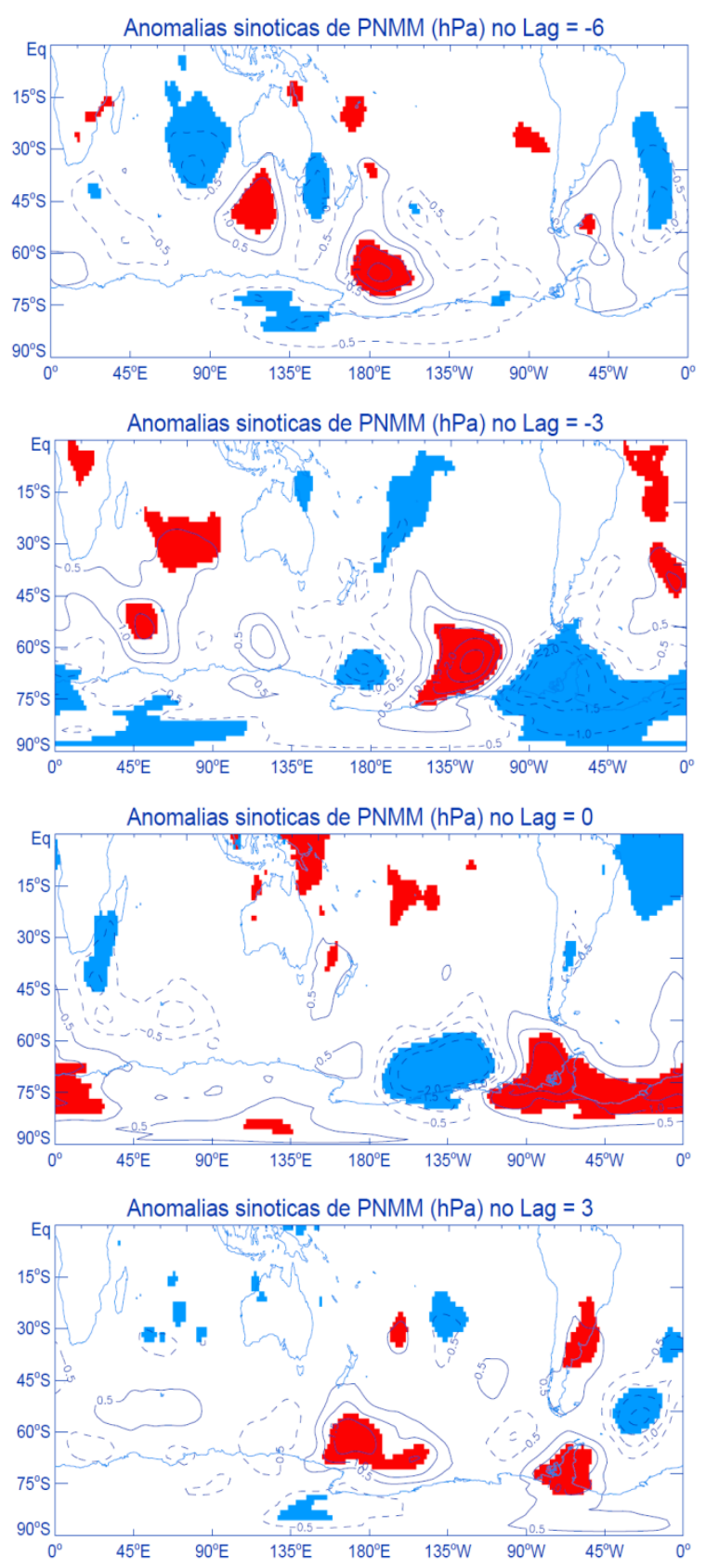

Figura 3.14: Composições defasadas das anomalias de alta frequência de PNMM (hPa) durante os eventos (a) ENGM e (b) EPGM no setor dos MBA, no lag $=-6$, lag $=-3$, lag $=0$ e lag $=+3$, no período de verão austral (1989-2007). Linhas contínuas (tracejadas) indicam valores positivos (negativos) de anomalias. Áreas coloridas são significativas ao nível de 95\%. 
a) ENGM
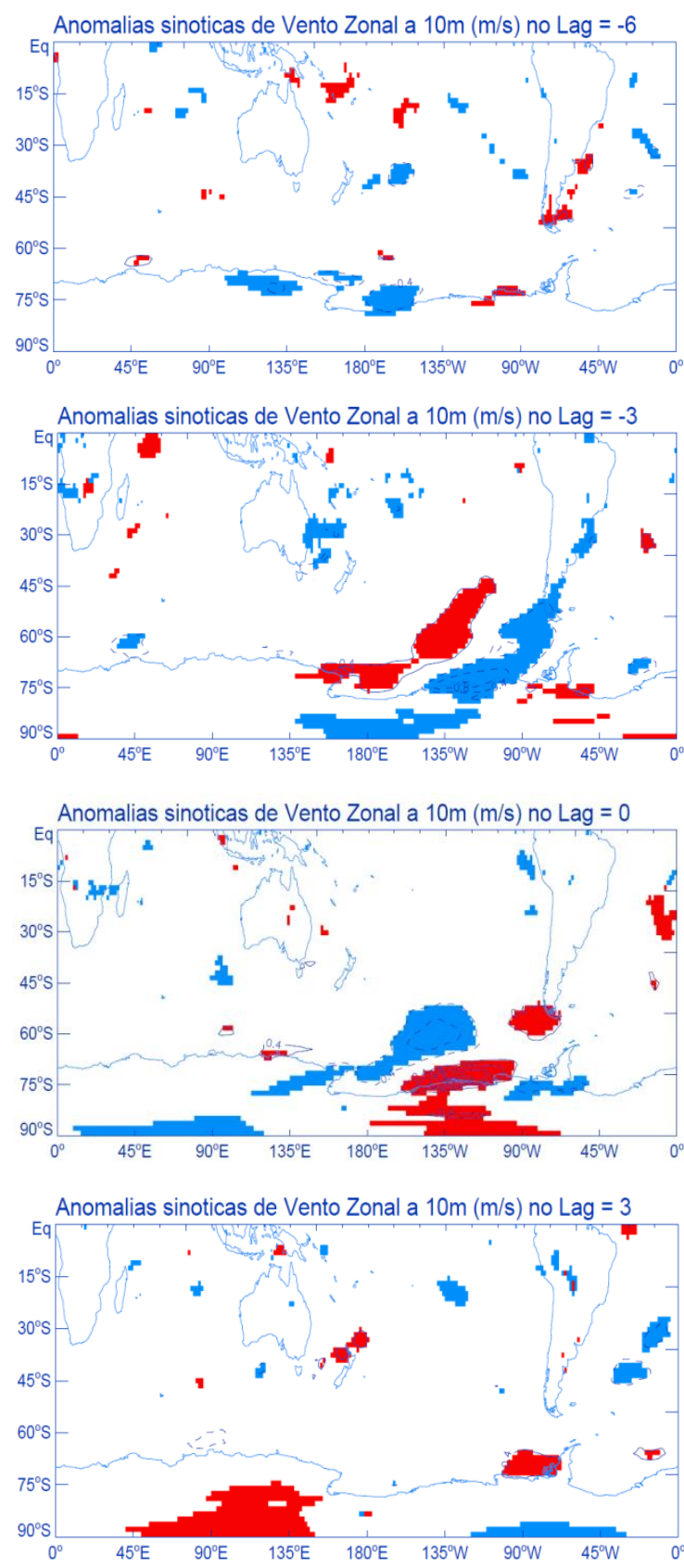

b) EPGM
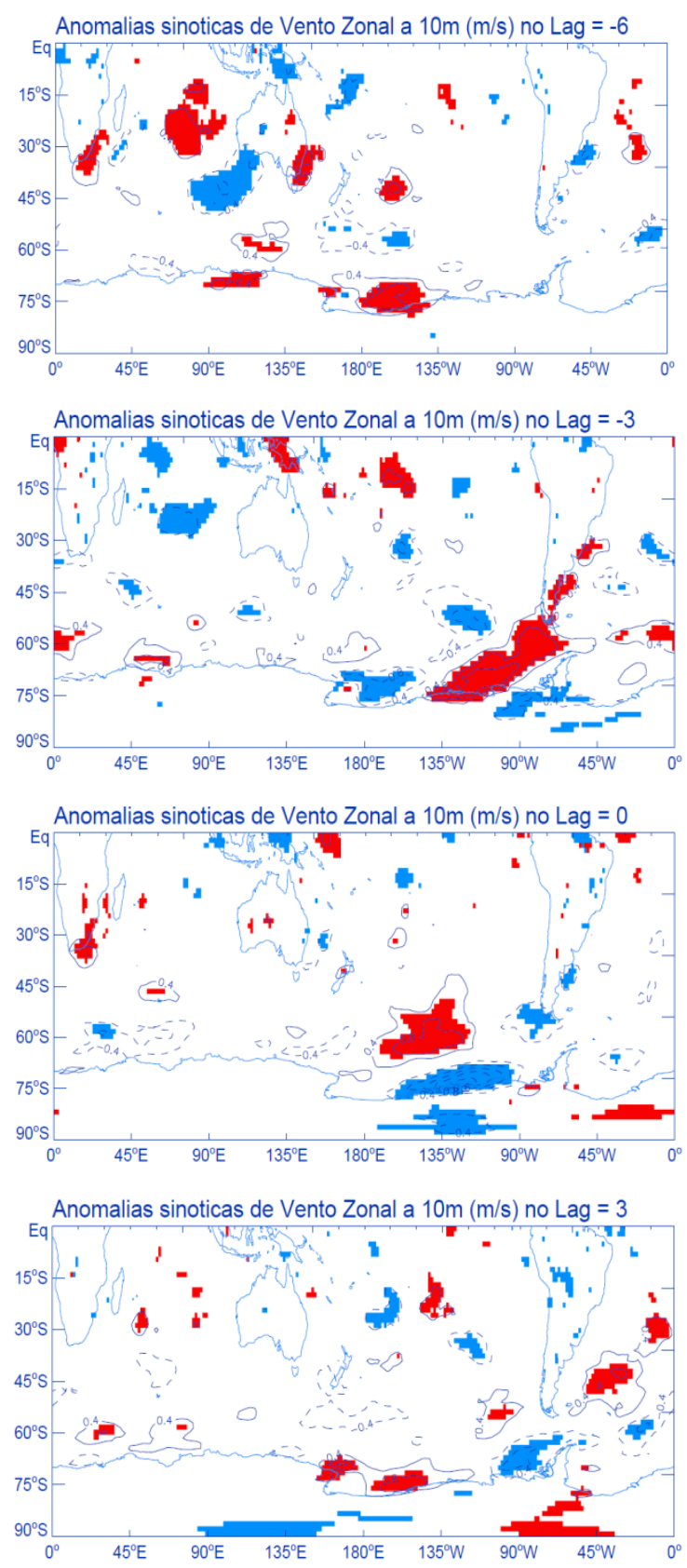

Figura 3.15: Similar à Figura 3.14, mas para as anomalias de alta frequência de vento zonal a $10 \mathrm{~m}$ $(\mathrm{m} / \mathrm{s})$. 
a) ENGM
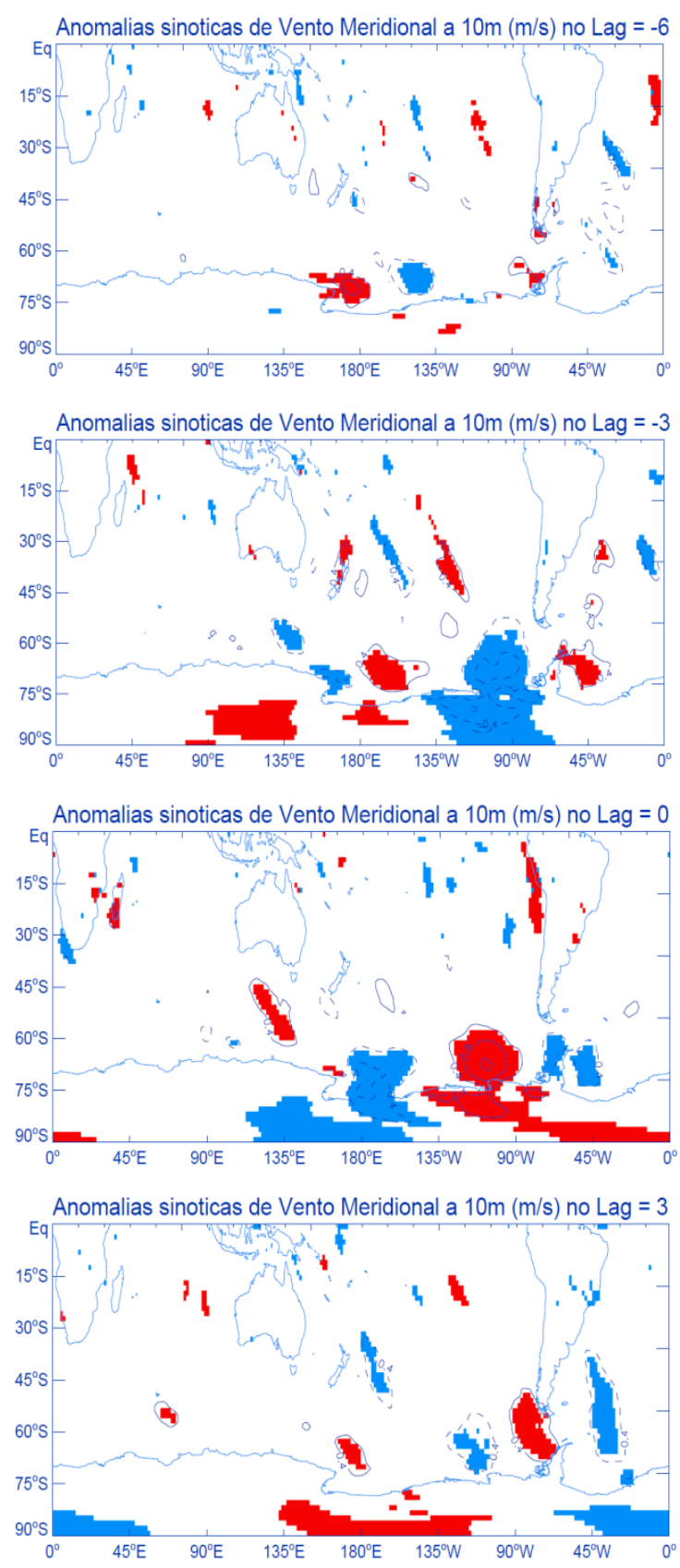

b) EPGM
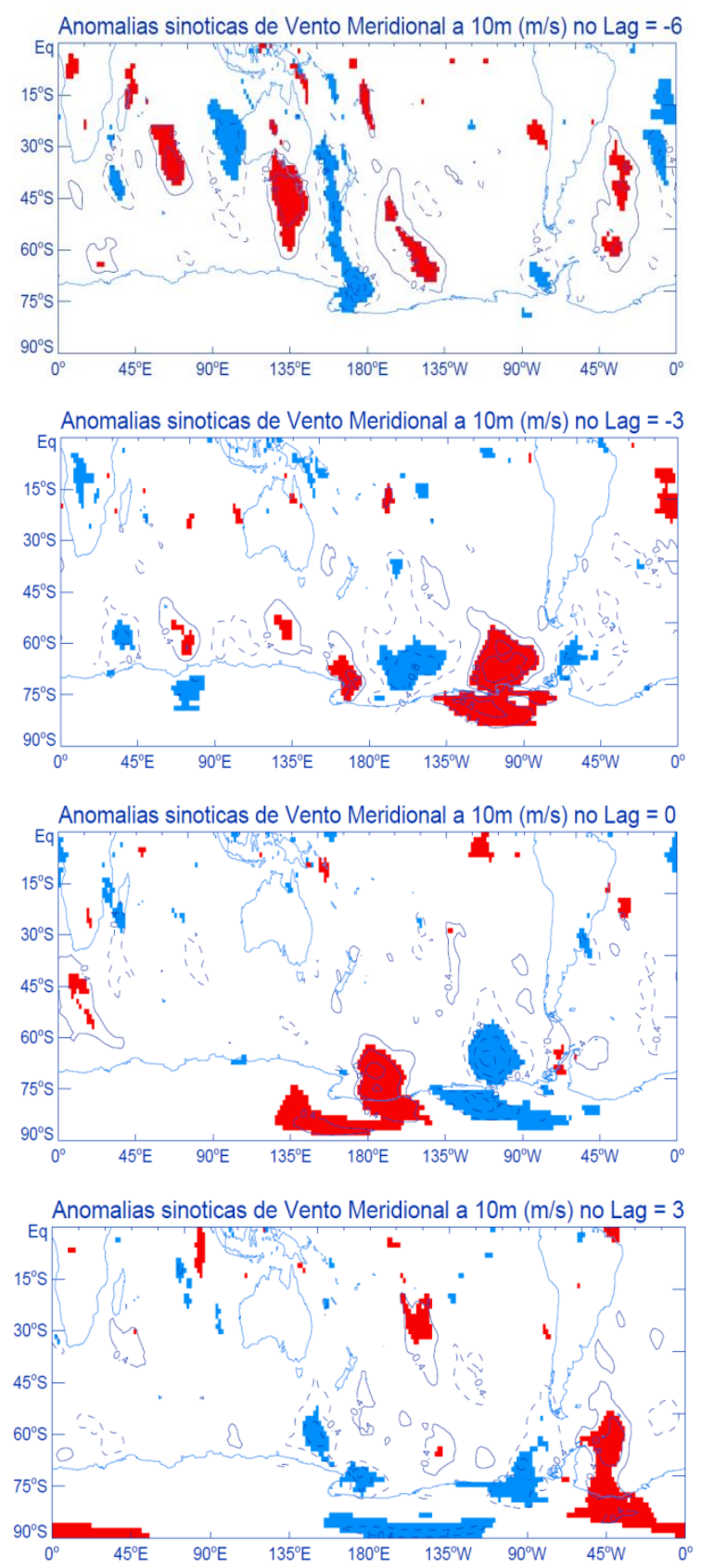

Figura 3.16: Similar à Figura 3.14, mas para as anomalias de alta frequência de vento meridional a $10 \mathrm{~m}(\mathrm{~m} / \mathrm{s})$. 
a) ENGM
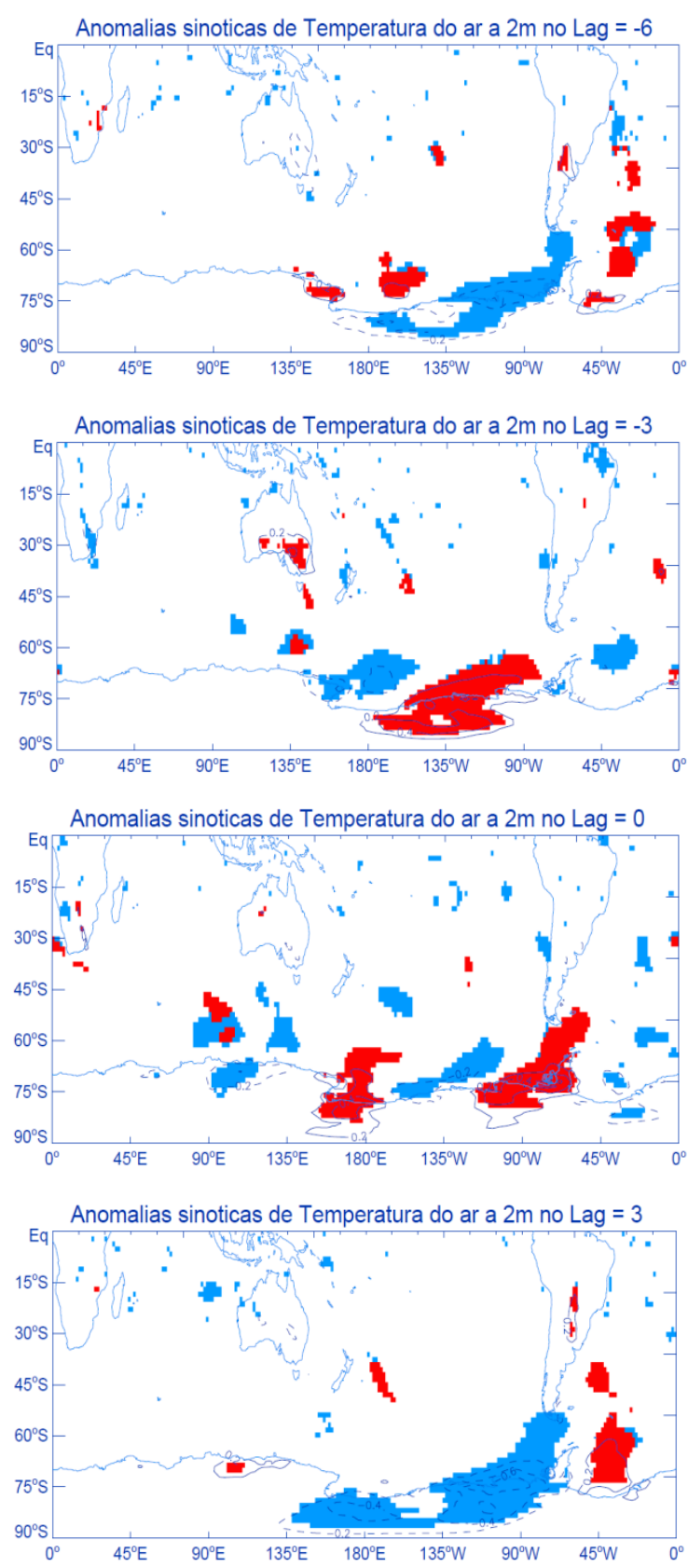

b) EPGM
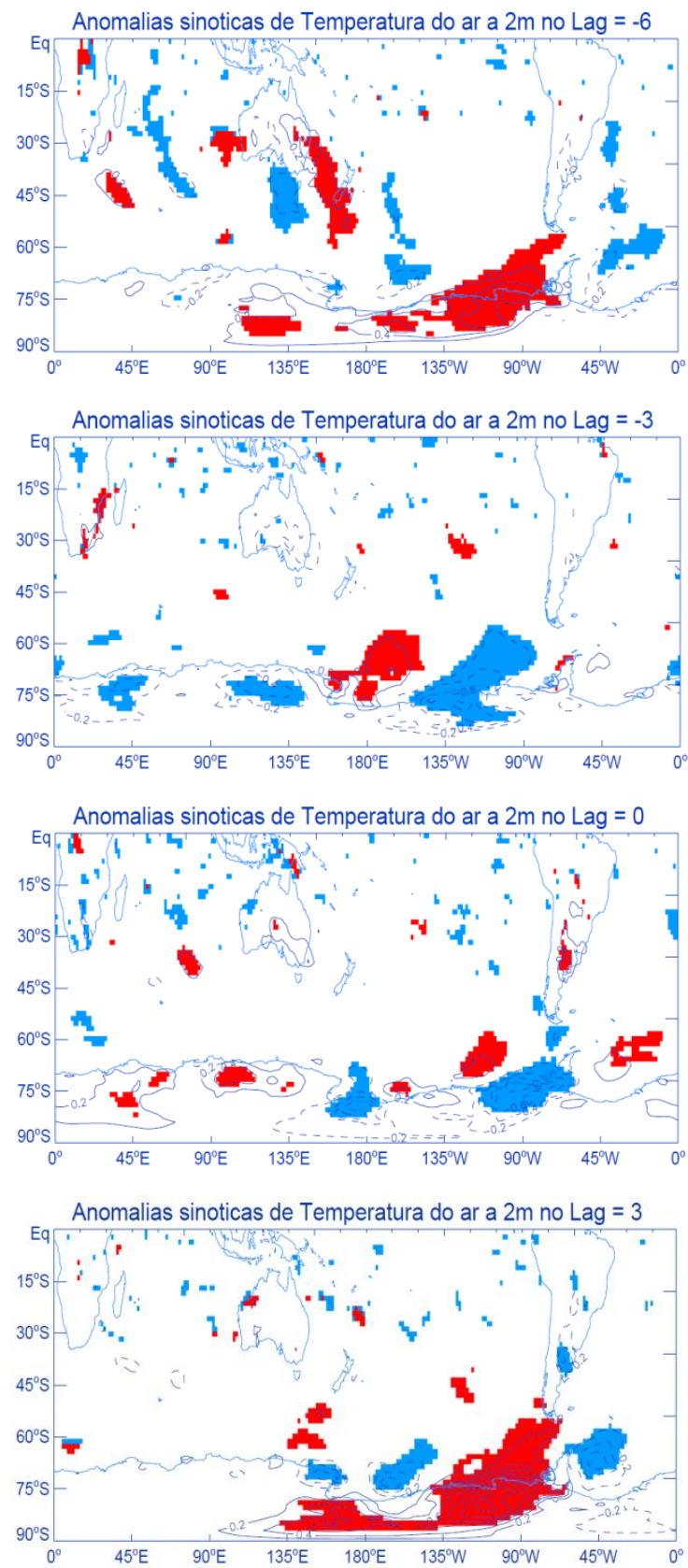

Figura 3.17: Similar à Figura 3.14, mas para as anomalias de alta frequência de temperatura do ar a $2 \mathrm{~m}\left({ }^{\circ} \mathrm{C}\right)$. 


\subsubsection{Setor do Mar de Weddell}

$\mathrm{Na}$ análise das anomalias de alta frequência de PNMM nos eventos ENGM e EPGM no setor do MW, observa-se que a configuração de padrões de trem de ondas não foi bem definida (Figura 3.18), com menor significância estatística e persistência no verão austral em relação ao inverno (Figura 3.10). Seis dias anteriores ao evento ENGM há uma anomalia anticiclônica no oeste do setor (Figura 3.18a), associada com anomalias de ventos de leste no norte e de ventos de oeste no sul (Figura 3.19a). Assim, na vanguarda da anomalia anticiclônica observa-se uma anomalia de ventos de norte no oeste do MW (Figura 3.20a), associada com as anomalias positivas de temperatura do ar (Figura 3.21a). No centro do setor, a anomalia negativa de temperatura do ar está associada com a anomalia de ventos de sul.

No lag $=-3$ verifica-se uma anomalia ciclônica sobre a Península Antártica e no oeste do setor (Figura 3.18a), associada com as anomalias de ventos de oeste no norte e de ventos de leste no sul (Figura 3.19a); e uma anomalia anticiclônica no leste do MW, com anomalias de ventos de leste no norte e de ventos de oeste no sul. Esse padrão de circulação gera um escoamento anômalo de norte no oeste do setor (Figura 3.20a), trazendo ar relativamente mais aquecido das latitudes médias, contribuiu para as anomalias positivas de temperatura do ar (Figura 3.21a). Assim, há o suporte dinâmico e térmico para que haja o derretimento de gelo marinho e/ou seu transporte em direção às altas latitudes pela ação mecânica dos ventos anômalos de norte, contribuindo assim para o evento ENGM.

No dia do evento ENGM (lag $=0)$ há uma mudança de fase nas anomalias dos campos atmosféricos, indicando que houve uma propagação do trem de ondas para leste. No lag $=+3$ as anomalias de alta frequência são observadas em fase oposta ao lag $=0$, com menos intensidade e significância estatística. $O$ trem de ondas se desintensifica gradativamente até desaparecer completamente no campo de PNMM no lag = +9 (figura não apresentada).

As anomalias de alta frequência dos campos atmosféricos em baixos níveis em todos os casos (composições defasadas) de eventos EPGM apresentam fases opostas em relação aos eventos ENGM (Figuras 3.18b, 3.19b, 3.20b, 3.21b). 
a) ENGM
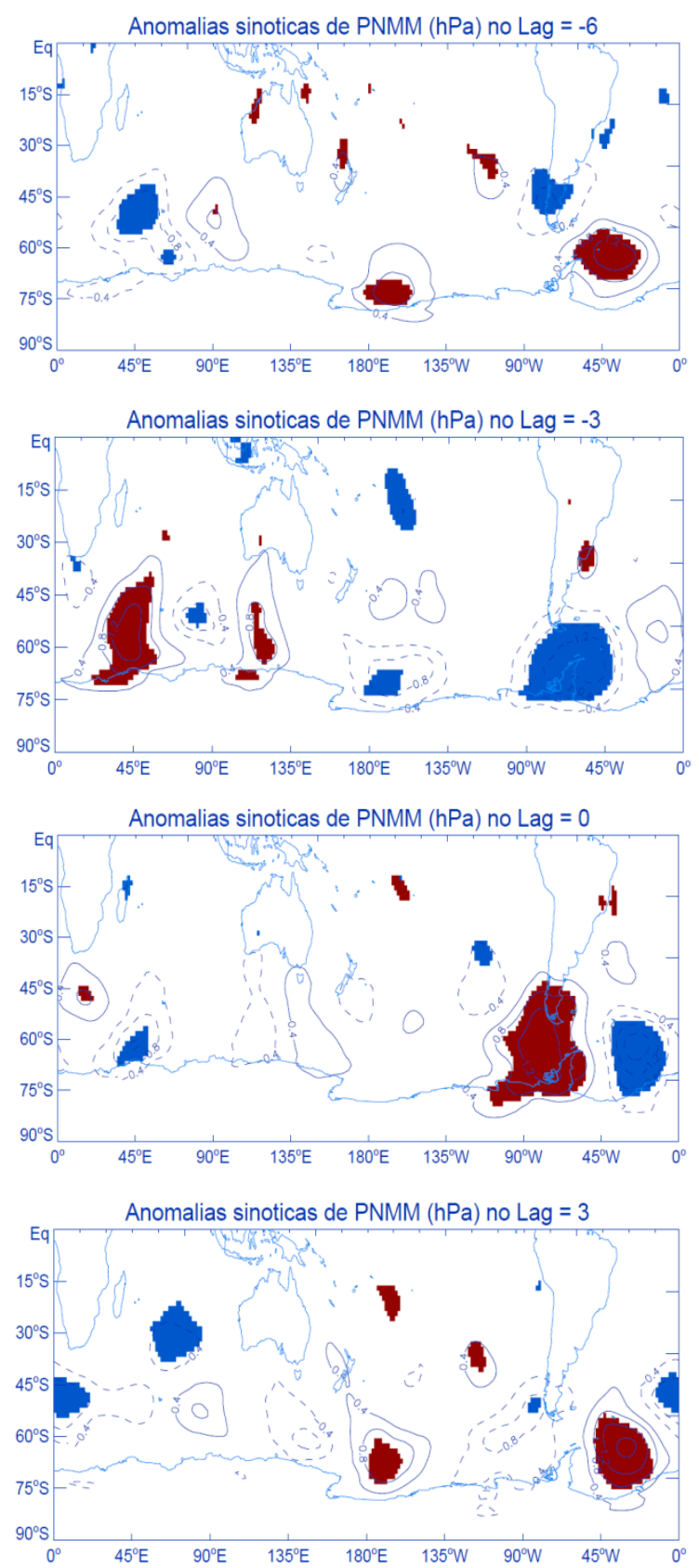

b) EPGM
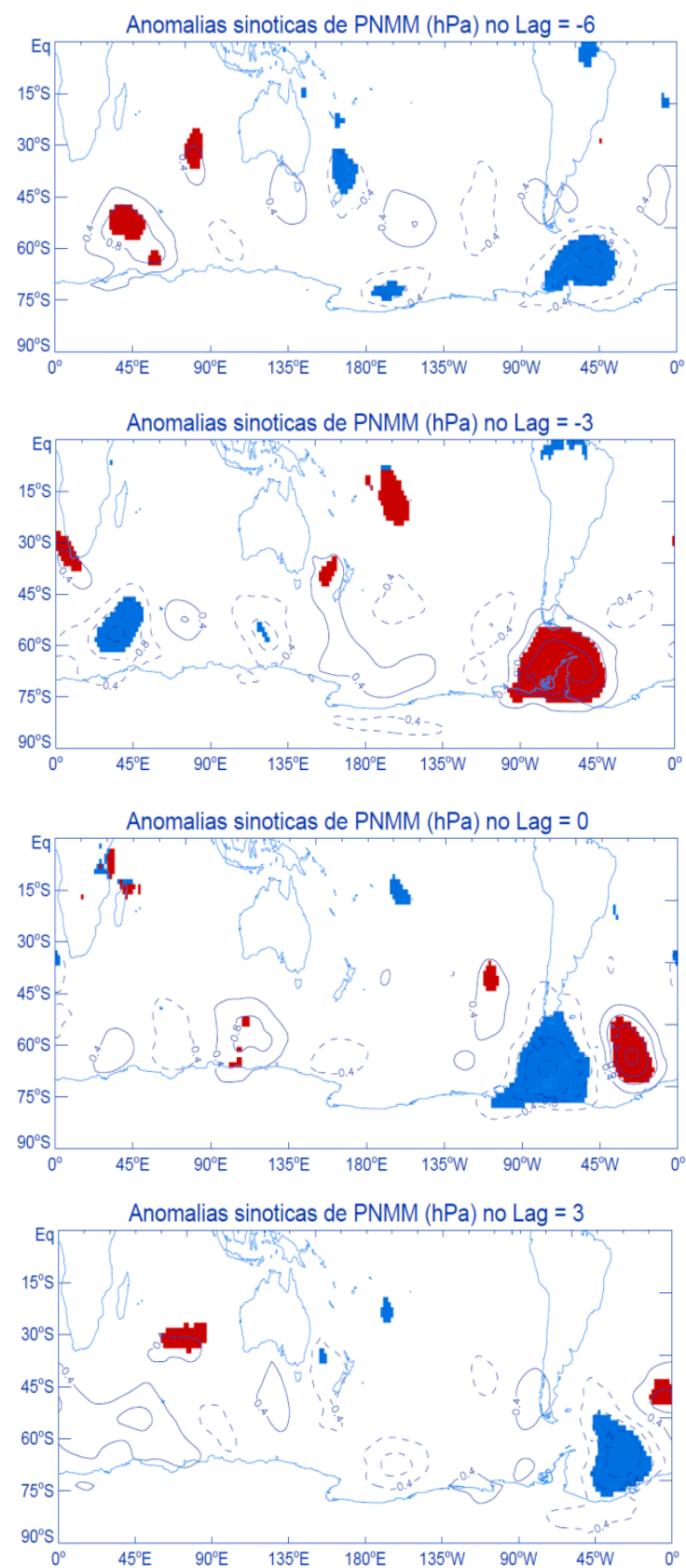

Figura 3.18: Composições defasadas das anomalias de alta frequência de PNMM (hPa) durante os eventos (a) ENGM e (b) EPGM no setor do MW, no lag = -6, lag $=-3$, lag $=0$ e lag $=+3$, no período de verão austral (1989-2007). Linhas contínuas (tracejadas) indicam valores positivos (negativos) de anomalias. Áreas coloridas são significativas ao nível de $95 \%$. 
a) ENGM
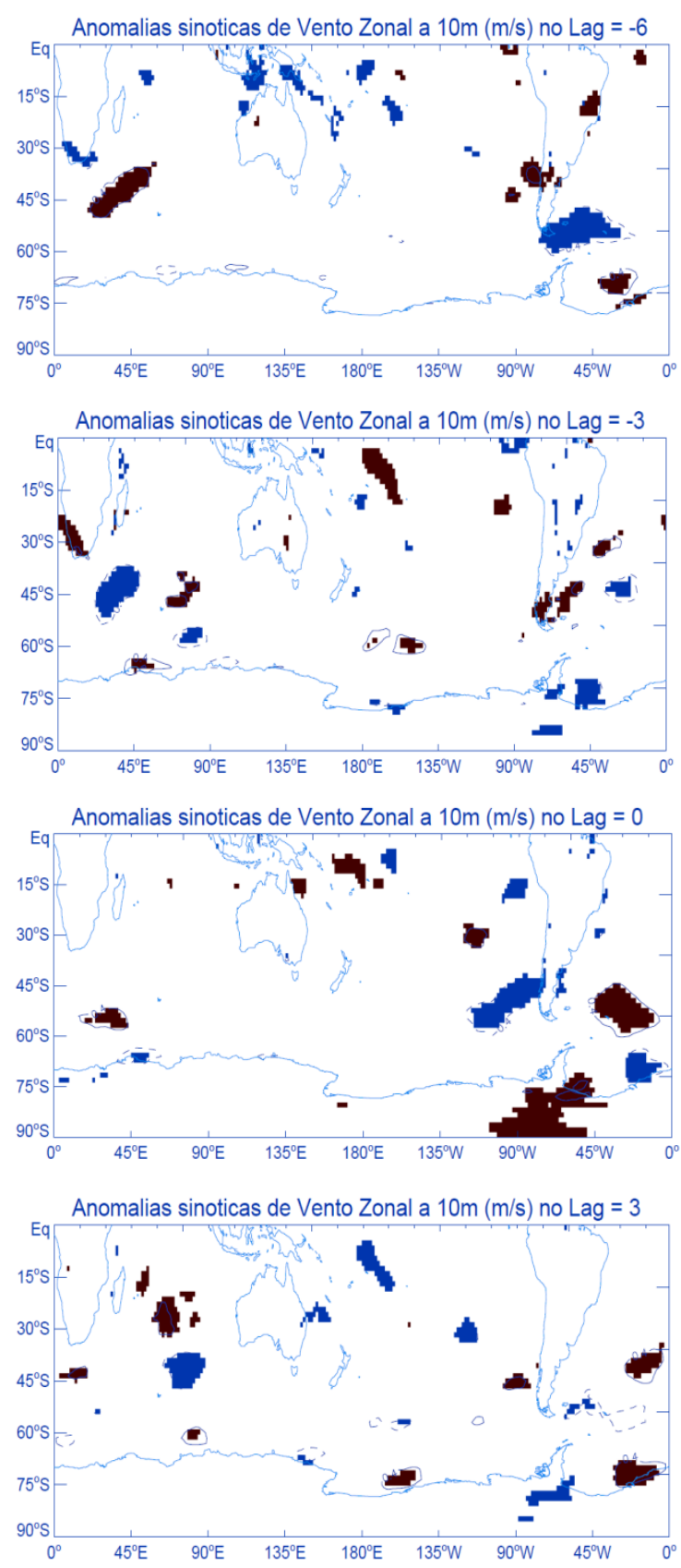

b) EPGM
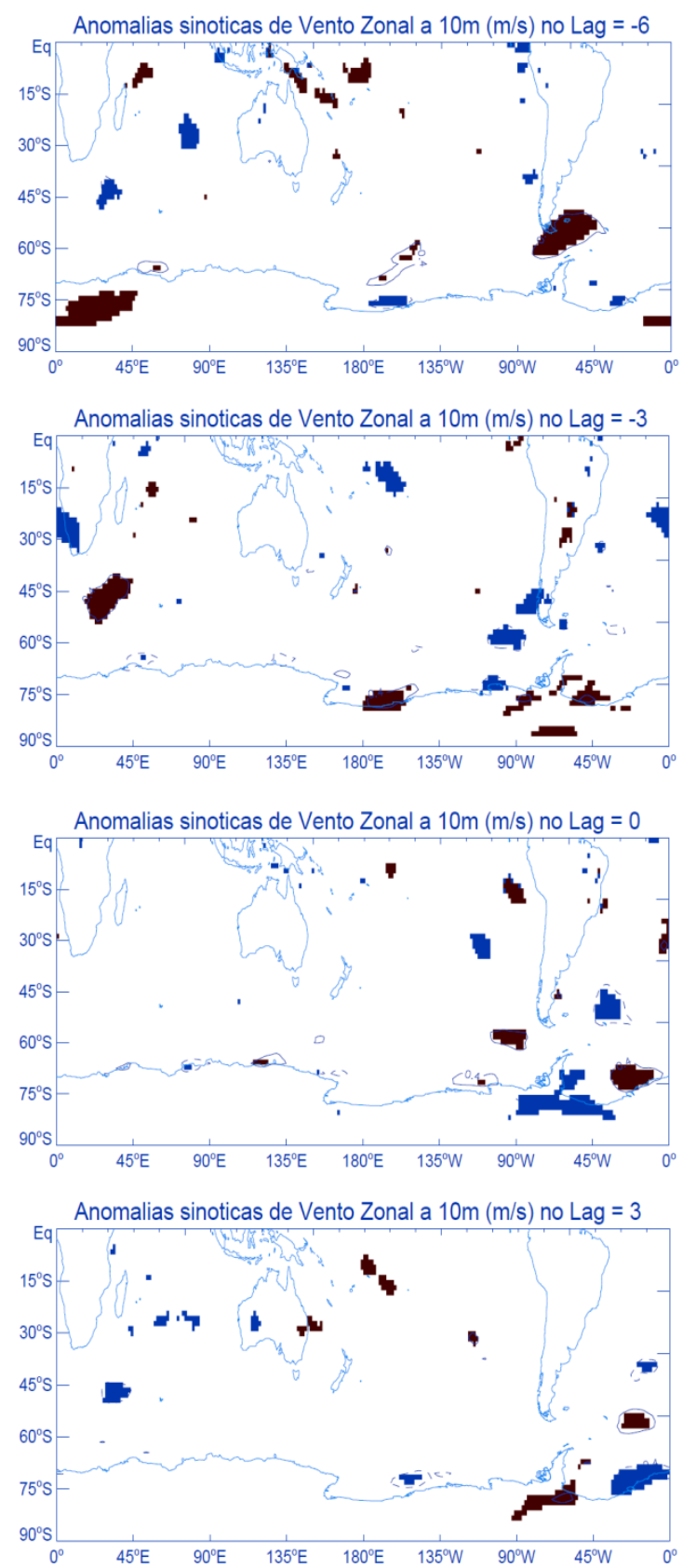

Figura 3.19: Similar à Figura 3.18, mas para as anomalias de alta frequência de vento zonal a $10 \mathrm{~m}$ $(\mathrm{m} / \mathrm{s})$. 
a) ENGM
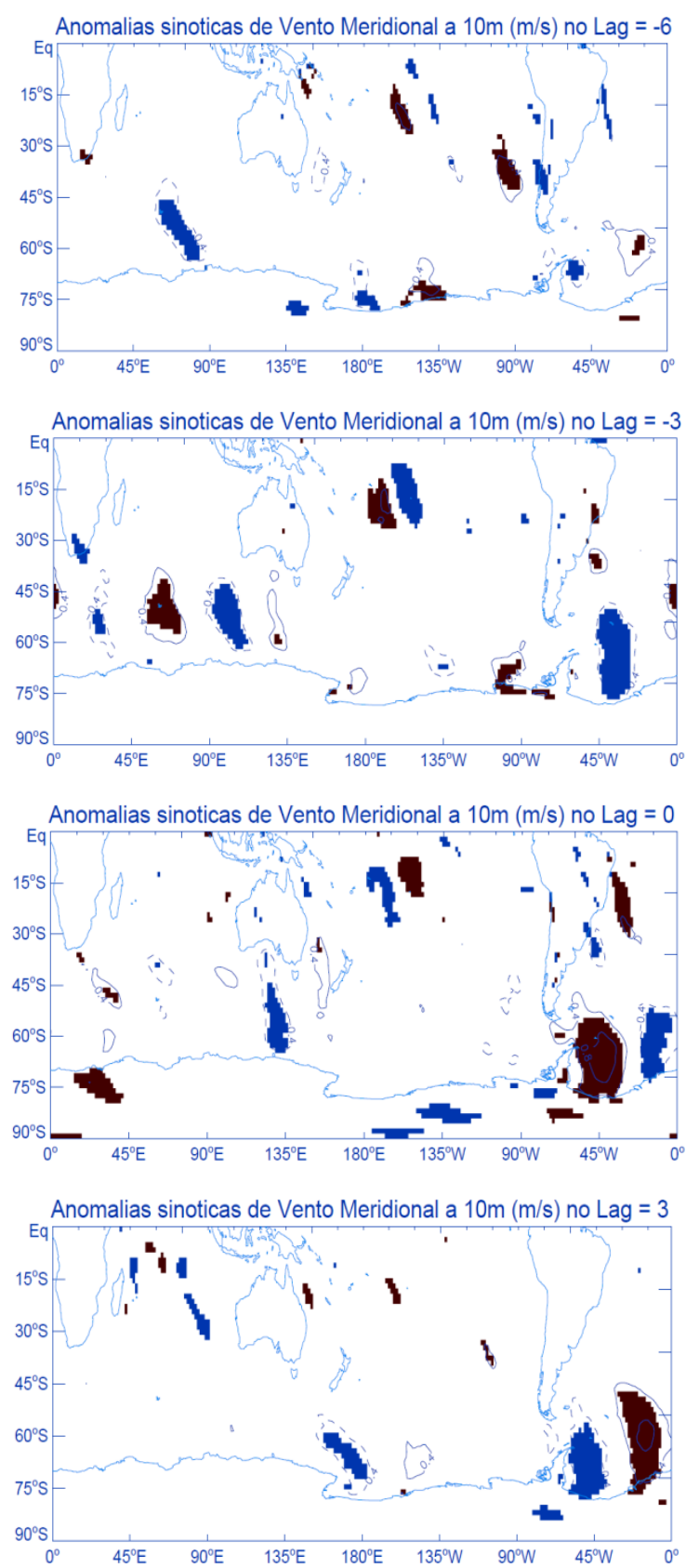

b) EPGM
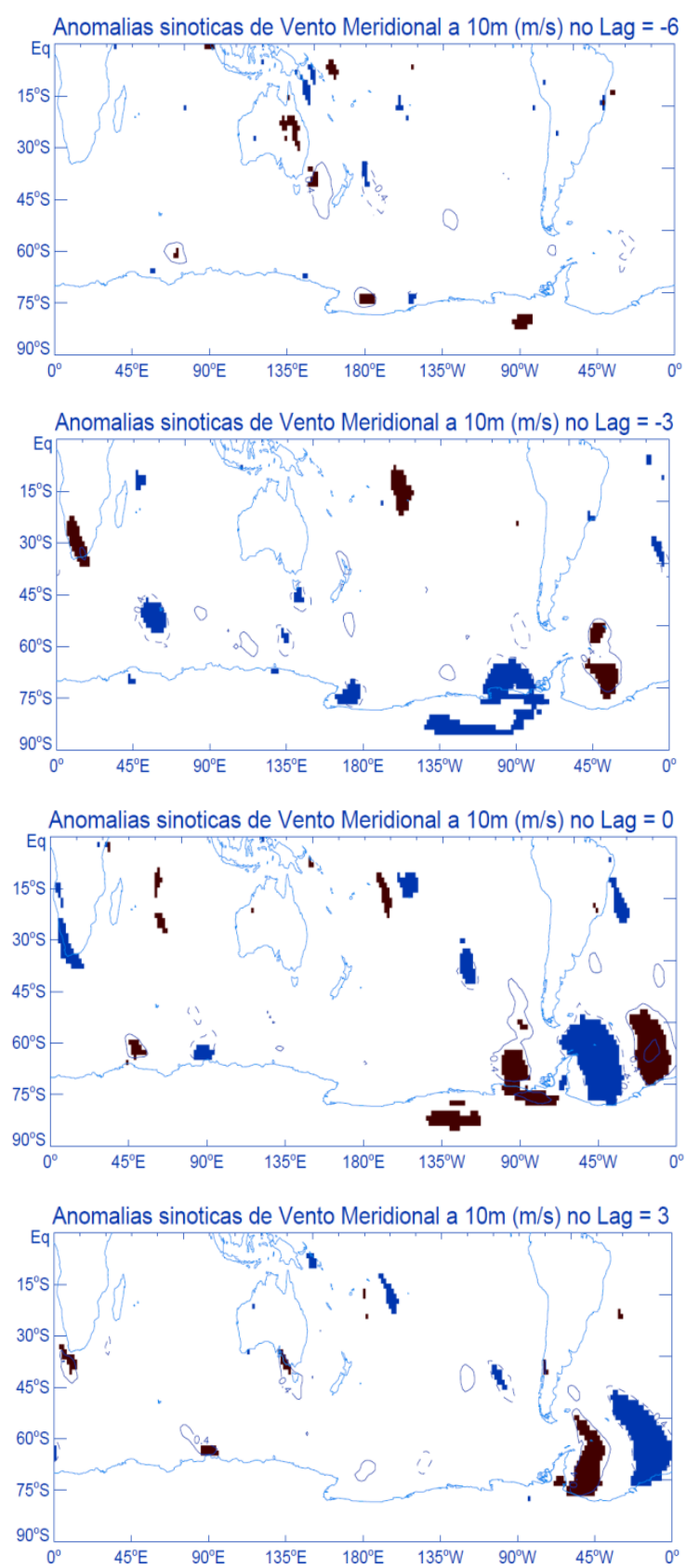

Figura 3.20: Similar à Figura 3.18, mas para as anomalias de alta frequência de vento meridional a $10 \mathrm{~m}(\mathrm{~m} / \mathrm{s})$. 
a) ENGM
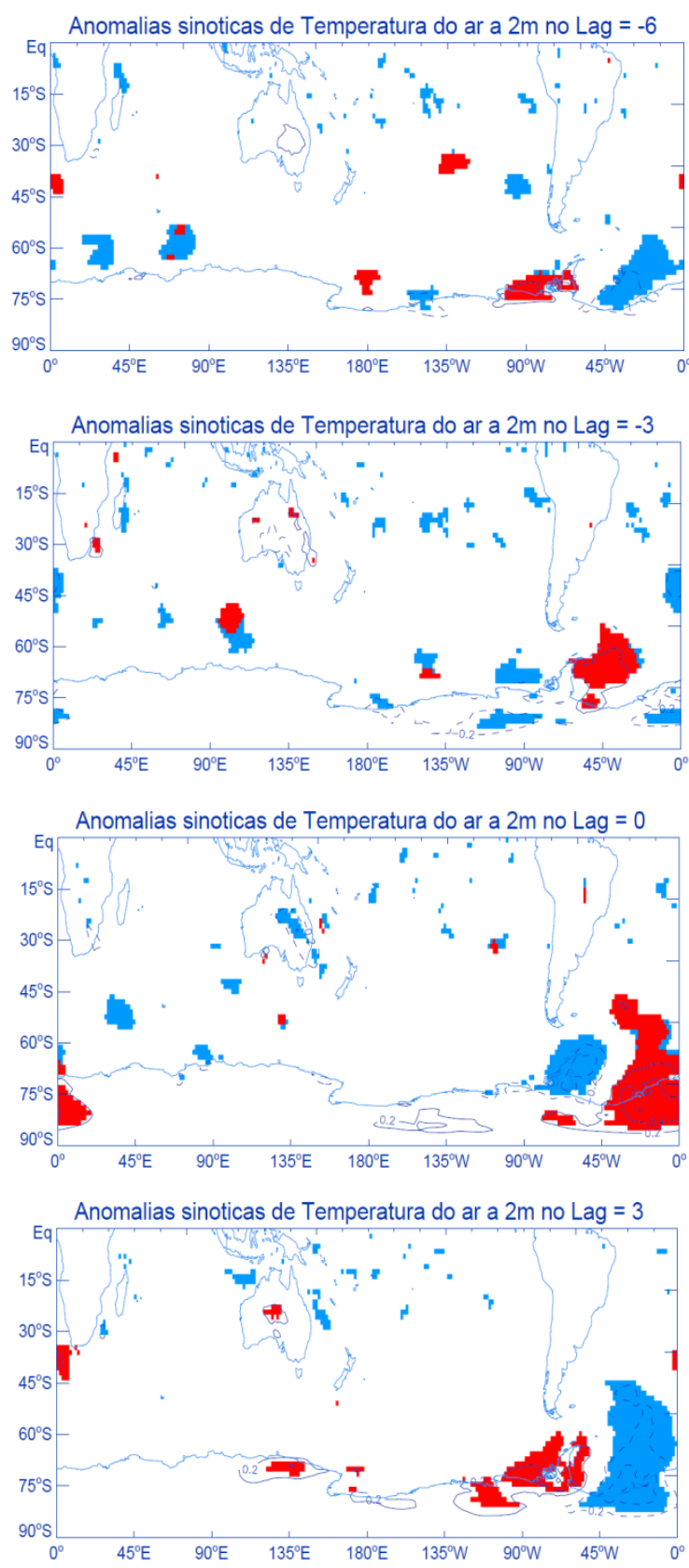

b) EPGM
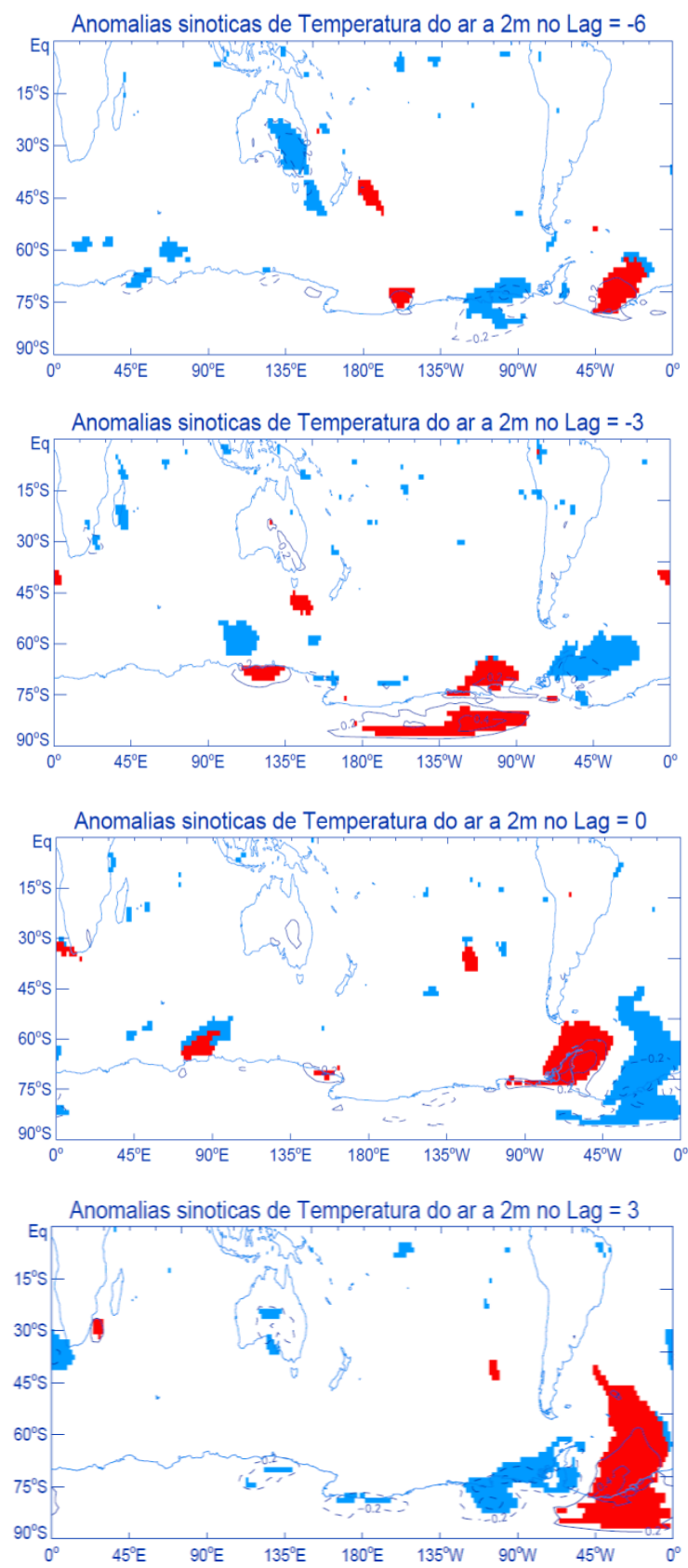

Figura 3.21: Similar à Figura 3.18, mas para as anomalias de alta frequência de temperatura do ar a $2 \mathrm{~m}\left({ }^{\circ} \mathrm{C}\right)$. 
Durante o verão austral, o padrão das anomalias de alta frequência dos campos atmosféricos associado aos eventos ENGM/EPGM nos MBA e no MW foi similar ao inverno, porém as anomalias foram menos significativas e o trem de ondas persistiu por menos tempo. Destaca-se que nos meses de verão a atividade dos sistemas transientes é menos frequente que no inverno (SIMMONDS; KEAY, 2000a; SIMMONDS; KEAY; LIM, 2003). Além disso, Cavalieri e Parkinson (1981) verificaram que durante dezembro e janeiro de 1974, o rápido decaimento de gelo marinho no Oceano Austral estaria relacionado ao fluxo de calor do fundo para a superfície oceânica devido ao bombeamento de Ekman e apenas indiretamente relacionado com os sistemas de baixa pressão. Isso porque a água sob o gelo marinho é relativamente mais aquecida do que o mesmo e, portanto, é capaz de derreter o gelo marinho. Assim, durante o verão austral o impacto dos transientes sobre as variações de alta frequência da cobertura de gelo marinho nos MBA e MW é reduzido e, portanto, outros mecanismos são responsáveis por tais variações, tais como o bombeamento de Ekman, as correntes oceânicas, os fatores geográficos locais, entre outros.

A anomalia ciclônica no oeste do setor e a anomalia anticiclônica no leste induzem a anomalias de ventos de norte e anomalias positivas de temperatura do ar a partir de três dias anteriores ao evento ENGM. Essa configuração contribui para o derretimento do gelo marinho e, sobretudo, para o arrasto de gelo marinho pelos anômalos ventos de norte em direção ao continente antártico, porém com menor intensidade do que no inverno. Em todos os casos de composições defasadas de anomalias de alta frequência dos campos atmosféricos em eventos EPGM apresentam fases opostas em relação aos eventos ENGM. Deste modo, fases distintas do trem de ondas modulam os extremos de gelo marinho opostos.

Lima (2007) associou a variabilidade extrema intrasazonal do gelo marinho nos mesmos setores analisados neste trabalho (MBA e MW) com a circulação atmosférica intrasazonal, e observou que os extremos de gelo marinho estão relacionados com os mesmos mecanismos encontrados no presente estudo, ou seja, anomalias de ventos de norte/sul e anomalias positivas/negativas de temperatura do ar. Portanto, conclui-se que os mecanismos que contribuem para a retração/expansão de gelo marinho nas escalas de tempo de alta frequência e intrasazonal são os mesmo nos setores dos MBA e MW, no período de verão e inverno austral, embora a persistência do trem de ondas seja diferente e estejam associados com fenômenos atmosféricos distintos. 


\subsection{Análise sinótica dos eventos extremos de gelo marinho em fases distintas do fenômeno El Niño: estudo de casos no setor dos mares de Bellingshausen-Amundsen durante o inverno austral}

\subsubsection{Evento extremo negativo de gelo marinho}

\subsubsection{Caso de El Niño}

Durante o evento ENGM nos MBA, que ocorreu entre os dias 11 e 12 de setembro de 2004, as anomalias de alta frequência de extensão de gelo marinho foram de $-28.281,6 \mathrm{~km}^{2}$ e $-29.949,7 \mathrm{~km}^{2}$, respectivamente. Neste mês o Índice de Niño Oceânico foi de +0,9. Analisando as anomalias de alta frequência dos campos atmosféricos três dias anteriores ao evento ENGM, observa-se sobre a Península Antártica e no oeste e extremo leste dos MBA anomalias ciclônicas (Figura 3.22a), associadas com anomalias de ventos de oeste no norte e de ventos de leste no sul (Figura 3.22c). No centro e leste dos MBA a anomalia é anticiclônica, com anomalias de ventos de leste no norte e de ventos de oeste no sul. Essa circulação anômala induz a uma anomalia de ventos de norte (Figura 3.22e) e anomalias positivas de temperatura do ar (Figura 3.22g), modulando os ENGM.

Na média troposfera, a anomalia de altura geopotencial é negativa sobre grande parte dos MBA, sendo positiva no extremo leste e sobre a Península Antártica (Figura 3.22i). Na altura geopotencial em $200 \mathrm{hPa}$ observa-se uma anomalia positiva no oeste dos MBA e uma anomalia negativa no leste do setor e sobre a Península Antártica (Figura 3.22k). Assim, as anomalias de altura geopotencial nos níveis médios estão fora de fase com as anomalias em níveis baixos e altos, o que indica que sobre o setor dos MBA há uma estrutura baroclínica da atmosfera. A circulação atmosférica em altos níveis, através das anomalias de vento zonal em $200 \mathrm{hPa}$, apresenta uma anomalia de ventos de leste sobre grande parte dos MBA, indicando um enfraquecimento do jato polar na região, e anomalia de ventos de oeste sobre a Península Antártica (Figura 3.22m). Ao norte, iniciando em cerca de cerca de $25^{\circ} \mathrm{S}$ em direção ao sudeste do Pacífico Sul, observa-se uma intensificação do jato subtropical através das anomalias de ventos de oeste em $200 \mathrm{hPa}$. Com a propagação para leste das anomalias sinóticas, no primeiro dia do evento ENGM, em 11/09/2004, as anomalias encontram-se praticamente em fase oposta em relação aos campos de três dias antes. 
a)

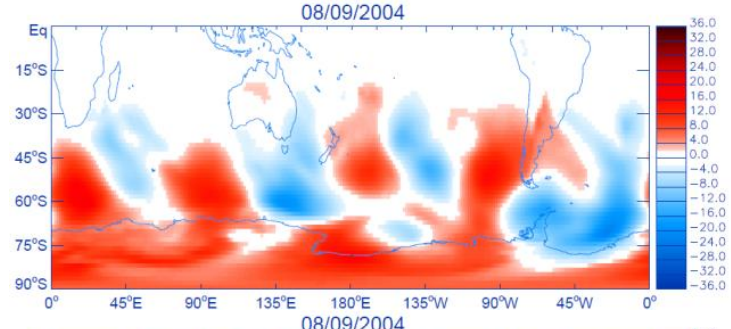

c)

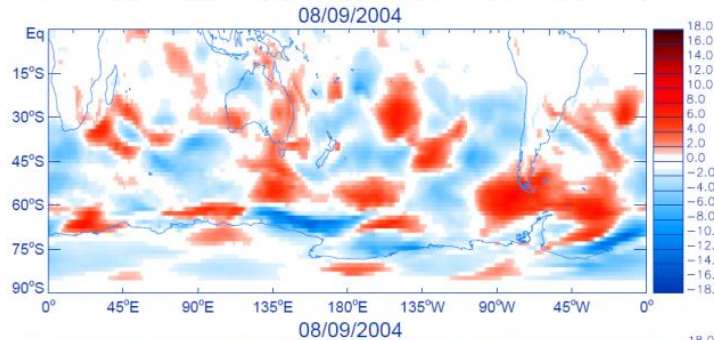

e)

g)

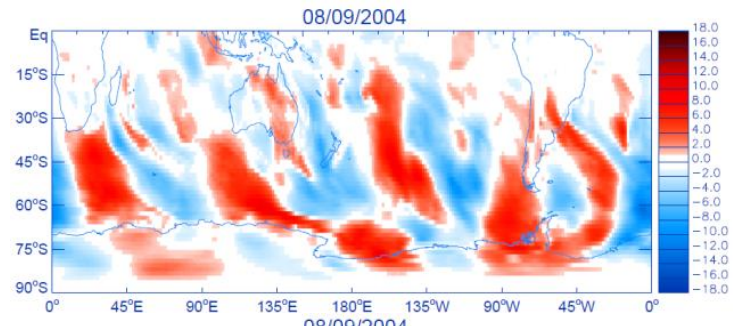

i)
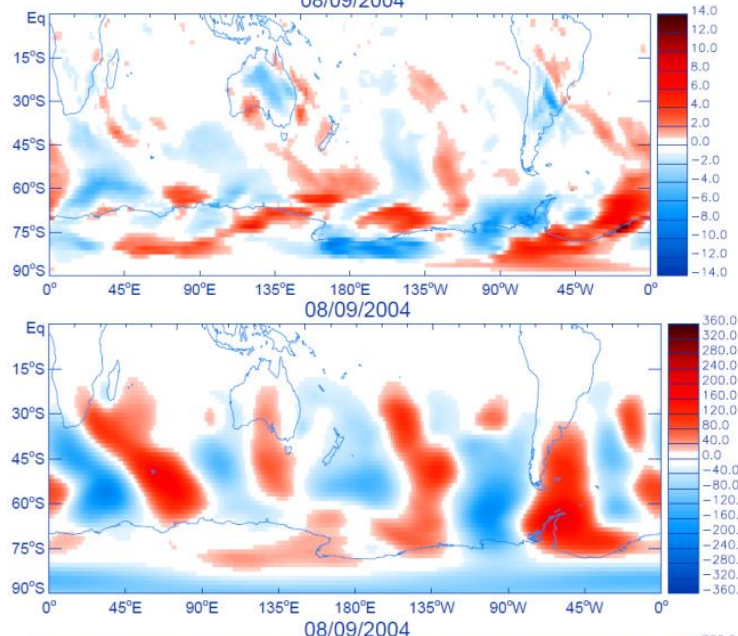

k)

m)
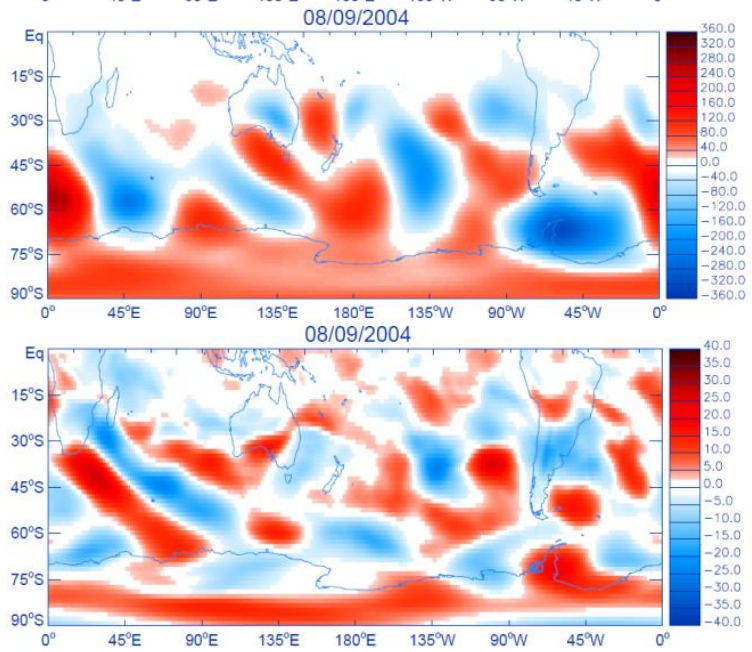

b)

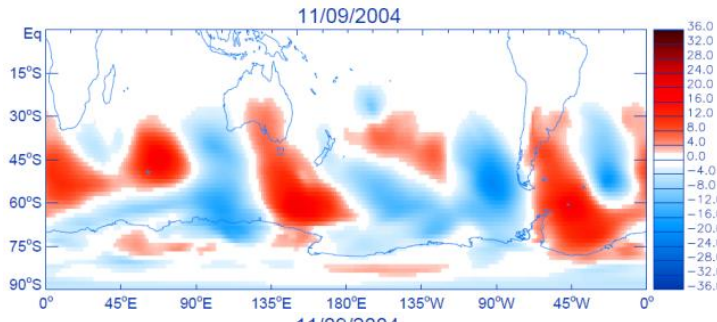

d)

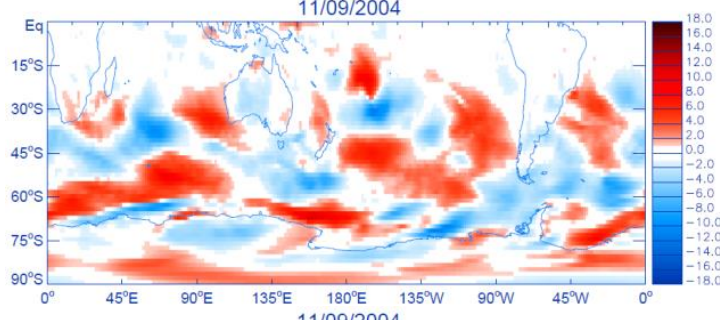

f)

h)
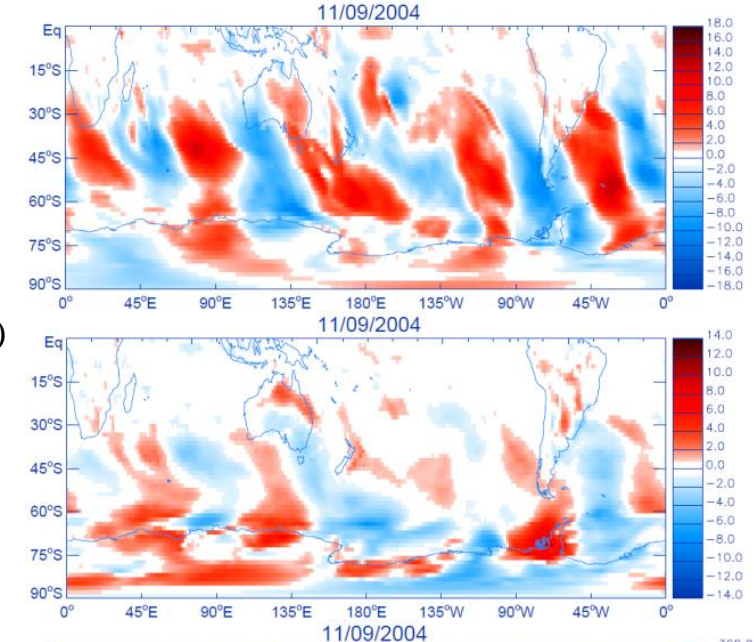

j)

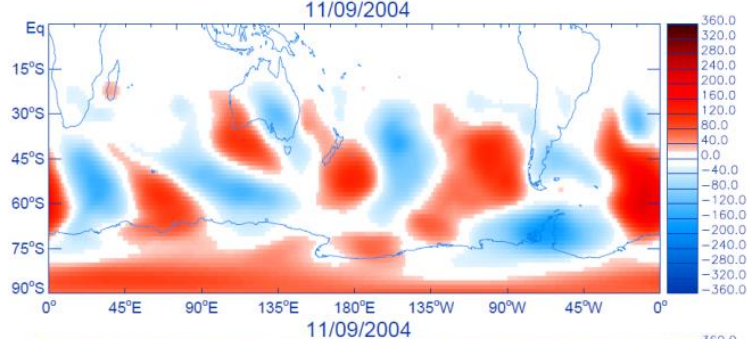

1)

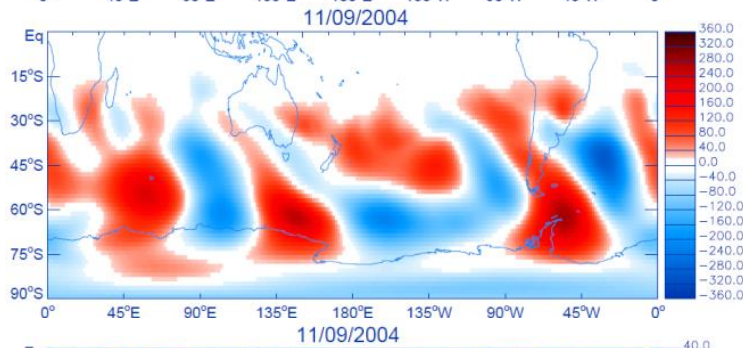

n)

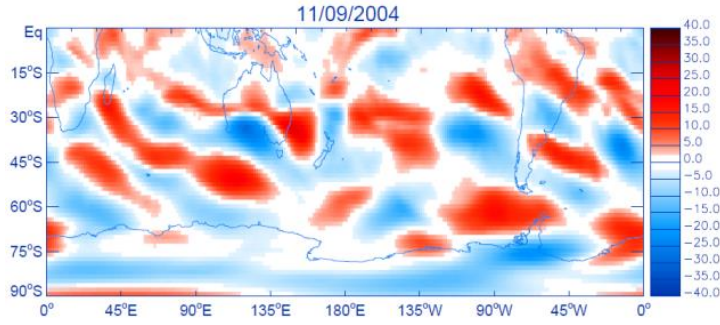

Figura 3.22: Anomalia de alta frequência de (a, b) PNMM, (c, d) vento zonal e (e, f) vento meridional a $10 \mathrm{~m},(\mathrm{~g}, \mathrm{~h})$ temperatura do ar a $2 \mathrm{~m},(\mathrm{i}, \mathrm{j})$ altura geopotencial em $500 \mathrm{hPa},(\mathrm{k}, \mathrm{l})$ altura geopotencial e $(\mathrm{m}, \mathrm{n})$ vento zonal em $200 \mathrm{hPa}$ no lag $=-3(08 / 09 / 2004)$ e no lag $=0(11 / 09 / 2004)$ no evento ENGM. 
$\mathrm{Na}$ análise sinótica três dias anteriores ao evento ENGM, às 12 UTC do dia 08/09/2004, observa-se um sistema de baixa pressão centrado em cerca de $140^{\circ} \mathrm{W} / 73^{\circ} \mathrm{S}$, com VR de até $-12 \times 10^{-5} \mathrm{~s}^{-1}$ e pressão central de $962 \mathrm{hPa}$ (Figura 3.23a). A circulação na vanguarda do sistema apresenta escoamento de norte em $10 \mathrm{~m}$, localizada na região oeste dos MBA (Figura 3.23b). Em 500 hPa observa-se uma baixa desprendida fechada, posicionada levemente à noroeste do sistema em superfície, imersa no eixo do cavado com VR ciclônica de até $-10 \times 10^{-5} \mathrm{~s}^{-1}$ (Figura 3.23c) e extensa área de nebulosidade associada (Figura 3.23d). Também há um sistema de baixa pressão ao norte da Península Antártica, centrado em cerca de $60^{\circ} \mathrm{W} / 62^{\circ} \mathrm{S}$, com pressão central de $961 \mathrm{hPa}$ e VR de até $-12 \times 10^{-5} \mathrm{~s}^{-1}$. Em níveis médios, no eixo entre a Península Antártica e o sul da América do Sul, observa-se uma região de cavado com intensa VR ciclônica e nebulosidade. No sudeste do Oceano Pacífico Sul há uma região de crista em superfície, associada a uma região de cristas em $500 \mathrm{hPa}$. Essa configuração, associada com a circulação na retaguarda do ciclone, localizado em $60^{\circ} \mathrm{W} /$ $62^{\circ} \mathrm{S}$, gera uma área abrangente com escoamento de norte sobre os MBA, contribuindo para o derretimento do gelo marinho e/ou do seu próprio transporte em direção as latitudes altas.

a)

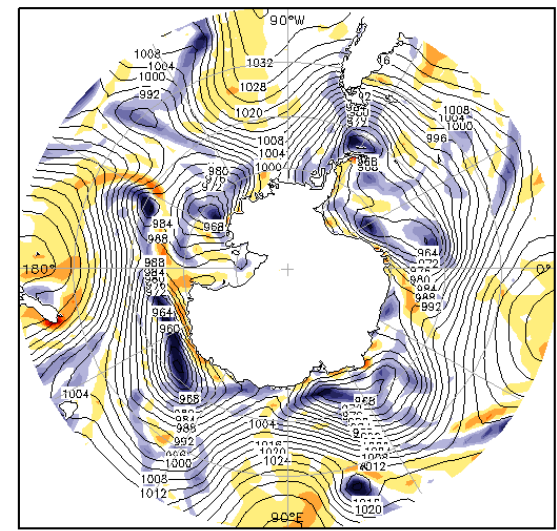

12 z08sep 2004

c)

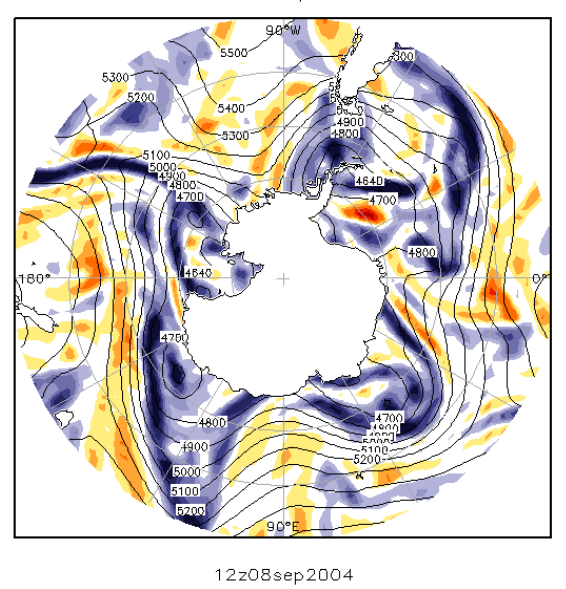

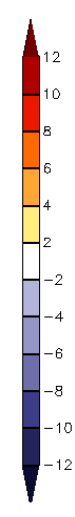

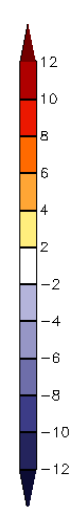

b)

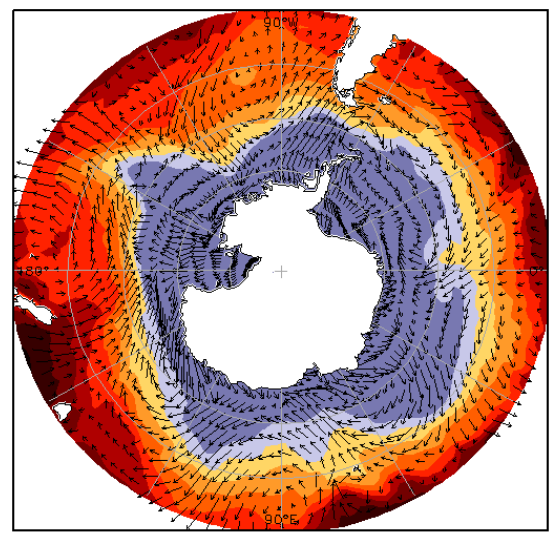

$12 z 08 \operatorname{sep} 2004 \quad \overrightarrow{30}$

d)

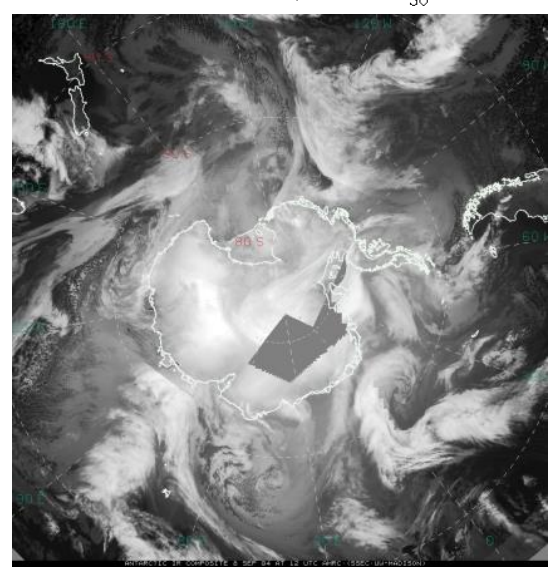

Figura 3.23: Dia 08/09/2004 às 12 UTC: (a) PNMM (linha contínua, em hPa) e VR em $1000 \mathrm{hPa}$ (sombreado, em $10^{-5} \mathrm{~s}^{-1}$ ); (b) temperatura do ar a $2 \mathrm{~m}$ (sombreado, em ${ }^{\circ} \mathrm{C}$ ) e vento horizontal a $10 \mathrm{~m}$ (vetores, em m/s); (c) altura geopotencial em $500 \mathrm{hPa}$ (sombreado, em m) e VR em $500 \mathrm{hPa}$ (sombreado, em $10^{-5} \mathrm{~s}^{-1}$ ); (d) composições de imagens de satélites no infravermelho. 
No dia 09/09/2004 (12 UTC), observa-se que o sistema que se encontrava junto à costa da Antártica manteve-se praticamente semi-estacionário, apresentando um abaixamento da pressão central para $959 \mathrm{hPa}$ e um aumento da VR para $-10 \times 10^{-5} \mathrm{~s}^{-1}$ (Figura 3.24a). Na média troposfera a baixa desprendida está posicionada praticamente sobre o ciclone em superfície, indicando que o sistema atingiu a fase barotrópica equivalente (Figura 3.24c). Isso quer dizer que os contornos de altura geopotencial e as isotermas são sempre paralelos e os ventos não mudam de direção com a altura. Contudo, a inclinação da superfície de pressão pode variar de um nível atmosférico para o outro, associado com as variações de espessura perpendicular aos contornos de altura geopotencial (WALLACE; HOBBS, 2006). Há também um sistema ciclônico em superfície, centrado em $120^{\circ} \mathrm{W} / 60^{\circ} \mathrm{S}$, embebido no eixo do cavado em superfície, o qual está orientado de noroeste para sudeste na região oeste dos MBA. Este sistema está localizado a oeste do eixo do cavado em $500 \mathrm{hPa}$, com intensa nebulosidade associada à frente fria e aos movimentos ascendentes gerados pelo sistema em superfície (Figura 3.24d). Na vanguarda desse sistema, associada à região de cristas em superfície no sudeste do Pacífico Sul e leste dos MBA, configura-se uma circulação de norte (Figura 3.24b).

a)

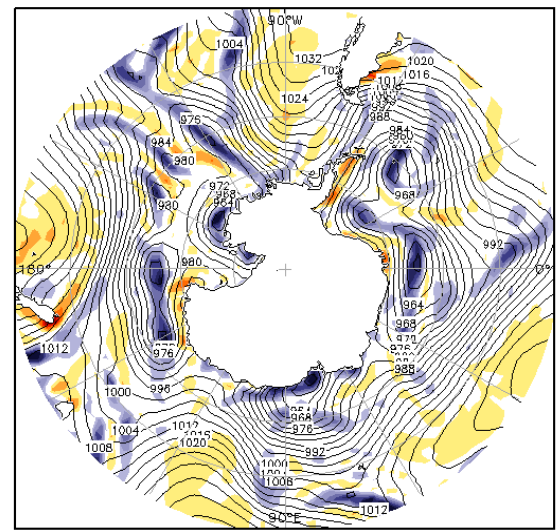

c)

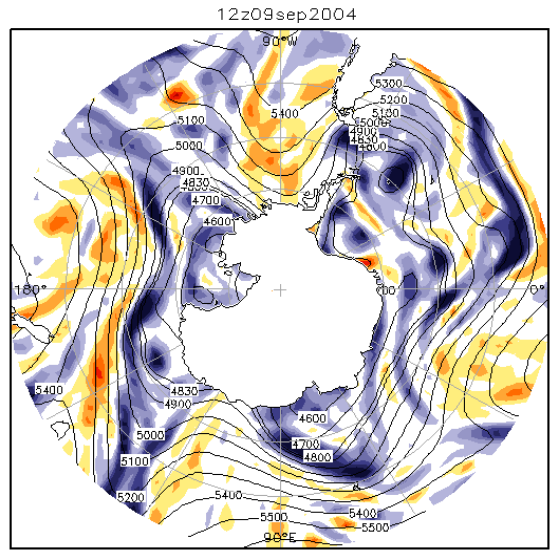

$12 z 09 \operatorname{sep} 2004$
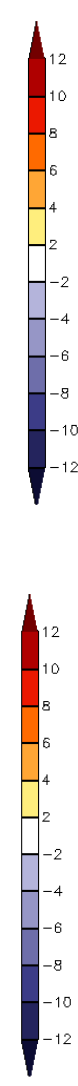

b)

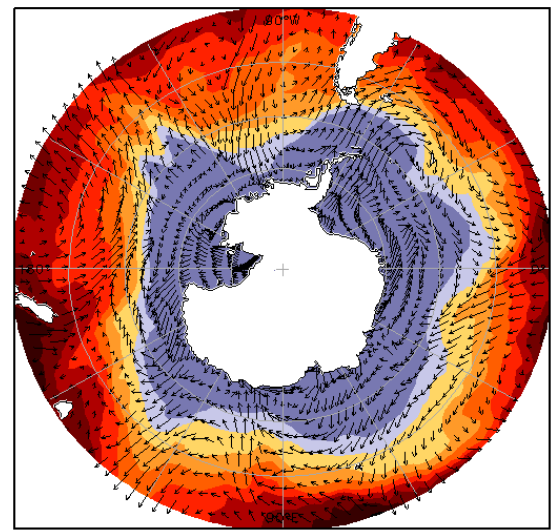

d)

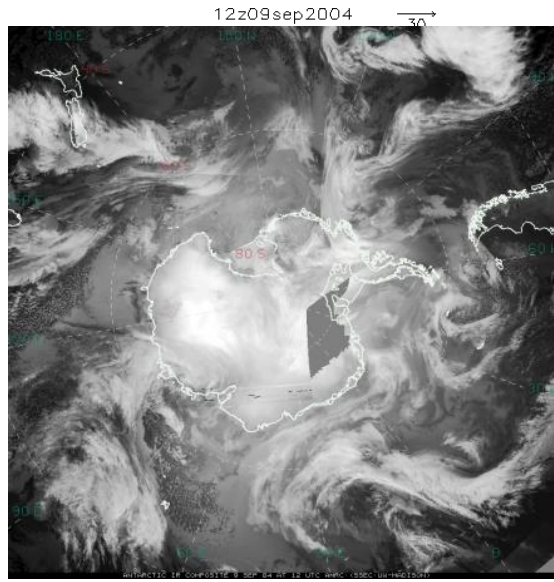

Figura 3.24: Dia 09/09/2004 às 12 UTC: (a) PNMM (linha contínua, em hPa) e VR em 1000 hPa (sombreado, em $10^{-5} \mathrm{~s}^{-1}$ ); (b) temperatura do ar a $2 \mathrm{~m}$ (sombreado, em ${ }^{\circ} \mathrm{C}$ ) e vento horizontal a $10 \mathrm{~m}$ (vetores, em m/s); (c) altura geopotencial em $500 \mathrm{hPa}$ (sombreado, em m) e VR em $500 \mathrm{hPa}$ (sombreado, em $10^{-5} \mathrm{~s}^{-1}$ ); (d) composições de imagens de satélites no infravermelho. 
Em 10/09/2004 às 12 UTC, o sistema analisado em 09/09/2004, sobre o noroeste dos MBA, desconfigura-se em superfície, embora exista uma região de cavado no oeste dos MBA, com VR de $-8 \times 10^{-5} \mathrm{~s}^{-1}$, orientada de noroeste para sudeste (Figura 3.25a). Em 500 $\mathrm{hPa}$ essa região está associada à VR de até $-8 \times 10^{-5} \mathrm{~s}^{-1}$ (Figura 3.25c). No extremo oeste dos MBA é observado um intenso ciclone em superfície oriundo do mar de Ross, centrado em $140^{\circ} \mathrm{W} / 67^{\circ} \mathrm{S}$. O sistema apresenta VR em $1000 \mathrm{hPa}$ no centro da região de baixa pressão superior à $-12 \times 10^{-5} \mathrm{~s}^{-1}$, pressão central de cerca de $940 \mathrm{hPa}$ e pronunciada circulação ciclônica do vento (Figura 3.25b). Toda a região de nebulosidade apresentou a forma de uma grande vírgula invertida, com intensa atividade convectiva a sudeste e extensa área de cirrus a noroeste do sistema em superfície (Figura 3.25d). Em 500 hPa observa-se uma baixa desprendida fechada posicionada exatamente sobre o ciclone em superfície, caracterizando o estágio barotrópico equivalente do sistema. A baixa desprendida está localizada a noroeste do cavado, associada à intensa VR negativa em $500 \mathrm{hPa}$. O sistema crista/cavado em superfície deslocase para leste, localizando-se sobre o sul da América do Sul. Assim, o padrão de circulação promove a incursão de ar relativamente aquecido para o setor dos MBA.

a)

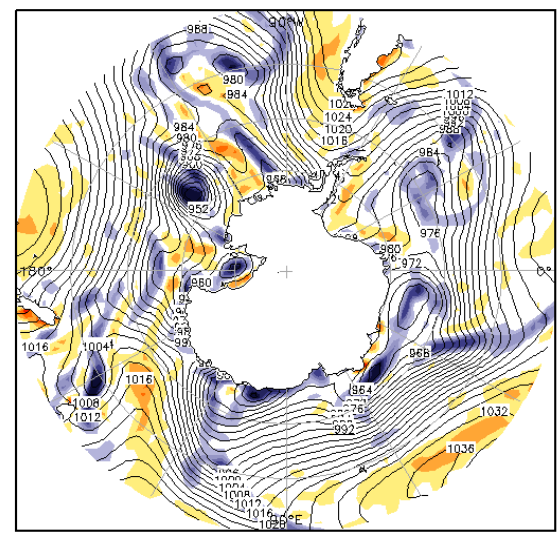

$12 z 10 \operatorname{sep} 2004$

c)

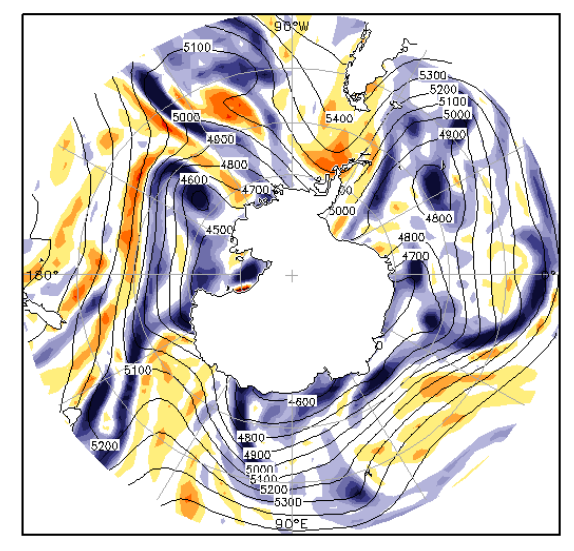

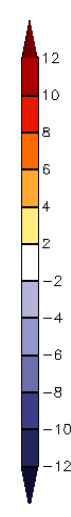

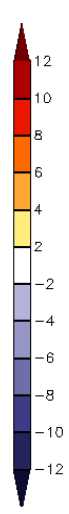

b)

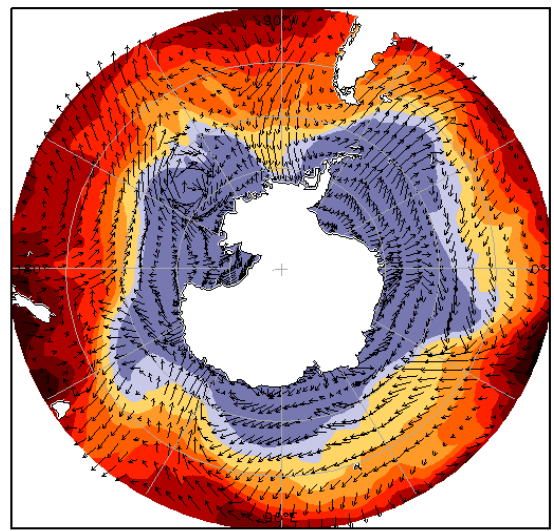

$12 z 10 \operatorname{sep} 2004 \quad \longrightarrow$

d)

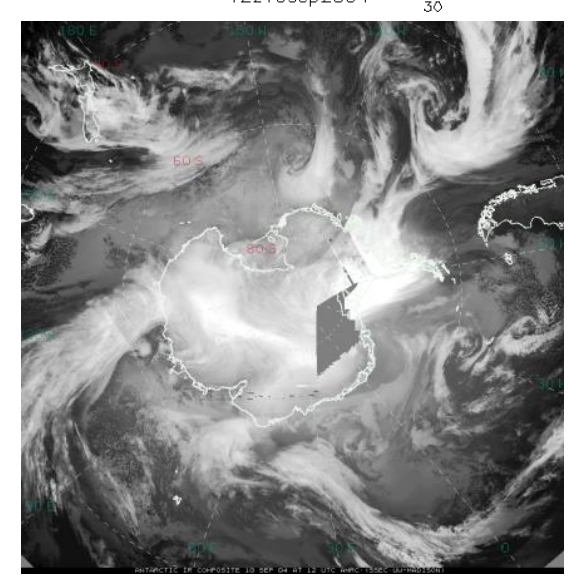

Figura 3.25: Dia 10/09/2004 às 12 UTC: (a) PNMM (linha contínua, em hPa) e VR em $1000 \mathrm{hPa}$ (sombreado, em $10^{-5} \mathrm{~s}^{-1}$ ); (b) temperatura do ar a $2 \mathrm{~m}$ (sombreado, em ${ }^{\circ} \mathrm{C}$ ) e vento horizontal a $10 \mathrm{~m}$ (vetores, em m/s); (c) altura geopotencial em $500 \mathrm{hPa}$ (sombreado, em m) e VR em $500 \mathrm{hPa}$ (sombreado, em $10^{-5} \mathrm{~s}^{-1}$ ); (d) composições de imagens de satélites no infravermelho. 
No dia do evento ENGM em 11/09/2004 (12 UTC), o ciclone em superfície deslocase para sudeste, centrado em $135^{\circ} \mathrm{W} / 70^{\circ} \mathrm{S}$, mantendo praticamente constantes os valores de VR ciclônica em 1000 hPa e a pressão central (Figura 3.26a). A intensa circulação ciclônica e a nebulosidade associada ao sistema em superfície e à frente fria, orientada de noroeste pra sudeste, podem ser vistas nas Figuras 3.26b e 3.26d. Em níveis médios, observa-se que a baixa desprendida ainda está configurada praticamente sobre a região do ciclone em superfície e está associada à intensa VR negativa sobre o eixo do cavado (Figura 3.26c). Assim, o sistema ainda encontra-se no estágio barotrópico equivalente. A nordeste desse sistema é observada uma região de cavados em superfície, orientada de noroeste pra sudeste, associada à VR ciclônica em 1000 e em 500 hPa. A leste dessa região é observada outra região de cavados, com orientação norte-sul, associada à VR ciclônica em níveis baixos e médios. Essas duas regiões podem ser verificadas através da extensa faixa de nebulosidade. Desta forma, a região a leste do cavado em superfície, localizada no extremo leste dos MBA e ao norte da Península Antártica, resulta em uma circulação de norte sobre o leste dos MBA, transportando ar aquecido das latitudes médias.

a)

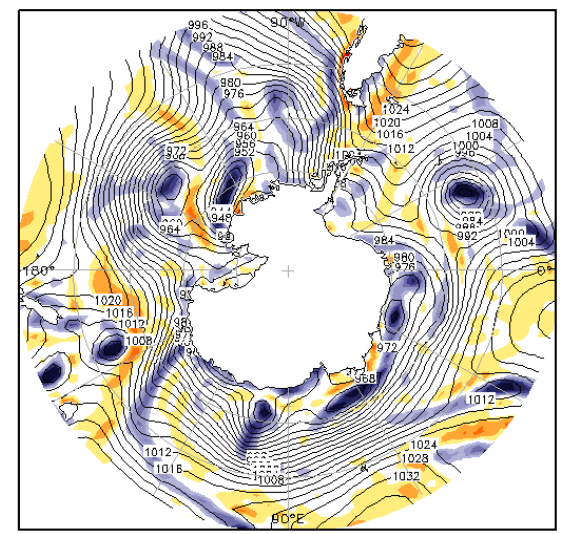

$12 z 11 \operatorname{sep} 2004$

c)

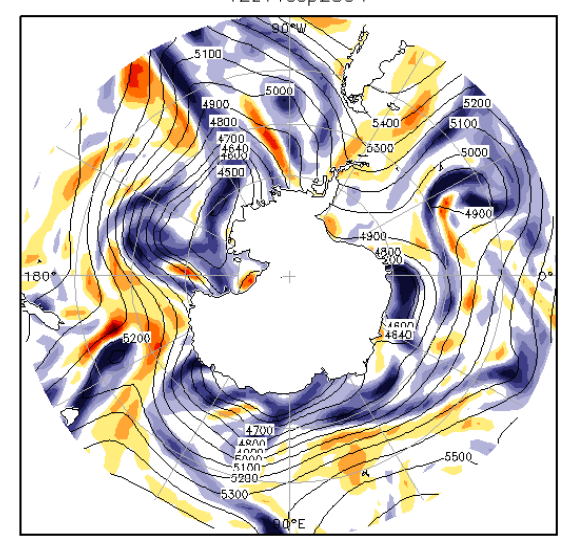

$12 z 11 \operatorname{sep} 2004$
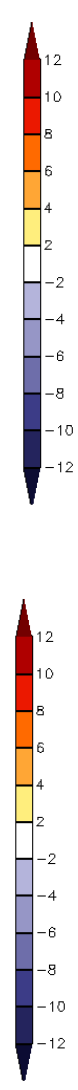

b)

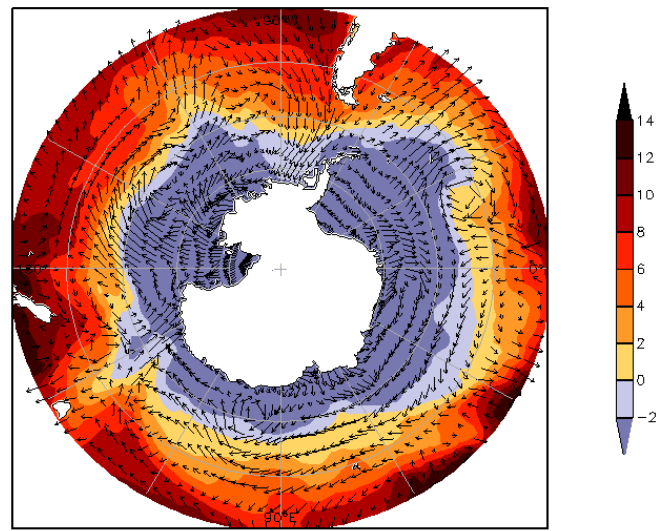

d)

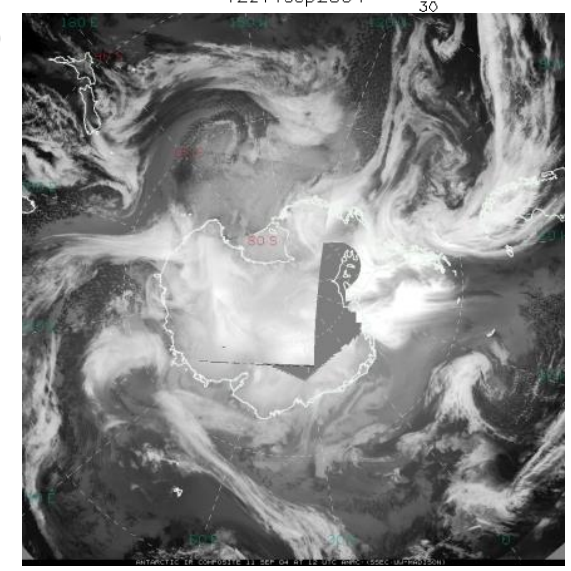

Figura 3.26: Dia 11/09/2004 às 12 UTC: (a) PNMM (linha contínua, em hPa) e VR em $1000 \mathrm{hPa}$ (sombreado, em $10^{-5} \mathrm{~s}^{-1}$ ); (b) temperatura do ar a $2 \mathrm{~m}$ (sombreado, em ${ }^{\circ} \mathrm{C}$ ) e vento horizontal a $10 \mathrm{~m}$ (vetores, em m/s); (c) altura geopotencial em $500 \mathrm{hPa}$ (sombreado, em m) e VR em $500 \mathrm{hPa}$ (sombreado, em $10^{-5} \mathrm{~s}^{-1}$ ); (d) composições de imagens de satélites no infravermelho. 
Assim, no estudo de caso de evento ENGM nos MBA em fase de El Niño, observase uma estrutura baroclínica sobre os MBA três dias anteriores ao evento ENGM, com anomalias de alta frequência de PNMM e de altura geopotencial em $200 \mathrm{hPa}$ positivas e anomalias de altura geopotencial em $500 \mathrm{hPa}$ negativas. Há um enfraquecimento do jato polar e um reforço do jato subtropical, analisado através das anomalias de alta frequência de vento zonal em $200 \mathrm{hPa}$. Na análise sinótica há um sistema de cristas e cavados bem organizado sobre os MBA. Esse padrão de circulação promove a incursão de ar relativamente aquecido sobre a região dos MBA, contribuindo para o evento ENGM. Verifica-se que os padrões atmosféricos identificados estão de acordo com as composições defasadas no tempo das anomalias de alta frequência dos campos atmosféricos em eventos ENGM nos MBA durante o inverno austral ( $c f$. seção 3.2.1). A configuração de menor atuação de sistemas ciclônicos na fase de El Niño é condizendo com os estudos feitos por Yuan (2004), pois o aquecimento tropical desloca a célula de circulação zonal para leste, de forma que o seu ramo ascendente ocorre no Pacífico tropical, intensificando e contraindo a Célula de Hadley nessa região. Consequentemente, a storm track desloca-se em direção ao equador no Pacífico Sul e sobre os MBA há uma menor atividade dos distúrbios transientes de alta frequência. A intensificação do jato subtropical, o enfraquecimento do jato polar e as mudanças na Célula de Hadley regional aparentemente resultam em um reforço da Célula de Ferrel no Pacífico Sul.

\subsubsection{Caso de La Niña}

O evento ENGM no setor dos MBA, ocorrido nos dias 14 e 15/09/1999, apresentou anomalias de alta frequência de gelo marinho de $-38.455,5 \mathrm{~km}^{2}$ e $-40.221,3 \mathrm{~km}^{2}$, respectivamente, e Índice de Niño Oceânico de -1,0 em setembro/1999. Analisando as anomalias de alta frequência no lag = -3 (11/09/1999), observa-se uma anomalia ciclônica no extremo oeste dos MBA (Figura 3.27a), associada a uma anomalia de ventos de oeste no norte e de ventos de leste no sul (Figura 3.27c); e uma anomalia anticiclônica no centro e leste do setor, associada às anomalias de ventos de leste no norte e de ventos de oeste no sul. Assim, verifica-se uma anomalia de ventos de norte sobre grande parte dos MBA (Figura 3.27e), juntamente com uma anomalia positiva de temperatura do ar (Figura 3.27g). Em níveis médios e altos a anomalia de altura geopotencial é positiva sobre praticamente todo o setor (Figuras 3.27i, 3.27k), associada em $200 \mathrm{hPa}$ com anomalias de vento de leste no norte e de ventos de oeste no sul (Figura 3.27m). Portanto, há uma leve intensificação do jato polar nos MBA. Como a anomalia anticiclônica é observada da superfície até 200 hPa, sobre os MBA há uma estrutura barotrópica equivalente. No dia do evento ENGM as anomalias foram opostas ao lag = -3 . 
a)

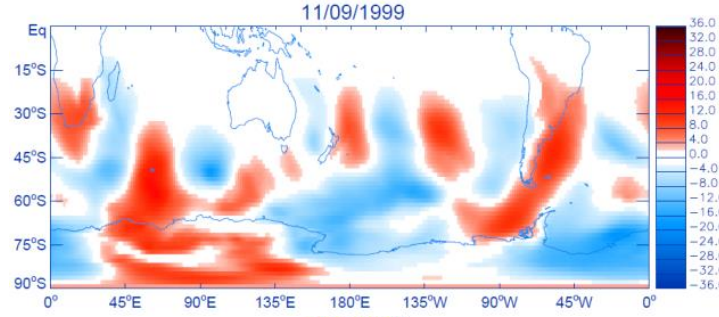

c)

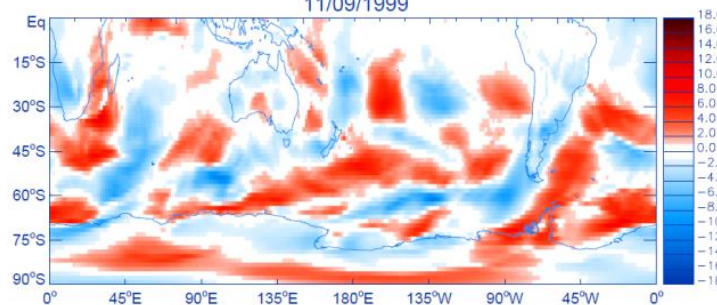

e)

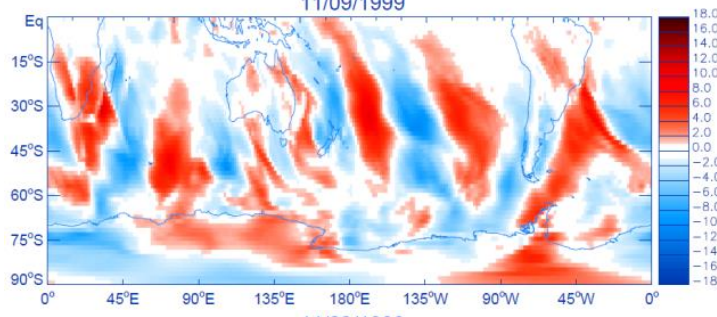

g)

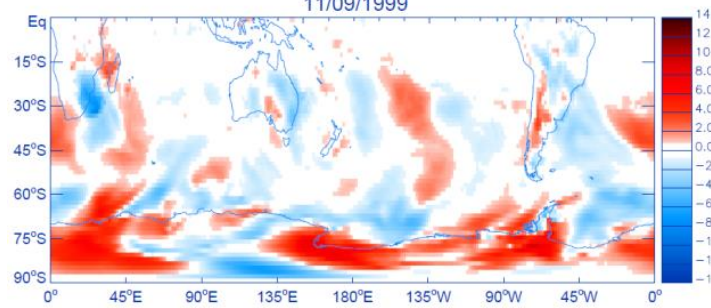

i)

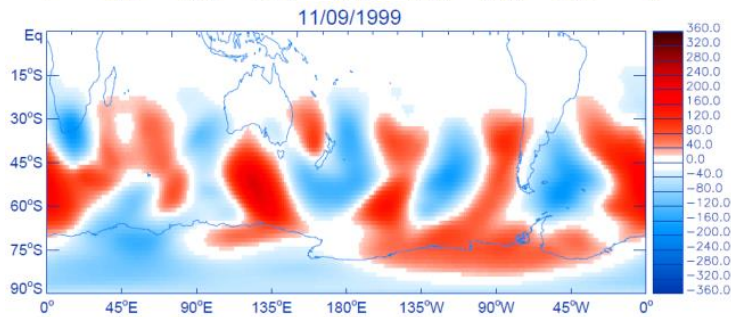

k)

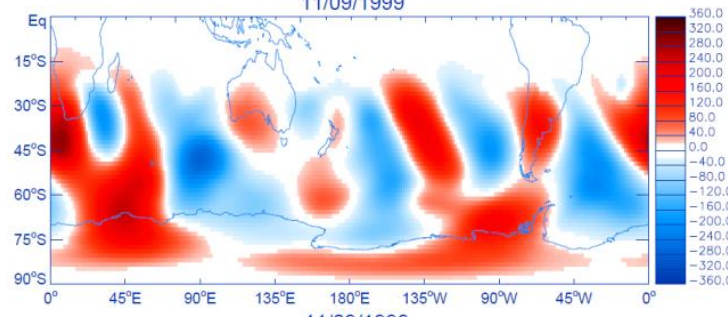

m)

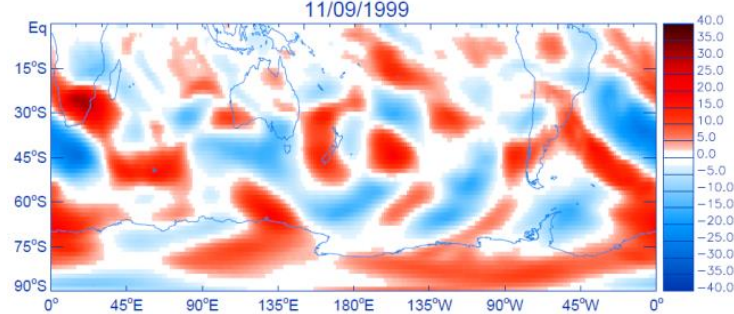

b)

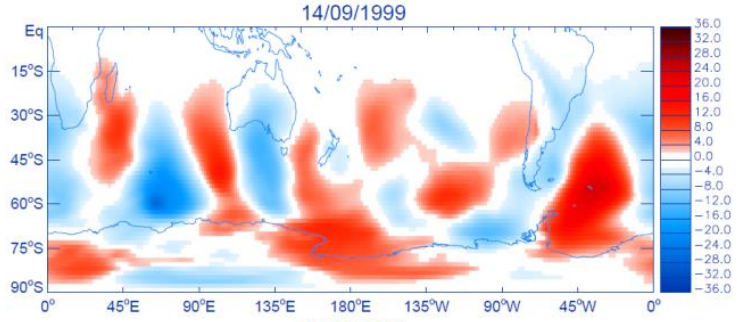

d)

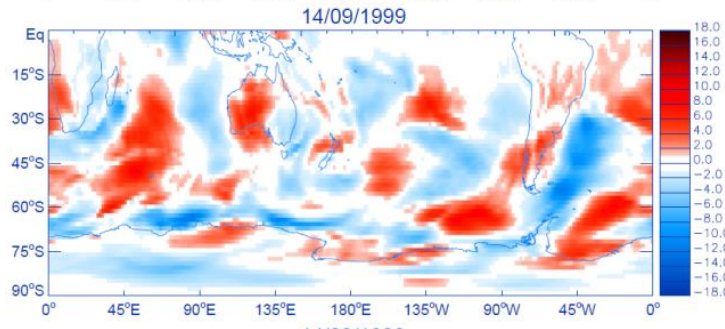

f)

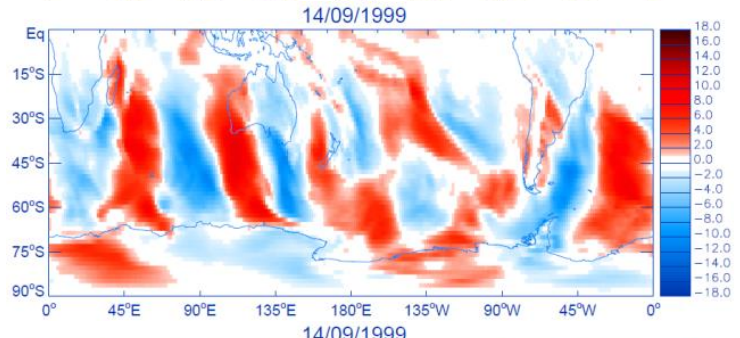

h)

j)
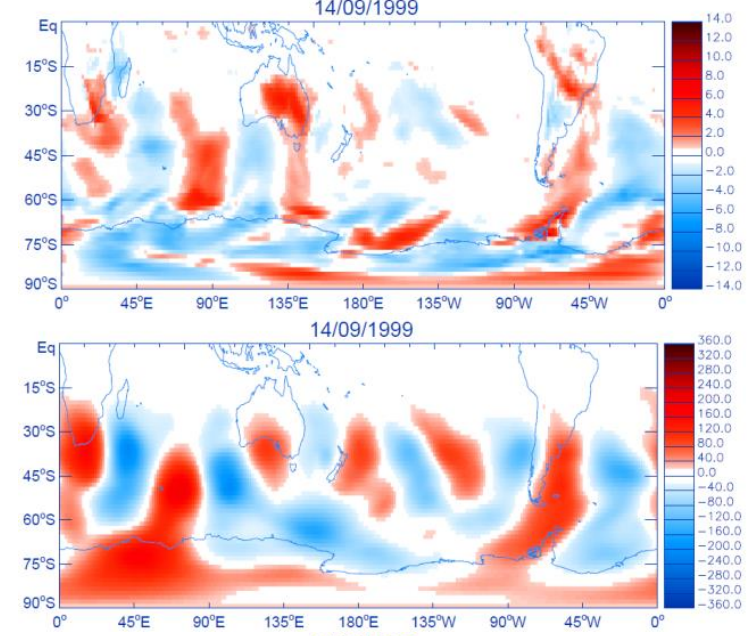

1)

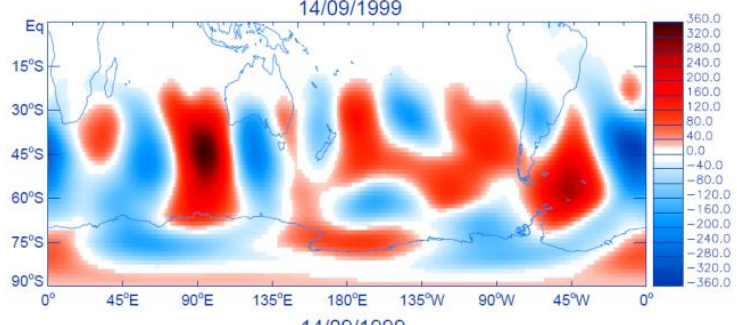

n)

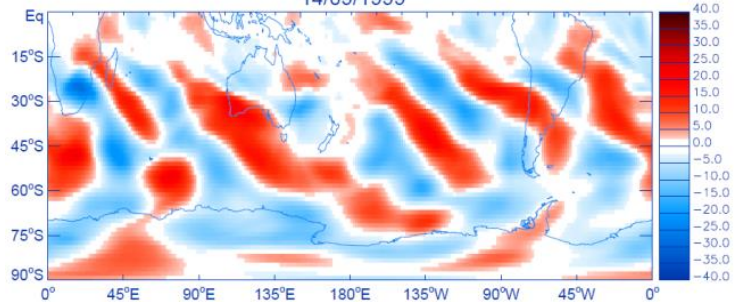

Figura 3.27: Anomalia de alta frequência de (a, b) PNMM, (c, d) vento zonal e (e, f) vento meridional a $10 \mathrm{~m},(\mathrm{~g}, \mathrm{~h})$ temperatura do ar a $2 \mathrm{~m},(\mathrm{i}, \mathrm{j})$ altura geopotencial em $500 \mathrm{hPa},(\mathrm{k}, \mathrm{l})$ altura geopotencial e $(\mathrm{m}, \mathrm{n})$ vento zonal em $200 \mathrm{hPa}$ no lag $=-3(11 / 09 / 1999)$ e no lag $=0(14 / 09 / 1999)$ no evento ENGM. 
Em 11/09/1999 (12 UTC) verifica-se um ciclone em superfície centrado em cerca de $134^{\circ} \mathrm{W} / 57^{\circ} \mathrm{S}$, com pressão central de $938 \mathrm{hPa}$ e VR em $1000 \mathrm{hPa}$ no centro do ciclone de $-10 \times 10^{-5} \mathrm{~s}^{-1}$ (Figura 3.28a). A intensa circulação ciclônica pode ser observada na Figura $3.28 \mathrm{~b}$, em que o seu centro está numa região com gradiente meridional de cerca de $0,6^{\circ} \mathrm{C}$ por ${ }^{\circ}$ lat. A nebulosidade possui a forma de espiral, com nuvens de topos mais altos no leste do que no centro do sistema em superfície, acoplada à frente fria, a qual está orientada de noroeste para sudeste (Figura 3.28d). Em $500 \mathrm{hPa}$, observa-se um contorno fechado de altura geopotencial praticamente sobre o sistema em superfície (Figura 3.28c), caracterizando o estágio barotrópico equivalente do ciclone, associado com intensa VR ciclônica. Ao sul desse sistema, observa-se uma região de cavados, com intensa VR ciclônica em cerca de $125^{\circ} \mathrm{W} /$ $59^{\circ} \mathrm{S}$. Em $500 \mathrm{hPa}$ observa-se uma baixa desprendida com intensa VR negativa, localizada à oeste da região de maior VR ciclônica em $1000 \mathrm{hPa}$. No leste dos MBA há um sistema de cristas em superfície, com VR de até $6 \times 10^{-5} \mathrm{~s}^{-1}$, associado à região de cristas e VR positiva em 500 hPa. Com essa configuração de circulação ciclônica no oeste e anticiclônica no leste dos MBA, há um escoamento predominantemente de norte sobre os MBA.

a)

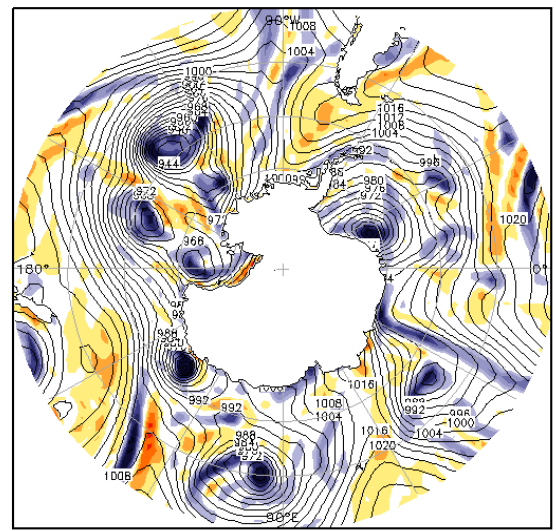

$12 z 11 \operatorname{sep} 1999$

c)

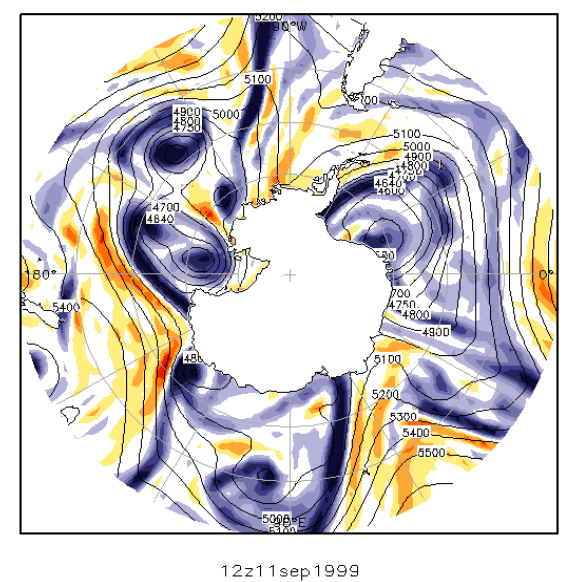

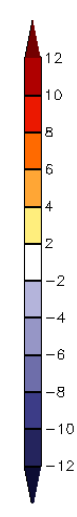

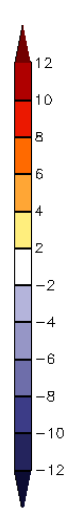

b)

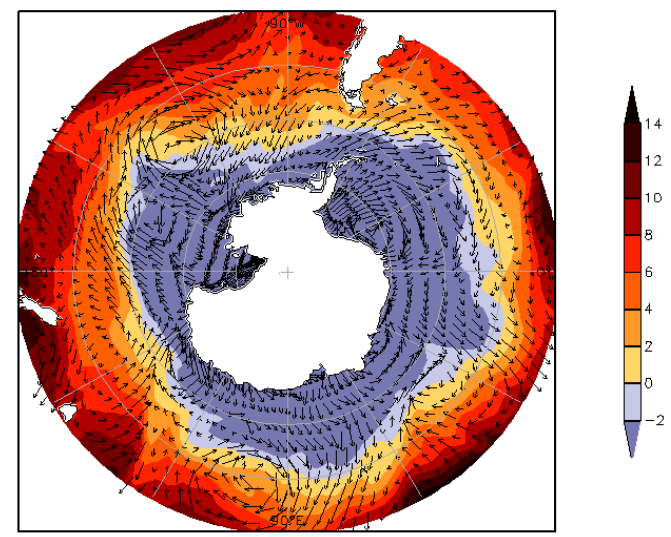

d)

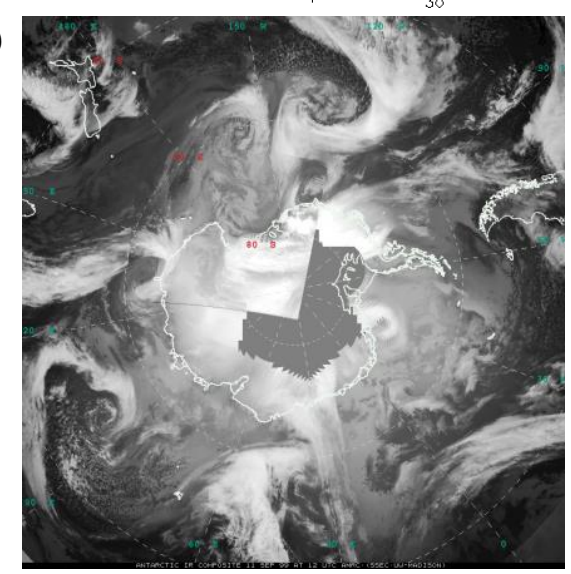

Figura 3.28: Dia 11/09/1999 às 12 UTC: (a) PNMM (linha contínua, em hPa) e VR em 1000 hPa (sombreado, em $10^{-5} \mathrm{~s}^{-1}$ ); (b) temperatura do ar a $2 \mathrm{~m}$ (sombreado, em ${ }^{\circ} \mathrm{C}$ ) e vento horizontal a $10 \mathrm{~m}$ (vetores, em $\mathrm{m} / \mathrm{s}$ ); (c) altura geopotencial em $500 \mathrm{hPa}$ (sombreado, em m) e VR em $500 \mathrm{hPa}$ (sombreado, em $10^{-5} \mathrm{~s}^{-1}$ ); (d) composições de imagens de satélites no infravermelho. 
Às 12 UTC do dia 12/09/1999, o sistema em superfície desloca-se para leste e adquire grandes dimensões espaciais, com diâmetro médio de cerca de $1.665 \mathrm{~km}$, centrado em torno de $121^{\circ} \mathrm{W} / 62^{\circ} \mathrm{S}$ (Figura 3.29a). O ciclone desintensifica, apresentando pressão central de $942 \mathrm{hPa}$ e VR no centro do sistema em superfície de $-8 \times 10^{-5} \mathrm{~s}^{-1}$ em $1000 \mathrm{hPa}$. A circulação ciclônica abrangente sobre o setor dos MBA resulta no predomínio de ventos de norte sobre o centro e leste do setor, associada à vanguarda do sistema (Figura 3.29b). A baixa desprendida ainda está configura em $500 \mathrm{hPa}$, praticamente sobre o sistema em superfície, e associada à VR negativa menos intensa. A nebulosidade devido aos movimentos ascendentes produzidos pelo ciclone em superfície e acoplada à frente fria pode ser vista na Figura 3.29d.

a)

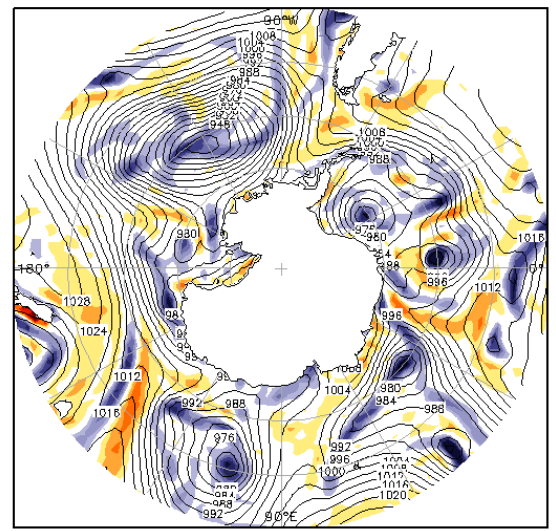

$12 z 12 \operatorname{sep} 1999$

c)

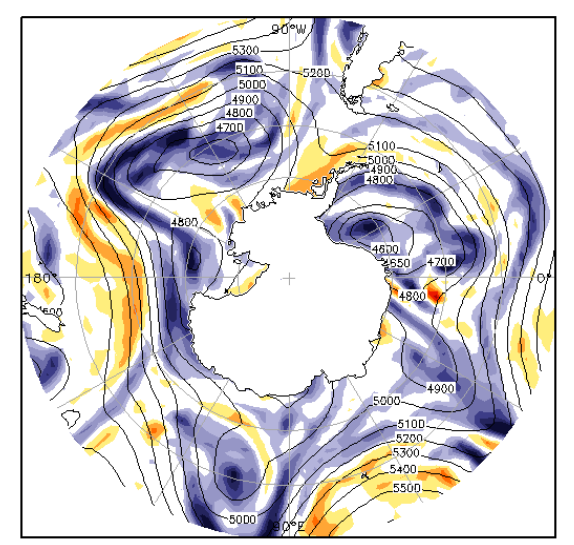

$12 z 12 \operatorname{sep} 1999$

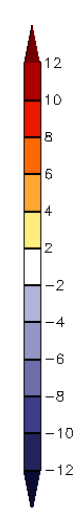

b)

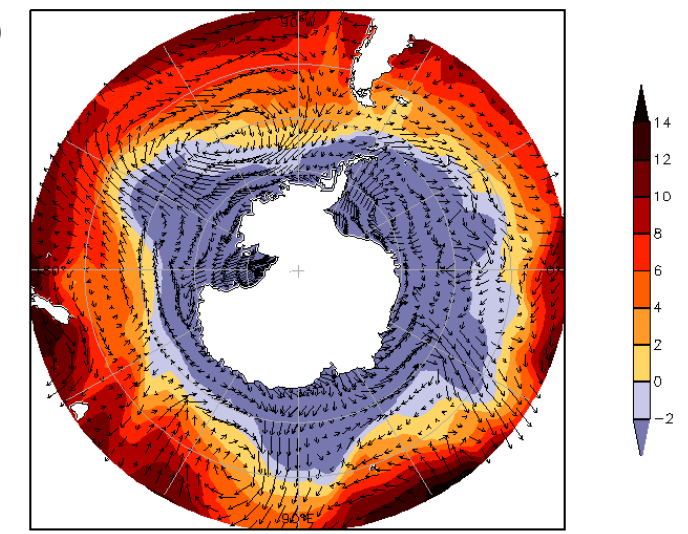

$12 z 12 \operatorname{sep} 1999 \quad \longrightarrow$

d)

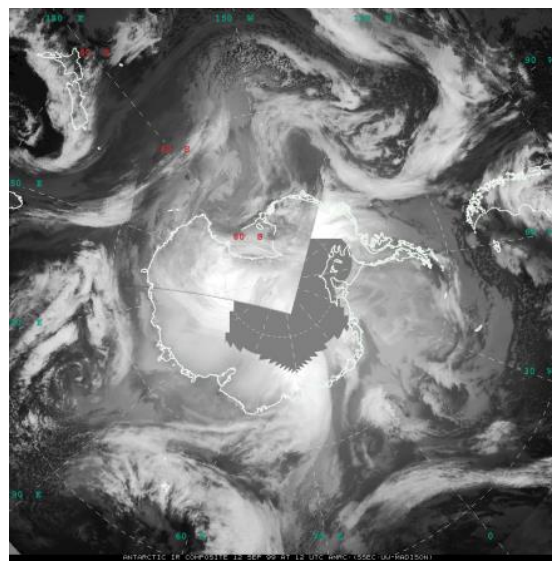

Figura 3.29: Dia 12/09/1999 às 12 UTC: (a) PNMM (linha contínua, em hPa) e VR em $1000 \mathrm{hPa}$ (sombreado, em $10^{-5} \mathrm{~s}^{-1}$ ); (b) temperatura do ar a $2 \mathrm{~m}$ (sombreado, em ${ }^{\circ} \mathrm{C}$ ) e vento horizontal a $10 \mathrm{~m}$ (vetores, em m/s); (c) altura geopotencial em $500 \mathrm{hPa}$ (sombreado, em m) e VR em $500 \mathrm{hPa}$ (sombreado, em $10^{-5} \mathrm{~s}^{-1}$ ); (d) composições de imagens de satélites no infravermelho.

Um dia anterior ao evento ENGM, ás 12 UTC do dia 13/09/1999, o ciclone em superfície desloca-se para sudeste, enfraquecendo ainda mais a pressão central, que aumenta para $945 \mathrm{hPa}$, e a VR em $1000 \mathrm{hPa}$ se mantém com valores de $-8 \times 10^{-5} \mathrm{~s}^{-1}$ (Figura 3.30a). Em 
$500 \mathrm{hPa}$ observa-se ainda a configuração da baixa desprendida sobre o ciclone em superfície, permanecendo no seu estágio barotrópico equivalente, e localizada no eixo do cavado em níveis médios, com intensa VR ciclônica associada (Figura 3.30c). Essa é a fase de maturidade do sistema em superfície, uma vez que ocorrerá uma queda de pressão na vanguarda do ciclone e um aumento na retaguarda - processo fundamental para o deslocamento do sistema. A nebulosidade em forma de espiral associada ao sistema em superfície e a faixa de nebulosidade associada à frente fria podem ser observadas na Figura 3.30d. No campo de vento horizontal a 10 m nota-se a circulação ciclônica do sistema, com ventos de norte na vanguarda dominantes sobre o setor dos MBA (Figura 3.30b).

a)

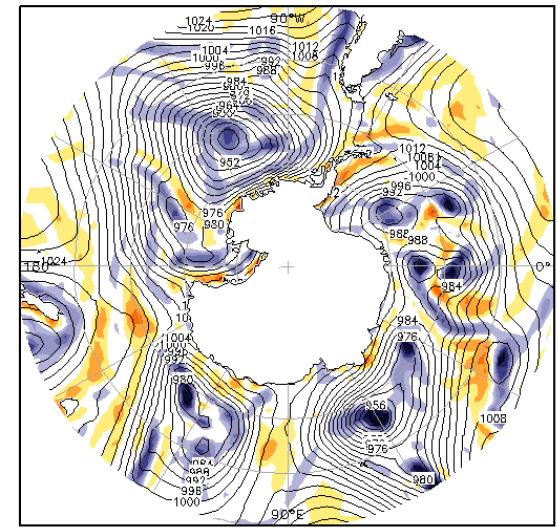

$12 z 13$ sep 1999

c)

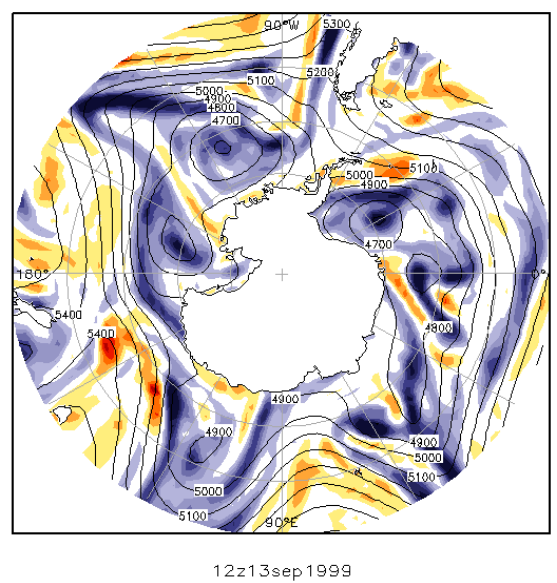

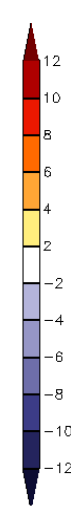

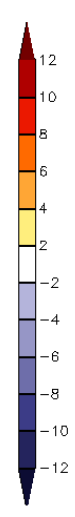

b)

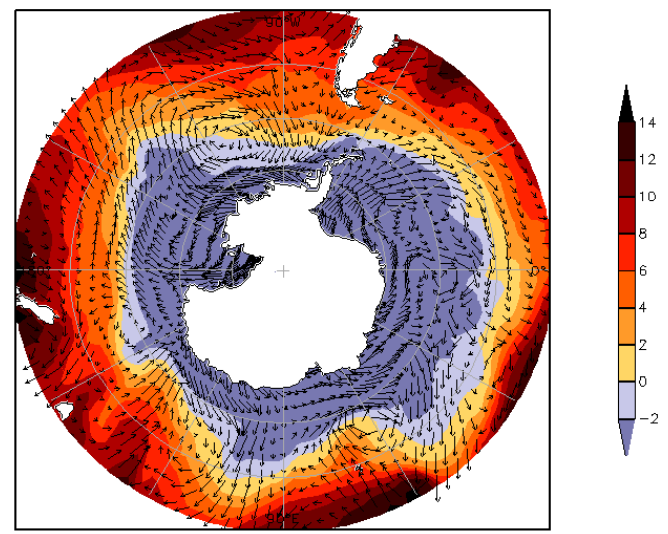

$12 z 13 \operatorname{sep} 1999 \quad \overrightarrow{30}$

d)

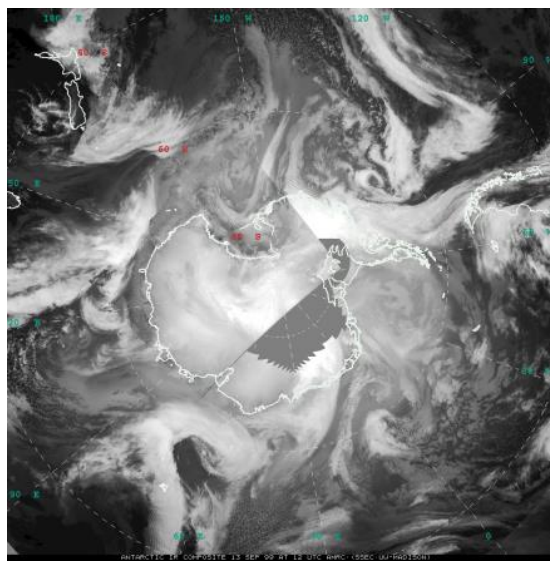

Figura 3.30: Dia 13/09/1999 às 12 UTC: (a) PNMM (linha contínua, em hPa) e VR em $1000 \mathrm{hPa}$ (sombreado, em $10^{-5} \mathrm{~s}^{-1}$ ); (b) temperatura do ar a $2 \mathrm{~m}$ (sombreado, em ${ }^{\circ} \mathrm{C}$ ) e vento horizontal a $10 \mathrm{~m}$ (vetores, em m/s); (c) altura geopotencial em $500 \mathrm{hPa}$ (sombreado, em m) e VR em $500 \mathrm{hPa}$ (sombreado, em $10^{-5} \mathrm{~s}^{-1}$ ); (d) composições de imagens de satélites no infravermelho.

No primeiro dia do evento ENGM, às 12 UTC de 14/09/1999, há o deslocamento do ciclone para sudeste, centrado em aproximadamente $115^{\circ} \mathrm{W} / 65^{\circ} \mathrm{S}$. O sistema apresentou uma leve intensificação de $1 \mathrm{hPa}$ na pressão central e manteve constante a VR ciclônica em 
1000 hPa (Figura 3.31a). Observa-se a circulação ciclônica nos campos de vento horizontal a $10 \mathrm{~m}$, destacando-se a abrangente circulação de norte, promovendo a incursão de ar aquecido em direção aos MBA (Figura 3.31b). Em níveis médios, a baixa desprendida encontra-se deslocada para oeste da posição do sistema em superfície, localizada no eixo no cavado e associada com intensa VR negativa (Figura 3.31c). Com os movimentos ascendentes devido ao sistema em superfície pode-se observar a nebulosidade na Figura 3.31d.

a)

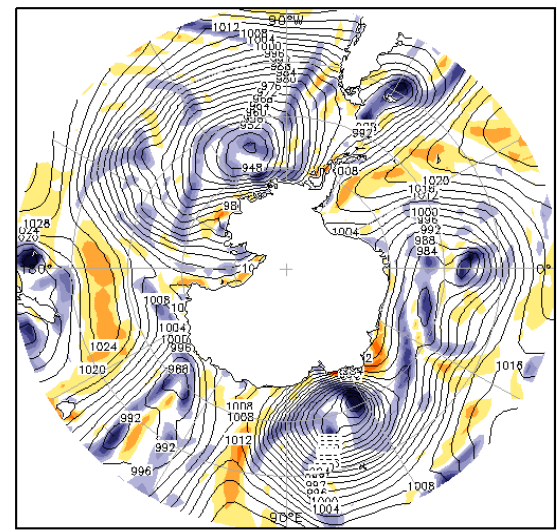

$12 z 14 \operatorname{sep} 1999$

c)

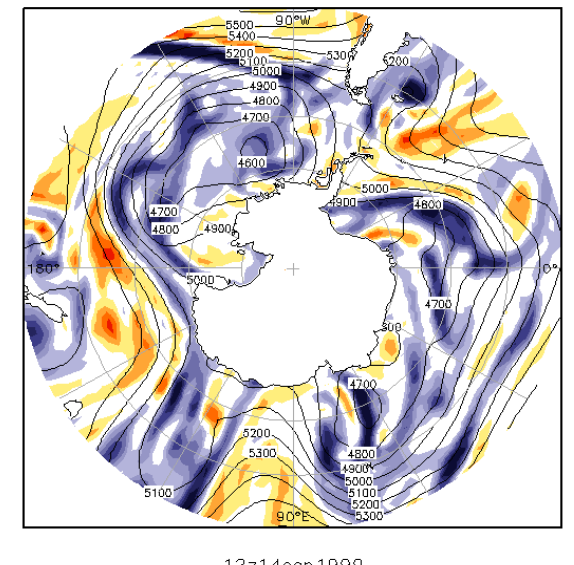

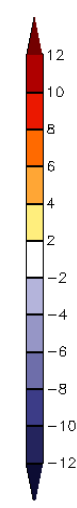

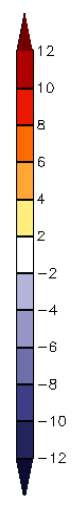

b)

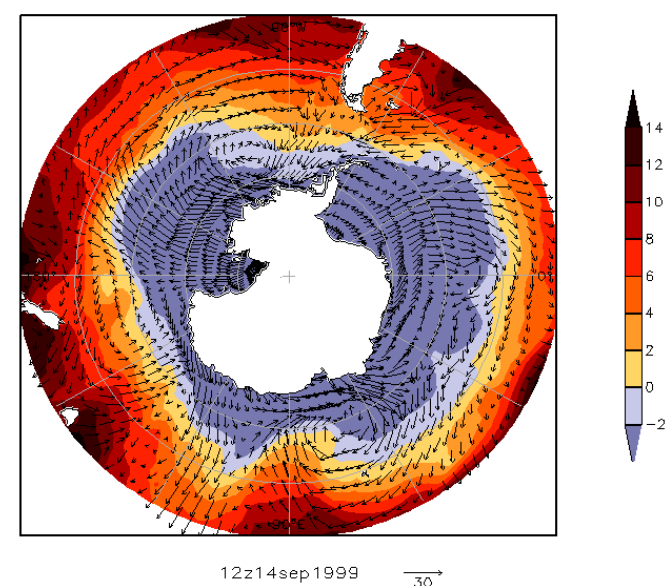

d)

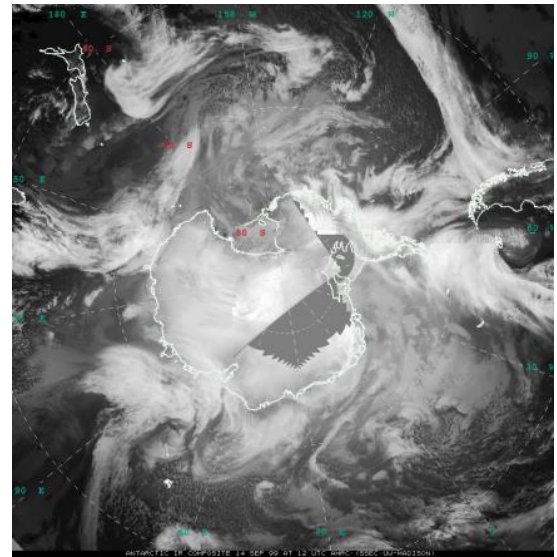

Figura 3.31: Dia 14/09/1999 às 12 UTC: (a) PNMM (linha contínua, em hPa) e VR em $1000 \mathrm{hPa}$ (sombreado, em $10^{-5} \mathrm{~s}^{-1}$ ); (b) temperatura do ar a $2 \mathrm{~m}$ (sombreado, em ${ }^{\circ} \mathrm{C}$ ) e vento horizontal a $10 \mathrm{~m}$ (vetores, em m/s); (c) altura geopotencial em $500 \mathrm{hPa}$ (sombreado, em m) e VR em $500 \mathrm{hPa}$ (sombreado, em $10^{-5} \mathrm{~s}^{-1}$ ); (d) composições de imagens de satélites no infravermelho.

No estudo de caso de evento ENGM nos MBA em fase de La Niña, sobre o setor é observada uma estrutura barotrópica equivalente três dias anteriores ao evento ENGM, com anomalias de alta frequência de PNMM, altura geopotencial em 500 e 200 hPa positivas. Há um reforço do jato polar sobre os MBA (anomalias de alta frequência positivas de vento zonal em $200 \mathrm{hPa}$ ). Os ventos de norte em baixos níveis estão associados à vanguarda dos sistemas ciclônicos atuantes na região, os quais contribuem para o evento ENGM nos MBA, o que está 
de acordo com o observado nas composições de anomalias de alta frequência dos campos atmosféricos na baixa atmosfera e em superfície ( $c f$. seção 3.2.1). Ao contrário do El Niño, durante o período de La Niña o resfriamento tropical atenua e expande a Célula de Hadley sobre o Pacífico Sul. Consequentemente, a storm track desloca-se em direção ao polo nessa região e, portanto, há uma maior atividade dos distúrbios de alta frequência sobre os MBA. As mudanças na corrente de jato (reforço no jato polar) e na Célula de Hadley regional resultam em um enfraquecimento da Célula de Ferrel no Pacífico Sul (YUAN, 2004).

\subsubsection{Caso neutro}

No evento ENGM, ocorrido entre os dias 23 e 26/09/2005, as anomalias de alta frequência de extensão de gelo marinho foram de $-32.681,2 \mathrm{~km}^{2},-36.318,5 \mathrm{~km}^{2},-27.843,4$ $\mathrm{km}^{2}$ e $-32.345,5 \mathrm{~km}^{2}$, respectivamente, e o Índice de Niño Oceânico em setembro de 2005 foi de $+0,2$. Três dias anteriores ao evento ENGM as anomalias de alta frequência de PNMM no oeste dos MBA foi ciclônica (Figura 3.32a), associada com anomalias de ventos de leste no sul (Figura 3.32c). No leste do setor a anomalia de PNMM foi anticiclônica, associada com anomalias de ventos de leste no norte e de ventos de oeste no sul. Como resultado desse padrão de anomalias de PNMM, as anomalias de vento meridional foram predominantemente de norte sobre os MBA (Figura 3.32e) e assim, predominaram anomalias de temperatura do ar positivas (Figura 3.32g). A altura geopotencial em $500 \mathrm{hPa}$ apresentou fracas anomalias negativas no oeste dos MBA e fracas anomalias positivas no centro e leste do setor, além de anomalias negativas no sudeste dos MBA (Figura 3.32i). Em altos níveis, a anomalia de altura geopotencial foi positiva no leste do setor e negativa no oeste (Figura 3.32k). Assim, sobre o setor há uma estrutura baroclínica, pois as anomalias de PNMM/altura geopotencial em 200 hPa e de altura geopotencial em $500 \mathrm{hPa}$ estão fora de fase. Sobre os MBA o jato polar é intensificado, com anomalias positivas de vento zonal em $200 \mathrm{hPa}$ (Figura 3.32m).

Com a propagação para leste das anomalias de alta frequência, no dia do evento ENGM sobre os MBA (23/09/2005) a anomalia de PNMM foi predominantemente ciclônica (Figura 3.32b), associada com anomalia de ventos de oeste no norte e de ventos de leste no sul (Figura 3.32d). No oeste dos MBA há anomalias de ventos de sul (Figura 3.32f), associadas com anomalias negativas de temperatura do ar (Figura 3.32h); e no leste do setor anomalias de ventos de norte, associadas com anomalias positivas de temperatura do ar. As anomalias em níveis médios e altos encontram-se praticamente em fase oposta ao dia 20/09/2005. 
a)

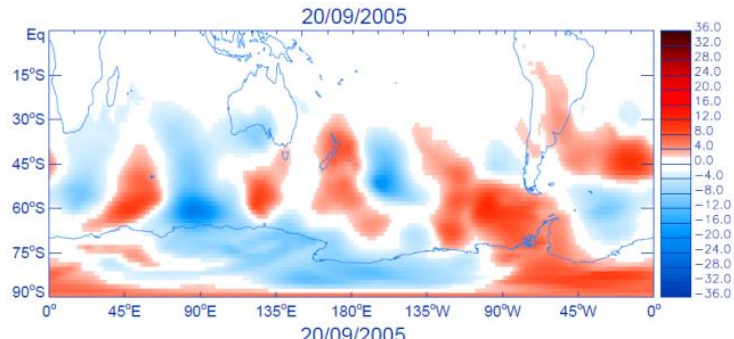

c)

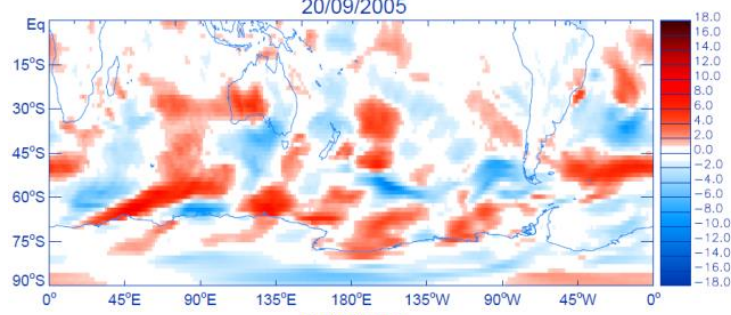

e)

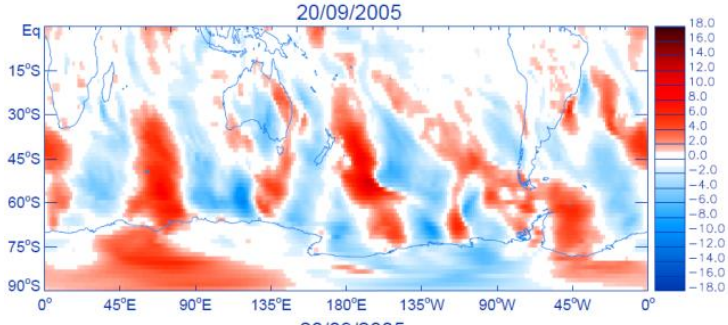

g)

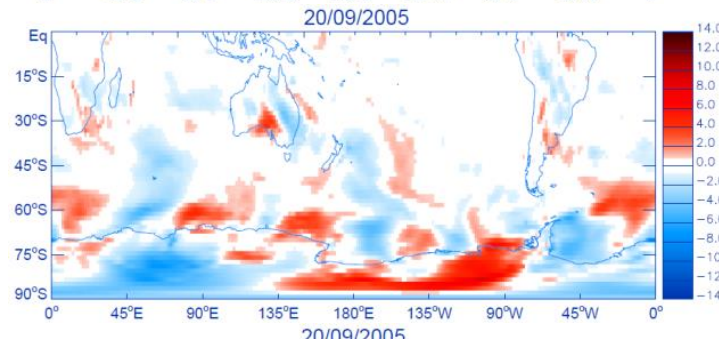

i)

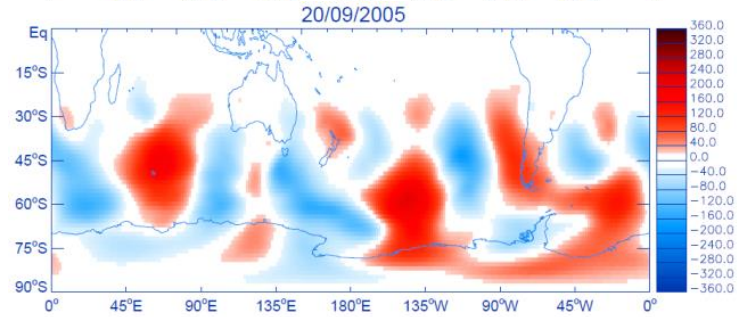

k)

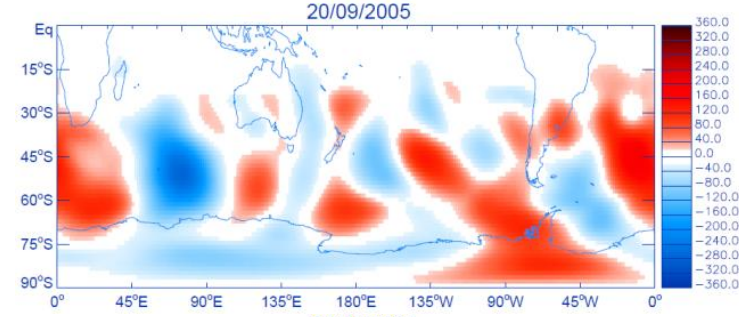

m)

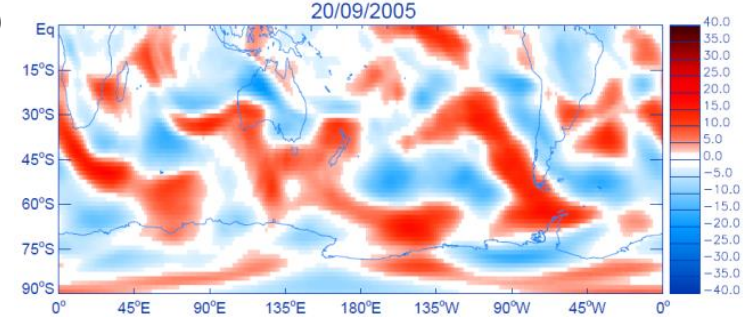

b)

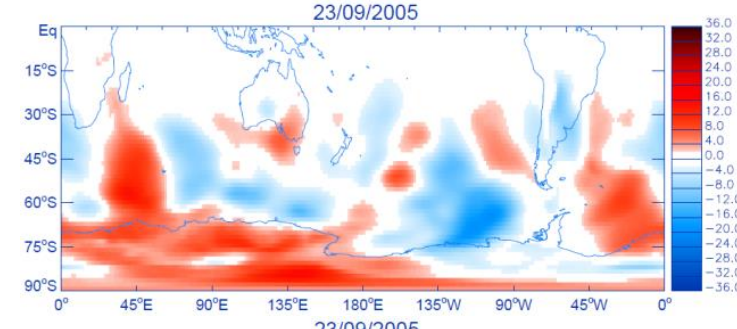

d)

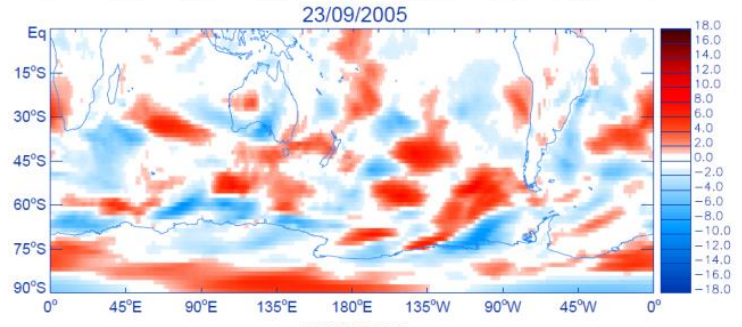

f)

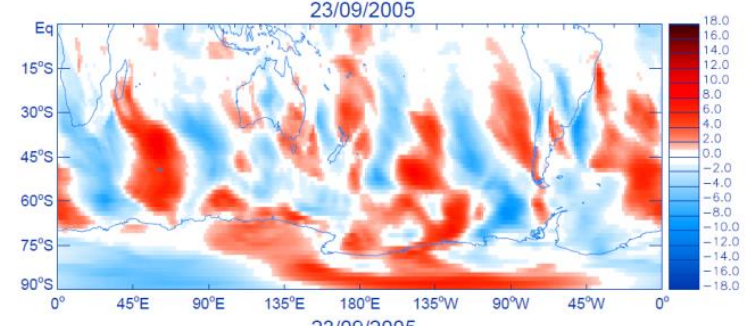

h)

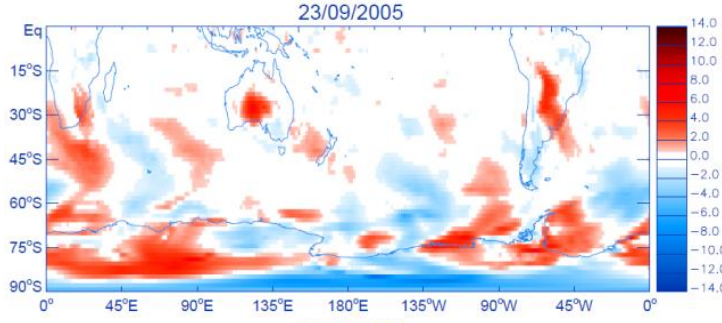

j)

1)
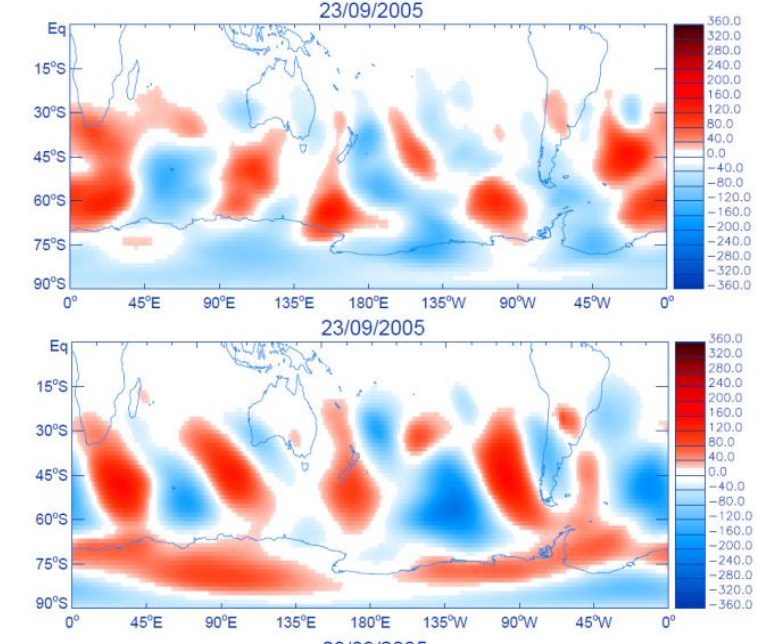

n)

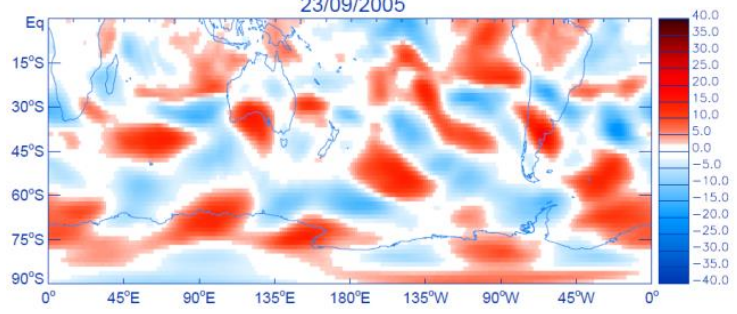

Figura 3.32: Anomalia de alta frequência de ( $a, b)$ PNMM, (c, d) vento zonal e (e, f) vento meridional a $10 \mathrm{~m},(\mathrm{~g}, \mathrm{~h})$ temperatura do ar a $2 \mathrm{~m},(\mathrm{i}, \mathrm{j})$ altura geopotencial em $500 \mathrm{hPa},(\mathrm{k}, \mathrm{l})$ altura geopotencial e $(\mathrm{m}, \mathrm{n})$ vento zonal em $200 \mathrm{hPa}$ no lag $=-3(20 / 09 / 2005)$ e no lag $=0(23 / 09 / 2005)$ no evento ENGM. 
No dia 20/09/2005 às 12 UTC, três dias anteriores ao evento ENGM, verifica-se um sistema de cavados orientado de norte para sul, com uma região alongada de VR ciclônica em $1000 \mathrm{hPa}$, associada a um sistema ciclônico em superfície centrado em aproximadamente $110^{\circ} \mathrm{W} / 61^{\circ} \mathrm{S}$ (Figura 3.33a), com pressão central de cerca de $992 \mathrm{hPa}$. Observa-se que a baixa em superfície está localizada no eixo do cavado em $500 \mathrm{hPa}$, associado com intensa VR negativa (Figura 3.33c). A faixa de nebulosidade associada pode ser visualizada na Figura 3.33d. A nordeste desse ciclone, em $90^{\circ} \mathrm{W} / 57^{\circ} \mathrm{S}$, identifica-se outro sistema com pressão central em torno de $994 \mathrm{hPa}$ e VR de $-8 \times 10^{-5} \mathrm{~s}^{-1}$ em $1000 \mathrm{hPa}$. Na média troposfera observase um contorno fechado de altura geopotencial praticamente sobre a região do ciclone em superfície e associado à VR negativa, caracterizando assim o estágio barotrópico equivalente do sistema. Ao sul verifica-se um sistema anticiclônico, com pressão central de $1011 \mathrm{hPa}$, associado à VR de $4 \times 10^{-5} \mathrm{~s}^{-1}$ no núcleo. A região a leste do cavado em superfície no oeste dos MBA induz a uma circulação de ventos de norte principalmente na região oeste e central do setor (Figura 3.33b).

a)

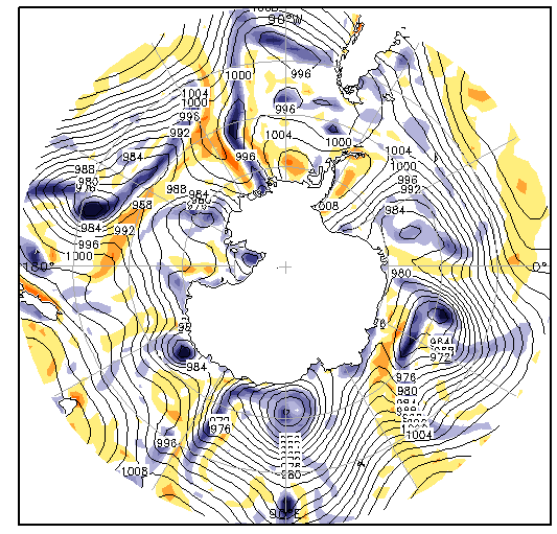

$12 z 20$ sep 2005

c)

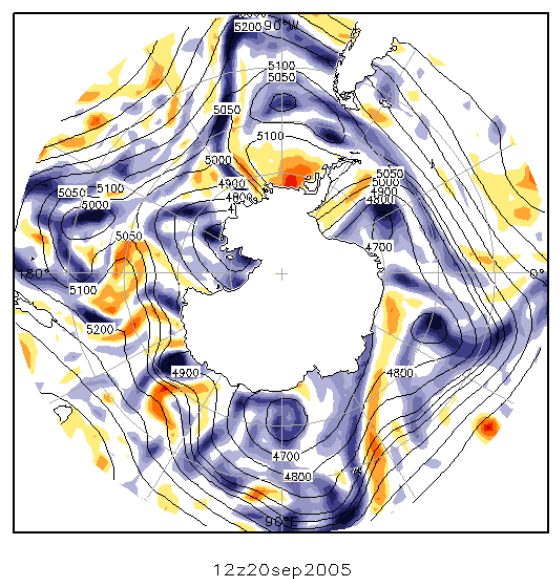

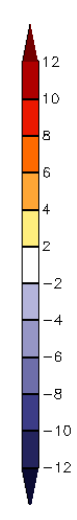

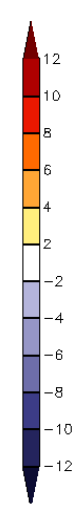

b)

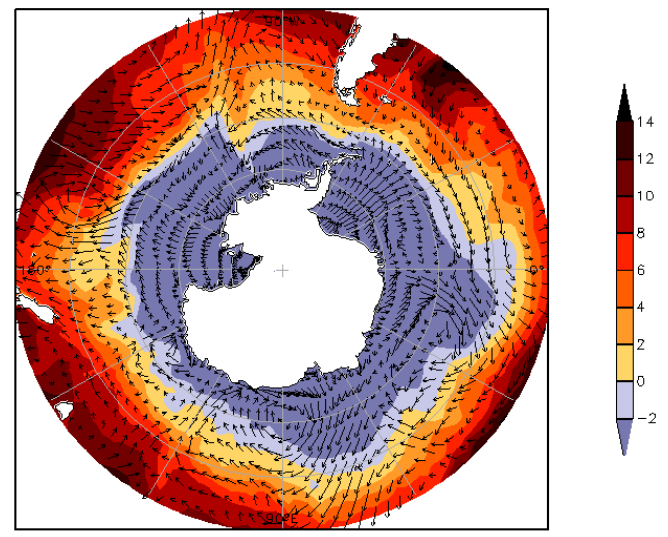

d)

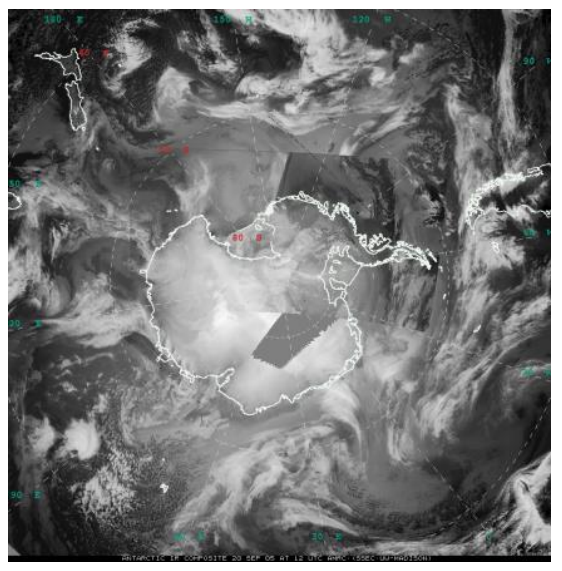

Figura 3.33: Dia 20/09/2005 às 12 UTC: (a) PNMM (linha contínua, em hPa) e VR em $1000 \mathrm{hPa}$ (sombreado, em $10^{-5} \mathrm{~s}^{-1}$ ); (b) temperatura do ar a $2 \mathrm{~m}$ (sombreado, em ${ }^{\circ} \mathrm{C}$ ) e vento horizontal a $10 \mathrm{~m}$ (vetores, em $\mathrm{m} / \mathrm{s}$ ); (c) altura geopotencial em $500 \mathrm{hPa}$ (sombreado, em m) e VR em $500 \mathrm{hPa}$ (sombreado, em $10^{-5} \mathrm{~s}^{-1}$ ); (d) composições de imagens de satélites no infravermelho. 
Em 21/09/2005 às 12 UTC, o sistema em superfície localizado anteriormente em $110^{\circ} \mathrm{W} / 61^{\circ} \mathrm{S}$ se dissipa, embora ainda existam cavados em superfície, com orientação de noroeste para sudeste, e VR ciclônica de até $-2 \times 10^{-5} \mathrm{~s}^{-1}$ (Figura 3.34a). Um novo ciclone é observado na região dos MBA, com pressão central de $973 \mathrm{hPa}$ e VR de até $-12 \times 10^{-5} \mathrm{~s}^{-1} \mathrm{em}$ $1000 \mathrm{hPa}$, centrado em $130^{\circ} \mathrm{W} / 64^{\circ} \mathrm{S}$. No campo de vento horizontal a $10 \mathrm{~m}$ pode-se observar a circulação ciclônica do sistema (Figura 3.34b). Em 500 hPa o eixo do cavado está associado ao ciclone em superfície, o que indica a fase de maturidade do sistema, apresentando intensa VR em níveis médios de até $-12 \times 10^{-5} \mathrm{~s}^{-1}$ (Figura 3.34c). A nebulosidade associada é observada na Figura 3.48d. Outro ciclone menos intenso é observado em torno de $91^{\circ} \mathrm{W} / 57^{\circ} \mathrm{S}$, com pressão central de $992 \mathrm{hPa}$ e VR negativa. Em níveis médios a baixa desprendida localiza-se praticamente sobre a baixa em superfície, caracterizando-se assim o estágio barotrópico equivalente do sistema.

a)

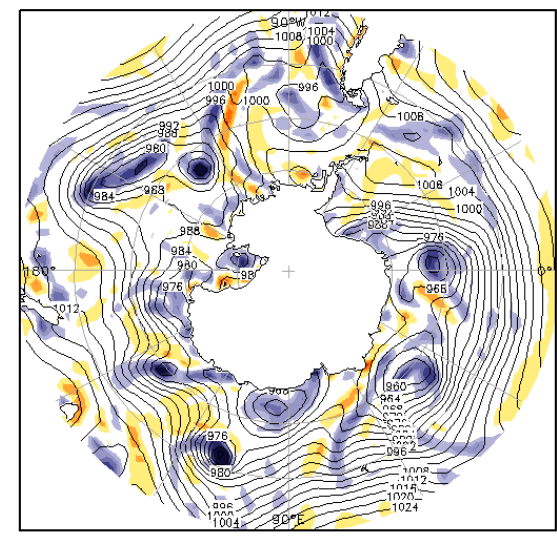

$12 z 21 \operatorname{sep} 2005$

c)

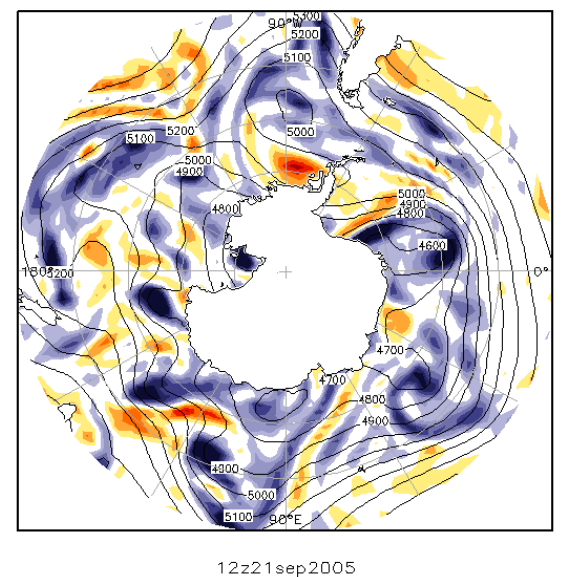

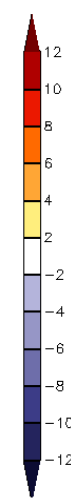

b)

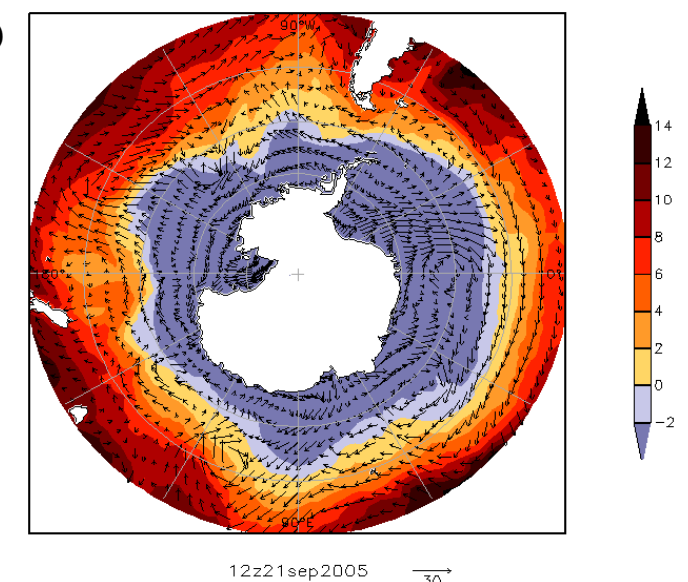

d)

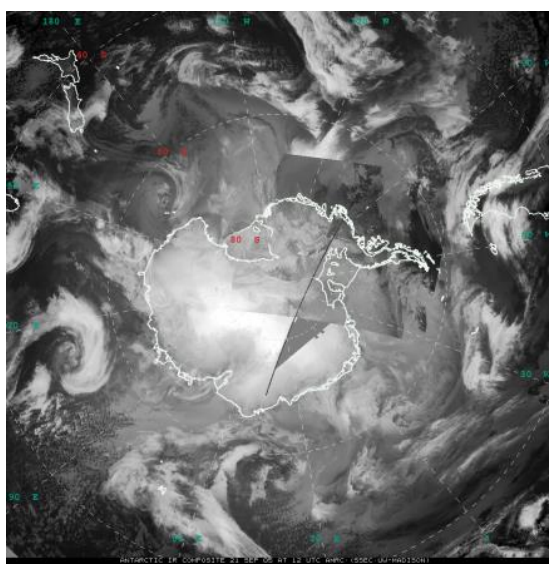

Figura 3.34: Dia 21/09/2005 às 12 UTC: (a) PNMM (linha contínua, em hPa) e VR em $1000 \mathrm{hPa}$ (sombreado, em $10^{-5} \mathrm{~s}^{-1}$ ); (b) temperatura do ar a $2 \mathrm{~m}$ (sombreado, em ${ }^{\circ} \mathrm{C}$ ) e vento horizontal a $10 \mathrm{~m}$ (vetores, em $\mathrm{m} / \mathrm{s}$ ); (c) altura geopotencial em $500 \mathrm{hPa}$ (sombreado, em m) e VR em $500 \mathrm{hPa}$ (sombreado, em $10^{-5} \mathrm{~s}^{-1}$ ); (d) composições de imagens de satélites no infravermelho. 
No dia 22/09/2005 às 12 UTC, o ciclone identificado anteriormente em $130^{\circ} \mathrm{W} /$ $64^{\circ} \mathrm{S}$ desloca-se pra sudeste, há o abaixamento da pressão central para $959 \mathrm{hPa}$ e a VR em $1000 \mathrm{hPa}$ aumenta para $-10 \times 10^{-5} \mathrm{~s}^{-1}$ (Figura 3.35a). A circulação ciclônica resulta em ventos de norte na região oeste e central dos MBA (Figura 3.35b). Em níveis médios, a baixa desprendida encontra-se sobre o sistema em superfície, associada com intensa VR ciclônica (Figura 3.35c). Assim, o ciclone encontra-se fechado desde a superfície até os níveis médios da troposfera. A nebulosidade associada à frente fria e aos movimentos ascendentes gerados pelo sistema em superfície pode ser vista na Figura 3.35d. Na Passagem de Drake, ao sul da América do Sul, um outro ciclone é observado com pressão central de $987 \mathrm{hPa}$, associado com VR de $-10 \times 10^{-5} \mathrm{~s}^{-1}$. Em $500 \mathrm{hPa}$, verifica-se o eixo do cavado localizado próximo à costa leste do sul da América do Sul, associado com VR ciclônica sobre a região do sistema em superfície. Na imagem de satélite observa-se claramente a faixa de intensa nebulosidade associada ao ciclone em superfície.

a)

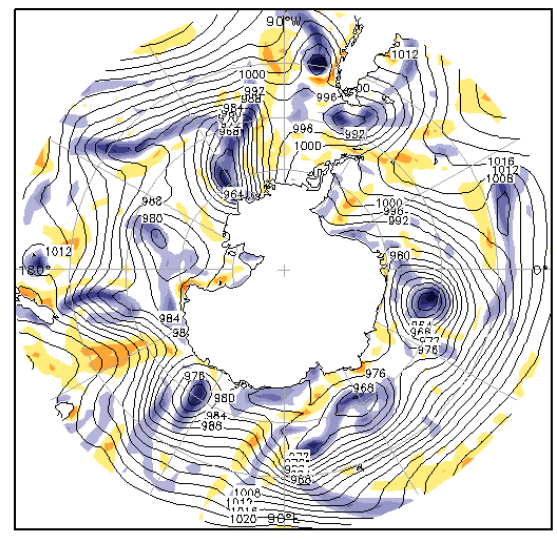

$12 z 22 \operatorname{sep} 2005$

c)

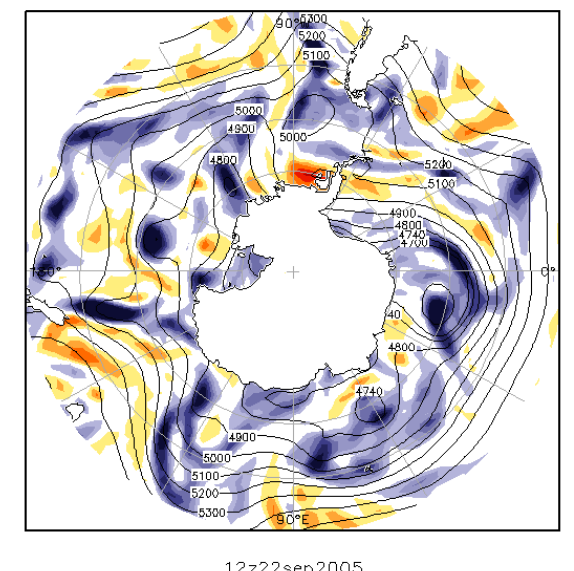

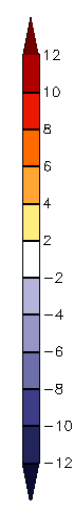

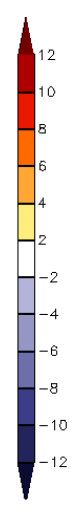

b)

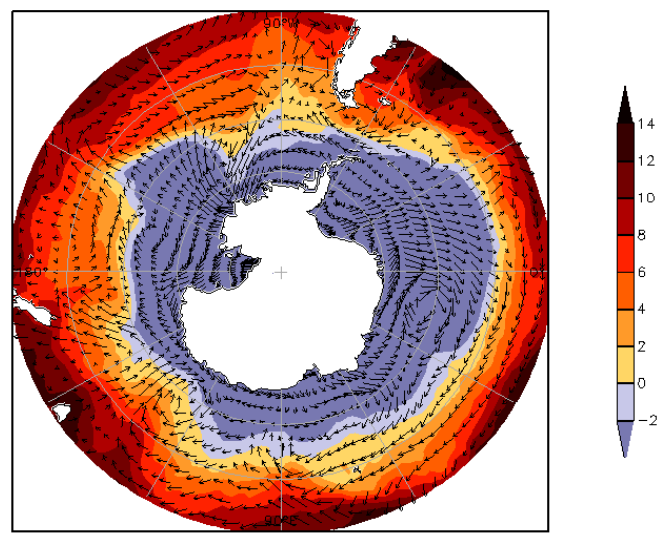

d)

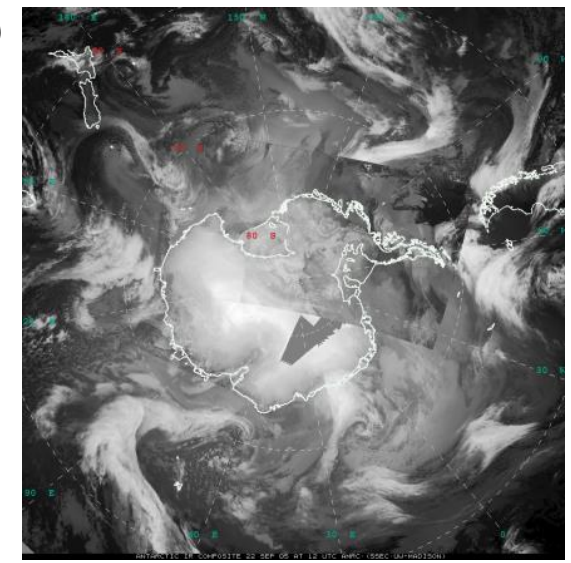

Figura 3.35: Dia 22/09/2005 às 12 UTC: (a) PNMM (linha contínua, em hPa) e VR em $1000 \mathrm{hPa}$ (sombreado, em $10^{-5} \mathrm{~s}^{-1}$ ); (b) temperatura do ar a $2 \mathrm{~m}$ (sombreado, em ${ }^{\circ} \mathrm{C}$ ) e vento horizontal a $10 \mathrm{~m}$ (vetores, em m/s); (c) altura geopotencial em $500 \mathrm{hPa}$ (sombreado, em m) e VR em $500 \mathrm{hPa}$ (sombreado, em $10^{-5} \mathrm{~s}^{-1}$ ); (d) composições de imagens de satélites no infravermelho. 
No primeiro dia do evento ENGM nos MBA, o ciclone localizado na Passagem de Drake desloca-se para sul se intensificando, apresentando VR de $-12 \times 10^{-5} \mathrm{~s}^{-1}$ e pressão central de $984 \mathrm{hPa}$ (Figura 3.36a). No campo de vento horizontal a $10 \mathrm{~m}$ verifica-se a circulação ciclônica do sistema, em que o centro desta circulação encontra-se sobre uma região com gradiente meridional de temperatura do ar de cerca de $0,6^{\circ} \mathrm{C}$ por ${ }^{\circ}$ lat (Figura 3.36b). Em $500 \mathrm{hPa}$ verifica-se uma baixa desprendida localizada sobre o ciclone em superfície (Figura 3.36c), caracterizando assim o estágio barotrópico do sistema. Ainda há intensa VR ciclônica em níveis médios, com intensa nebulosidade associada (Figura 3.36d). No oeste do setor dos MBA, junto à região costeira da Antártica, o ciclone em superfície se intensifica, apresentando pressão central de $958 \mathrm{hPa}$ e VR de $-12 \times 10^{-5} \mathrm{~s}^{-1}$ em $1000 \mathrm{hPa}$. A baixa desprendida ainda está configurada em $500 \mathrm{hPa}$, exatamente sobre o ciclone em superfície. Nesse dia há o predomínio de ventos de sul sobre o setor dos MBA.

a)

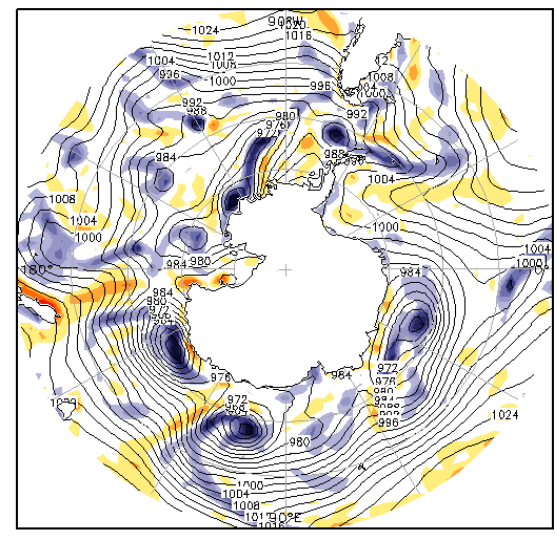

c)

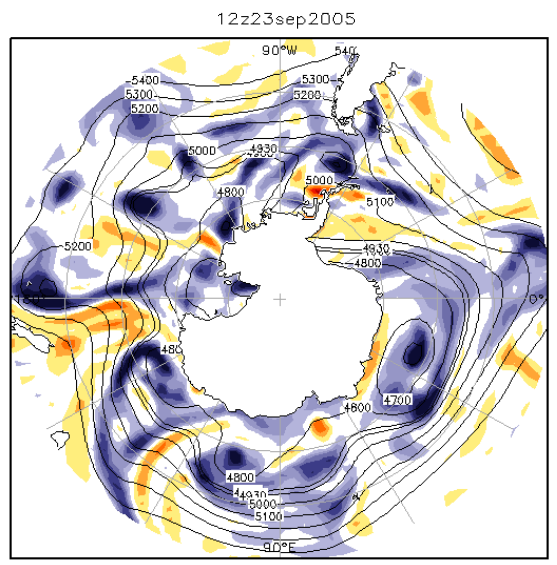

$12 z 23 \operatorname{sep} 2005$
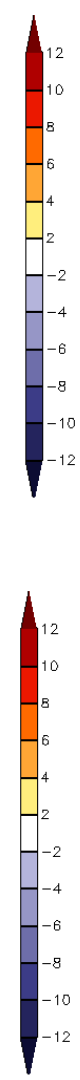

b)

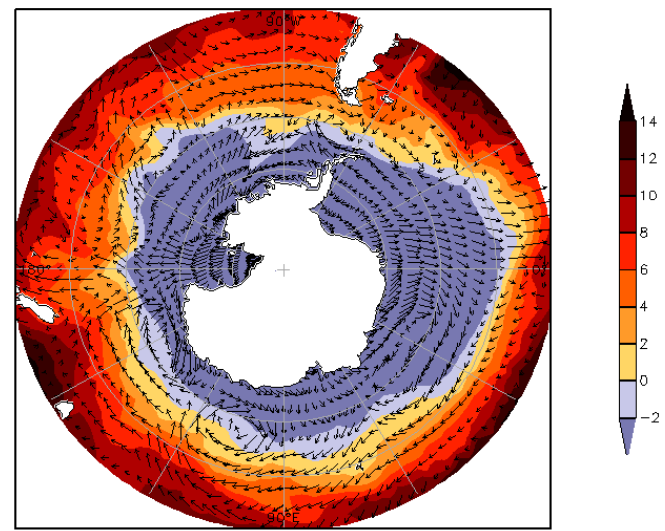

d)

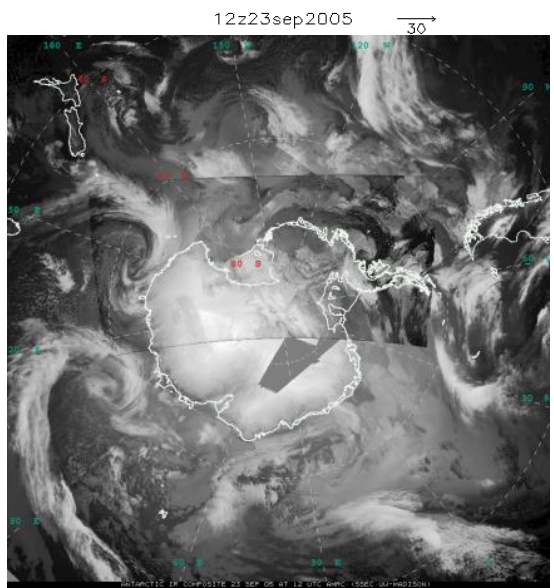

Figura 3.36: Dia 23/09/2005 às 12 UTC: (a) PNMM (linha contínua, em hPa) e VR em 1000 hPa (sombreado, em $10^{-5} \mathrm{~s}^{-1}$ ); (b) temperatura do ar a $2 \mathrm{~m}$ (sombreado, em ${ }^{\circ} \mathrm{C}$ ) e vento horizontal a $10 \mathrm{~m}$ (vetores, em m/s); (c) altura geopotencial em $500 \mathrm{hPa}$ (sombreado, em m) e VR em $500 \mathrm{hPa}$ (sombreado, em $10^{-5} \mathrm{~s}^{-1}$ ); (d) composições de imagens de satélites no infravermelho.

No estudo de caso de evento ENGM nos MBA em evento Neutro, sobre o setor há uma estrutura baroclínica, com anomalias de alta frequência de PNMM positivas sobre os 
MBA, anomalias de altura geopotencial em 500 (200) hPa negativas (positivas) no leste e positivas (negativas) no oeste do setor. O jato polar é intensificado e a circulação de norte é induzida pelo sistema de cristas/cavados e pela vanguarda dos ciclones em superfície. Embora as anomalias de circulação atmosférica durante a fase Neutra sejam muito semelhantes com as da fase de La Niña, verificou-se a atuação não somente de sistemas ciclônicos sobre os MBA, mas também de cristas e cavados. Contudo, o jato polar apresentou intensificação no setor, como observado no estudo de caso em evento de La Niña. O padrão atmosférico associado com o evento ENGM nos MBA está em concordância com o observado na seção 3.2.1.

\subsubsection{Evento extremo positivo de gelo marinho}

\subsubsection{Caso de El Niño}

O evento EPGM nos MBA, ocorrido nos dias 20 e 21/09/1997, apresentou anomalias de alta frequência de $+24.237,7 \mathrm{~km}^{2}$ e $+20.432,7 \mathrm{~km}^{2}$, respectivamente, e Índice de Niño Oceânico no mês de setembro de 1997 de +2,2. Três dias anteriores ao evento EPGM, a anomalia de PNMM foi anticiclônica no extremo oeste dos MBA (Figura 3.37a), associada com anomalia de ventos de oeste no sul e de ventos de leste no norte (Figura 3.37c), e anomalia ciclônica no leste do setor, com anomalias de ventos de leste no sul e de ventos de oeste no norte. Com essa configuração, observa-se no oeste dos MBA anomalias de ventos de sul (Figura 3.37e), associada com anomalias negativas de temperatura do ar (Figura 3.37g). A anomalia de altura geopotencial em $500 \mathrm{hPa}$ foi negativa no oeste do setor e positiva no extremo leste e ao norte da Península Antártica (Figura 3.37i). Já em altos níveis a altura geopotencial apresentou fracas anomalias negativas sobre o oeste e centro dos MBA (Figura $3.37 \mathrm{k}$ ), associada com anomalia de ventos de oeste no norte e de ventos de leste no sul em $200 \mathrm{hPa}$ (Figura 3.37m). Houve uma intensificação do jato subtropical e um enfraquecimento do jato polar. Observa-se uma estrutura baroclínica nos MBA da superfície até os altos níveis.

Já no dia do evento EPGM (20/09/1997) a anomalia de PNMM foi positiva sobre todo o setor dos MBA (Figura 3.37b), associada com anomalia de ventos de oeste no sul e de ventos de leste no norte (Figura 3.37d). A anomalia de vento meridional foi de sul no centro dos MBA e sobre a Península Antártica e de ventos de norte no leste do setor (Figura 3.37f). A anomalia de temperatura do ar foi de até $+2,0^{\circ} \mathrm{C}$ junto à região costeira dos MBA e negativa no oeste e norte da Península Antártica (Figura 3.37h). As anomalias de altura geopotencial em 500 e $200 \mathrm{hPa}$, assim como de vento zonal em $200 \mathrm{hPa}$, encontram-se em fase oposta ao dia 17/09/1997. 
a)

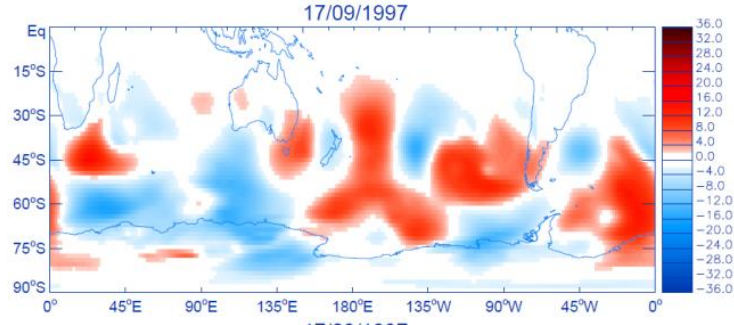

c)

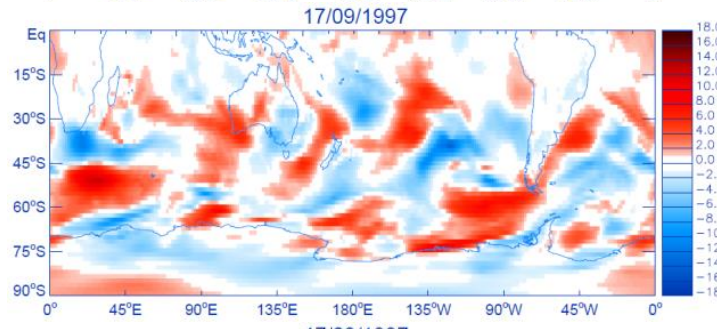

e)

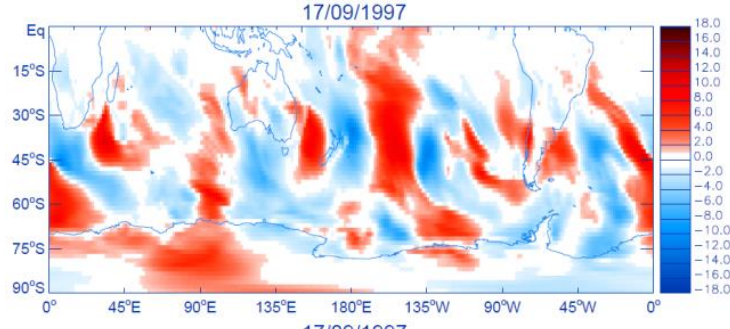

g)

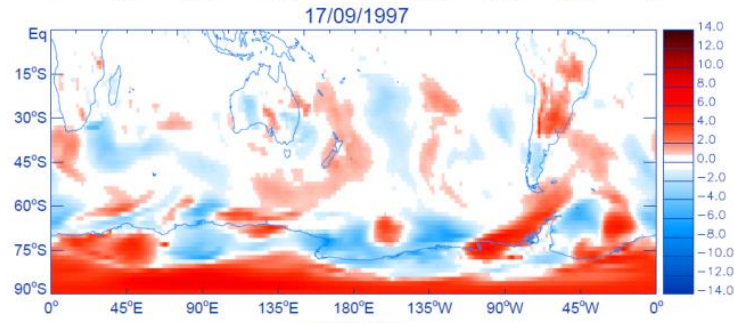

i)

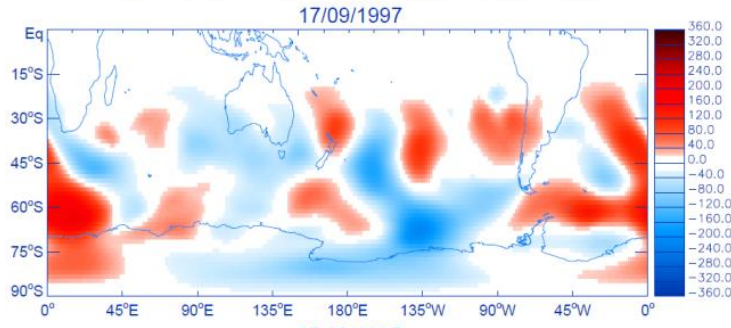

k)

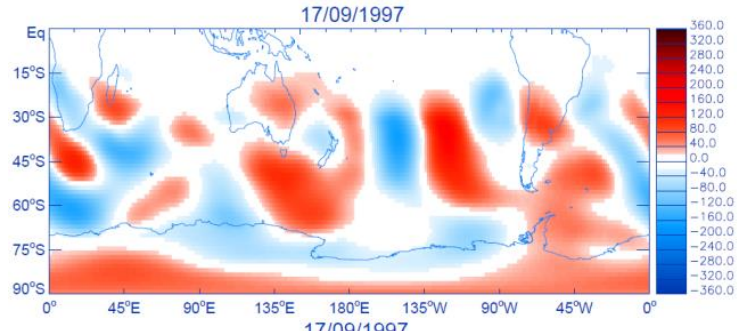

m)

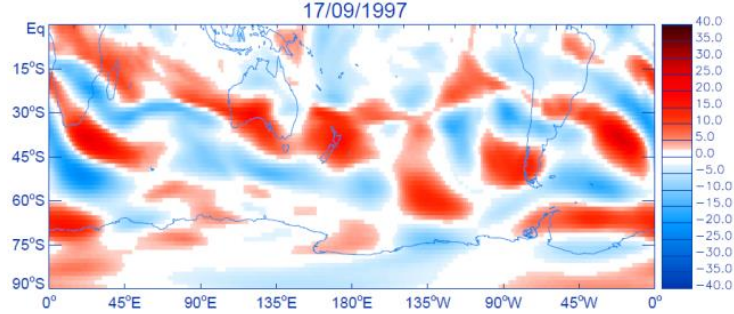

b)

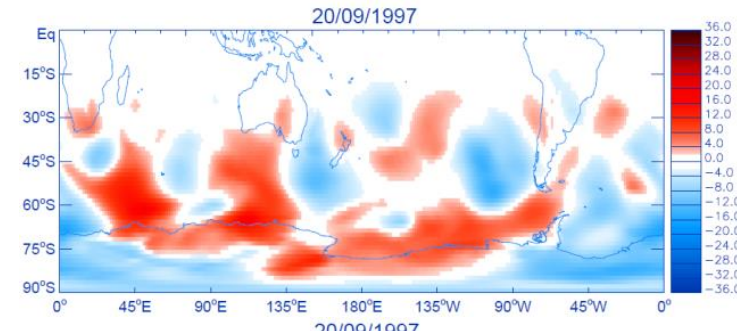

d)

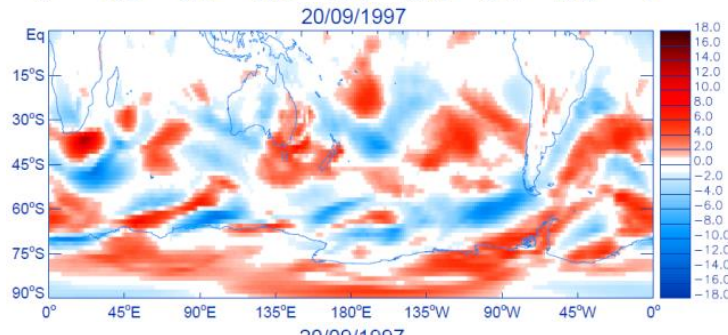

f)

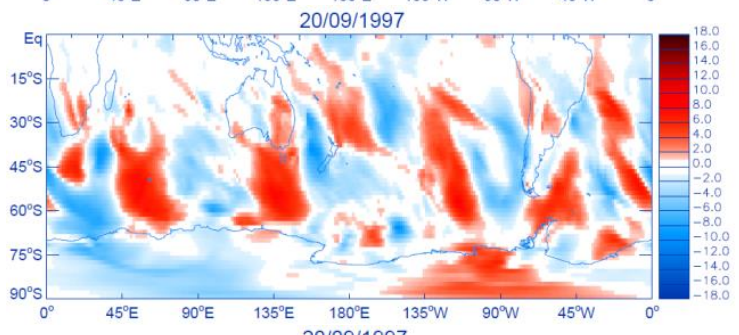

h)

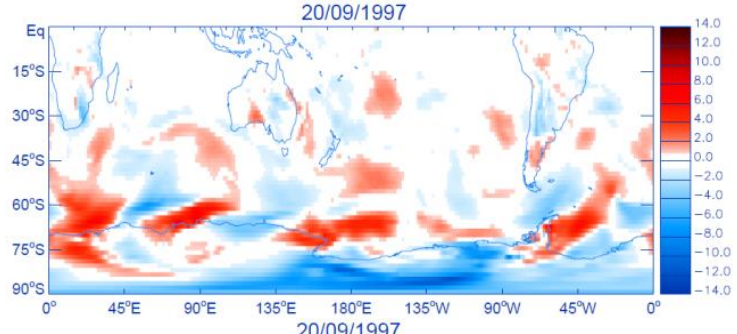

j)

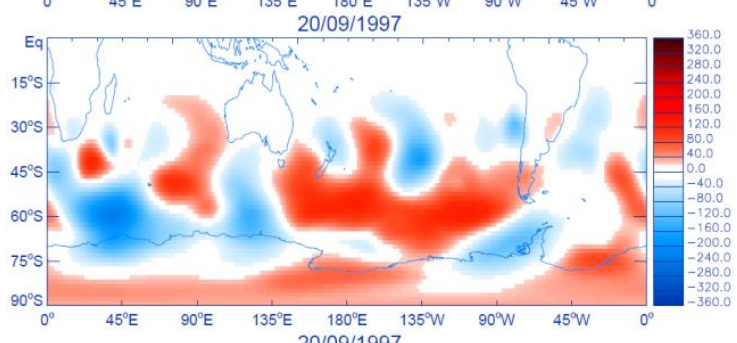

1)

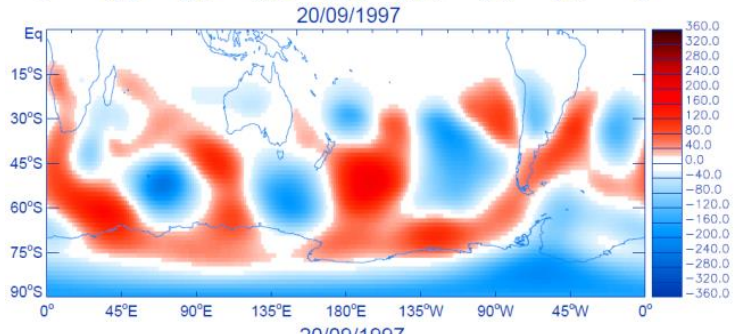

n)

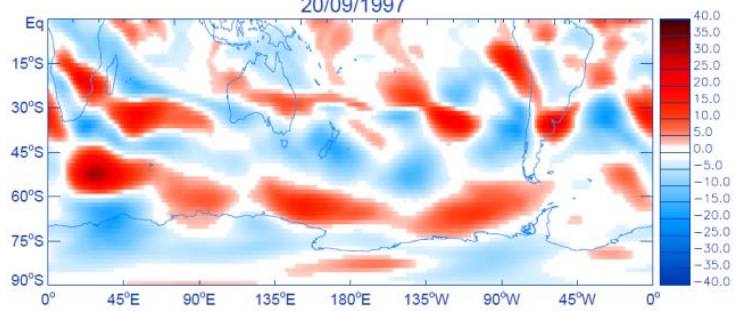

Figura 3.37: Anomalia de alta frequência de ( $a, b)$ PNMM, (c, d) vento zonal e (e, f) vento meridional a $10 \mathrm{~m},(\mathrm{~g}, \mathrm{~h})$ temperatura do ar a $2 \mathrm{~m},(\mathrm{i}, \mathrm{j})$ altura geopotencial em $500 \mathrm{hPa},(\mathrm{k}, \mathrm{l})$ altura geopotencial e $(\mathrm{m}, \mathrm{n})$ vento zonal em $200 \mathrm{hPa}$ no lag $=-3(17 / 09 / 1997)$ e no lag $=0(20 / 09 / 1997)$ no evento EPGM. 
No dia 17/09/1997 às 12 UTC observa-se um ciclone em superfície, localizado em torno de $91^{\circ} \mathrm{W} / 70^{\circ} \mathrm{S}$, com pressão central de $972 \mathrm{hPa}$ e VR em $1000 \mathrm{hPa}$ de até $-12 \times 10^{-5} \mathrm{~s}^{-1}$ (Figura 3.38a). Devido à retaguarda deste sistema, há o predomínio de ventos de sul sobre grande parte dos MBA (Figura 3.38b). Em níveis médios, verifica-se um cavado associado ao ciclone em superfície, com VR de $-12 \times 10^{-5} \mathrm{~s}^{-1}$ (Figura 3.38c). A nebulosidade associada, cuja frente fria estende-se de noroeste para sudeste, pode ser vista na Figura 3.38d. Ao norte desse sistema observa-se um anticiclone, com pressão central de $1015 \mathrm{hPa}$ e VR de até $4 \times 10^{-5} \mathrm{~s}^{-1}$ em $1000 \mathrm{hPa}$. A circulação anticiclônica domina grande parte da região sudeste do Oceano Pacífico Sul, trazendo ventos de noroeste para a latitude de $60^{\circ} \mathrm{S}$ no setor dos MBA. Em $500 \mathrm{hPa}$, o anticiclone em superfície está associado a uma região de cristas e intensa VR positiva. Ao norte da Península Antártica, uma região de cavado está orientada de noroeste pra sudeste, associada com VR ciclônica de até $-6 \times 10^{-5} \mathrm{~s}^{-1}$ em $1000 \mathrm{hPa}$. Em médios níveis, essa região está associada ao eixo do cavado e à intensa VR ciclônica. A nebulosidade associada pode ser vista na Figura 3.38d.

a)

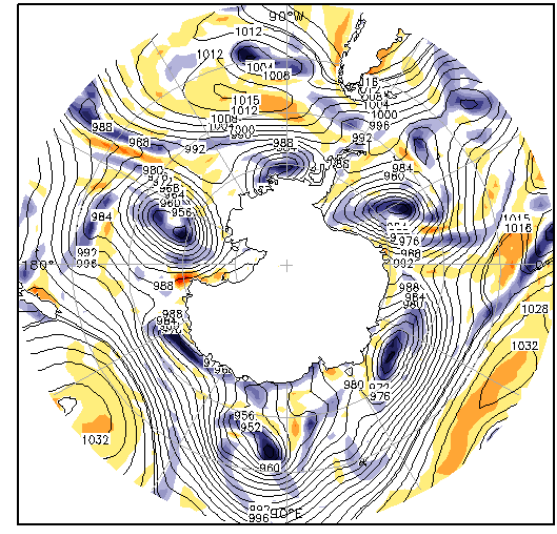

$12 z 17 \operatorname{sep} 1997$

c)

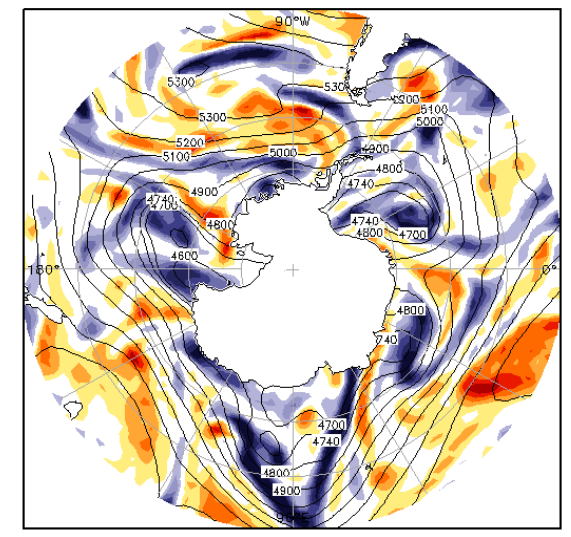

$12 z 17 \operatorname{sep} 1997$
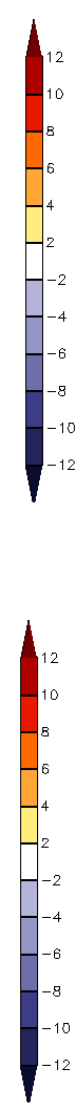

b)

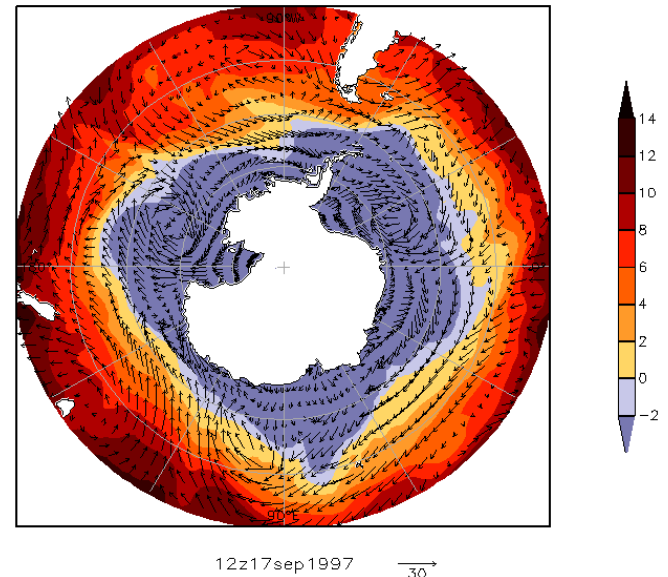

d)

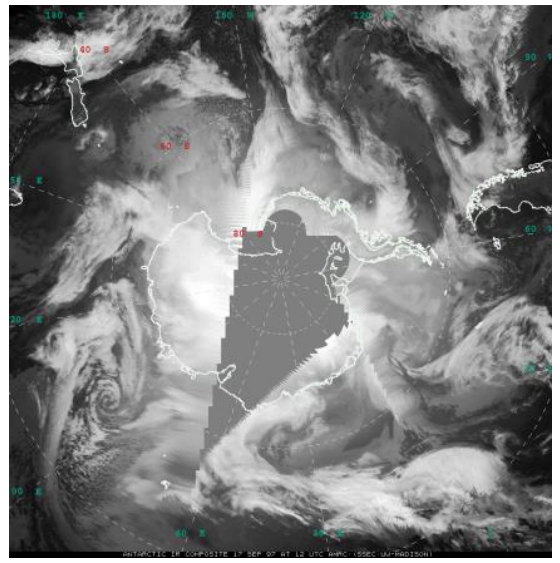

Figura 3.38: Dia 17/09/1997 às 12 UTC: (a) PNMM (linha contínua, em hPa) e VR em $1000 \mathrm{hPa}$ (sombreado, em $10^{-5} \mathrm{~s}^{-1}$ ); (b) temperatura do ar a $2 \mathrm{~m}$ (sombreado, em ${ }^{\circ} \mathrm{C}$ ) e vento horizontal a $10 \mathrm{~m}$ (vetores, em m/s); (c) altura geopotencial em $500 \mathrm{hPa}$ (sombreado, em m) e VR em $500 \mathrm{hPa}$ (sombreado, em $10^{-5} \mathrm{~s}^{-1}$ ); (d) composições de imagens de satélites no infravermelho. 
No dia 18/09/1997 às 12 UTC, dois dias anteriores ao evento EPGM, o ciclone junto à costa antártica desintensifica e desloca-se para nordeste, localizando-se na costa oeste da Península Antártica (Figura 3.39a). O sistema apresenta pressão central de 976 hPa e VR de até $-10 \times 10^{-5} \mathrm{~s}^{-1} \mathrm{em} 1000 \mathrm{hPa}$. Observam-se ventos de sul associados à retaguarda do ciclone (Figura 3.39b). Em níveis médios, nota-se um sistema de cavados sobre a região, com VR ciclônica de até $-10 \times 10^{-5} \mathrm{~s}^{-1}$ (Figura 3.39c). Na Figura 3.39d pode-se visualizar a nebulosidade associada ao sistema em superfície. O anticiclone no sul do Oceano Pacífico Sul desloca-se para leste, localizando-se exatamente ao norte do setor dos MBA. Assim, o anticiclone, juntamente com a região oeste do cavado em superfície, contribui com o escoamento de ventos de sul, promovendo a incursão de ar frio na região leste dos MBA.

a)

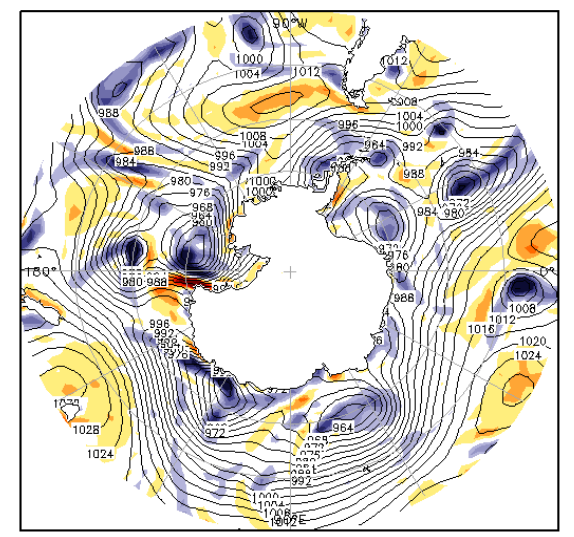

c)

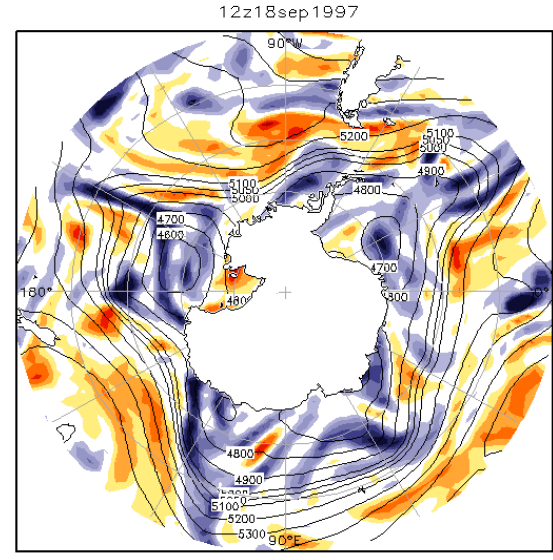

$12 z 18 \operatorname{sep} 1997$

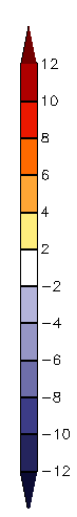

b)

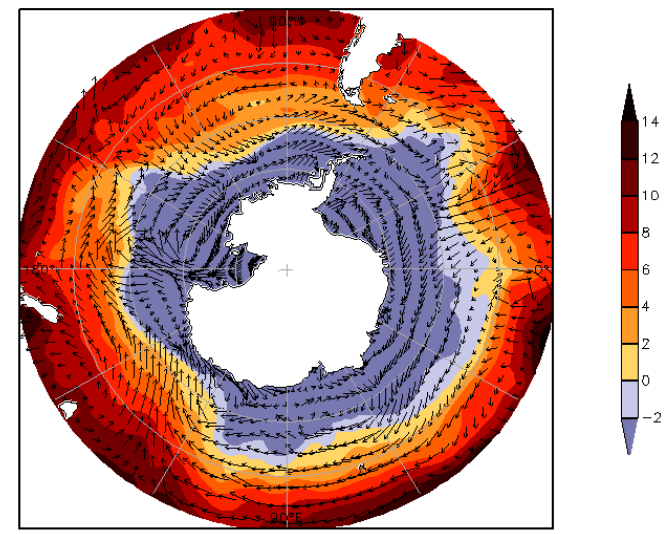

d)

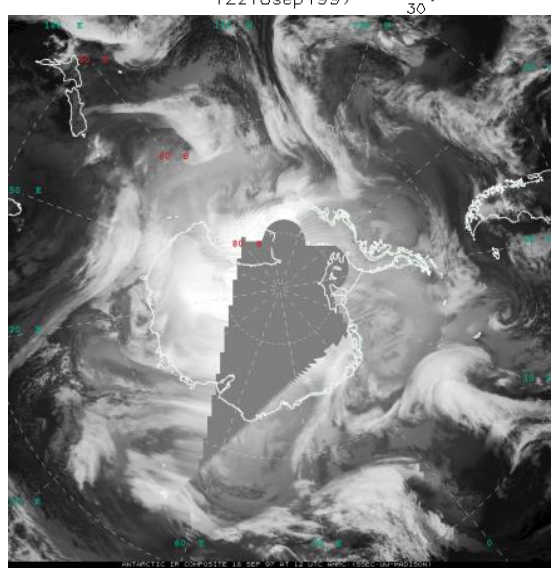

Figura 3.39: Dia 18/09/1997 às 12 UTC: (a) PNMM (linha contínua, em hPa) e VR em $1000 \mathrm{hPa}$ (sombreado, em $10^{-5} \mathrm{~s}^{-1}$ ); (b) temperatura do ar a $2 \mathrm{~m}$ (sombreado, em ${ }^{\circ} \mathrm{C}$ ) e vento horizontal a $10 \mathrm{~m}$ (vetores, em $\mathrm{m} / \mathrm{s}$ ); (c) altura geopotencial em $500 \mathrm{hPa}$ (sombreado, em m) e VR em $500 \mathrm{hPa}$ (sombreado, em $10^{-5} \mathrm{~s}^{-1}$ ); (d) composições de imagens de satélites no infravermelho.

Um dia anterior ao evento EPGM, em 19/09/1997 às 12 UTC, o sistema próximo à Península Antártica desloca-se em direção à Passagem de Drake e desconfigura-se. No oeste da Península Antártica verifica-se VR de até $-4 \times 10^{-5} \mathrm{~s}^{-1}$ em $1000 \mathrm{hPa}$ (Figura 3.40a), 
associada com a porção oeste de um cavado em 500 hPa (Figura 3.40c). A circulação é de ventos de sudoeste no leste dos MBA, associado a essa região (Figura 3.40b). Observa-se ainda uma região de cavado em superfície associada à VR de até $-8 \times 10^{-5} \mathrm{~s}^{-1}$, orientada de oeste para leste, junto à costa da Antártica no setor dos MBA. Em 500 hPa, a região está relacionada com o eixo do cavado de intensa VR ciclônica, o qual está associado com uma baixa desprendida localizada em cerca de $160^{\circ} \mathrm{W} / 74^{\circ} \mathrm{S}$. A nebulosidade associada pode ser vista através da Figura 3.40d. O anticiclone desconfigura-se, e uma região de cristas é observada mais ao sul, sobre o setor dos MBA e ao sul da América do Sul. Em 500 hPa há uma região de cristas com VR de até $6 \times 10^{-5} \mathrm{~s}^{-1}$. Esse padrão resulta em ventos de norte no oeste dos MBA.

a)

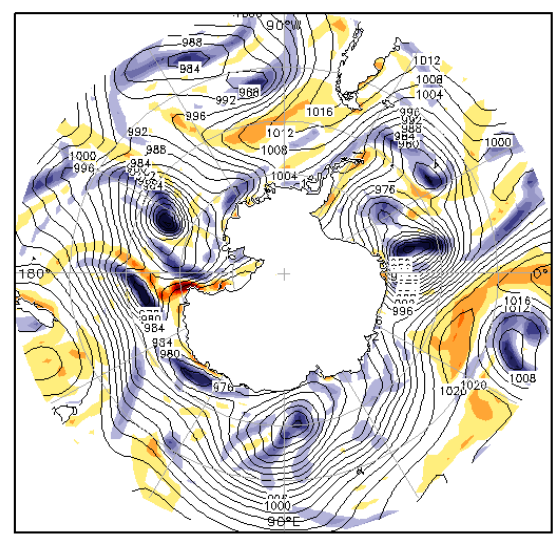

c)

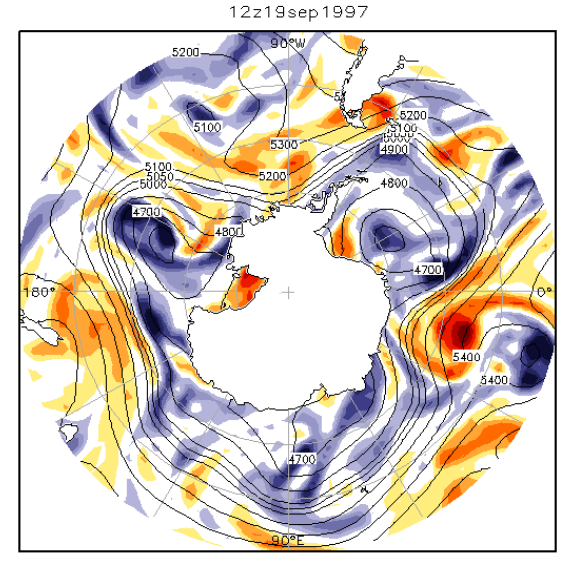

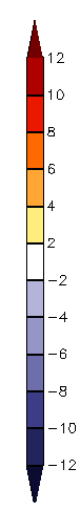

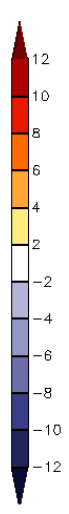

b)

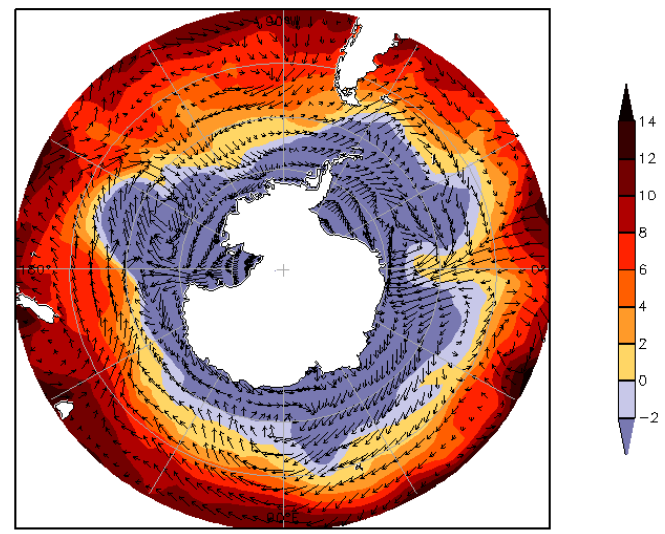

d)

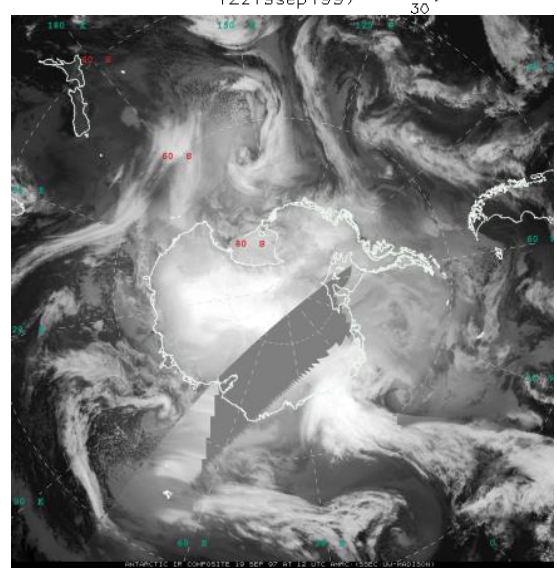

Figura 3.40: Dia 19/09/1997 às 12 UTC: (a) PNMM (linha contínua, em hPa) e VR em $1000 \mathrm{hPa}$ (sombreado, em $10^{-5} \mathrm{~s}^{-1}$ ); (b) temperatura do ar a $2 \mathrm{~m}$ (sombreado, em ${ }^{\circ} \mathrm{C}$ ) e vento horizontal a $10 \mathrm{~m}$ (vetores, em m/s); (c) altura geopotencial em $500 \mathrm{hPa}$ (sombreado, em m) e VR em $500 \mathrm{hPa}$ (sombreado, em $10^{-5} \mathrm{~s}^{-1}$ ); (d) composições de imagens de satélites no infravermelho.

No primeiro dia do evento EPGM, em 20/09/1997 às 12 UTC, verifica-se um sistema oriundo do sul do Oceano Pacífico Sul, localizado em cerca de $110^{\circ} \mathrm{W} / 60^{\circ} \mathrm{S}$, com pressão central de 974 hPa e VR de até $-10 \times 10^{-5} \mathrm{~s}^{-1}$ em 1000 hPa (Figura 3.41a). Esse sistema contribui para a circulação de ventos de nordeste na região central dos MBA, sobre a latitude 
de $60^{\circ} \mathrm{S}$ (Figura 3.41b). Em níveis médios o ciclone está associado ao eixo do cavado e VR de até $-12 \times 10^{-5} \mathrm{~s}^{-1}$ (Figura 3.41c). Associada aos movimentos ascendentes do sistema em superfície, pode-se observar intensa nebulosidade com a forma de uma vírgula invertida, com intensa atividade convectiva a sudoeste e extensa área de cirrus a nordeste do ciclone em superfície (Figura 3.41d). Grande parte do setor dos MBA é dominado por cristas em superfície, associadas com VR anticiclônica de até $4 \times 10^{-5} \mathrm{~s}^{-1}$ em $1000 \mathrm{hPa}$. Em $500 \mathrm{hPa}$ observa-se uma região de cristas, com VR de até $10 \times 10^{-5} \mathrm{~s}^{-1}$.

a)

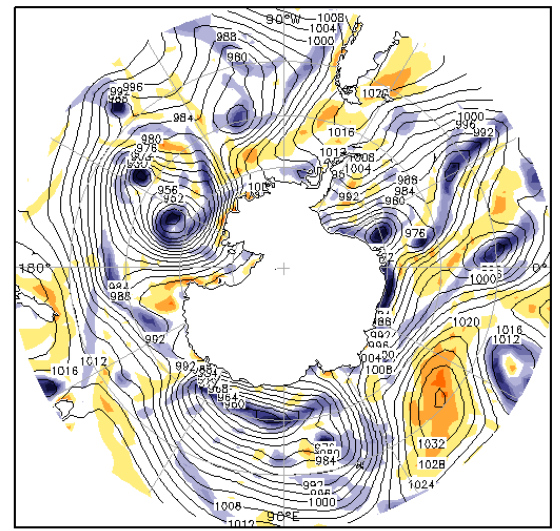

c)

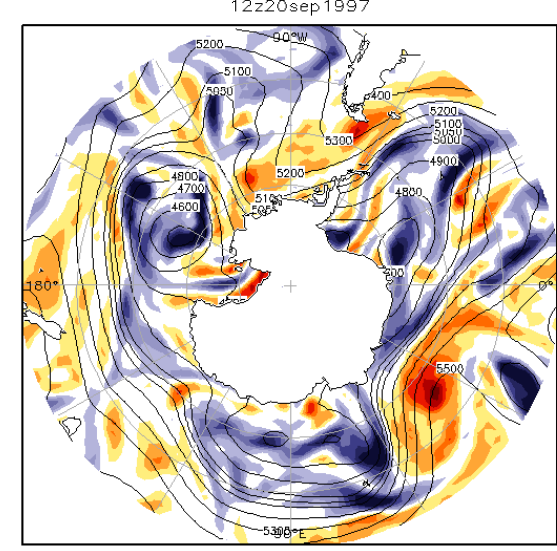

$12 z 20$ sep 1997 b)

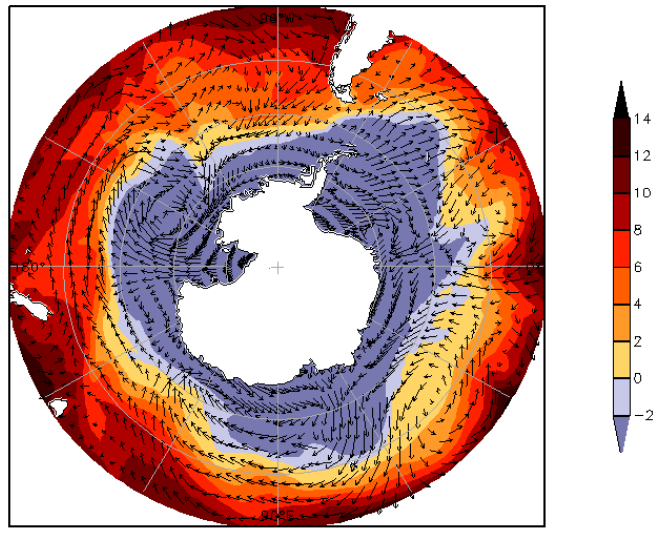

d)

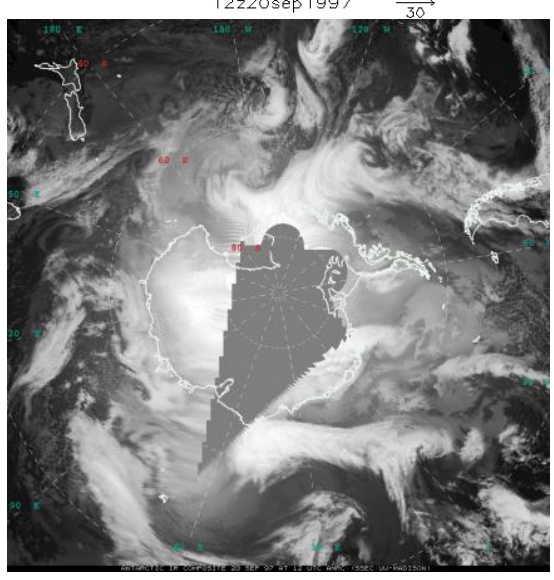

Figura 3.41: Dia 20/09/1997 às 12 UTC: (a) PNMM (linha contínua, em hPa) e VR em $1000 \mathrm{hPa}$ (sombreado, em $10^{-5} \mathrm{~s}^{-1}$ ); (b) temperatura do ar a $2 \mathrm{~m}$ (sombreado, em ${ }^{\circ} \mathrm{C}$ ) e vento horizontal a $10 \mathrm{~m}$ (vetores, em m/s); (c) altura geopotencial em $500 \mathrm{hPa}$ (sombreado, em m) e VR em $500 \mathrm{hPa}$ (sombreado, em $10^{-5} \mathrm{~s}^{-1}$ ); (d) composições de imagens de satélites no infravermelho.

No estudo de caso de El Niño em evento EPGM nos MBA observa-se uma estrutura baroclínica, com anomalias de alta frequência de PNMM positivas no oeste e negativas no centro/leste do setor. As anomalias de altura geopotencial em $500 \mathrm{hPa}$ foram negativas no oeste e positivas no extremo leste dos MBA. Já as anomalias de altura geopotencial em 200 $\mathrm{hPa}$ foram fracamente negativas no oeste/centro. Houve uma intensificação do jato subtropical e um enfraquecimento do jato polar. A circulação de sul foi induzida principalmente pelo sistema de cristas e cavados, embora tenha havido a contribuição de 
sistemas ciclônicos (retaguarda) e anticiclônicos (vanguarda) para tal circulação. Assim, o padrão atmosférico associado ao evento EPGM é o mesmo em relação ao evento ENGM observado em fase de El Niño, ou seja, menor atuação de ciclones na região devido ao deslocamento para norte das storm tracks, associada com o reforço e contração da Célula de Hadley e, consequentemente, com a intensificando da Célula de Ferrel e do escoamente de norte em direção às altas latitudes (YUAN, 2004). Além disso, a configuração dos campos atmosféricos associada ao evento EPGM nos MBA no estudo de caso está de acordo com o observado nas composições das anomalias atmosféricas de alta frequência (cf. seção 3.2.1).

\subsubsection{Caso de La Niña}

O evento EPGM ocorrido entre os dias 17 e 21/09/1999 no setor dos MBA, apresentou anomalias de alta frequência de extensão de gelo marinho variando de $+18.592,9 \mathrm{~km}^{2} \mathrm{a}+40.116,9 \mathrm{~km}^{2}$ e Índice de Niño Oceânico no mês de setembro de 1999 de -1,0. Três dias anteriores ao evento EPGM (14/09/1999) a anomalia de alta frequência de PNMM no noroeste dos MBA foi anticiclônica (Figura 3.42a), associada com as anomalias de ventos de oeste no sul e de ventos de leste no norte (Figura 3.42c). No restante do setor a anomalia foi ciclônica, associada com anomalias de ventos de leste no sul e de ventos de oeste no norte. Devido a essa configuração, observa-se anomalia de ventos de sul (Figura 3.42e) e anomalia negativa de temperatura do ar sobre grande parte dos MBA, com exceção da região leste e sobre a Península Antártica (Figura 3.42g). Em $500 \mathrm{hPa}$ a anomalia de altura geopotencial foi predominantemente positiva sobre o setor (Figura 3.42i). Já em $200 \mathrm{hPa}$ a anomalia de altura geopotencial foi positiva no noroeste dos MBA e negativa sobre o restante do setor (Figura 3.42k), associada com anomalia de ventos de oeste no norte e de ventos de leste no sul (Figura 3.42m). Assim, há uma desintensificação do jato subtropical e uma intensificação do jato polar, embora sobre os MBA o jato polar seja enfraquecido. As anomalias de altura geopotencial entre os níveis médios estão fora de fase com as anomalias em níveis baixos e altos, o que indica que sobre o setor dos MBA há uma estrutura baroclínica. Com a propagação para leste dos distúrbios de alta frequência, a anomalia de PNMM no dia 17/09/1999 sobre os MBA foi predominantemente negativa (Figura 3.42b), associada com as anomalias de ventos de oeste no norte e de ventos de leste no sul (Figura 3.42d). A anomalia de vento meridional (Figura 3.42f) e temperatura do ar (Figura 3.42h) estão em fase oposta ao dia 14/09/1999, com anomalias de ventos de norte no oeste e centro do setor, associado com anomalia positiva de temperatura do ar, e anomalias de ventos de sul no leste dos MBA, associada com anomalia negativa de temperatura do ar. Em níveis médios 
as anomalias de altura geopotencial apresentaram-se também em fase oposta ao dia 14/09/1999, com valores positivos no oeste e negativos no leste dos MBA (Figura 3.42j). Em $200 \mathrm{hPa}$ a anomalia de altura geopotencial foi negativa nos MBA (Figura 3.421), associada com anomalia de ventos de oeste no norte e de ventos de leste no sul (Figura 3.42n).

a)

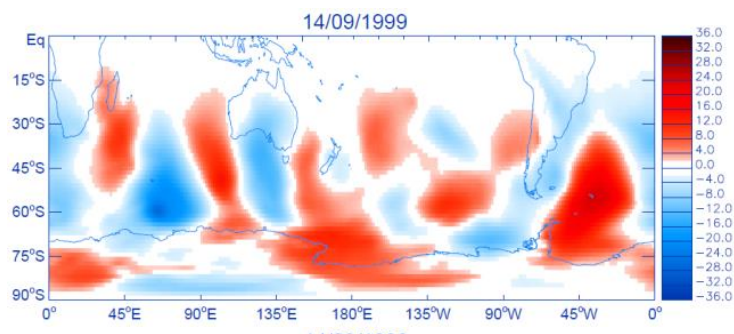

c)

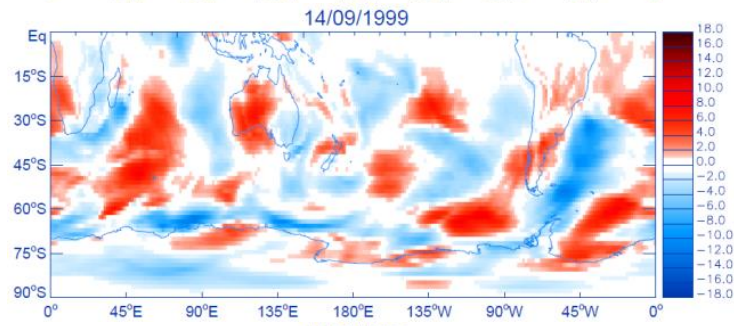

e)

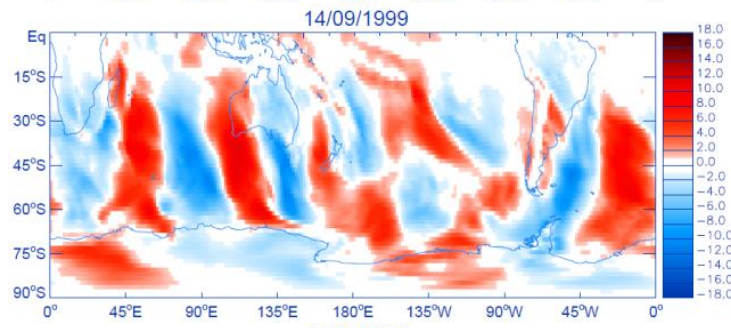

g)

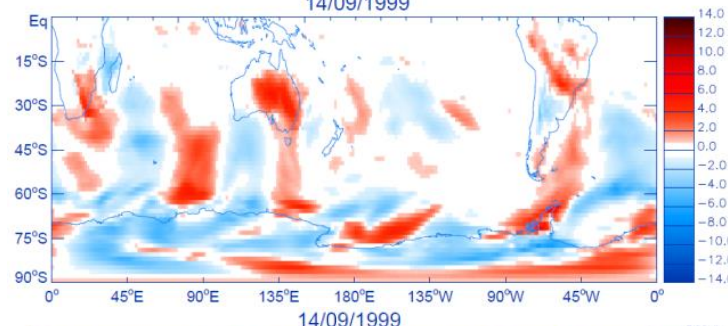

i)

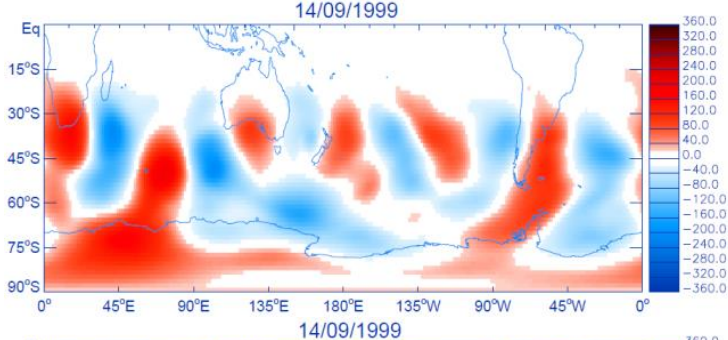

k)

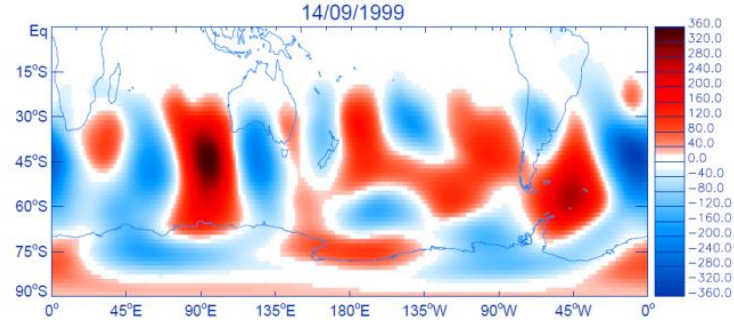

b)

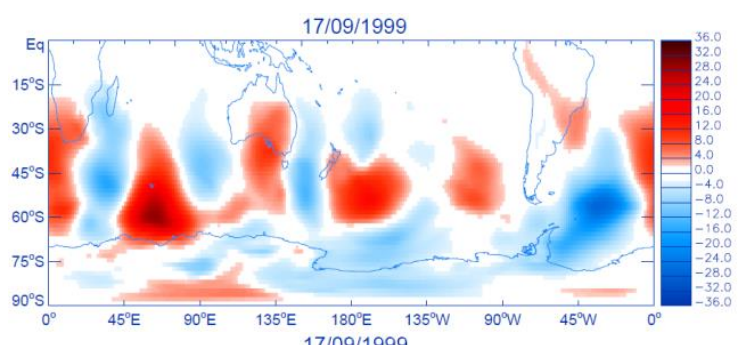

d)

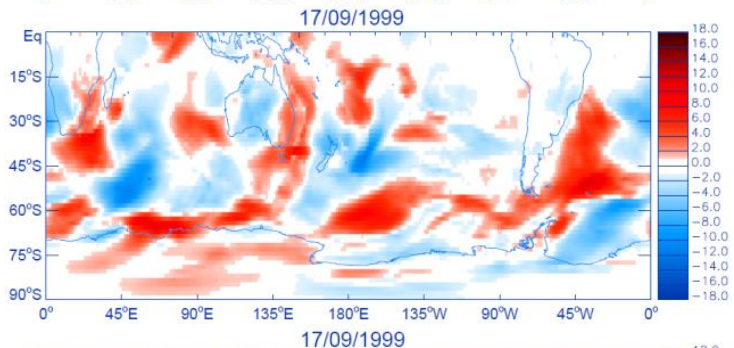

f)

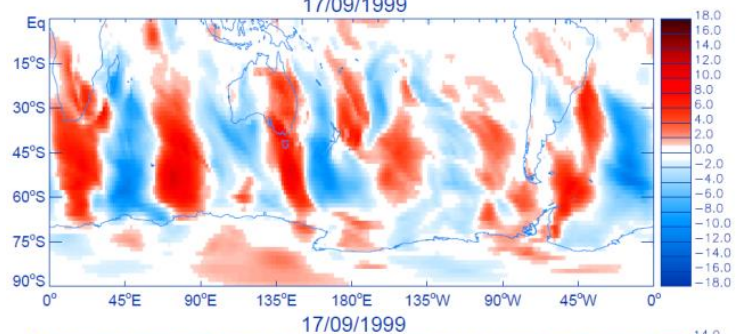

h)

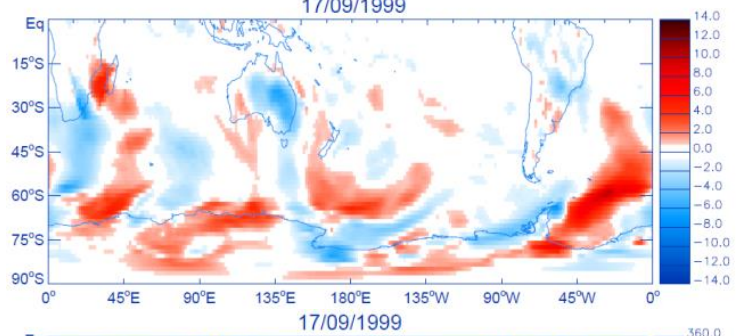

j)

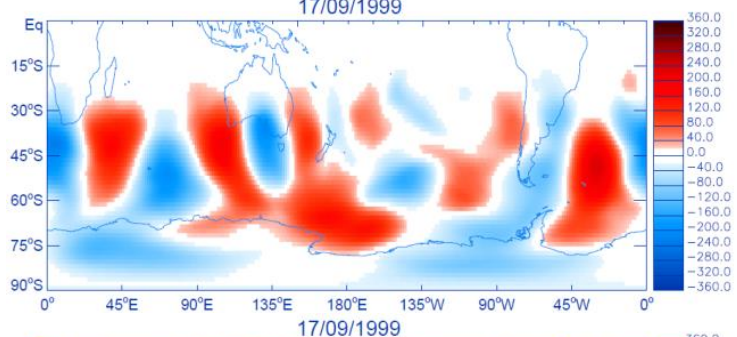

1)

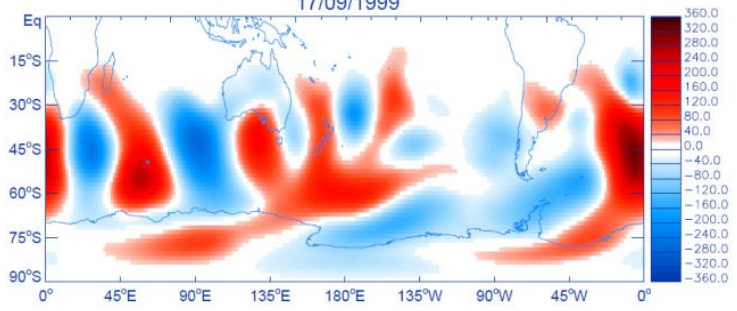

Figura 3.42: Anomalia de alta frequência de (a, b) PNMM, (c, d) vento zonal e (e, f) vento meridional a $10 \mathrm{~m},(\mathrm{~g}, \mathrm{~h})$ temperatura do ar a $2 \mathrm{~m},(\mathrm{i}, \mathrm{j})$ altura geopotencial em $500 \mathrm{hPa},(\mathrm{k}, \mathrm{l})$ altura geopotencial e $(\mathrm{m}, \mathrm{n})$ vento zonal em $200 \mathrm{hPa}$ no lag $=-3(14 / 09 / 1999)$ e no lag $=0(17 / 09 / 1999)$ no evento EPGM. 
m)

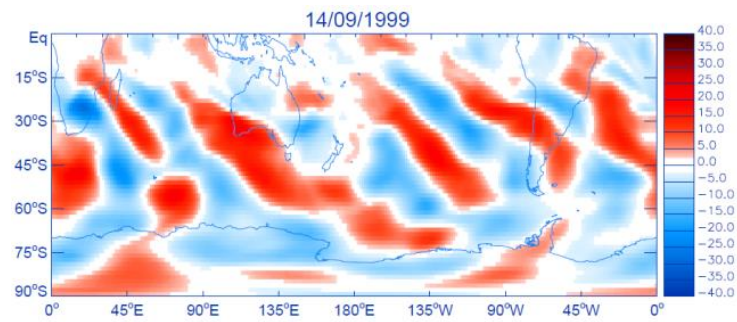

n)

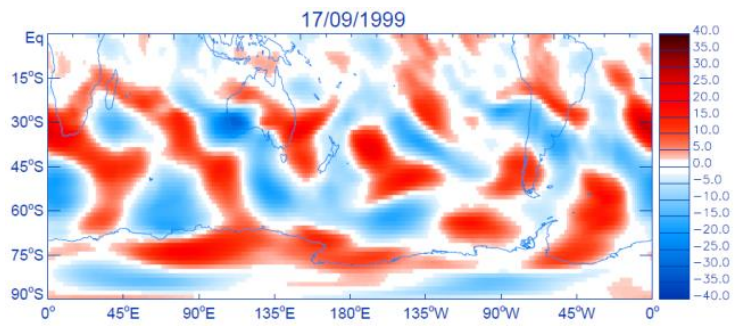

Figura 3.42: Continuação.

Três dias anteriores ao evento EPGM, em 14/09/1999 às 12 UTC, observa-se sobre os MBA um ciclone em superfície localizado em torno de $105^{\circ} \mathrm{W} / 65^{\circ} \mathrm{S}$, com pressão central de $944 \mathrm{hPa}$ e VR de $-8 \times 10^{-5} \mathrm{~s}^{-1}$ em $1000 \mathrm{hPa}$ (Figura 3.43a). A vanguarda desse sistema induz a uma circulação de ventos de norte no leste dos MBA e a retaguarda ventos de sul no centro e oeste do setor (Figura 3.43b). Em 500 hPa, verifica-se uma baixa desprendida localizada praticamente sobre o sistema em superfície, caracterizando assim o estágio barotrópico equivalente do ciclone, associada à VR de até $-8 \times 10^{-5} \mathrm{~s}^{-1}$ (Figura 3.43c). A nebulosidade associada devido aos movimentos ascendentes do ciclone em superfície e à frente fria, orientada de noroeste para sudeste, pode ser vista na Figura 3.43d.

a)

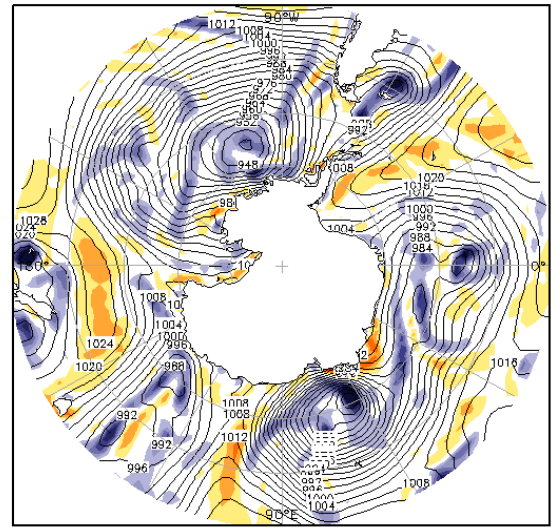

c)

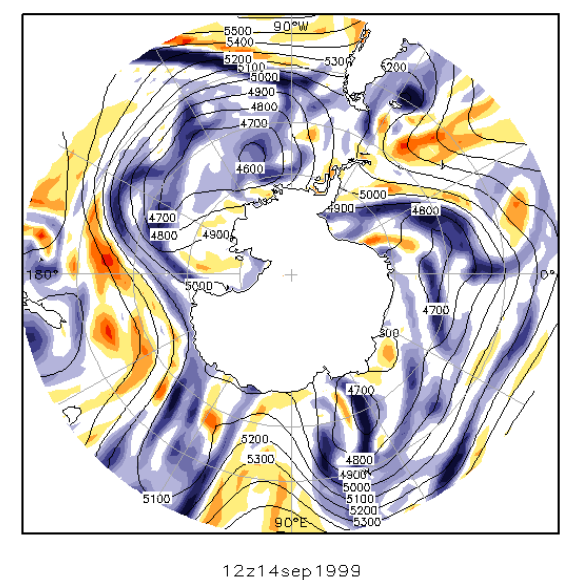

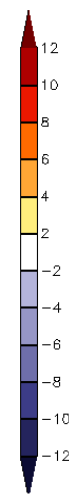

b)

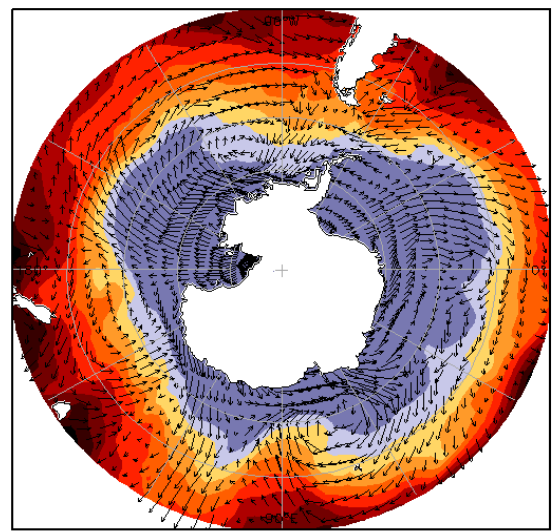

d)

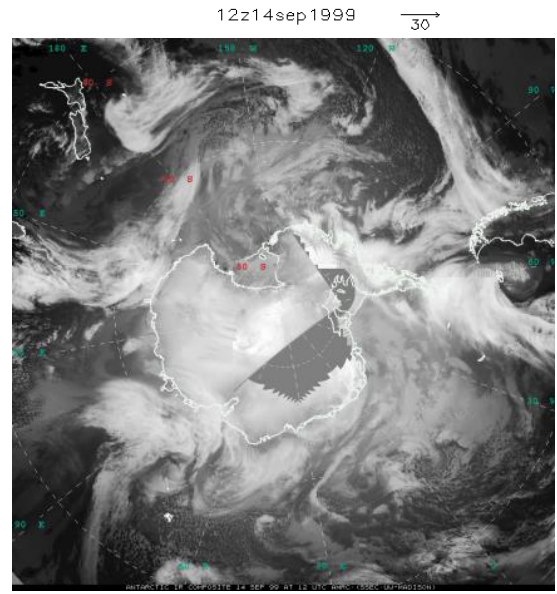

Figura 3.43: Dia 14/09/1999 às 12 UTC: (a) PNMM (linha contínua, em hPa) e VR em $1000 \mathrm{hPa}$ (sombreado, em $10^{-5} \mathrm{~s}^{-1}$ ); (b) temperatura do ar a $2 \mathrm{~m}$ (sombreado, em ${ }^{\circ} \mathrm{C}$ ) e vento horizontal a $10 \mathrm{~m}$ (vetores, em m/s); (c) altura geopotencial em $500 \mathrm{hPa}$ (sombreado, em m) e VR em $500 \mathrm{hPa}$ (sombreado, em $10^{-5} \mathrm{~s}^{-1}$ ); (d) composições de imagens de satélites no infravermelho. 
No dia 15/09/1999 às 12 UTC, o ciclone em superfície desloca-se para sudoeste e desintensifica, centrado em cerca de $115^{\circ} \mathrm{W} / 67^{\circ} \mathrm{S}$, com pressão central de $950 \mathrm{hPa}$ e VR de $-6 \times 10^{-5} \mathrm{~s}^{-1} \mathrm{em} 1000 \mathrm{hPa}$ (Figura 3.44a). Com a circulação na retaguarda desse sistema, são observados ventos de sul sobre o centro e oeste dos MBA (Figura 3.44b). Em níveis médios a baixa desprendida ainda está configurada, localizada sobre o sistema em superfície (Figura 3.44c). A nebulosidade associada, cuja frente fria estende-se de sudoeste para nordeste, pode ser visualizada na Figura 3.44d. Ao norte desse ciclone, em torno de $117^{\circ} \mathrm{W} / 54^{\circ} \mathrm{S}$, verificase outro sistema em superfície, com pressão central de $961 \mathrm{hPa}$ e VR de $-12 \times 10^{-5} \mathrm{~s}^{-1} \mathrm{em}$ 1000 hPa. A circulação ciclônica do sistema induz a ventos de norte na região norte e central dos MBA. Observa-se que o ciclone em superfície está localizado a leste do cavado em 500 hPa. Com esta configuração há um suporte dinâmico para a intensificação do ciclone em superfície, pois a região a leste do cavado em níveis médios favorece a convergência de massa em superfície, gerando movimentos ascendentes. A nebulosidade possui aspecto de vírgula invertida, associada ao ciclone em superfície e à região da frente fria, orientada de noroeste para sudeste.

a)

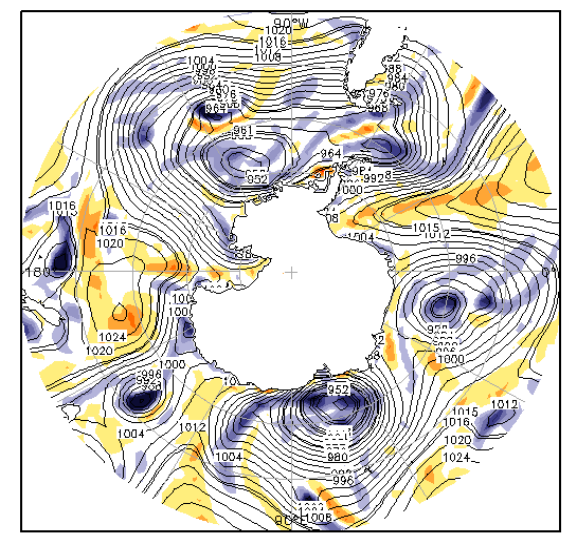

$12 z 15 \operatorname{sep} 1999$

c)

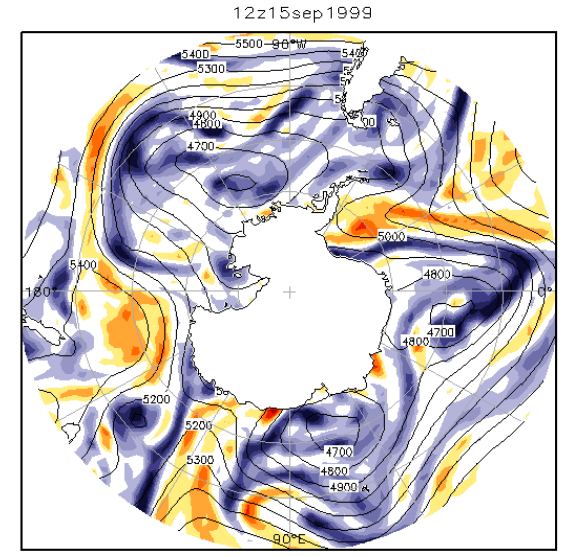

$12 z 15$ sep 1999

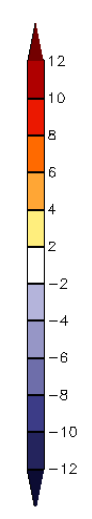

b)

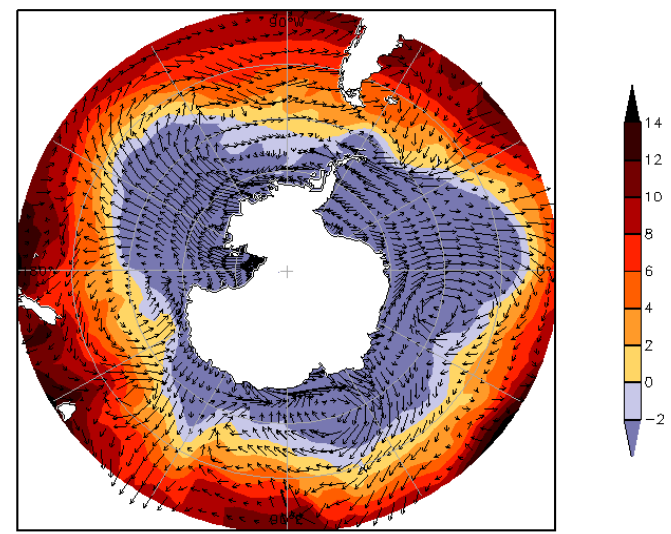

d)

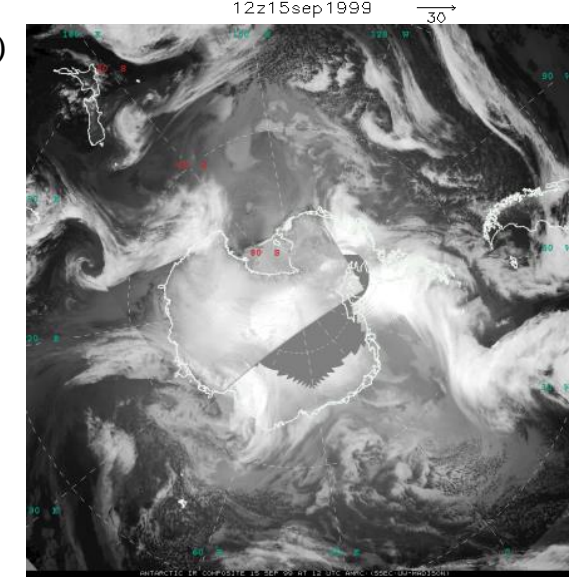

Figura 3.44: Dia 15/09/1999 às 12 UTC: (a) PNMM (linha contínua, em hPa) e VR em 1000 hPa (sombreado, em $10^{-5} \mathrm{~s}^{-1}$ ); (b) temperatura do ar a $2 \mathrm{~m}$ (sombreado, em ${ }^{\circ} \mathrm{C}$ ) e vento horizontal a $10 \mathrm{~m}$ (vetores, em m/s); (c) altura geopotencial em $500 \mathrm{hPa}$ (sombreado, em m) e VR em $500 \mathrm{hPa}$ (sombreado, em $10^{-5} \mathrm{~s}^{-1}$ ); (d) composições de imagens de satélites no infravermelho. 
Um dia anterior ao evento EPGM, em 16/09/1999 às 12 UTC, o sistema localizado anteriormente mais ao sul desloca-se para norte e desintensifica ainda mais, com pressão central de $951 \mathrm{hPa}$ e VR de até $-6 \times 10^{-5} \mathrm{~s}^{-1}$ em $1000 \mathrm{hPa}$ (Figura 3.45a). Já o ciclone localizado mais ao norte 24 horas atrás, desloca-se para sudeste e encontra-se na posição em torno de $100^{\circ} \mathrm{W} / 62^{\circ} \mathrm{S}$, com redução da pressão central para $948 \mathrm{hPa}$ e VR de $-12 \times 10^{-5} \mathrm{~s}^{-1}$ em $1000 \mathrm{hPa}$. Com a circulação na retaguarda do sistema localizado mais a oeste, verificamse ventos de sul sobre o centro e oeste dos MBA. Já com a circulação na vanguarda do sistema mais a leste, observam-se ventos de norte no oeste do setor (Figura 3.45b). Ambos os ciclones em superfície estão associados com baixas desprendidas em $500 \mathrm{hPa}$, posicionadas praticamente sobre os sistemas em superfície (Figura 3.45c). A nebulosidade associada aos ciclones em superfície pode ser vista na Figura 3.45d.

a)

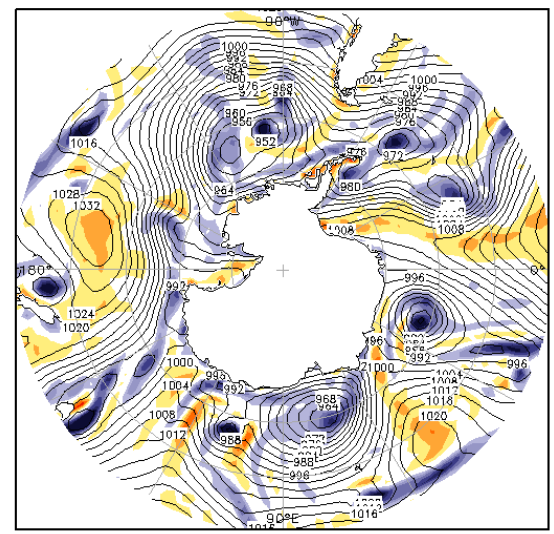

$12 z 16$ sep 1999

c)

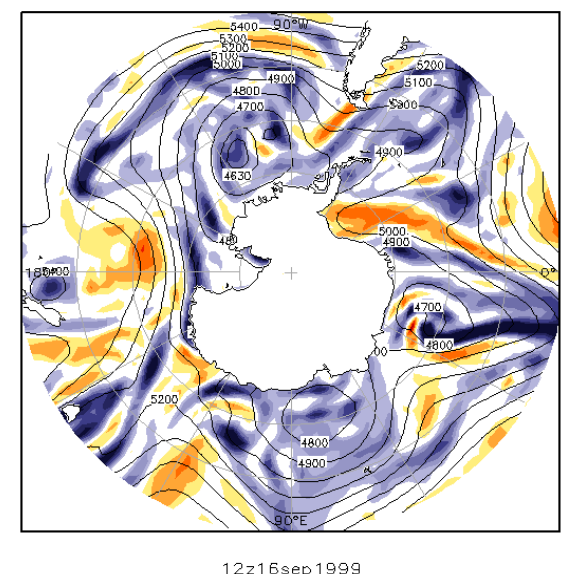

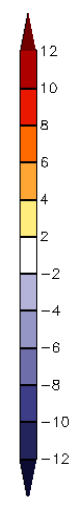

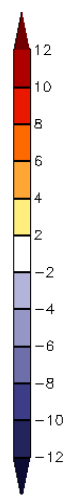

b)

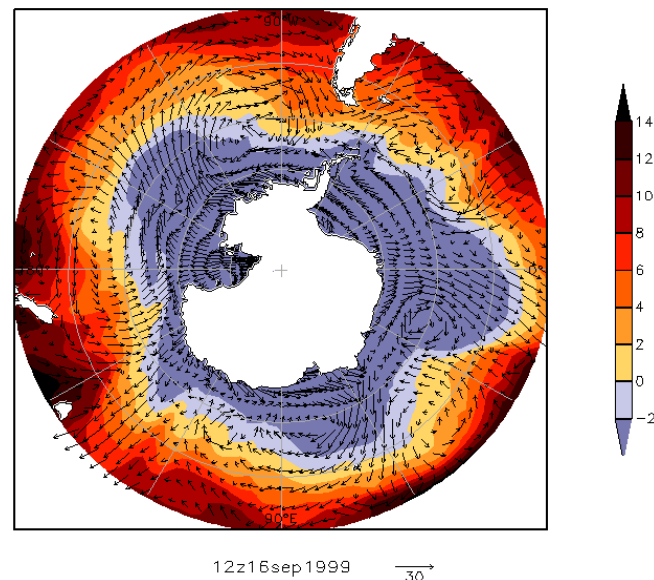

d)

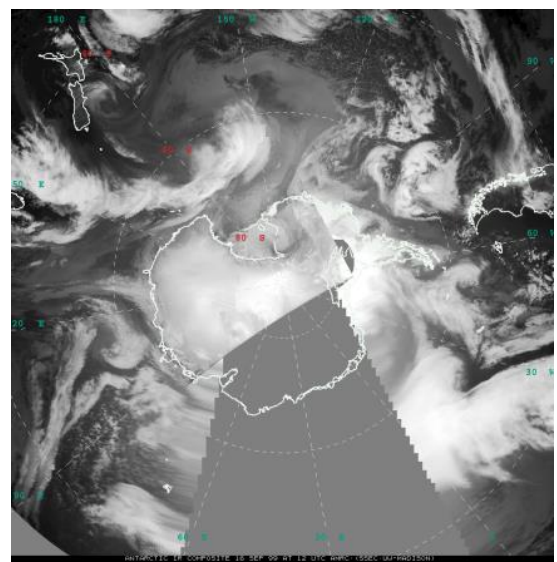

Figura 3.45: Dia 16/09/1999 às 12 UTC: (a) PNMM (linha contínua, em hPa) e VR em $1000 \mathrm{hPa}$ (sombreado, em $10^{-5} \mathrm{~s}^{-1}$ ); (b) temperatura do ar a $2 \mathrm{~m}$ (sombreado, em ${ }^{\circ} \mathrm{C}$ ) e vento horizontal a $10 \mathrm{~m}$ (vetores, em $\mathrm{m} / \mathrm{s}$ ); (c) altura geopotencial em $500 \mathrm{hPa}$ (sombreado, em m) e VR em $500 \mathrm{hPa}$ (sombreado, em $10^{-5} \mathrm{~s}^{-1}$ ); (d) composições de imagens de satélites no infravermelho. 
Por fim, no primeiro dia do evento EPGM, em 17/09/1999 às 12 UTC, verifica-se que o sistema localizado anteriormente mais a oeste nos MBA desconfigura-se em superfície. Já o sistema localizado mais a leste desloca-se para sudeste, posicionado em torno de $104^{\circ} \mathrm{W}$ / $65^{\circ} \mathrm{S}$, com aumento da pressão para $952 \mathrm{hPa}$ e da VR para $-8 \times 10^{-5} \mathrm{~s}^{-1} \mathrm{em} 1000 \mathrm{hPa}$ (Figura 3.46a). Esse sistema, juntamente com a região de VR ciclônica no oeste dos MBA, induz a um escoamento de ventos de sul sobre grande parte do setor dos MBA (Figura 3.46b). Em $500 \mathrm{hPa}$, as baixas desprendidas continuam configuradas, sendo que a localizada mais a leste está associada ao ciclone em superfície (Figura 3.46c). Assim, o sistema em superfície continua no seu estágio barotrópico equivalente. Na Figura 3.46d observa-se a nebulosidade associada ao ciclone em superfície.

a)

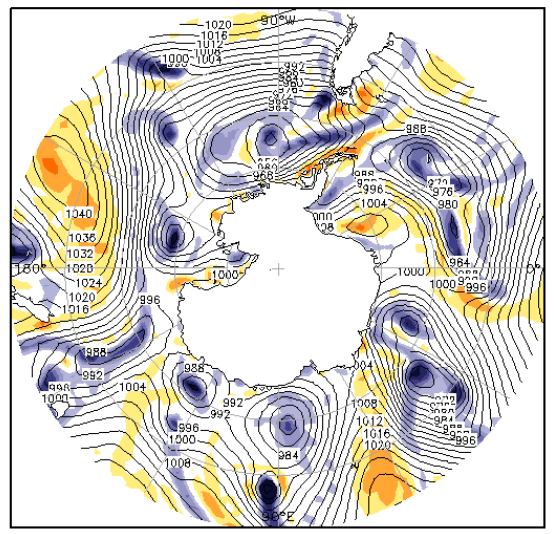

c)

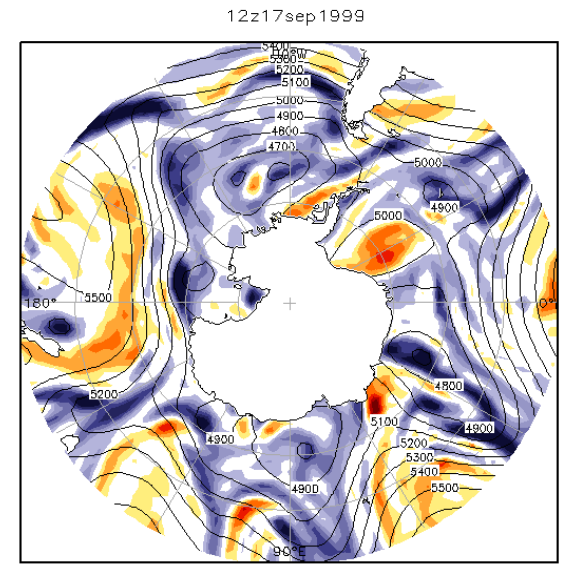

$12 z 17 \operatorname{sep} 199$

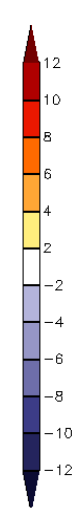

b)

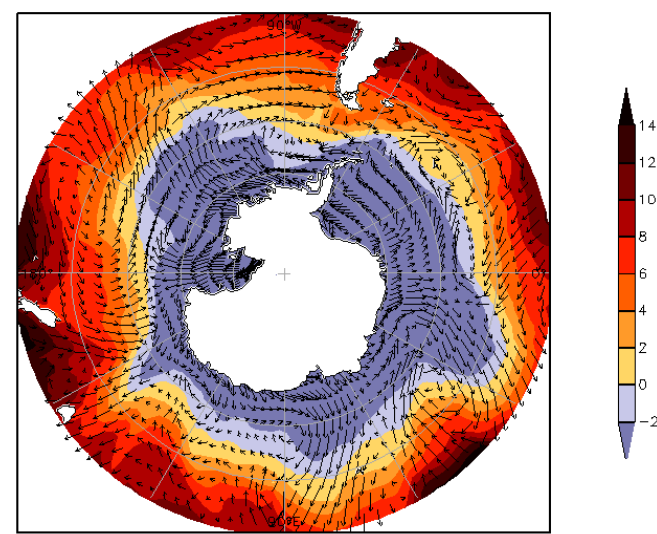

d)

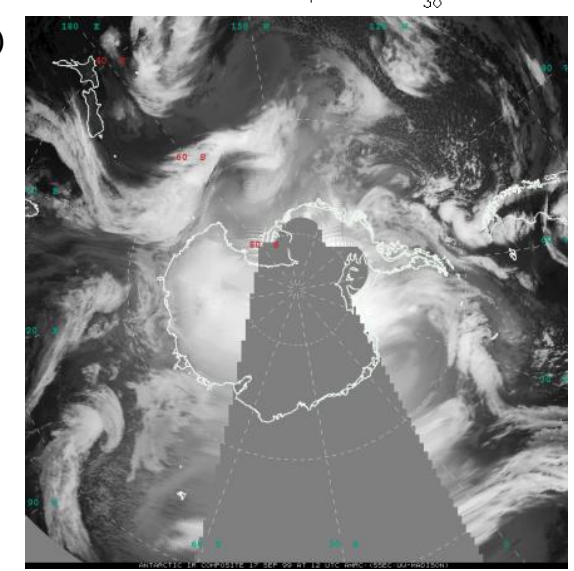

Figura 3.46: Dia 17/09/1999 às 12 UTC: (a) PNMM (linha contínua, em hPa) e VR em 1000 hPa (sombreado, em $10^{-5} \mathrm{~s}^{-1}$ ); (b) temperatura do ar a $2 \mathrm{~m}$ (sombreado, em ${ }^{\circ} \mathrm{C}$ ) e vento horizontal a $10 \mathrm{~m}$ (vetores, em m/s); (c) altura geopotencial em $500 \mathrm{hPa}$ (sombreado, em m) e VR em $500 \mathrm{hPa}$ (sombreado, em $10^{-5} \mathrm{~s}^{-1}$ ); (d) composições de imagens de satélites no infravermelho.

No estudo de caso de La Niña em evento EPGM nos MBA, também observou-se uma estrutura baroclínica, com anomalias de alta frequência de PNMM e altura geopotencial em $200 \mathrm{hPa}$ positivas no noroeste do setor e negativas no restante da área, e anomalias de 
altura geopotencial em $500 \mathrm{hPa}$ em fase oposta. O jato subtropical apresentou uma desintensificação e o jato polar uma intensificação, embora sobre os MBA o jato polar tenha enfraquecido. $\mathrm{Na}$ análise sinótica verifica-se uma intensa atividade ciclônica sobre o setor dos MBA. Assim, a circulação associada com a retaguarda dos sistemas em superfície contribuiram para a incursão de ar frio sobre os MBA através dos intensos ventos de sul. $\mathrm{O}$ mesmo padrão é observado no estudo de caso em evento ENGM em fase de La Niña, contudo o evento ENGM (EPGM) está associado com a circulação predominantemente de norte (de sul) na vanguarda (retaguarda) dos ciclones em superfície. Como observado anteriormente, durante a fase de La Niña a storm track é deslocada para sul, em direção ao setor dos MBA (YUAN, 2004). Por isso a maior contribuição dos sistemas ciclônicos nos estudos de caso em fase de La Niña.

\subsubsection{Caso neutro}

O evento EPGM ocorrido entre os dias 27 e 29/09/2000, apresentou anomalias de alta frequência de extensão de gelo marinho de $+50.350,3 \mathrm{~km}^{2},+71.825,5 \mathrm{~km}^{2}$ e $+38.314,8 \mathrm{~km}^{2}$, e Índice de Niño Oceânico no mês de setembro de 2000 de $-0,4$. Três dias anteriores ao evento EPGM (24/09/2000) a anomalia foi anticiclônica no oeste dos MBA (Figura 3.47a), associada com anomalia de ventos de oeste no sul e de ventos de leste no norte (Figura 3.47c); e ciclônica no centro e leste do setor, associada com anomalia de ventos de leste no sul e de ventos de oeste no norte. Associada a essa configuração, observa-se anomalia de ventos de sul (Figura 3.47e) e anomalia negativa de temperatura do ar sobre grande parte dos MBA, com exceção do leste e sobre a Península Antártica (Figura 3.47g).

Em $500 \mathrm{hPa}$ a anomalia de altura geopotencial foi negativa no oeste e centro dos MBA e positiva no leste e sobre a Península Antártica (Figura 3.47i). Em 200 hPa a anomalia de altura geopotencial foi predominantemente negativa nos MBA (Figura 3.47k), associada com anomalia de ventos de oeste no norte e de ventos de leste no sul (Figura $3.47 \mathrm{~m}$ ); e positiva sobre a Península Antártica, associada com anomalia de ventos de leste no norte e de ventos de oeste no sul. O jato polar é intensificado sobre os MBA (Figura 3.47m). Como os campos de PNMM, altura geopotencial em 500 e 200 hPa não estão totalmente em fase no setor, verifica-se assim uma estrutura baroclínica na região dos MBA. Com a propagação para leste das anomalias de alta frequência, no dia do evento EPGM, em 27/09/2000, as anomalias encontram-se em fase oposta às anomalias do dia 24/09/2000. 
a)

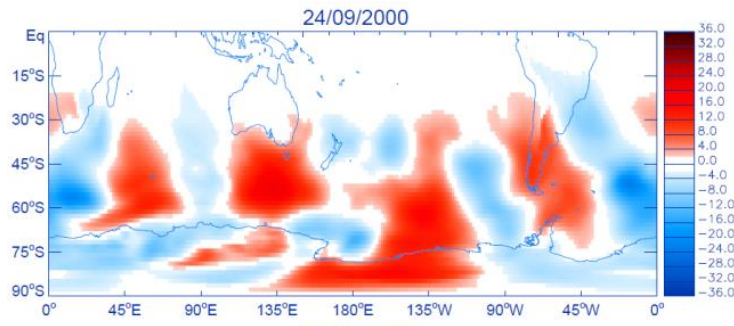

c)

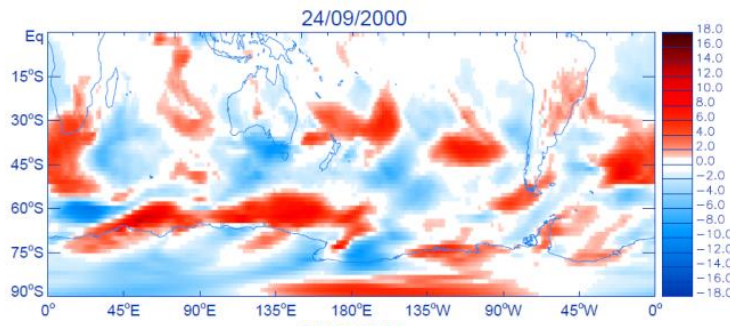

e)

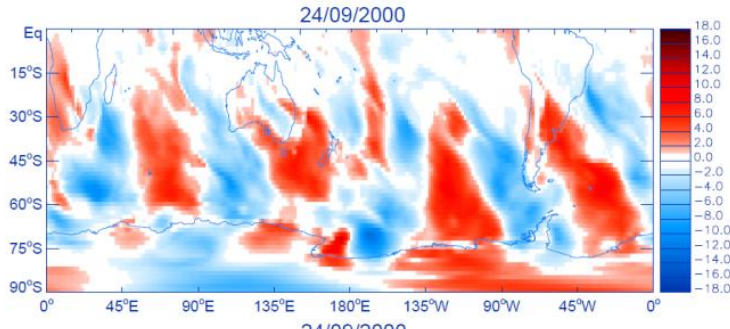

g)

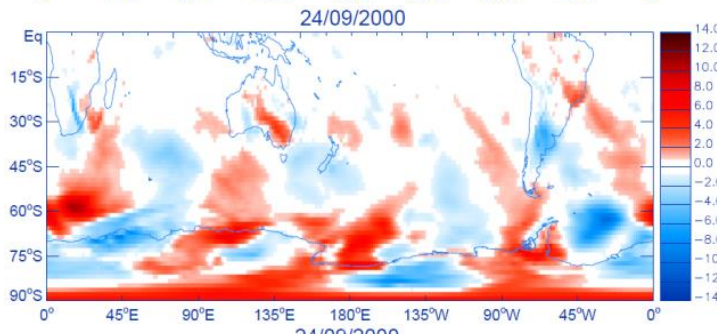

i)

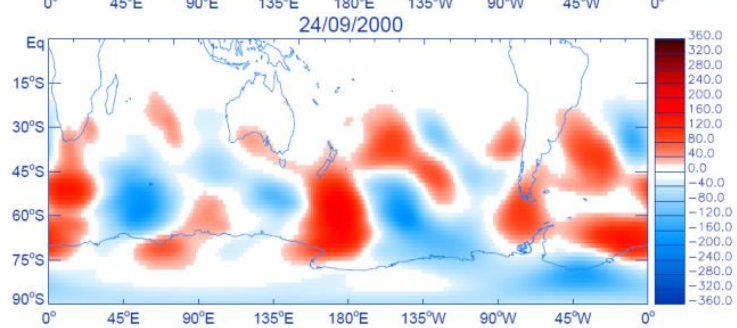

k)

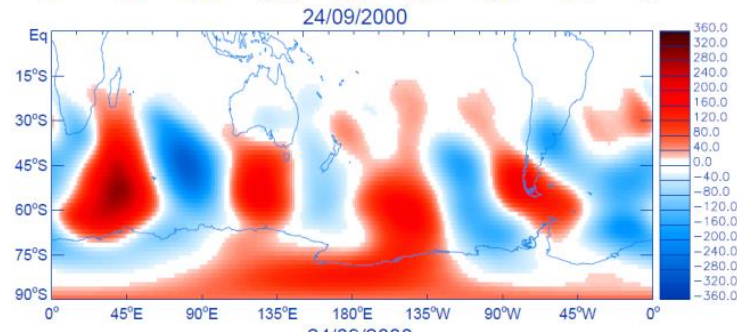

m)

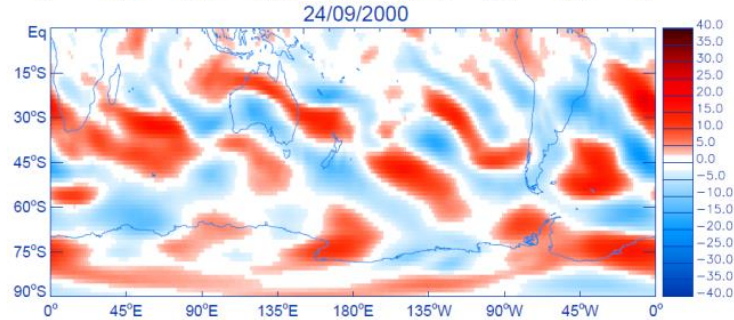

b)

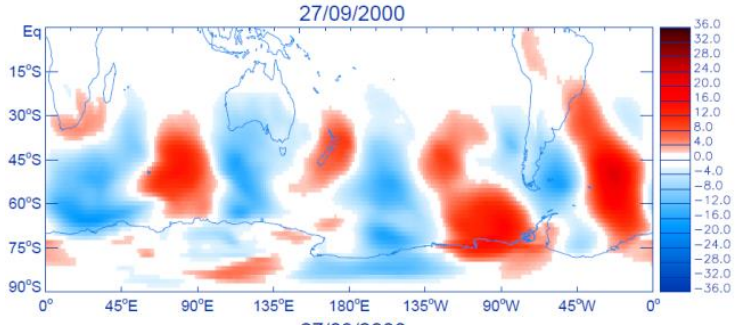

d)

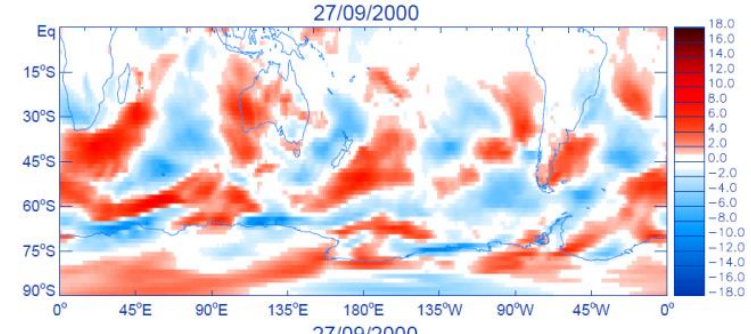

f)

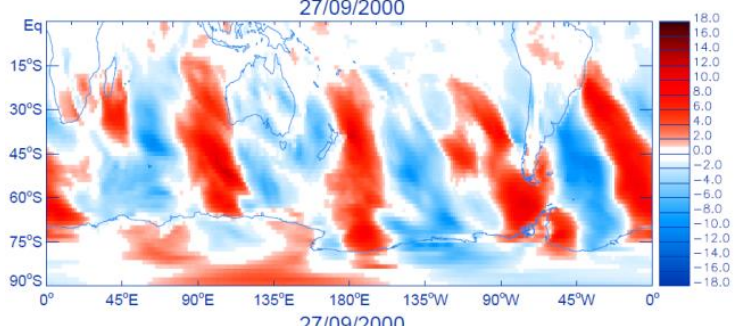

h)

j)

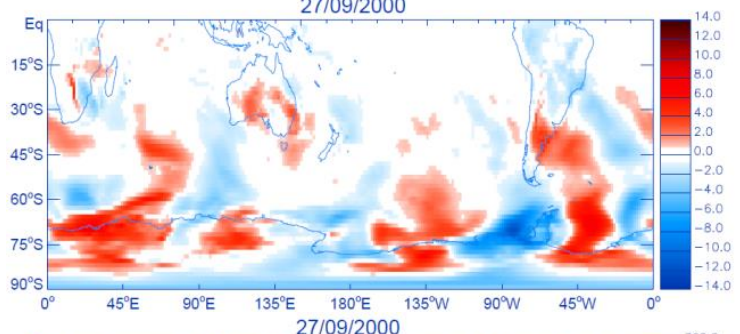

1)

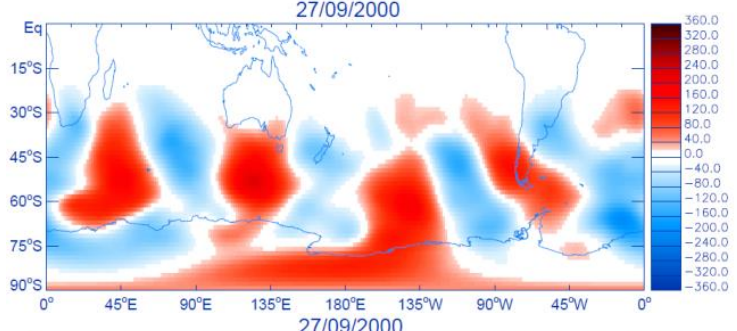

n)
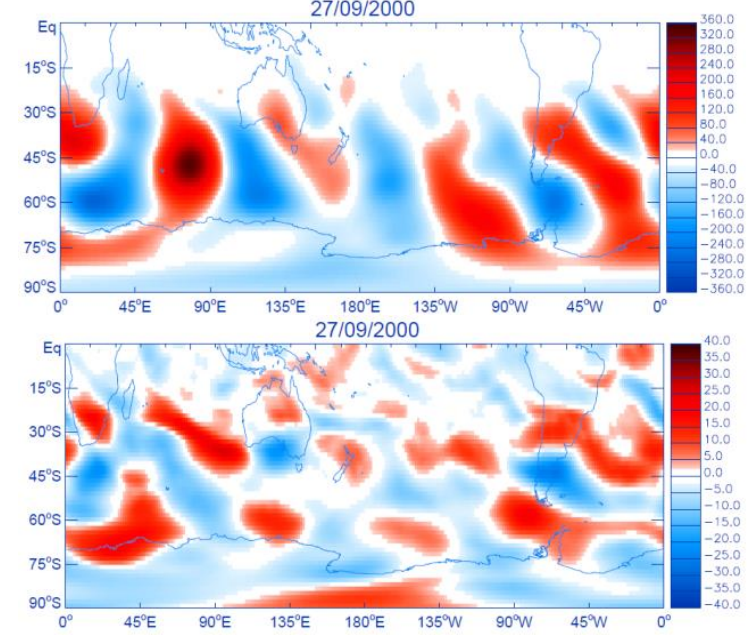

Figura 3.47: Anomalia de alta frequência de ( $a, b)$ PNMM, (c, d) vento zonal e (e, f) vento meridional a $10 \mathrm{~m},(\mathrm{~g}, \mathrm{~h})$ temperatura do ar a $2 \mathrm{~m},(\mathrm{i}, \mathrm{j})$ altura geopotencial em $500 \mathrm{hPa},(\mathrm{k}, \mathrm{l})$ altura geopotencial e $(\mathrm{m}, \mathrm{n})$ vento zonal em $200 \mathrm{hPa}$ no lag $=-3(24 / 09 / 2000)$ e no lag $=0(27 / 09 / 2000)$ no evento EPGM. 
Na análise sinótica três dias anteriores ao evento EPGM, em 24/09/2000 às 12 UTC, observa-se um ciclone em superfície localizado em torno de $113^{\circ} \mathrm{W} / 61^{\circ} \mathrm{S}$, com pressão central de $975 \mathrm{hPa}$ e VR de $-10 \times 10^{-5} \mathrm{~s}^{-1} \mathrm{em} 1000 \mathrm{hPa}$ (Figura 3.48a). A circulação ciclônica induz a um escoamento de sul na retaguarda do sistema, localizada no oeste dos MBA, e uma circulação de ventos de norte no leste do setor, junto à Península Antártica (Figura 3.48b). O sistema em superfície está localizado no eixo do cavado em $500 \mathrm{hPa}$, associado com VR de até $-10 \times 10^{-5} \mathrm{~s}^{-1}$ (Figura 3.48c). Junto à região costeira dos MBA e próximo à Península Antártica, verifica-se uma região de cavado em superfície associada à VR ciclônica em 1000 $\mathrm{hPa}$ e em $500 \mathrm{hPa}$.

a)

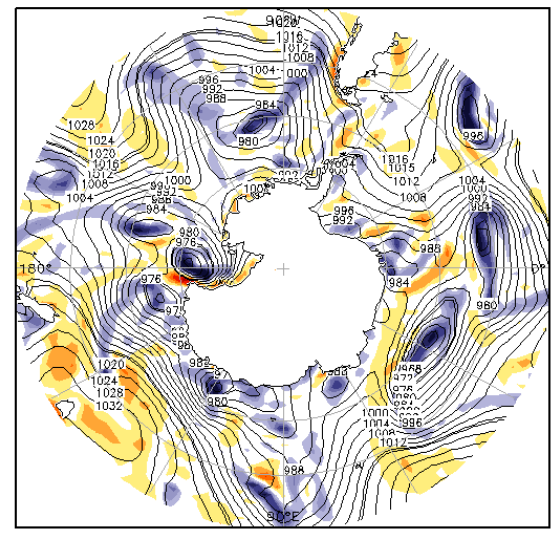

$12 z 24 \operatorname{sep} 2000$

c)

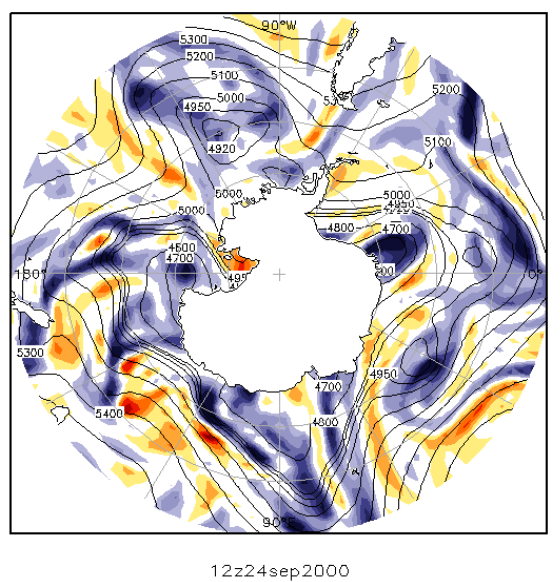

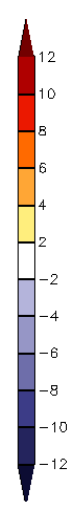

b)

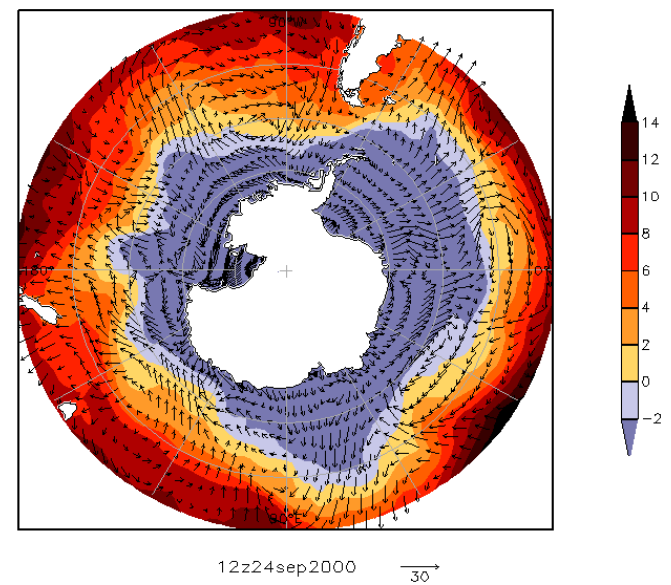

d)

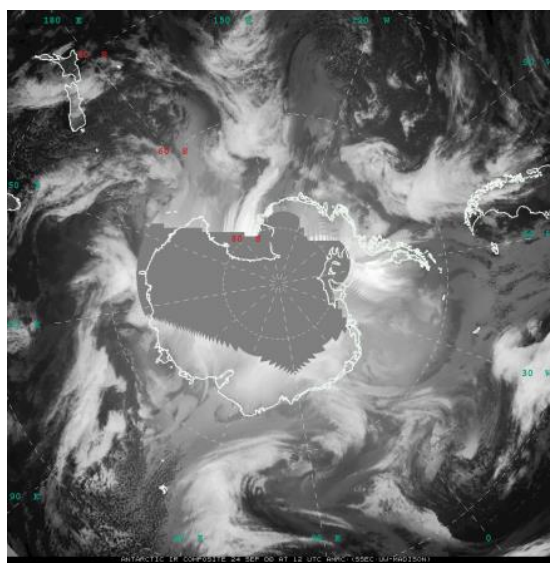

Figura 3.48: Dia 24/09/2000 às 12 UTC: (a) PNMM (linha contínua, em hPa) e VR em $1000 \mathrm{hPa}$ (sombreado, em $10^{-5} \mathrm{~s}^{-1}$ ); (b) temperatura do ar a $2 \mathrm{~m}$ (sombreado, em ${ }^{\circ} \mathrm{C}$ ) e vento horizontal a $10 \mathrm{~m}$ (vetores, em m/s); (c) altura geopotencial em $500 \mathrm{hPa}$ (sombreado, em m) e VR em $500 \mathrm{hPa}$ (sombreado, em $10^{-5} \mathrm{~s}^{-1}$ ); (d) composições de imagens de satélites no infravermelho.

No dia 25/09/2000 às 12 UTC, o sistema em superfície desloca-se para sudeste e se intensifica, apresentando pressão central de $963 \mathrm{hPa}$ e VR de $-8 \times 10^{-5} \mathrm{~s}^{-1}$ em $1000 \mathrm{hPa}$ (Figura 3.49a). Em níveis médios configura-se uma baixa desprendida sobre o ciclone em 
superfície, com intensa VR ciclônica associada (Figura 3.49c). A nebulosidade associada ao sistema em superfície e à frente fria pode ser visualizada através da Figura 3.49d. No oeste dos MBA verifica-se uma região de cristas em superfície e em $500 \mathrm{hPa}$, associada com fraca VR positiva em níveis baixos e médios. Essa região, juntamente com a retaguarda do ciclone, induz a um escoamento de sul, promovendo a incursão de ar frio sobre a região marginal de gelo marinho no centro e leste dos MBA (Figura 3.49b).

a)

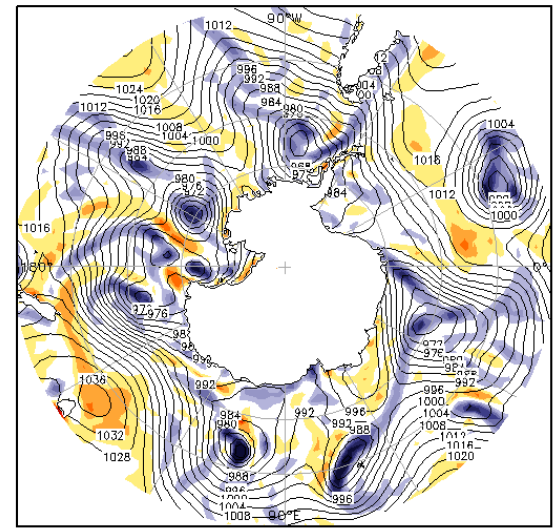

c)

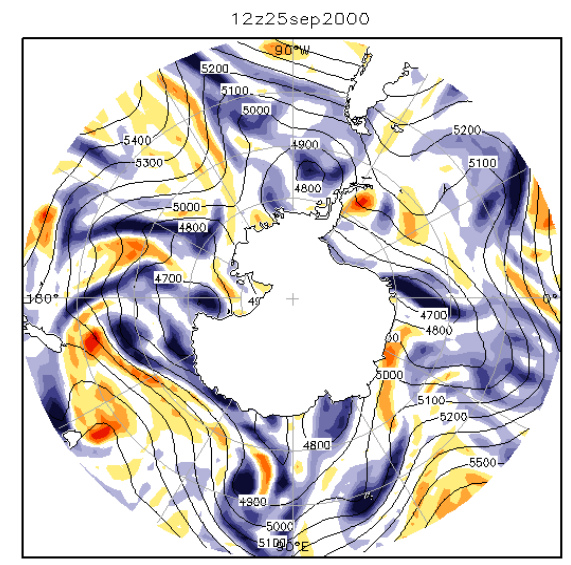

$12725 \operatorname{sep} 2000$

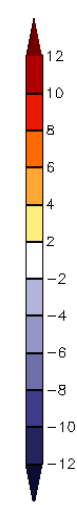

b)

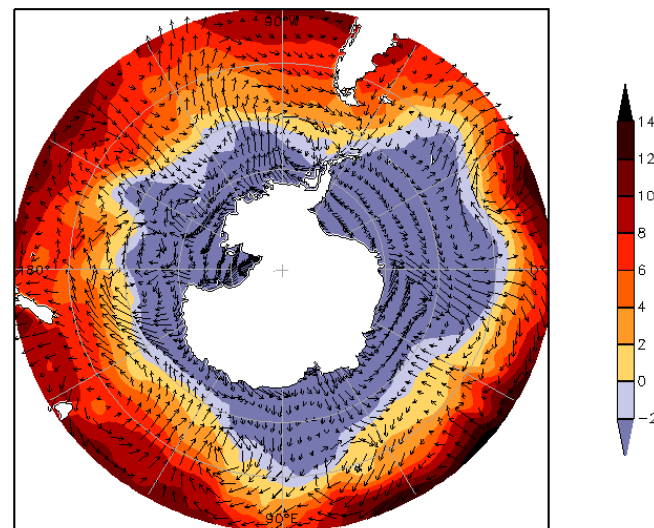

d)

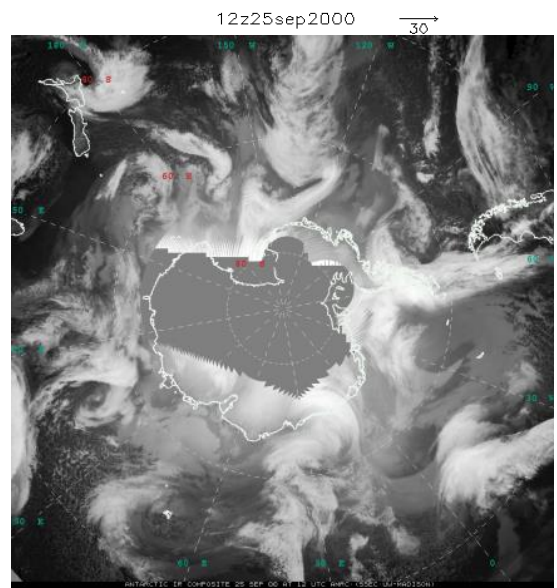

Figura 3.49: Dia 25/09/2000 às 12 UTC: (a) PNMM (linha contínua, em hPa) e VR em $1000 \mathrm{hPa}$ (sombreado, em $10^{-5} \mathrm{~s}^{-1}$ ); (b) temperatura do ar a $2 \mathrm{~m}$ (sombreado, em ${ }^{\circ} \mathrm{C}$ ) e vento horizontal a $10 \mathrm{~m}$ (vetores, em m/s); (c) altura geopotencial em $500 \mathrm{hPa}$ (sombreado, em m) e VR em $500 \mathrm{hPa}$ (sombreado, em $10^{-5} \mathrm{~s}^{-1}$ ); (d) composições de imagens de satélites no infravermelho.

Um dia anterior ao evento EPGM, em 26/09/2000 às 12 UTC, o sistema continua se deslocando para sudeste, localizando-se junto à costa oeste da Península Antártica, com um leve aumento na pressão central para $964 \mathrm{hPa}$ e VR em $1000 \mathrm{hPa}$ de $-8 \times 10^{-5} \mathrm{~s}^{-1}$ (Figura 3.50a). Na média troposfera a baixa desprendida continua configurada praticamente sobre o ciclone em superfície, associada com intensa VR negativa (Figura 3.50c) e nebulosidade em forma de vírgula invertida (Figura 3.50d). A região a leste da crista, localizada no oeste e centro do setor dos MBA, associada com a retaguarda do ciclone, contribuem para o 
escoamento de sul em 10 m no leste dos MBA (Figura 3.50b). Já no oeste do setor verifica-se uma circulação de ventos de norte em 10 m associada com a região oeste da crista em superfície.

a)

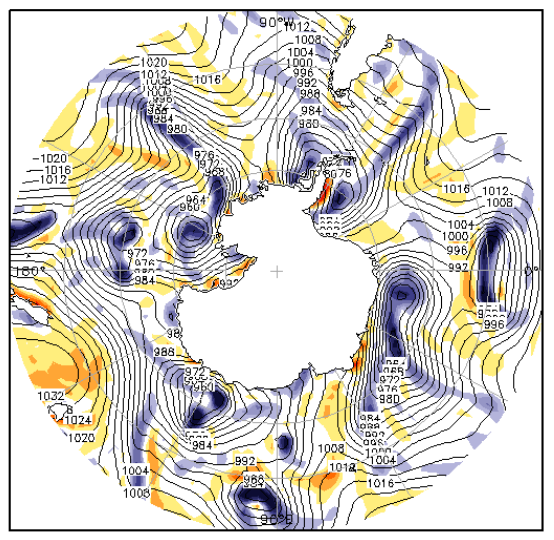

$12 z 26 \operatorname{sep} 2000$

c)

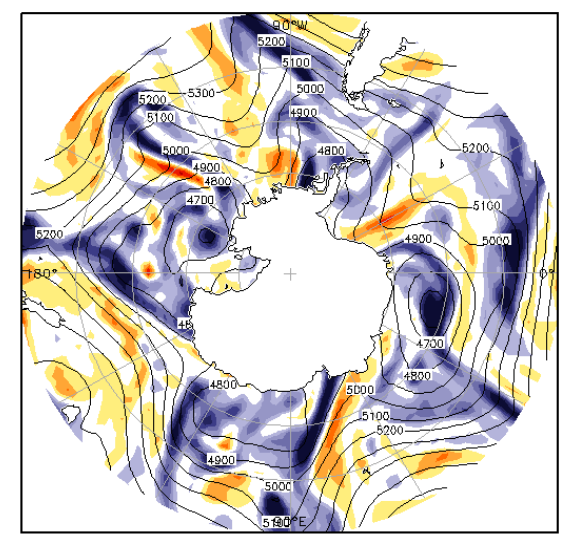

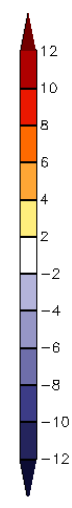

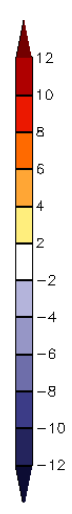

b)

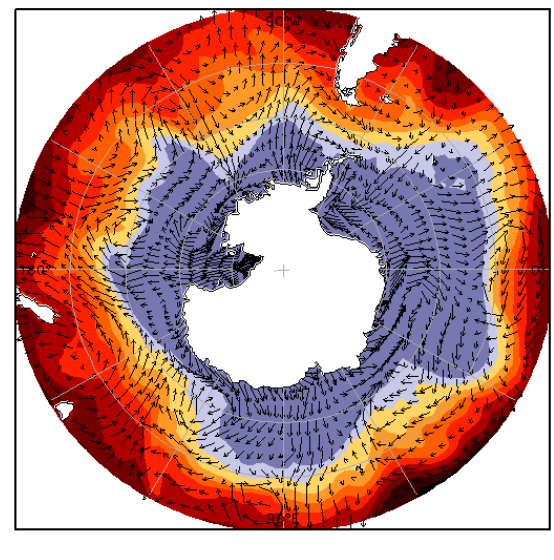

$12 z 26 \operatorname{sep} 2000 \quad \overrightarrow{30}$

d)

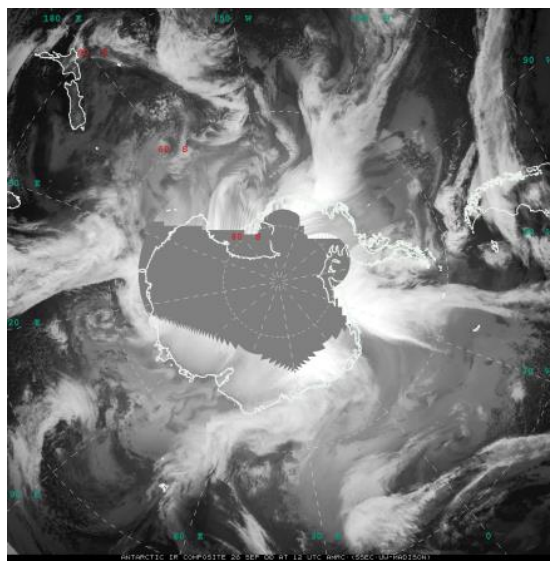

Figura 3.50: Dia 26/09/2000 às 12 UTC: (a) PNMM (linha contínua, em hPa) e VR em $1000 \mathrm{hPa}$ (sombreado, em $10^{-5} \mathrm{~s}^{-1}$ ); (b) temperatura do ar a $2 \mathrm{~m}$ (sombreado, em ${ }^{\circ} \mathrm{C}$ ) e vento horizontal a $10 \mathrm{~m}$ (vetores, em m/s); (c) altura geopotencial em $500 \mathrm{hPa}$ (sombreado, em m) e VR em $500 \mathrm{hPa}$ (sombreado, em $10^{-5} \mathrm{~s}^{-1}$ ); (d) composições de imagens de satélites no infravermelho.

No primeiro dia do evento EPGM, em 27/09/2000 às 12 UTC, o ciclone desloca-se para norte, em direção à Passagem de Drake, e desconfigura-se. Essa região está associada à VR ciclônica de até $-8 \times 10^{-5} \mathrm{~s}^{-1}$ em $1000 \mathrm{hPa}$ (Figura 3.51a). A baixa desprendida em 500 hPa permanece configurada e associada com intensa VR negativa (Figura 3.51c). O eixo da crista em superfície está localizado na região centro-leste dos MBA e no oeste do setor identifica-se uma região de cavado, com uma faixa de nebulosidade associada (Figura 3.51d). Com essa configuração, no leste dos MBA há escoamento de sul e no centro do setor ventos de norte (Figura 3.51b). 
a)

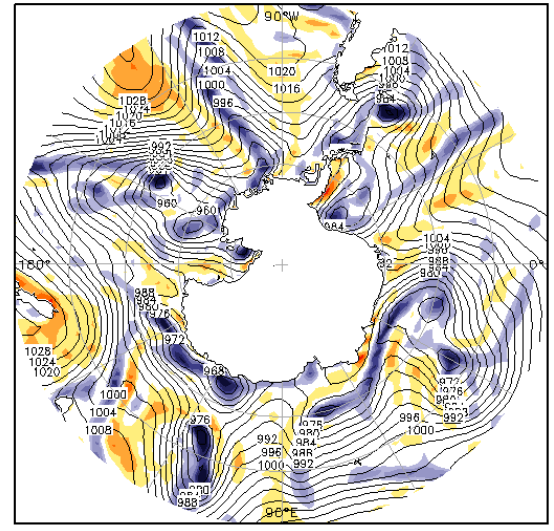

$12 z 27 \operatorname{sep} 2000$

c)

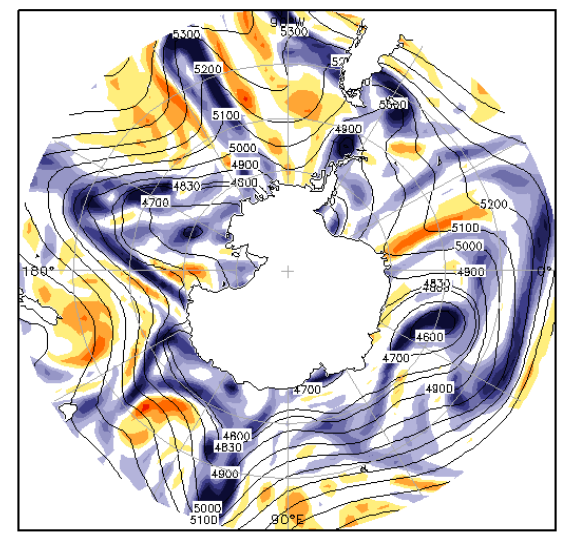

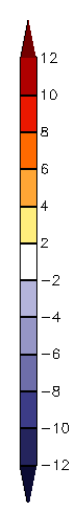

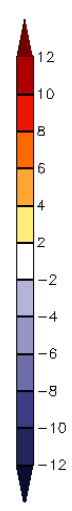

b)

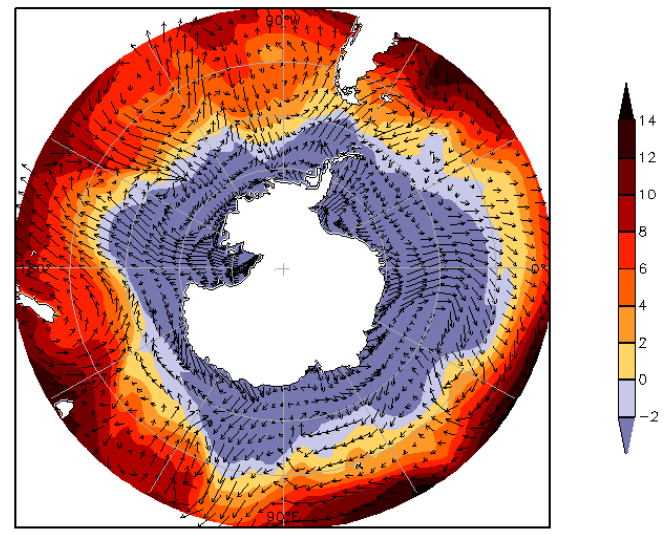

d)

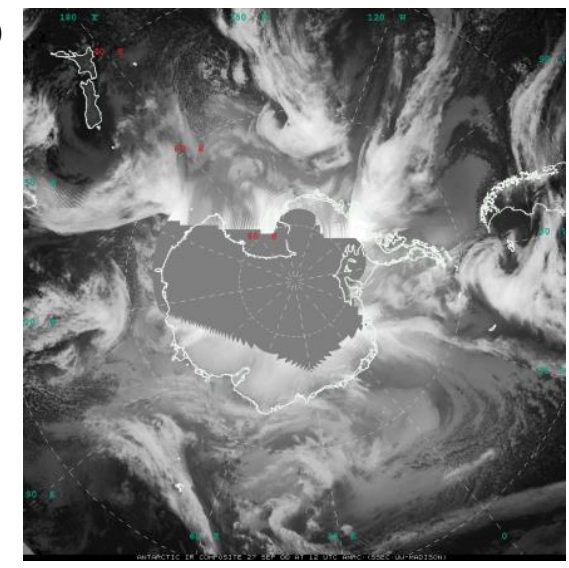

Figura 3.51: Dia 27/09/2000 às 12 UTC: (a) PNMM (linha contínua, em hPa) e VR em $1000 \mathrm{hPa}$ (sombreado, em $10^{-5} \mathrm{~s}^{-1}$ ); (b) temperatura do ar a $2 \mathrm{~m}$ (sombreado, em ${ }^{\circ} \mathrm{C}$ ) e vento horizontal a $10 \mathrm{~m}$ (vetores, em m/s); (c) altura geopotencial em $500 \mathrm{hPa}$ (sombreado, em m) e VR em $500 \mathrm{hPa}$ (sombreado, em $10^{-5} \mathrm{~s}^{-1}$ ); (d) composições de imagens de satélites no infravermelho.

No estudo de caso em evento EPGM nos MBA durante a fase Neutra, ainda verificase uma estrutura baroclínica da atmosfera, com anomalia de alta frequência de PNMM positiva no oeste e negativa no centro e leste dos MBA. As anomalias de altura geopotencial em $500 \mathrm{hPa}$ foram negativas no oeste e centro do setor e positivas no leste. Já as anomalias de altura geopotencial em $200 \mathrm{hPa}$ foram negativas sobre os MBA. O jato polar é intensificado sobre os MBA. Na análise sinótica verifica-se que a circulação de sul é devido à retaguarda dos ciclones em superfície e ao sistema de cristas e cavados, assim como observado no estudo de caso de evento ENGM em fase Neutra. A fase Neutra do fenômeno oceânico El Niño apresenta padrões atmosféricos semelhantes à fase de La Niña. Assim, verificou-se intensificação do jato polar sobre os MBA, embora não se tenha verificado o predomínio da atuação de sistemas ciclônicos (retaguarda) para a retração do gelo marinho no setor. A configuração da atmosfera que induz ao evento EPGM nos MBA está em concordância com o observado nas composições dos campos atmosféricos de alta frequência ( $c f$. seção 3.2.1). 


\subsection{Extremos de gelo marinho associados à circulação atmosférica na escala interanual}

\subsubsection{Inverno austral: Setor dos Mares de Bellingshausen-Amundsen}

Durante o inverno austral a composição das anomalias interanuais de PNMM em relação aos eventos ENGM nos MBA, na mesma escala de tempo, apresentou no lag = -365 (cerca de um ano antes) uma anomalia anticiclônica sobre todo o setor dos MBA, Península Antártica e sudeste do Oceano Pacífico Sul (Figura 3.52a), com anomalias de ventos de leste no norte e de ventos de oeste no sul (Figura 3.53a). Essa circulação anômala gera um escoamento de norte em $10 \mathrm{~m}$ sobre toda a região dos MBA (Figura 3.54a) e, consequentemente, anomalias positivas de temperatura do ar a $2 \mathrm{~m}$ (Figura 3.55a). Sobre o Pacífico Sul é observada uma anomalia negativa de PNMM ao norte de $45^{\circ} \mathrm{S}$ e uma anomalia positiva de temperatura do ar localizada próxima a costa oeste da América do Sul.

No lag = -183 (cerca de seis meses antes) observa-se claramente um padrão de dipolo zonal nas anomalias de PNMM entre a região sudoeste do Pacífico Sul/mar de Ross e sudeste do Pacífico Sul/MBA. Essas regiões apresentaram, respectivamente, anomalias ciclônicas (Figura 3.52a), associada com anomalias de ventos de oeste no norte e de ventos de leste no sul (Figura 3.53a), e anomalias anticiclônicas, associadas com anomalias de ventos de leste no norte e de ventos de oeste no sul. Esse padrão de circulação anômalo promove a incursão de ar relativamente aquecido para a região dos MBA (Figura 3.54a) através dos anômalos ventos de norte (Figura 3.55a). Na região do Pacífico tropical as anomalias positivas de temperatura do ar são mais abrangentes.

Já no dia do evento ENGM (lag = 0), há uma inversão de fase das anomalias sobre o sudeste do Pacífico Sul/MBA, incluindo também o sudoeste do Pacífico Sul/mar de Ross, apresentando anomalias ciclônicas (Figuras 3.52a), com anomalias de ventos de oeste no norte e de ventos de leste no sul (Figuras 3.53a). Ao norte dessas anomalias, no Pacífico Sul central e tropical, observa-se uma anomalia anticiclônica, com anomalias de ventos de oeste no norte e de ventos de leste no sul. Assim, cria-se um padrão de dipolo meridional entre as latitudes baixas/médias (de $15^{\circ}$ a $45^{\circ} \mathrm{S}$ ) e médias/altas (de $45^{\circ}$ a $75^{\circ} \mathrm{S}$ ) sobre o Pacífico $\mathrm{Sul}$. Com a circulação ciclônica anômala sobre os MBA, configuram-se anomalias de ventos de sul no extremo oeste do setor (Figura 3.54a), associadas com anomalias negativas de temperatura do ar (Figura 3.55a); e anomalias de ventos de norte no centro e leste dos MBA, com anomalias positivas de temperatura do ar. No Pacífico tropical as anomalias de temperatura do ar estão em fase oposta, com valores negativos. O mesmo padrão de 
anomalias interanuais de PNMM e temperatura do ar no lag $=0$ foram encontrados por Yuan e Martinson (2001) como o principal modo da EOF de PNMM e temperatura do ar em superfície na escala interanual entre 1975 e 1999, contendo $28 \%$ e $18 \%$ da variância total, respectivamente. A EOF da temperatura do ar mostra um padrão característico do ENSO, com máxima amplitude centrada no Pacífico tropical central. Associado com a porção tropical deste padrão ENSO, observa-se um padrão que se assemelha com o DPA na cobertura de gelo marinho, mostrando um polo próximo a $60^{\circ} \mathrm{S}$ no Pacífico Sul e outro polo de fase oposta sobre o MW. O principal modo de PNMM mostra um contraste zonal entre o Pacífico tropical central e leste, refletindo a Oscilação Sul, bem como um contraste meridional marcante entre as regiões de latitudes tropical/média e subpolar/polar no Pacífico (YUAN; MARTINSON, 2001).

No lag $=+183$ dias, o dipolo de anomalias de PNMM desconfigura, embora sobre o centro-sul e sudeste do Pacífico Sul/MBA ainda exista uma fraca anomalia ciclônica (Figura 3.52a), com anomalias de ventos de oeste no norte e de ventos de leste no sul (Figura 3.53a). Assim, há também um enfraquecimento das anomalias de ventos de sul no extremo oeste do setor (Figura 3.54a), associadas com as anomalias negativas de temperatura do ar (Figura 3.55a), e anomalias menos intensas de ventos de norte no centro e leste dos MBA, relacionadas com anomalias positivas de temperatura do ar. Na região do Pacífico tropical as anomalias negativas de temperatura do ar são mais amenas e as anomalias de PNMM são predominantemente próximas ou iguais à zero.

O padrão de anomalias de PNMM e de temperatura do ar a $2 \mathrm{~m}$ do lag $=-365$ ao lag $=0$ é muito semelhante ao encontrado por Yuan (2004) em eventos de El Niño persistentes. O centro de alta pressão sobre o mar de Bellingshausen persiste por duas estações depois do El Niño maduro nos trópicos. A alta pressão é enfraquecida do outono para o inverno depois do evento quente de ENSO. Contudo as anomalias no DPA de temperatura do ar e gelo marinho ainda são amplificadas e persistentes após três estações do evento maduro quente. O DPA não é apenas um reflexo da variação do ENSO em altas latitudes. Aparentemente, a anomalia de ENSO nos trópicos modifica a circulação atmosférica e começa a afetar os campos de pressão e temperatura do ar nas altas latitudes do HS no verão austral. À medida que se aproxima o inverno austral no HS, a anomalia de ENSO no sistema acoplado ar-mar-gelo cresce e persiste, provavelmente causada por um feedback positivo entre a atmosfera, oceanos e criosfera. Assim, o DPA evolui e desenvolve as suas 
características de alta latitude no sistema acoplado ar-mar-gelo após a forçante tropical ser enfraquecida (YUAN, 2004).

Em relação ao evento EPGM nos MBA, durante o inverno austral, verifica-se que as anomalias interanuais encontram-se em fase oposta em relação ao evento ENGM na região dos MBA, porém a intensidade e a configuração das anomalias no HS apresentam algumas diferenças em relação às anomalias no evento ENGM. No lag $=-365$ observam-se anomalias ciclônicas sobre o mar de Ross, MBA, Península Antártica e MW, incluindo o sudeste do Pacífico Sul (Figura 3.52b), associadas com anomalias de ventos de oeste no norte e de ventos de leste no sul (Figura 3.53b). Em contraste, há anomalias anticiclônicas entre as latitudes em torno de $30^{\circ}$ e $60^{\circ} \mathrm{S}$ e as longitudes de $60^{\circ} \mathrm{E}$ e $110^{\circ} \mathrm{W}$. Com essa configuração gera-se um escoamento de sul sobre grande parte da região dos MBA (Figura 3.54b), associada com anomalias negativas de temperatura do ar (Figura 3.55b). Na região tropical do Pacífico também são observadas anomalias negativas de temperatura do ar e anomalias positivas de PNMM.

No lag $=-183$ o padrão de anomalias sobre os MBA permanece o mesmo, com anomalia ciclônica (Figura 3.52b) associada às anomalias de ventos de oeste no norte e de ventos de leste no sul (Figura 3.53b). Assim, verificam-se anomalias de ventos de sul no oeste dos MBA, as quais contribuem para as anomalias negativas de temperatura do ar sobre grande parte do setor (Figura 3.52b), e anomalias de ventos de norte no leste do setor (Figura 3.53b). Sobre o Pacífico tropical as anomalias de temperatura do ar permanecem negativas, assim como as anomalias de PNMM permanecem positivas.

No lag $=0$ o padrão de anomalias de PNMM se assemelha com o Modo Anular Sul (South Annular Mode - SAM), que é um dos mais importantes modos de variabilidade da circulação atmosférica entre as médias e altas latitudes do HS, atuando em escalas temporais que variam de intrasazonal a interanual (THOMPSON; WALLACE, 2000). É marcado por anomalias de pressão zonalmente simétricas e fora de fase entre as latitudes médias e altas (MARSHALL, 2003; L'ECUYER; THOMPSON, 2009). No lag $=+183$ as anomalias dos campos atmosféricos estão em fase oposta em relação às anomalias dos eventos ENGM no lag $=+183$, respectivamente. 
a) ENGM
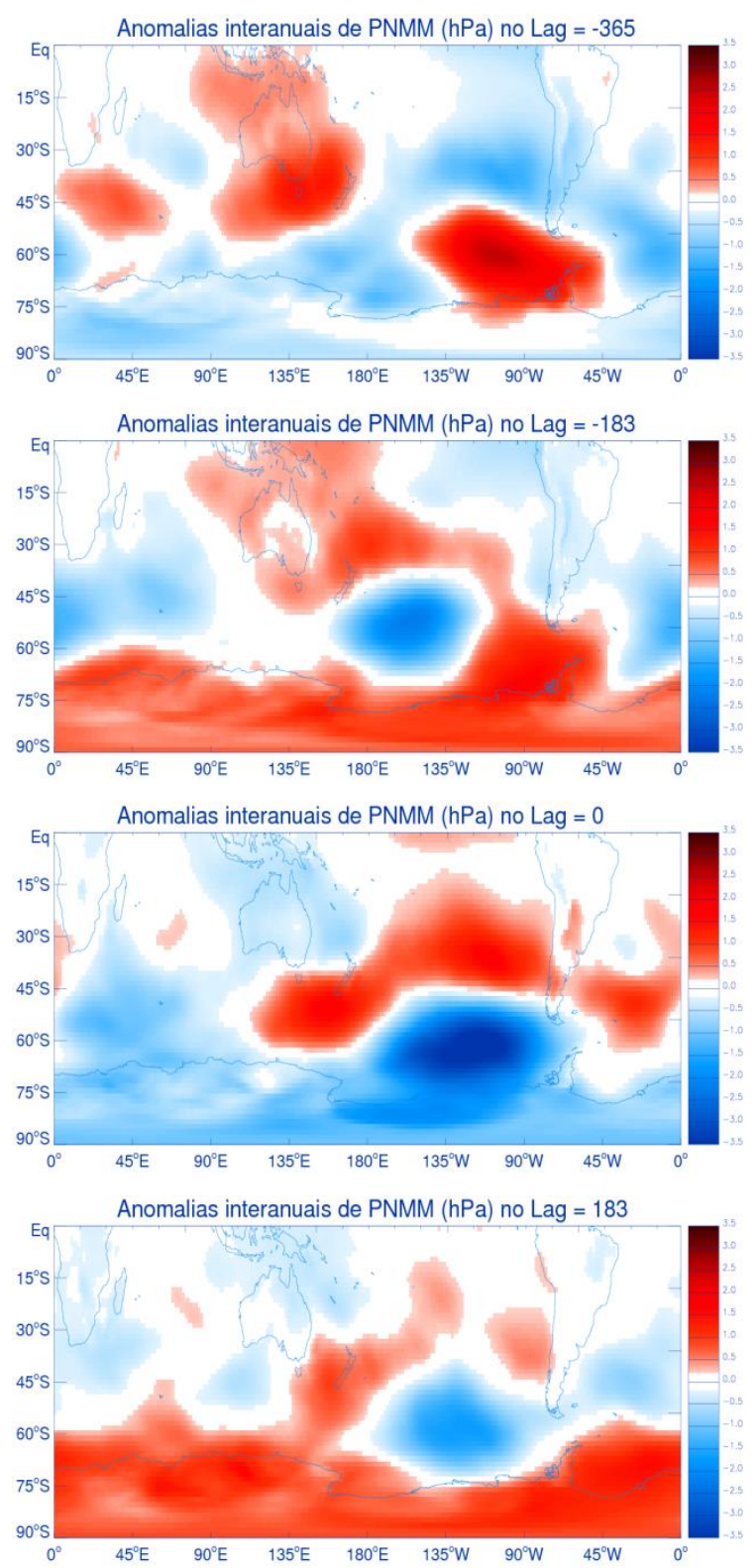

b) EPGM
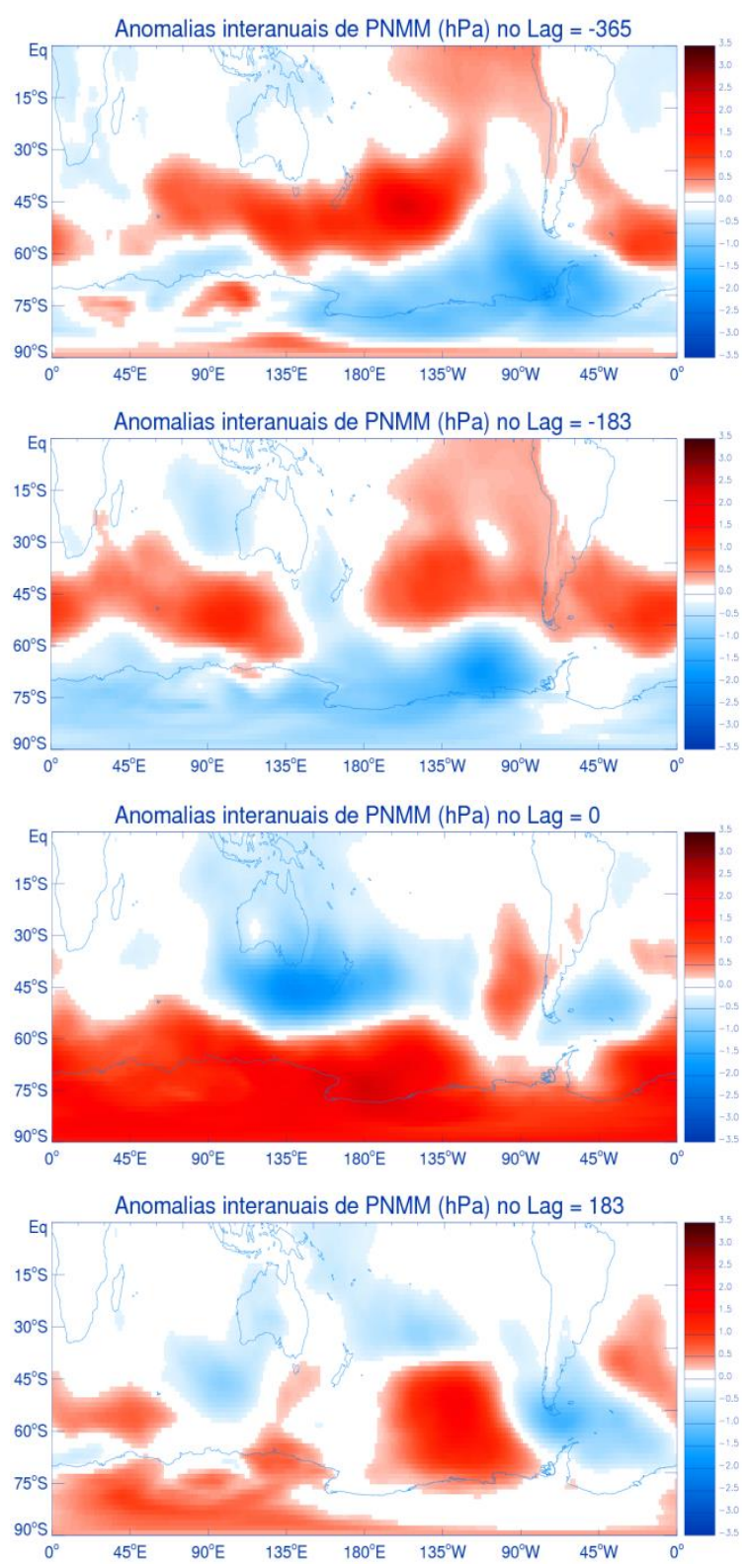

Figura 3.52: Composições defasadas das anomalias interanuais de PNMM (hPa) durante os eventos (a) ENGM e (b) EPGM no setor dos MBA, no lag $=-365$, lag $=-183$, lag $=0$ e lag $=+183$, no período de inverno austral (1989-2007). 
a) ENGM
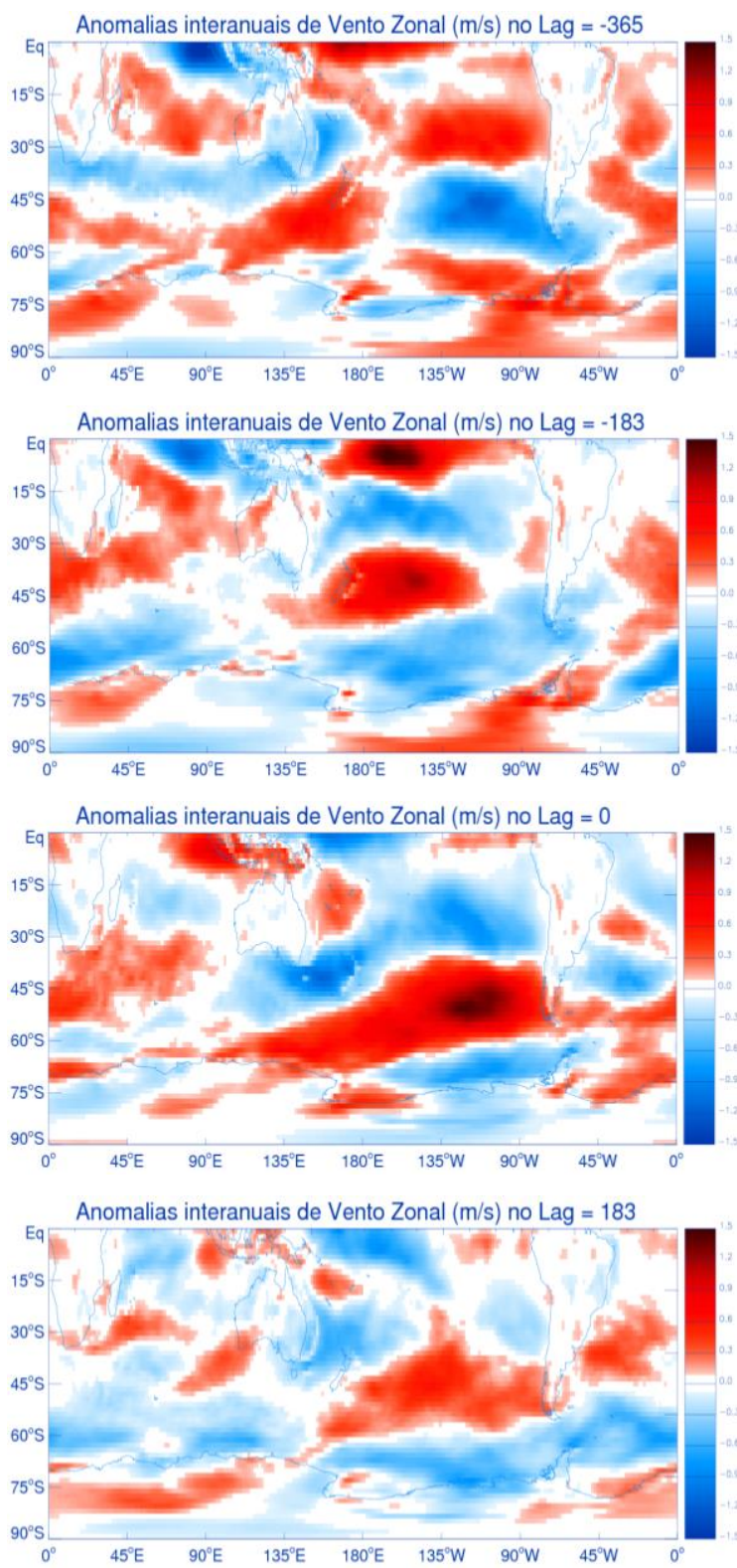

\section{b) EPGM}
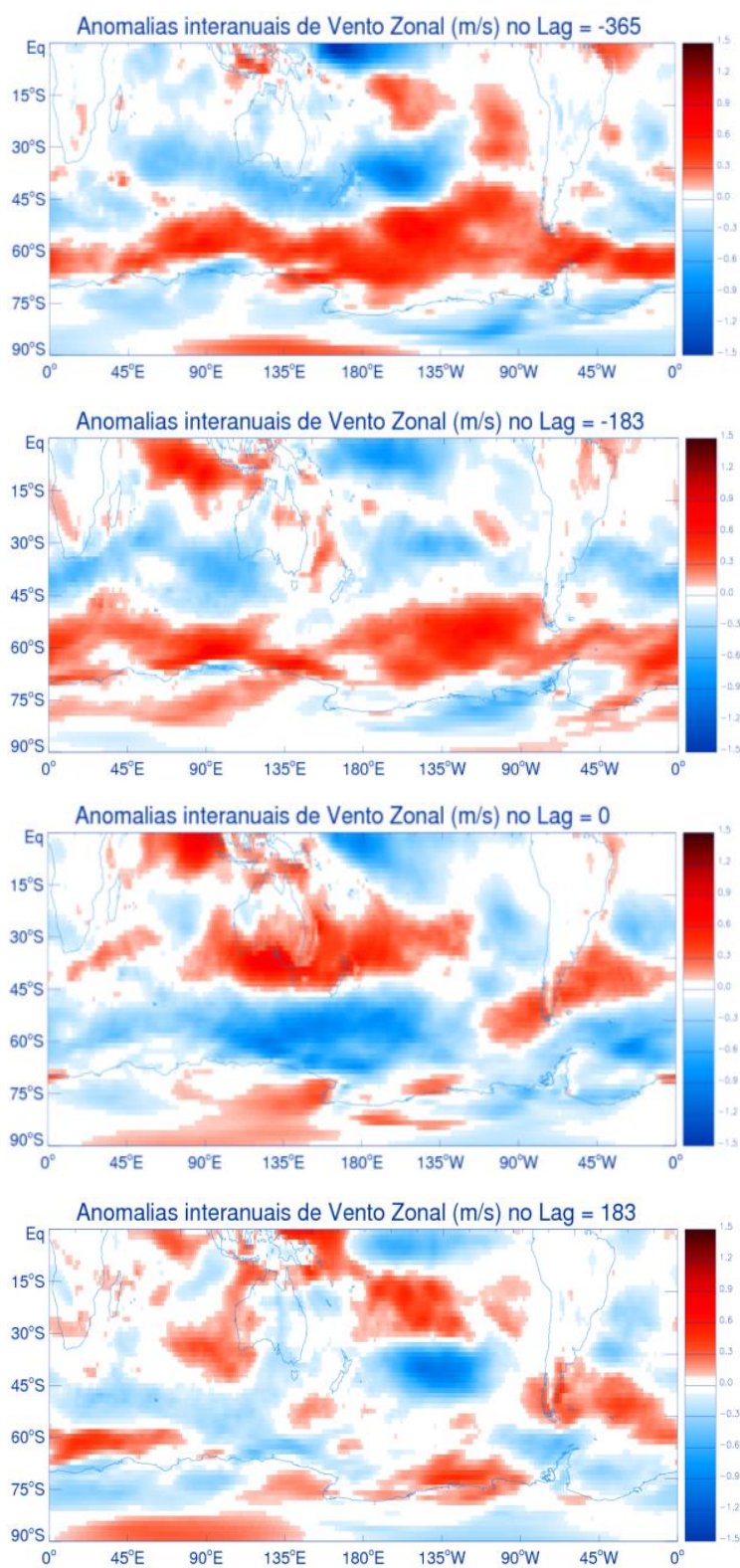

Figura 3.53: Similar à Figura 3.52, mas para as anomalias interanuais de vento zonal a $10 \mathrm{~m}(\mathrm{~m} / \mathrm{s})$. 
a) ENGM
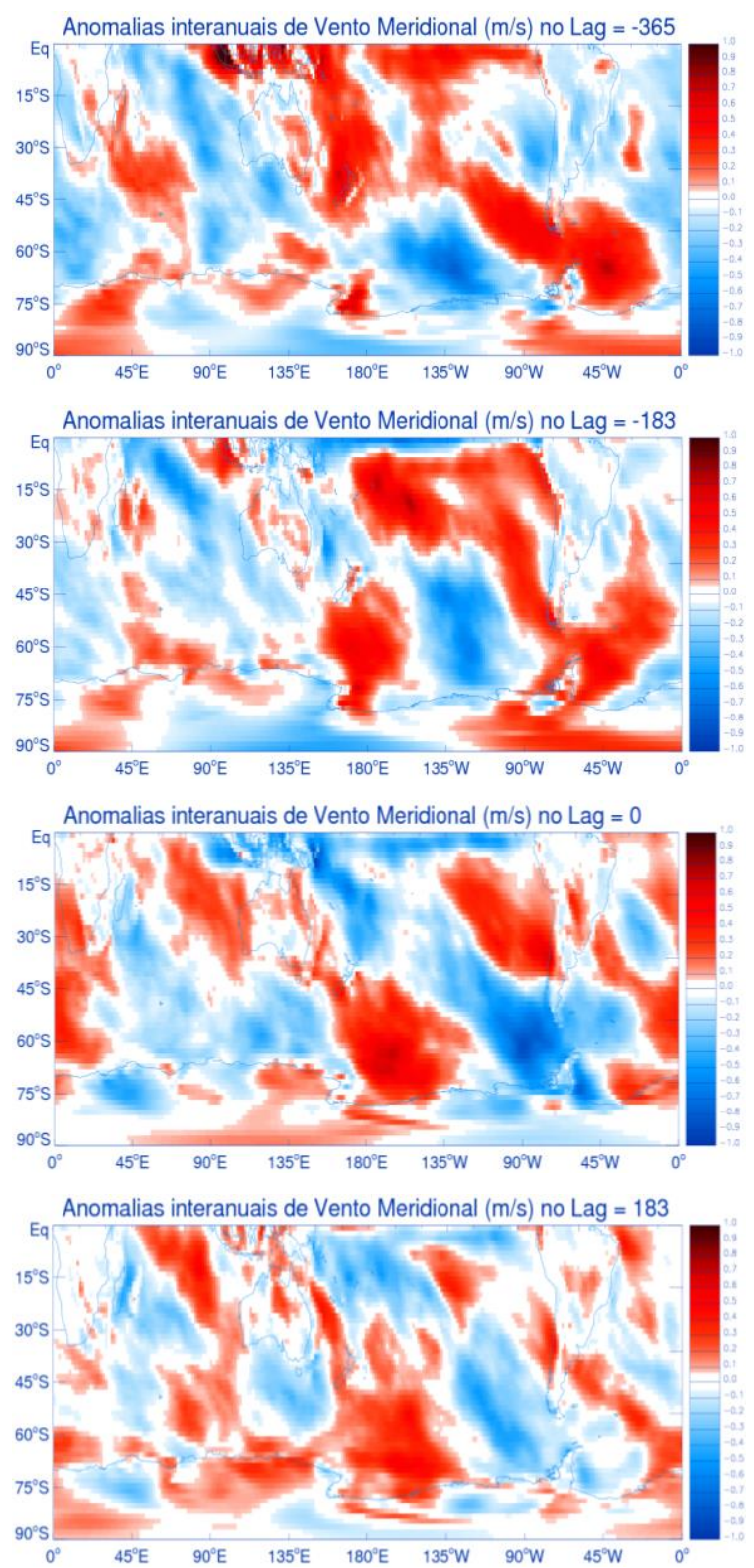

b) EPGM
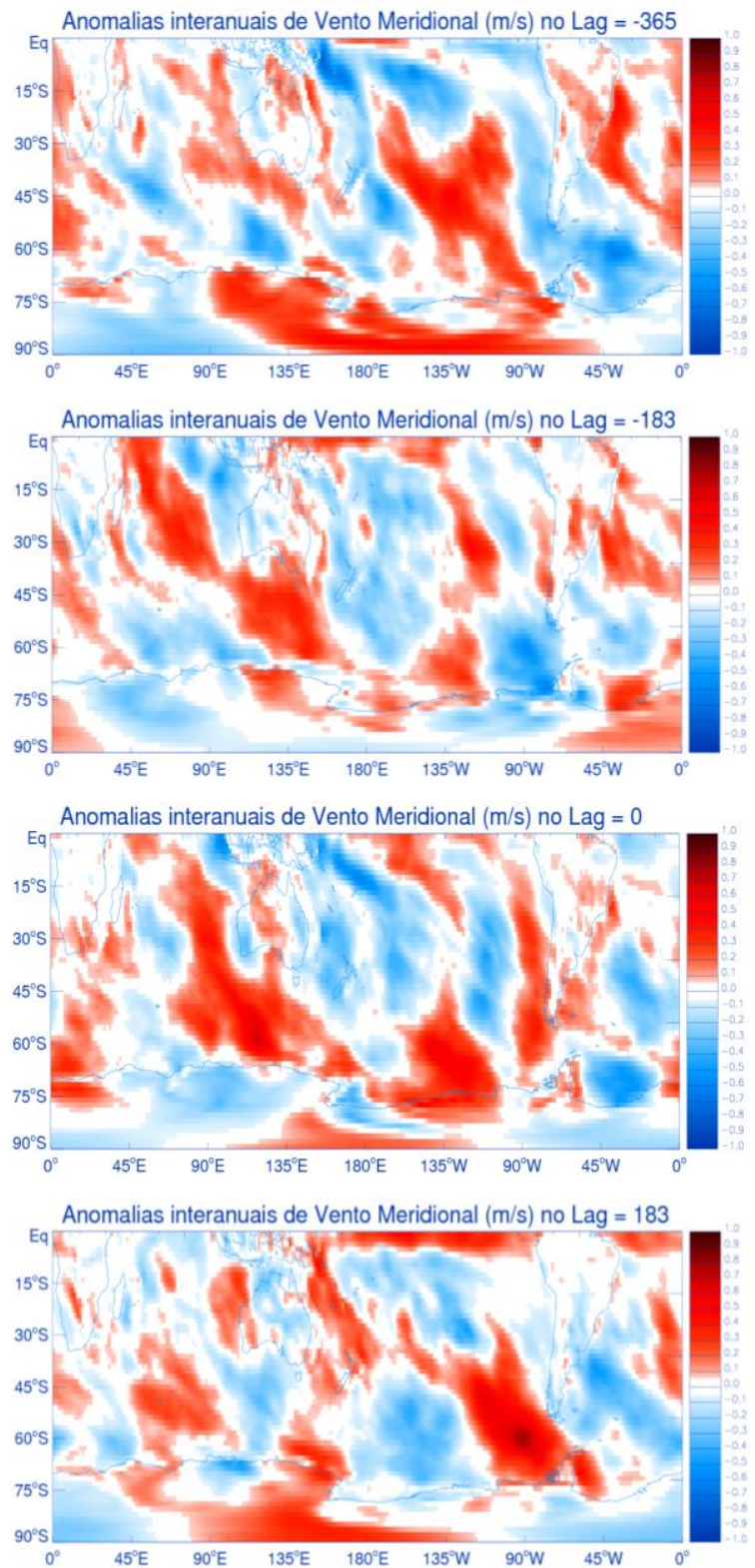

Figura 3.54: Similar à Figura 3.52, mas para as anomalias interanuais de vento meridional a $10 \mathrm{~m}$ $(\mathrm{m} / \mathrm{s})$. 
a) ENGM
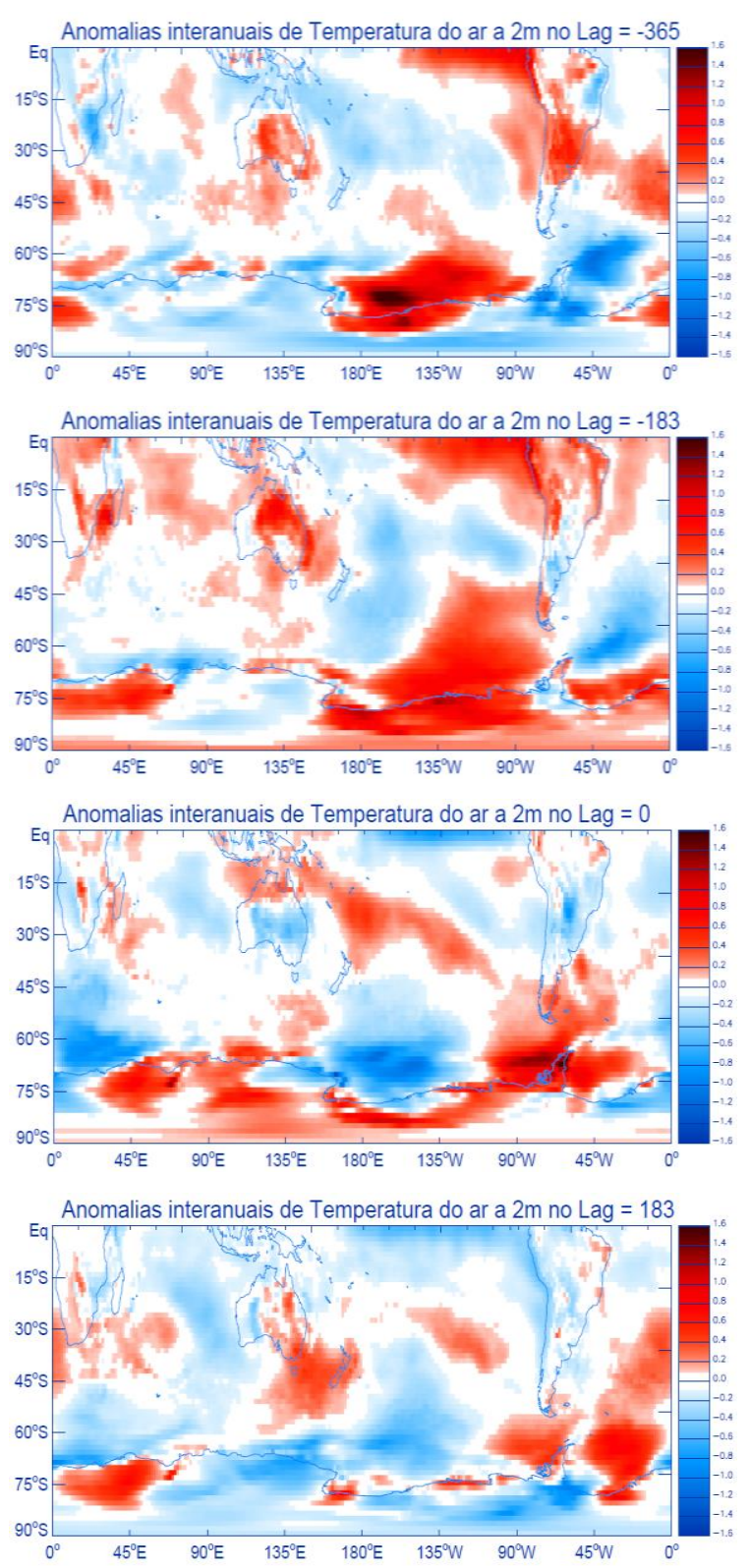

b) EPGM
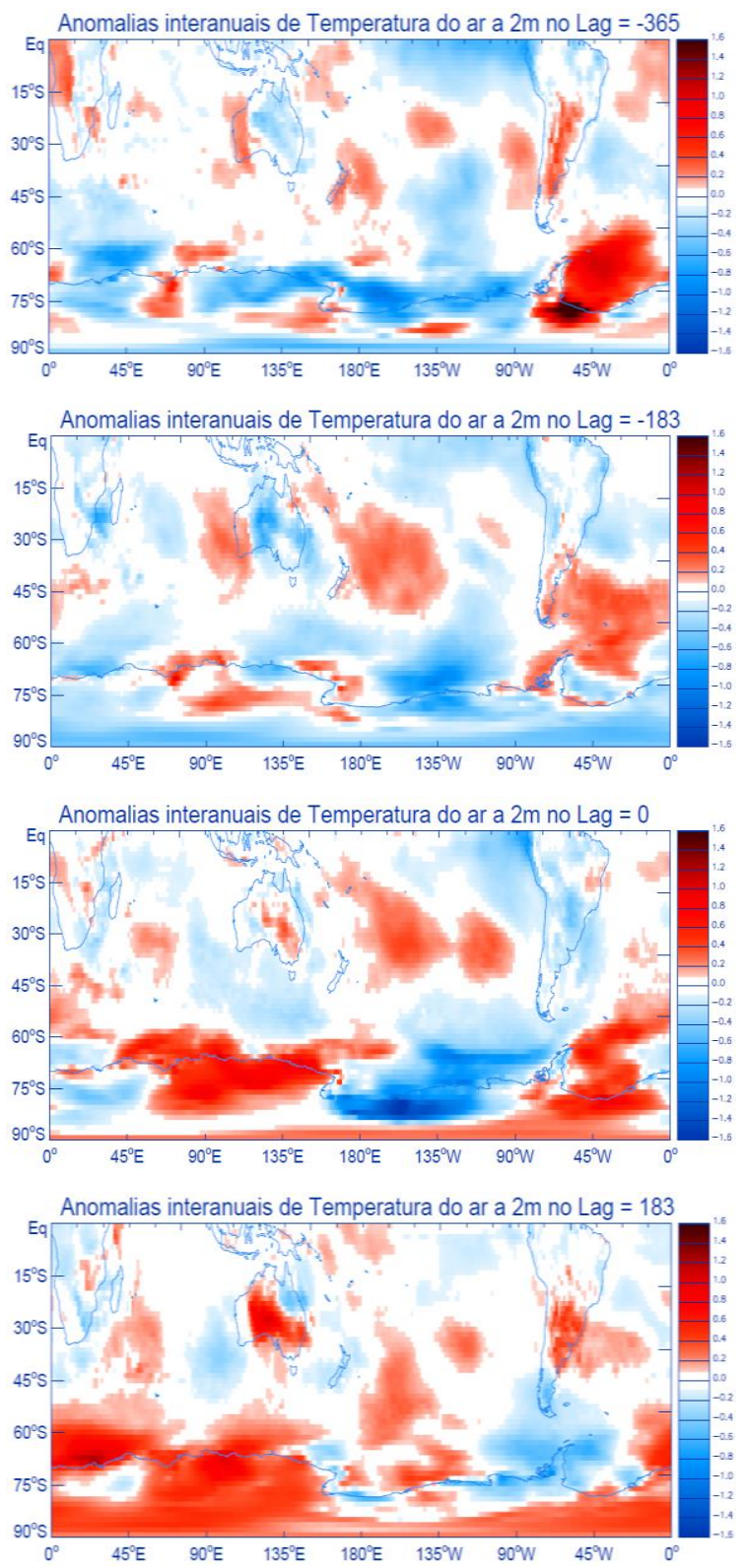

Figura 3.55: Similar à Figura 3.52, mas para as anomalias interanuais de temperatura do ar a $2 \mathrm{~m}$ $\left({ }^{\circ} \mathrm{C}\right)$. 


\subsubsection{Inverno austral: Setor do Mar de Weddell}

Durante o inverno austral, em relação aos eventos ENGM no setor do MW, a anomalia interanual de PNMM no lag = -365 foi ciclônica sobre todo o MW, Península Antártica, MBA e mar de Ross, além do centro-sul e sudeste do Pacífico Sul (Figura 3.56a). Destaca-se que o núcleo mais intenso de anomalia negativa foi observada em cerca de $145^{\circ} \mathrm{W}$ / $60^{\circ} \mathrm{S}$, com valores superiores a $-5,5 \mathrm{hPa}$. Ao norte, há anomalias anticiclônicas, criando-se assim um padrão de dipolo entre as latitudes baixas/médias e médias/altas, que é um padrão semelhante ao SAM. Devido a essa circulação anômala, verifica-se anomalia de ventos de oeste no sul do Pacífico Sul e sobre o MW e anomalia de ventos de leste sobre os MBA e sobre o continente antártico, junto à costa do MW (Figura 3.57a). Devido à anomalia ciclônica, a anomalia de vento meridional foi de norte sobre grande parte dos MBA, Península Antártica e extremo oeste e leste do MW (Figura 3.58a), associada com uma anomalia positiva de temperatura do ar sobre grande parte do MW e dos MBA (Figura 3.59a). Na região tropical do Pacífico observa-se uma anomalia negativa de temperatura do ar e uma anomalia positiva de PNMM. O padrão de anomalias de PNMM e temperatura do ar a $2 \mathrm{~m}$ é muito semelhante ao principal modo da EOF da variabilidade interanual de PNMM e temperatura do ar em superfície encontrado por Yuan e Martinson (2001), apresentando 28\% e $18 \%$ da variância total, respectivamente.

No lag = -183 há uma desintensificação das anomalias de PNMM sobre toda a região localizada a oeste da Península Antártica, enquanto que no centro e leste do MW a anomalia é anticiclônica (Figura 3.56a). Observam-se anomalias de ventos de leste (Figura 3.57a) no norte da anomalia anticiclônica e anomalias de ventos de norte em grande parte do MW (Figura 3.58a), associada com intensas anomalias positivas de temperatura do ar (Figura 3.59a). As anomalias de temperatura do ar sobre o Pacífico tropical permanecem negativas e as de PNMM positivas, embora menos intensas.

No dia do evento ENGM há uma intensificação das anomalias ciclônicas sobre os MBA e MW (Figura 3.56a), acompanhadas por anomalias de ventos de oeste no norte, sobre ambos os setores, e de ventos de leste no sul, sobre o continente (Figura 3.57a). Sobre a Península Antártica e no oeste e centro do MW a anomalia é de ventos de norte (Figura 3.58a), associada com anomalia de temperatura do ar de até $+1,6^{\circ} \mathrm{C}$ (Figura 3.59a). Já no leste do MW a anomalia é de ventos de sul, devido à região leste da anomalia anticiclônica. $\mathrm{Na}$ região tropical do Pacífico as anomalias negativas de temperatura do ar são enfraquecidas. 
Após 183 dias, a anomalia de PNMM sobre o MW passa a ser anticiclônica no oeste e ciclônica no leste do setor (Figura 3.56a). Essa configuração anômala gera anomalias de ventos de sul (Figura 3.58a), com anomalias negativas de temperatura do ar (Figura 3.59a). As anomalias de temperatura do ar no Pacífico tropical permanecem negativas e as anomalias de PNMM permanecem positivas, embora menos intensas que no lag $=0$.

O padrão de anomalias interanuais de PNMM e de temperatura do ar a 2 m foi muito semelhante ao observado por Yuan (2004), o qual verificou a evolução sazonal de eventos de La Niña a partir da primavera austral, quando as anomalias de TSM frias se acumularam no Pacífico tropical. Nessa estação a TSM e o gelo marinho sobre o Oceano Austral ainda não responderam claramente à forçante em um padrão coerente, apesar de um centro de baixa PNMM se desenvolver sobre o mar de Amundsen. Durante a próxima estação (DJF) os eventos frios atingem a maturidade, com amplas anomalias frias de TSM e temperatura em superfície no Pacífico tropical. No Oceano Austral, o centro de baixa PNMM move-se para leste, enquanto começa a estabelecerem-se anomalias negativas de TSM e temperatura em superfície no Pacífico Sul e anomalias positivas no mar de Weddell. A cobertura de gelo marinho está em seu mínimo no verão austral, embora uma fraca anomalia positiva no leste do mar de Ross e uma fraca anomalia negativa no mar de Weddell já existem no campo de gelo marinho. Nas três estações seguintes, o centro de baixa PNMM (que é uma parte do padrão PSA) estabelece no leste do Pacífico Sul e persiste. Ao mesmo tempo, as anomalias no DPA de TSM, temperatura em superfície e gelo marinho estão totalmente desenvolvidos e amplificados, persistindo enquanto as anomalias de TSM são atenuadas em evento de La Niña nos trópicos. As anomalias mais intensas na temperatura do ar e gelo marinho ocorrem no inverno austral (YUAN, 2004).

Em relação aos eventos EPGM no MW, durante o inverno austral, verifica-se que os campos atmosféricos na baixa troposfera apresentaram anomalias interanuais praticamente em fase oposta ou deslocadas em relação aos eventos ENGM. No caso da anomalia de PNMM no lag $=+365$, a anomalia anticiclônica sobre o MW está posicionada mais ao sul do setor e sobre o continente, e no oeste do MW predomina uma fraca anomalia ciclônica (Figura 3.56b). Sobre a região tropical do Pacífico a anomalia de PNMM é negativa, enquanto que a anomalia de temperatura do ar é positiva (Figura 3.59b). No lag $=-183$ a anomalia anticiclônica mais intensa sobre os MBA se estende sobre o oeste do MW, embora na região leste do setor a anomalia encontra-se em fase oposta ao evento ENGM, ou seja, a anomalia é ciclônica (Figura 3.56b). A anomalia negativa de PNMM e positiva de temperatura do ar permanecem sobre o Pacífico tropical (Figura 3.59b). No dia do evento EPGM as anomalias 
interanuais dos campos atmosféricos estão em fase oposta ao evento ENGM (Figura 3.56b). No lag $=+183$ predomina anomalia positiva de PNMM principalmente sobre o oeste e centro do MW (Figura 3.56b). No Pacífico tropical a anomalia de PNMM é negativa e a anomalia de temperatura do ar é positiva (Figura 3.59b), com fraca intensidade.

\section{a) ENGM}
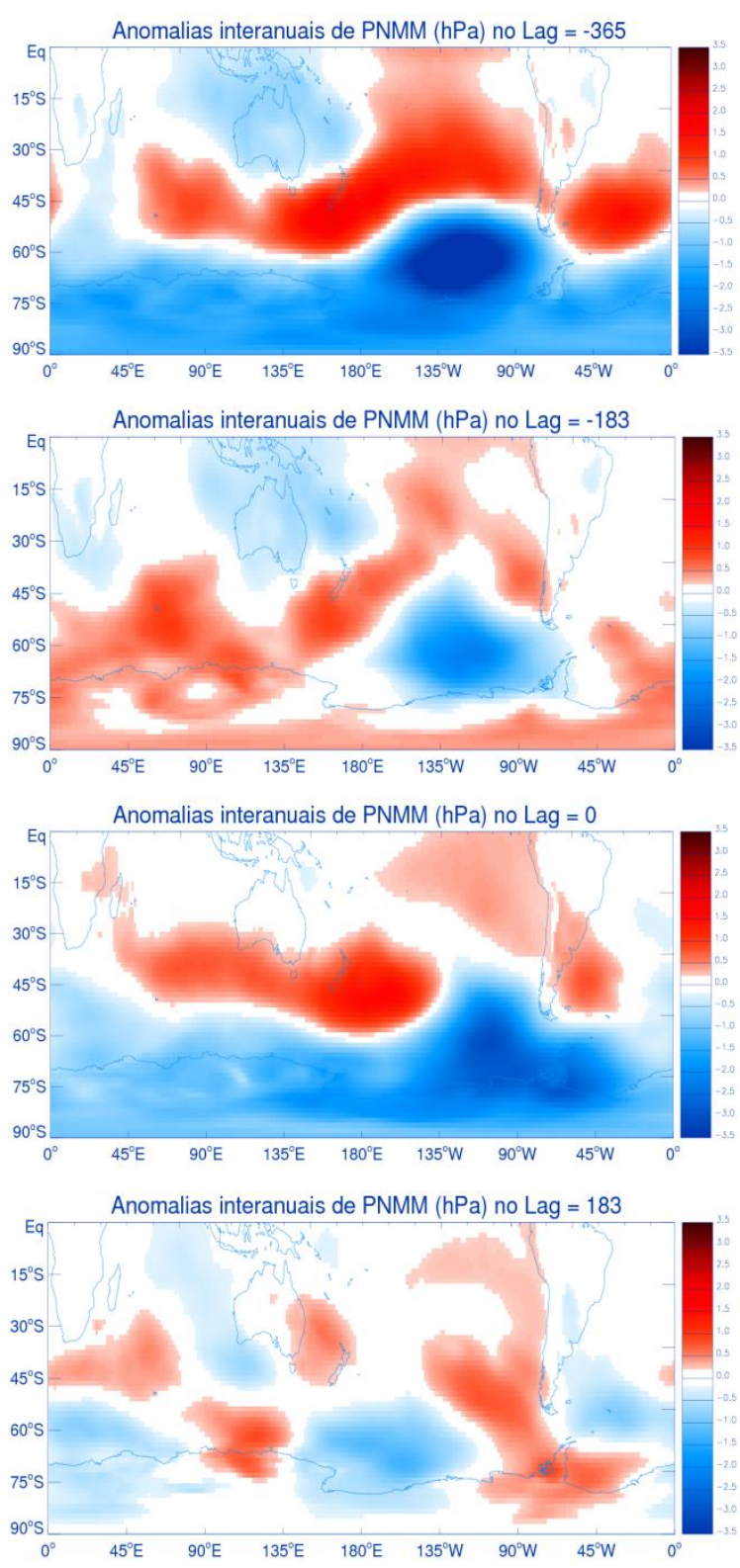

b) EPGM
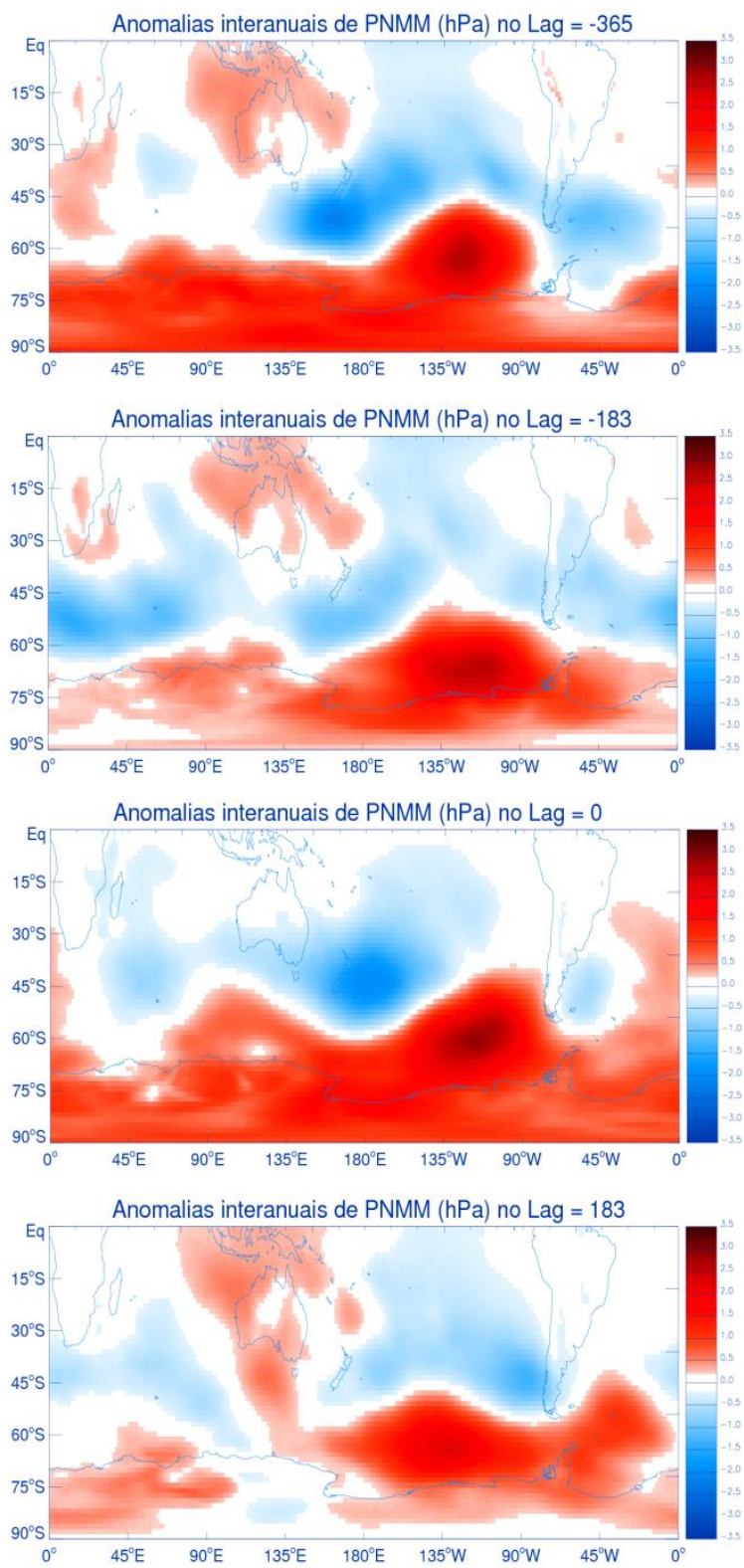

Figura 3.56: Composições defasadas das anomalias interanuais de PNMM (hPa) durante os eventos (a) ENGM e (b) EPGM no setor do MW, no lag $=-365$, lag $=-183$, lag $=0$ e lag $=+183$, no período de inverno austral (1989-2007). 
a) ENGM
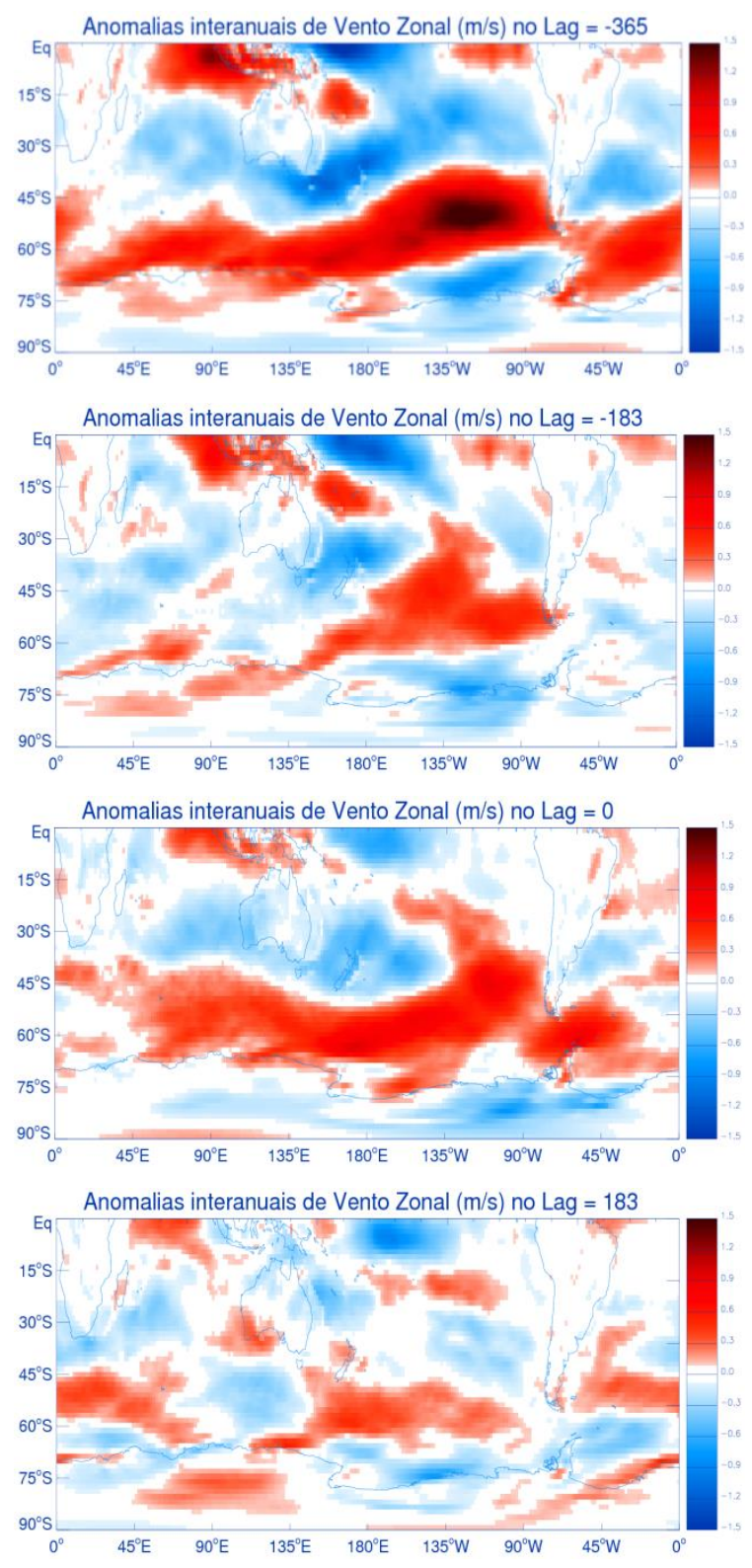

b) EPGM
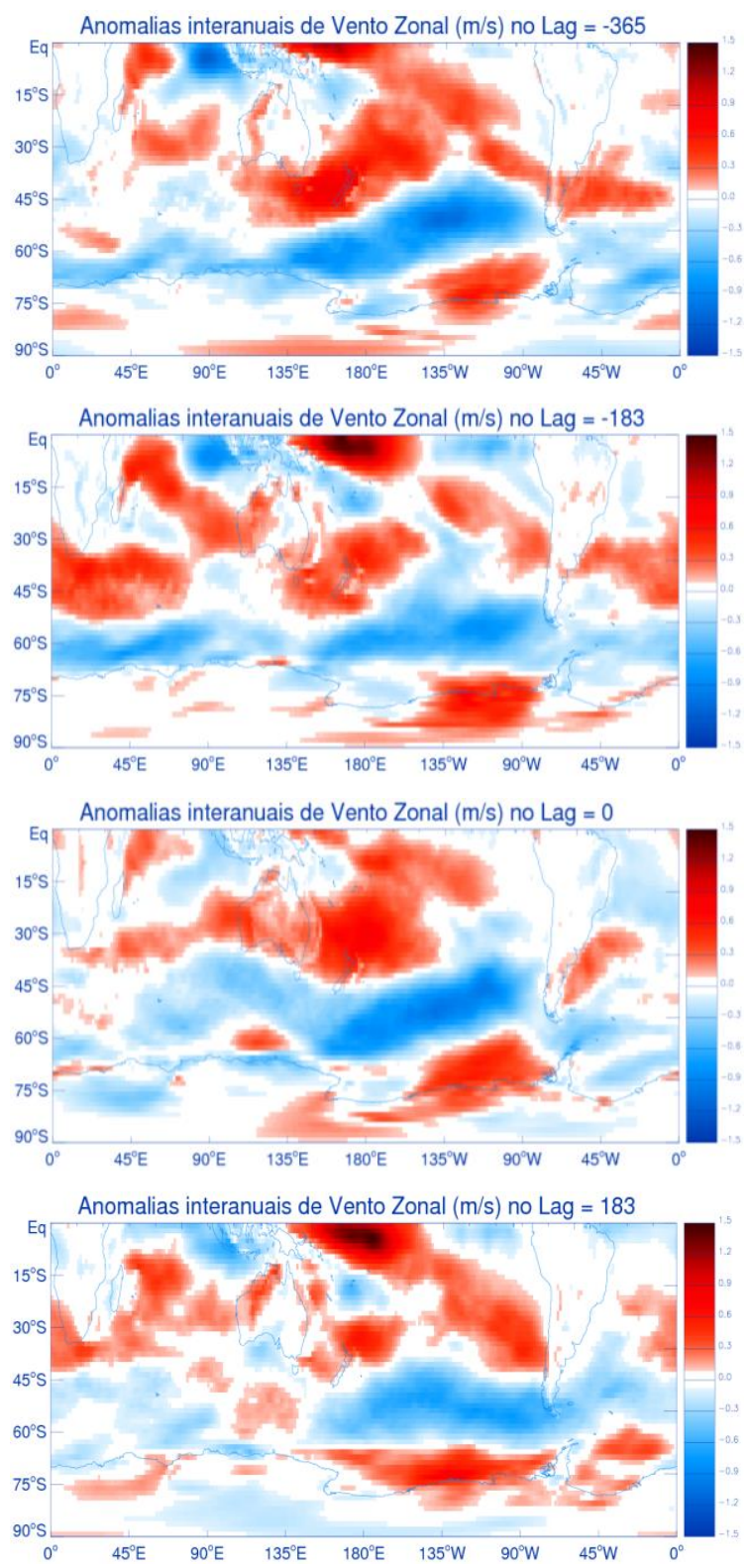

Figura 3.57: Similar à Figura 3.56, mas para as anomalias interanuais de vento zonal a $10 \mathrm{~m}(\mathrm{~m} / \mathrm{s})$. 
a) ENGM
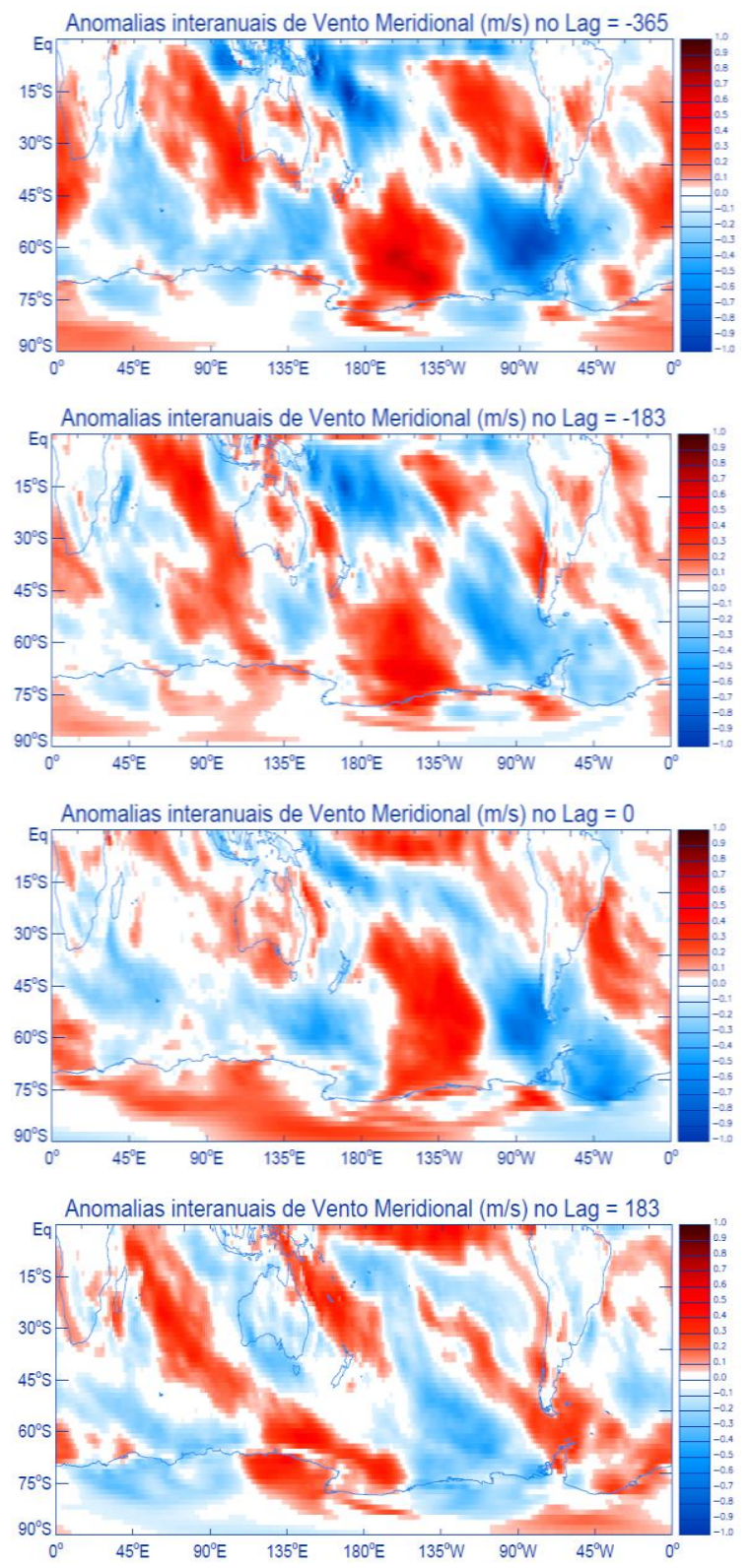

b) EPGM
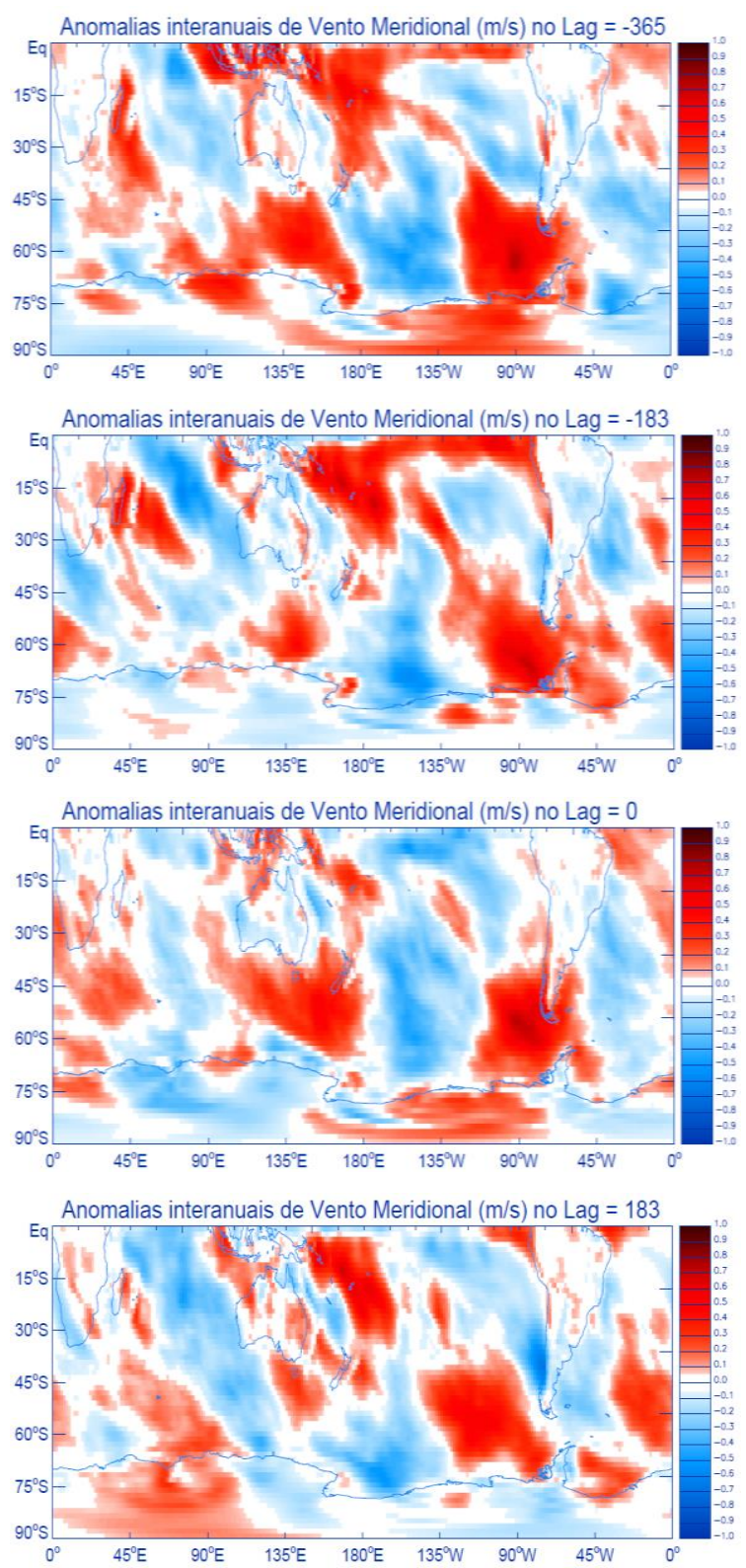

Figura 3.58: Similar à Figura 3.56, mas para as anomalias interanuais de vento meridional a $10 \mathrm{~m}$ $(\mathrm{m} / \mathrm{s})$. 
a) ENGM
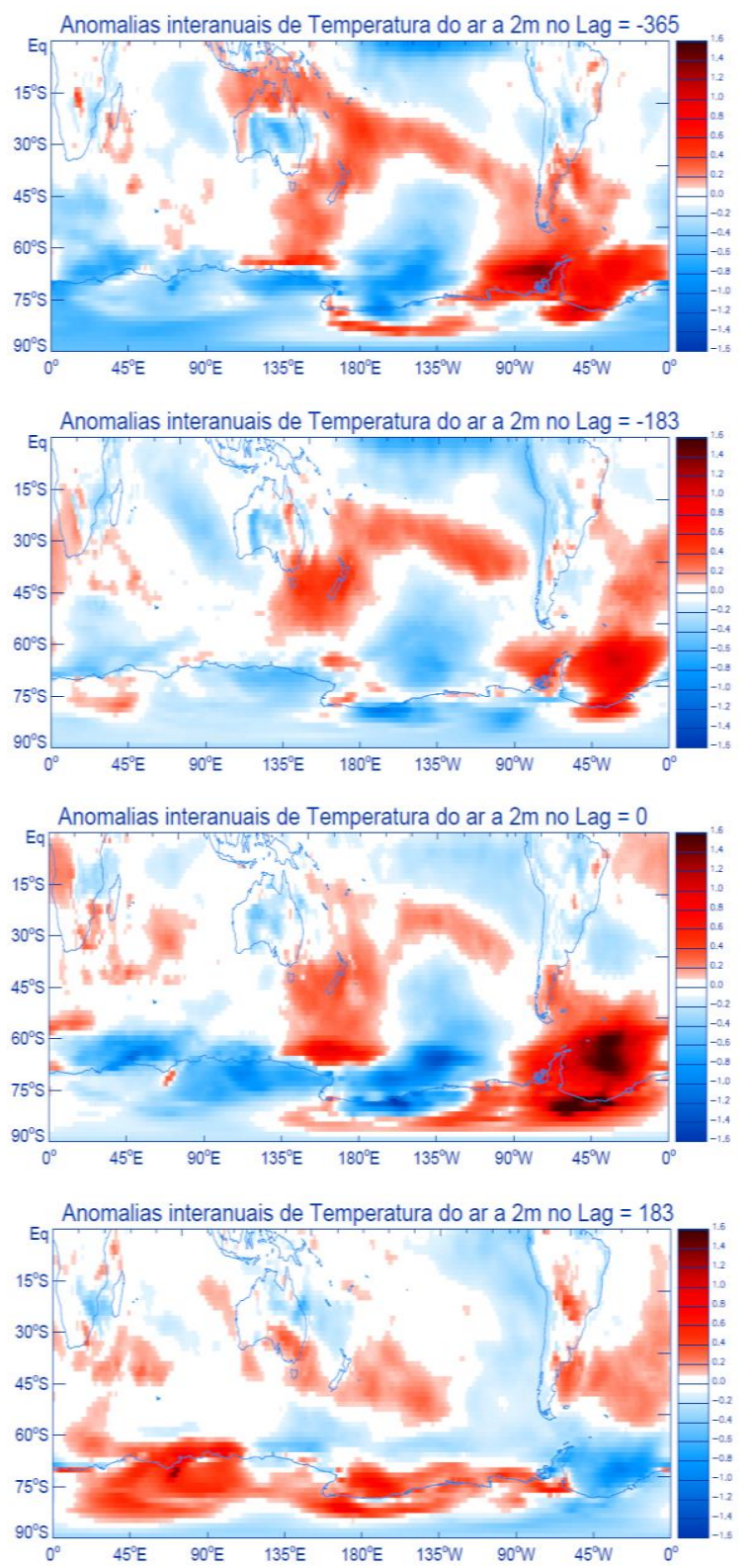

b) EPGM
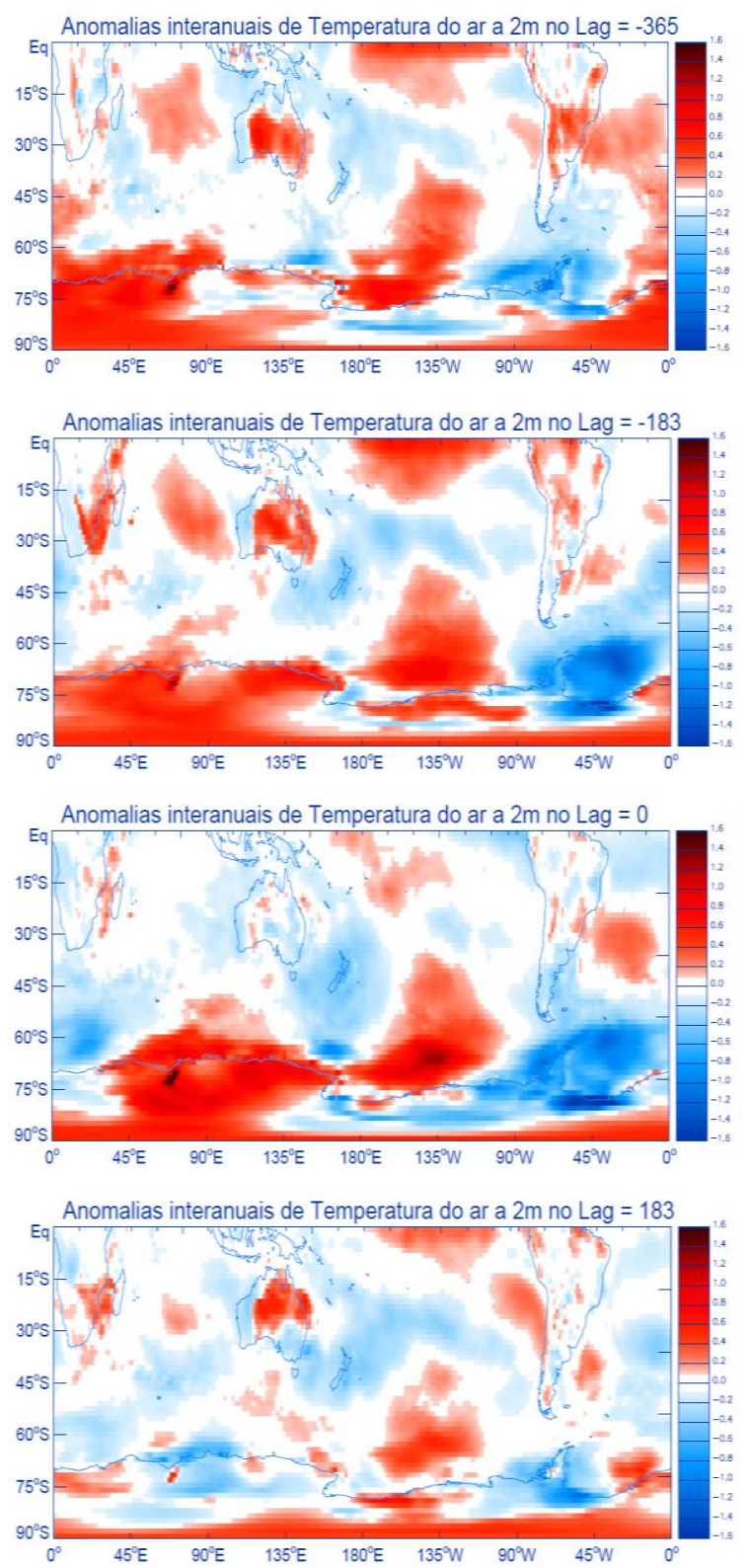

Figura 3.59: Similar à Figura 3.56, mas para as anomalias interanuais de temperatura do ar a $2 \mathrm{~m}$ $\left({ }^{\circ} \mathrm{C}\right)$. 
As anomalias de temperatura do ar e gelo marinho na região do DPA geralmente persistem por três a quatro estações após um evento de ENSO nos trópicos (YUAN, 2004). Isso justificaria o fato de os eventos ENGM e EPGM na escala interanual estarem associados com as anomalias dos campos atmosféricos ocorridos a partir de um ano antes do evento (lag = -365). Conforme Yuan (2004), o desenvolvimento de anomalias no DPA é diferente entre eventos frios e quentes de ENSO. O dipolo de anomalias de temperatura em superfície tem um melhor desenvolvimento temporal e persiste por mais tempo em caso de La Niña do que de El Niño, pois o El Niño apresenta uma maior variabilidade nas respostas de evento para evento em altas latitudes. Além disso, durante a primavera austral (SON), quando o El Niño está se desenvolvendo, a alta de bloqueio é rapidamente estabelecida no Pacífico Sudeste e gera anomalias de temperatura e gelo marinho no DPA na fase quente. Por outro lado, as anomalias de temperatura e gelo marinho no DPA na fase fria não são estabelecidas até o verão devido à grande variabilidade em todos os campos nesta fase inicial de desenvolvimento das anomalias no DPA na fase fria (YUAN, 2004).

\subsubsection{Verão austral: Setor dos Mares de Bellingshausen-Amundsen}

As composições em relação aos eventos ENGM nos MBA, durante o verão austral, apresentaram fracas anomalias negativas de PNMM sobre o mar de Ross e MBA no lag $=-365$, sendo mais intensas sobre a Península Antártica e no setor do MW (Figura 3.60a). Ao norte, observa-se uma faixa de anomalias positivas entre as latitudes de $45^{\circ}$ e $60^{\circ} \mathrm{S}$. As anomalias ciclônicas ao sul estão associadas com as anomalias de ventos de oeste no norte e de ventos de leste no sul (Figura 3.61a). Devido à fraca anomalia ciclônica sobre os MBA, fracas anomalias de vento meridional a $10 \mathrm{~m}$ e de temperatura do ar a $2 \mathrm{~m}$ são observadas. Contudo, no leste do setor verificam-se anomalias de ventos de sul (Figura 3.62a) e anomalias negativas de temperatura do ar (Figura 3.63a), associadas com a região oeste da anomalia ciclônica sobre a Península Antártica e MW. Na região do Pacífico tropical são observadas anomalias negativas de temperatura do ar. 
No lag = -183 , sobre os MBA e mar de Ross há uma intensa anomalia anticilônica (Figura 3.60a), associada com anomalias de ventos de leste no norte e de ventos de oeste no sul (Figura 3.61a). Essa circulação anômala resulta em anomalias de ventos de norte (Figura 3.62a), as quais promovem a incursão de ar relativamente aquecido para a região dos MBA, como pode ser observado pelas anomalias positivas de temperatura do ar a $2 \mathrm{~m}$ de mais de $+1,6^{\circ} \mathrm{C}$ (Figura 3.63a). No Pacífico tropical as anomalias de temperatura do ar estão em fase oposta ao lag $=-365$, apresentando assim anomalias positivas (Figura 3.63a) e anomalias negativas de PNMM.

No dia do evento ENGM, há um dipolo de anomalias de PNMM entre o sudoeste do Pacífico Sul/mar de Ross e os MBA/MW (Figura 3.60a). A anomalia ciclônica está associada com as anomalias de ventos de oeste no norte e de ventos de leste no sul (Figura 3.61a), enquanto que a anomalia anticiclônica está associada com as anomalias de ventos de leste no norte e de ventos de oeste no sul. Assim, configura-se uma circulação anômala de norte sobre o setor dos MBA (Figura 3.62a), a qual contribui para as anomalias positivas de temperatura do ar (Figura 3.63a). Na região tropical do Pacífico as anomalias positivas de temperatura do ar e negativas de PNMM permanecem, embora menos intensas. Por fim, no lag = +183 há um padrão de anomalias semelhante ao lag $=-183$, porém em fase oposta.

As anomalias interanuais dos campos atmosféricos em todos os casos (composições defasadas) de eventos EPGM (Figuras 3.60b, 3.61b, 3.62b, 3.63b) apresentam fases praticamente opostas em relação aos eventos ENGM. 
a) ENGM
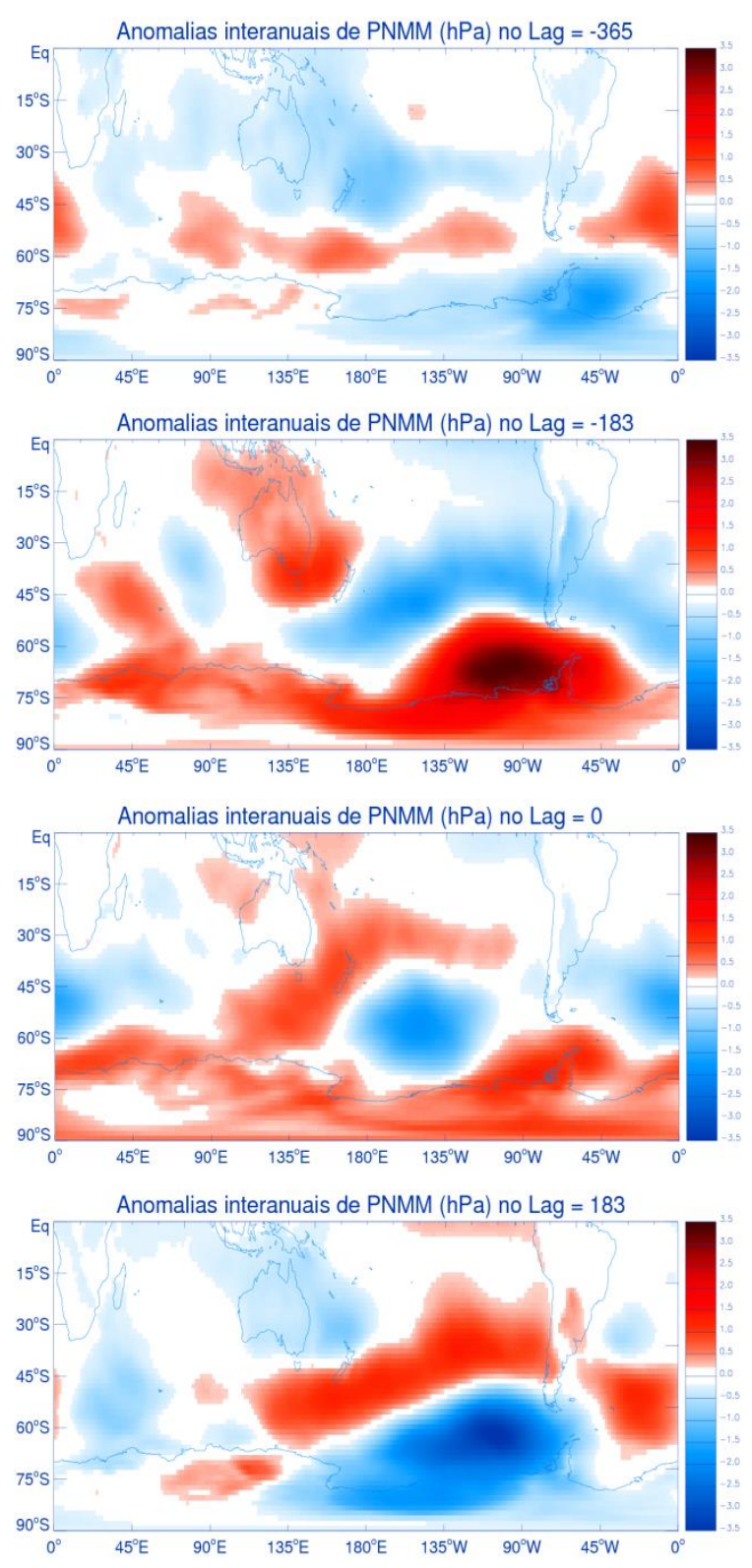

b) EPGM
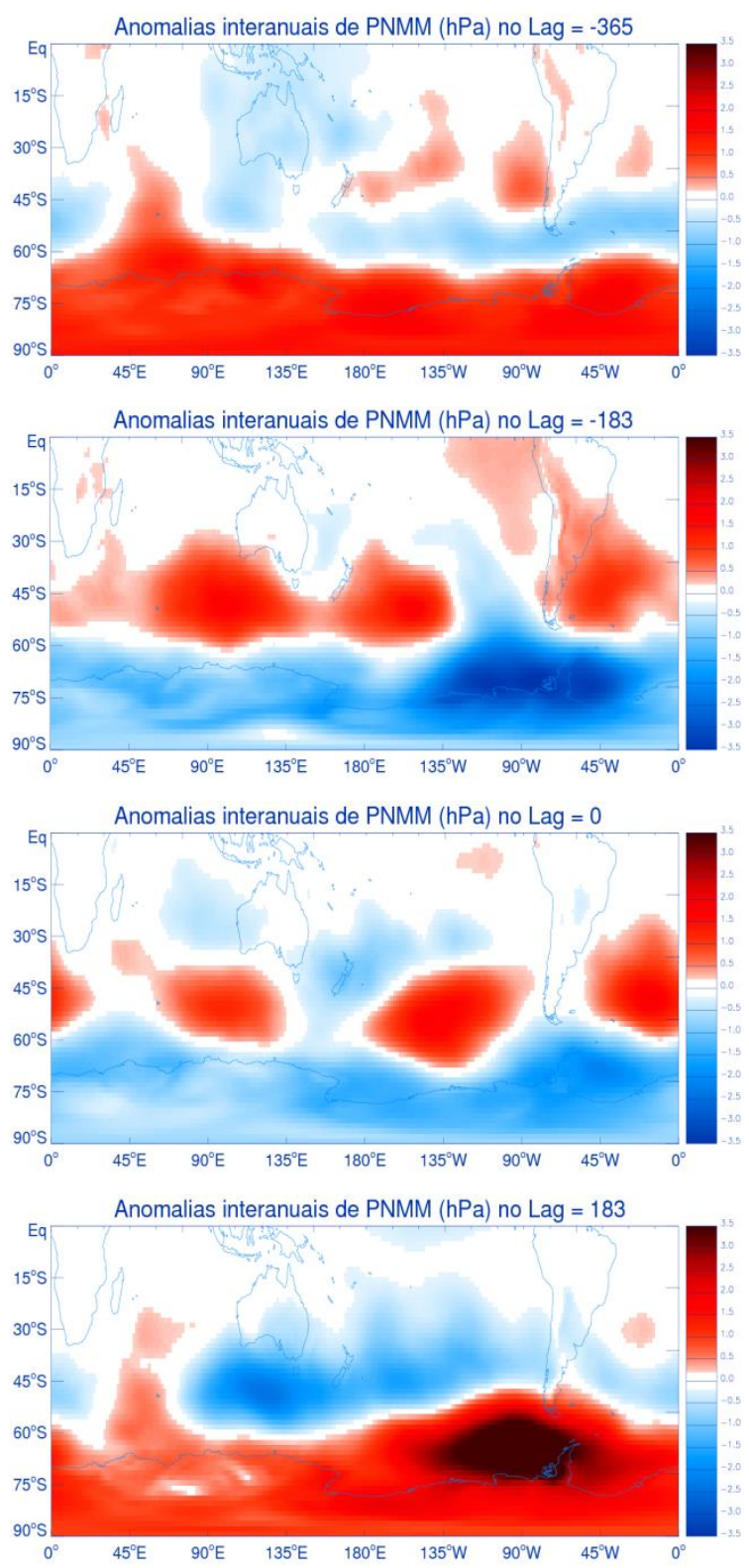

Figura 3.60: Composições defasadas das anomalias interanuais de PNMM (hPa) durante os eventos (a) ENGM e (b) EPGM no setor dos MBA, no lag $=-365$, lag $=-183$, lag $=0$ e lag $=+183$, no período de verão austral (1989-2007). 
a) ENGM
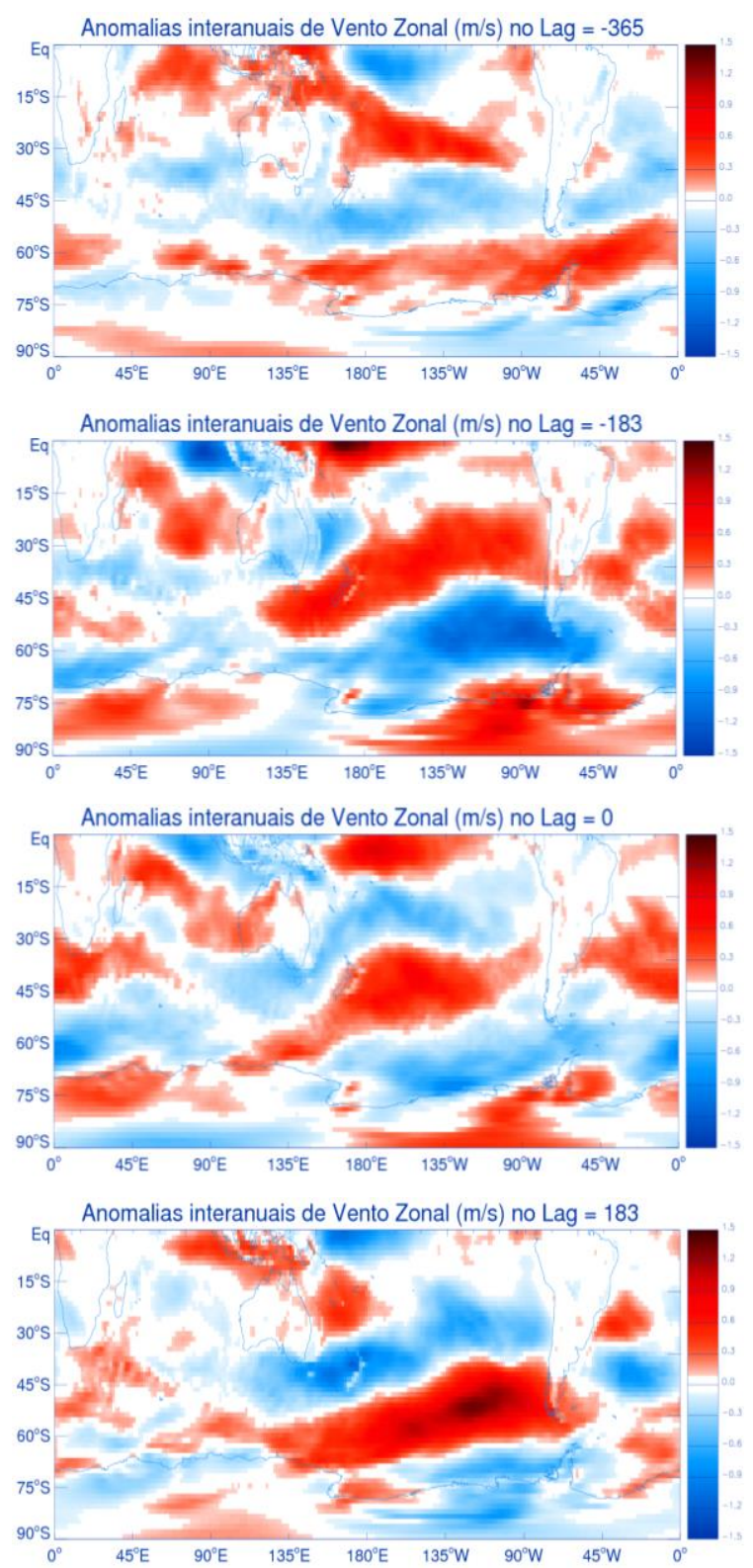

b) EPGM
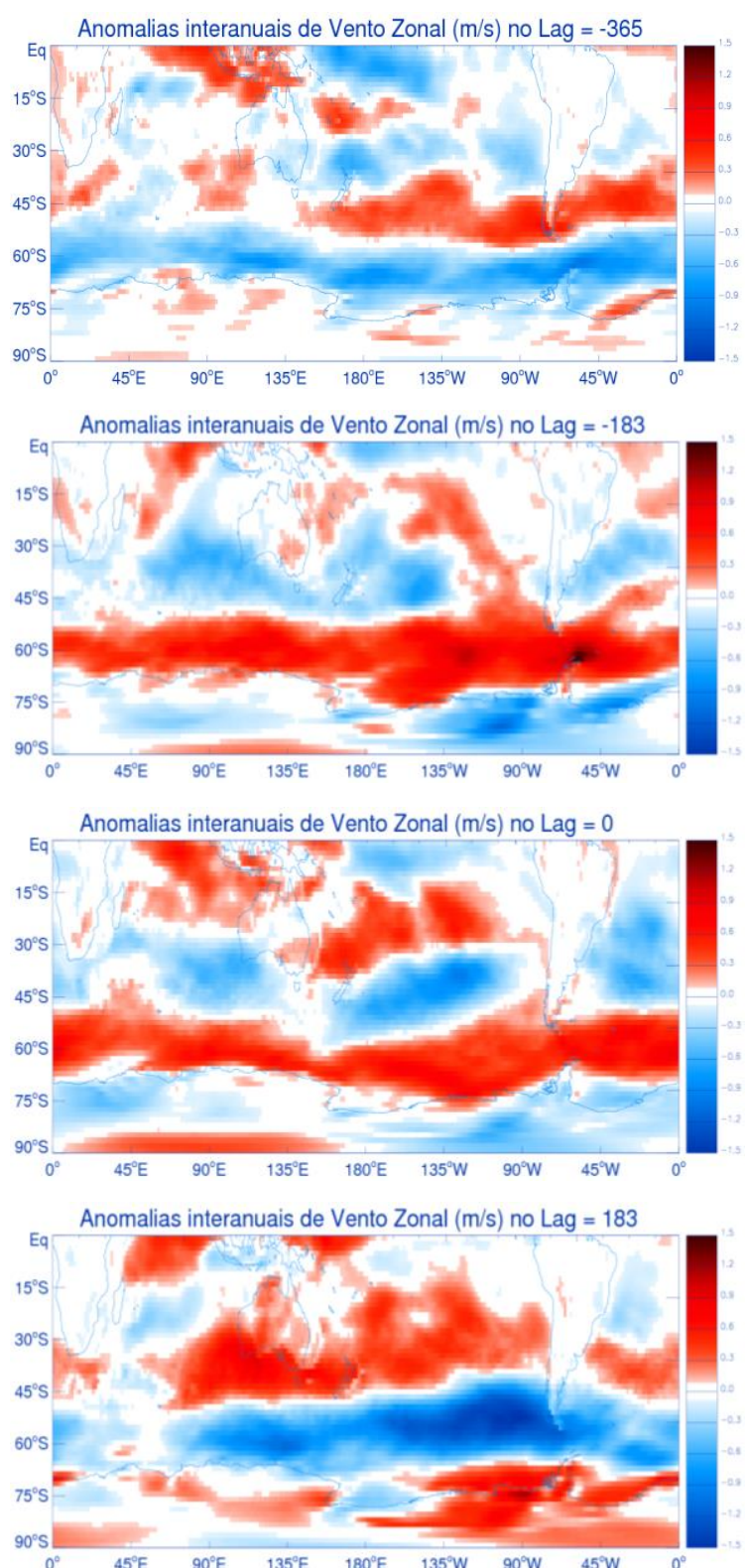

Figura 3.61: Similar à Figura 3.60, mas para as anomalias interanuais de vento zonal a $10 \mathrm{~m}$ (m/s). 
a) ENGM
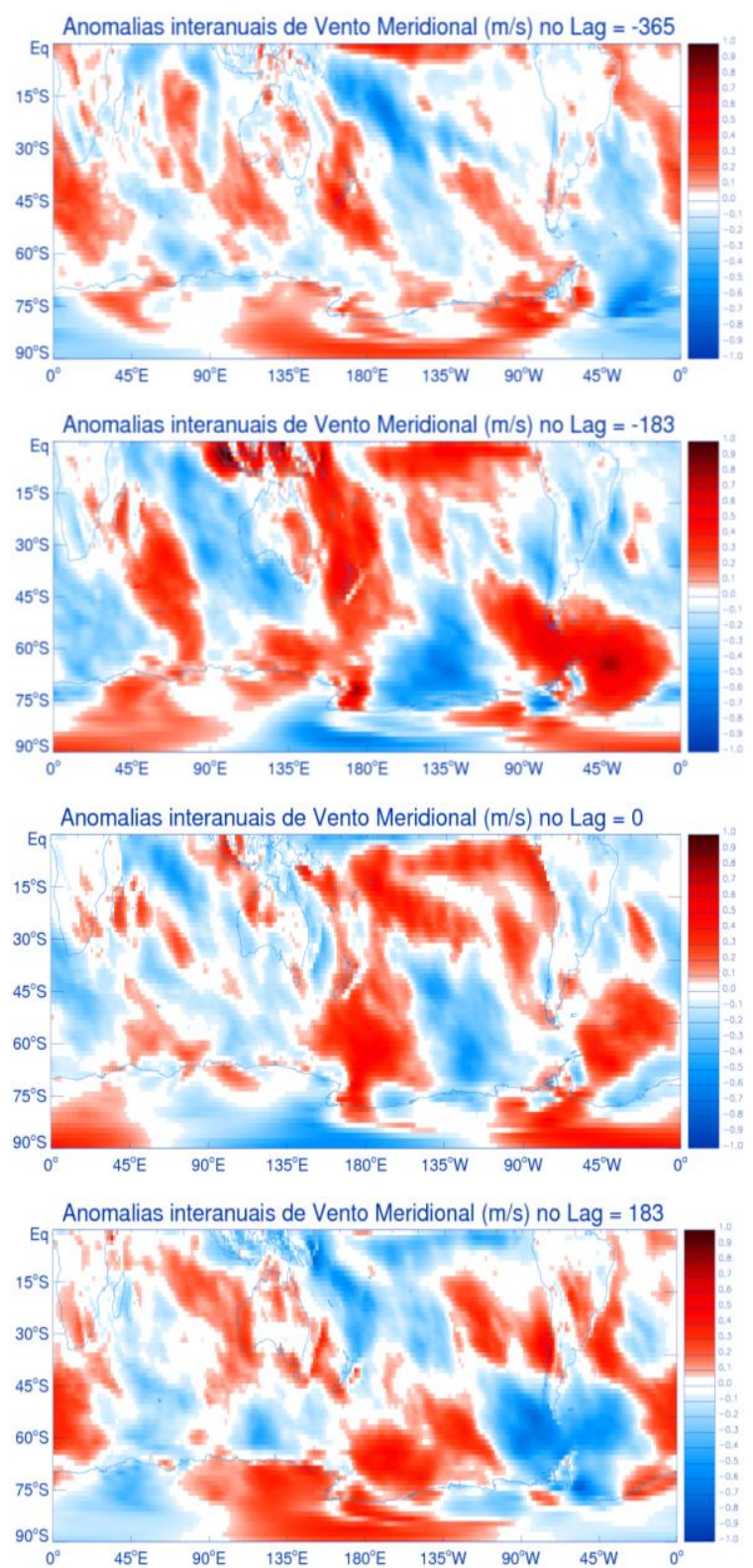

b) EPGM
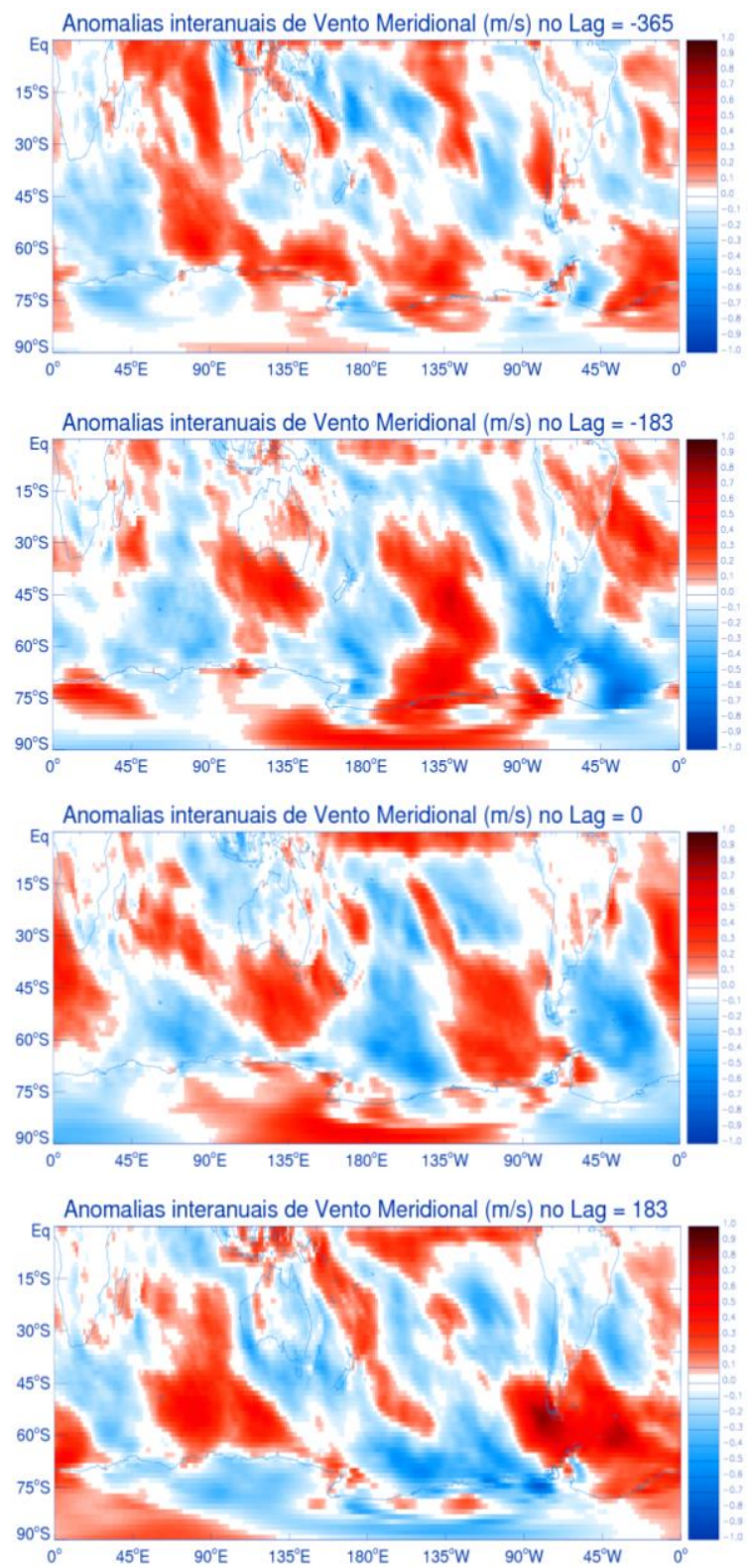

Figura 3.62: Similar à Figura 3.60, mas para as anomalias interanuais de vento meridional a $10 \mathrm{~m}$ $(\mathrm{m} / \mathrm{s})$. 
a) ENGM
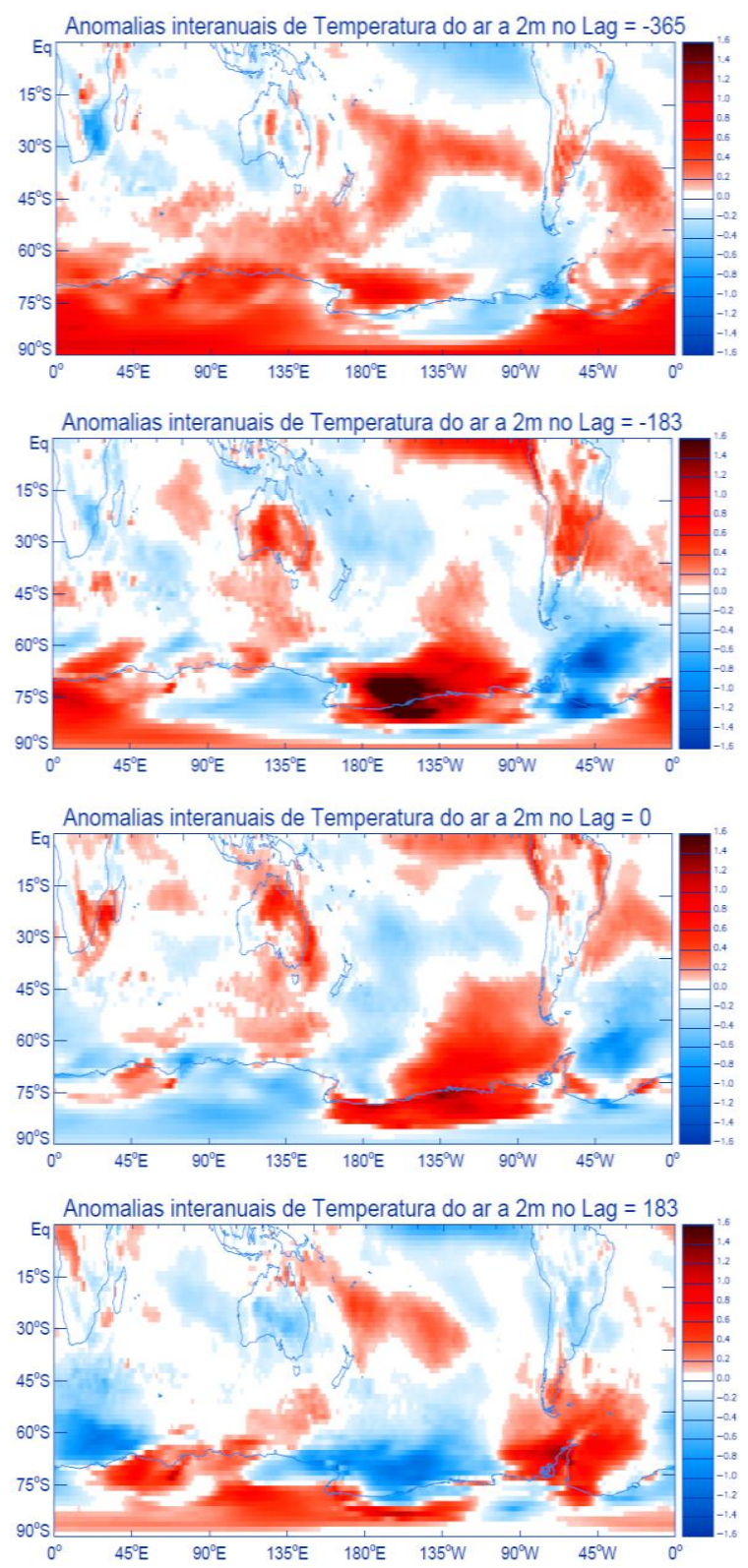

b) EPGM
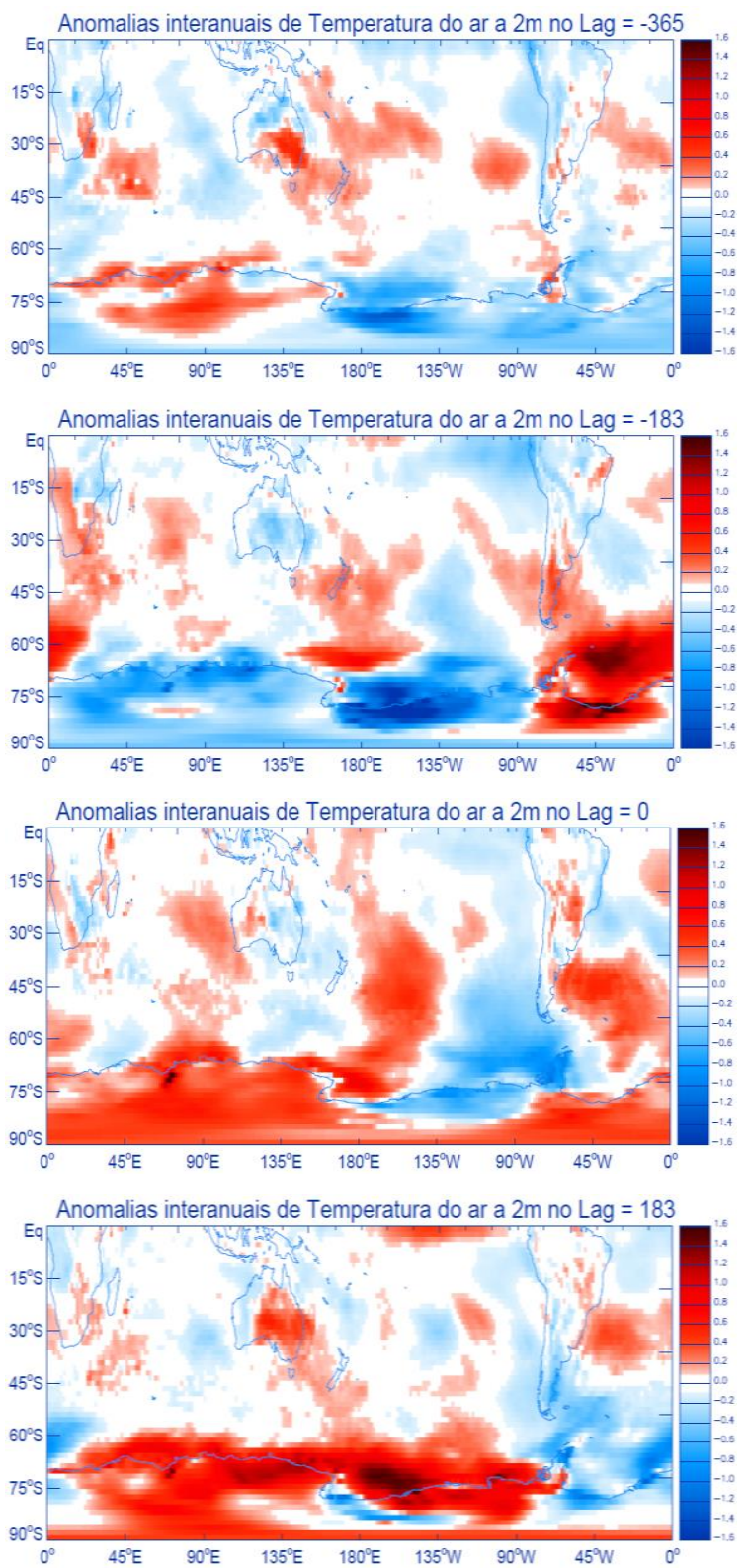

Figura 3.63: Similar à Figura 3.60, mas para as anomalias interanuais de temperatura do ar a $2 \mathrm{~m}$ $\left({ }^{\circ} \mathrm{C}\right)$. 


\subsubsection{Verão austral: Setor do Mar de Weddell}

No evento ENGM no MW, durante o verão austral, observa-se uma fraca anomalia anticiclônica sobre a Península Antártica e no oeste do MW (Figura 3.64a). Sobre grande parte do MW a anomalia é ciclônica. Observam-se anomalias de ventos de oeste na latitude de $45^{\circ} \mathrm{S}$, entre $90^{\circ}-180^{\circ} \mathrm{E}$ e $180^{\circ} \mathrm{W}-0^{\circ}$, e na latitude de $60^{\circ} \mathrm{S}$, entre $0^{\circ}$ e $90^{\circ} \mathrm{E}$ (Figura 3.65a). Ao sul dessas regiões a anomalia é de ventos de leste. Com esse padrão de circulação anômalo, sobre o oeste do MW gera-se uma anomalia de ventos de sul (Figura 3.66a) e uma anomalia negativa de temperatura do ar sobre a Península Antártica (Figura 3.67a). Sobre o leste do setor há uma anomalia de ventos de norte, associada com anomalias positivas de temperatura do ar sobre grande parte do MW. No Pacífico tropical a anomalia de temperatura do ar é positiva.

Aproximadamente 6 meses anteriores ao evento ENGM, no lag $=-183$, a anomalia de PNMM sobre todo o Oceano Austral é negativa, com um pico mais intenso sobre os MBA de até -3,5 hPa (Figura 3.64a). Associada a essa anomalia de PNMM observam-se anomalias de ventos de oeste em praticamente todo o Oceano Austral, com exceção da região costeira dos MBA e do oeste do MW (Figura 3.65a). Predomina sobre o MW e Península Antártica anomalia de ventos de norte (Figura 3.66a) e anomalia de temperatura do ar de até $+1,6^{\circ} \mathrm{C}$ (Figura 3.67a). Na região tropical do Pacífico a anomalia de temperatura do ar passa a ser negativa, enquanto que a anomalia de PNMM é positiva.

No dia do evento ENGM a anomalia ciclônica sobre o Oceano Austral desintensifica, apresentando seu pico sobre a Península Antártica (Figura 3.64a). O padrão de anomalias de vento zonal se mantém, embora menos intensas (Figura 3.65a). Já as anomalias de vento meridional são predominantemente negativas sobre o MW, com anomalias positivas no leste do setor (Figura 3.66a). Há um enfraquecimento das anomalias negativas de temperatura do ar sobre a região tropical do Pacífico, embora sejam mais abrangentes (Figura 3.67a). A anomalia de temperatura do ar é positiva sobre todo o MW. No lag $=+183$ há uma inversão de fase das anomalias sobre os MBA, Península Antártica e sobre grande parte do MW, além da região equatorial do Pacífico.

As anomalias interanuais dos campos atmosféricos em praticamente todos os casos (composições defasadas) de eventos EPGM (Figuras 3.64b, 3.65b, 3.66b, 3.67b) apresentam fases opostas em relação aos eventos ENGM. A exceção é no lag $=+183$, em que predominam anomalias em fase (anticiclônicas) com as anomalias no evento ENGM sobre os MBA, Península Antártica e no oeste do MW (Figura 3.64b), embora com menor intensidade. 
a) ENGM
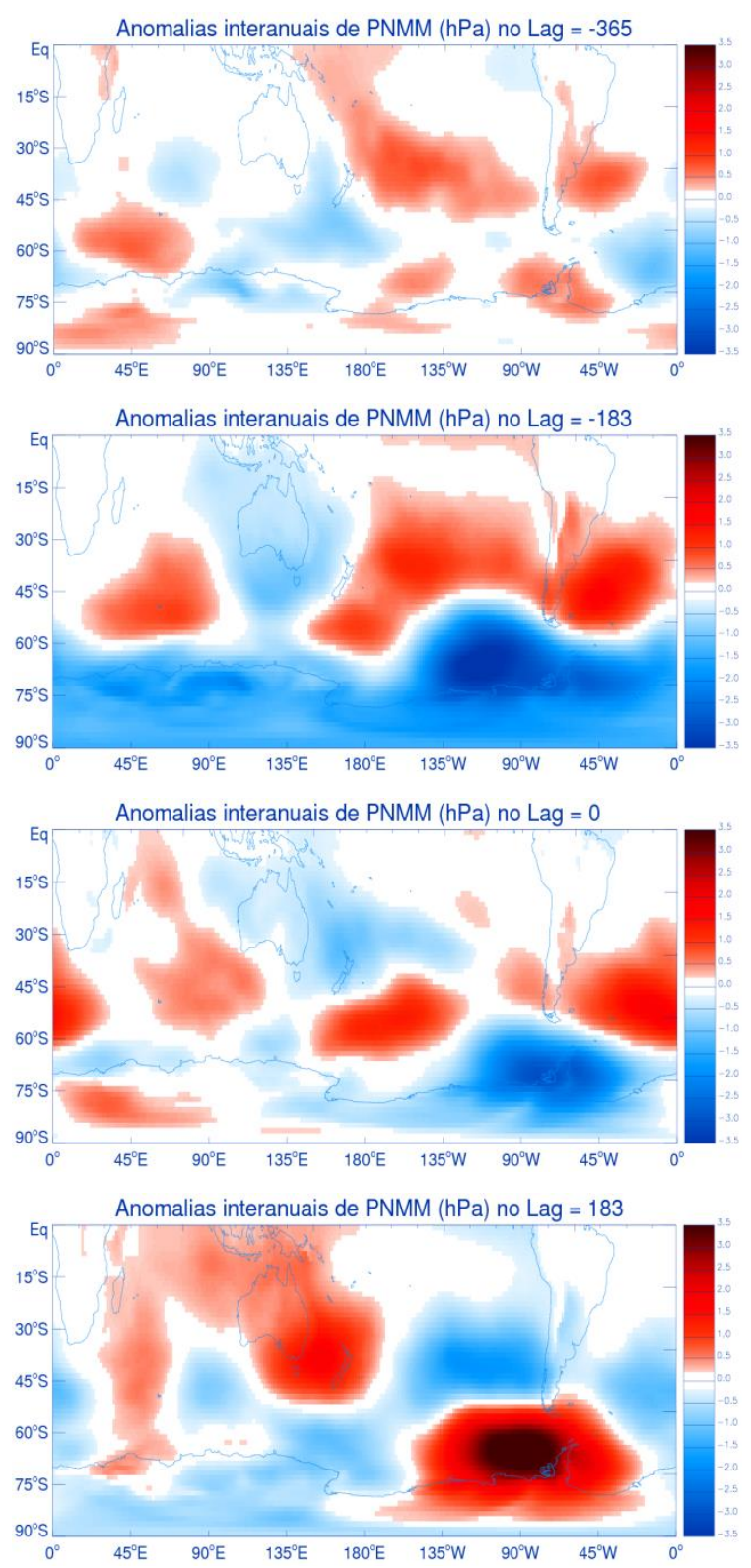

b) EPGM
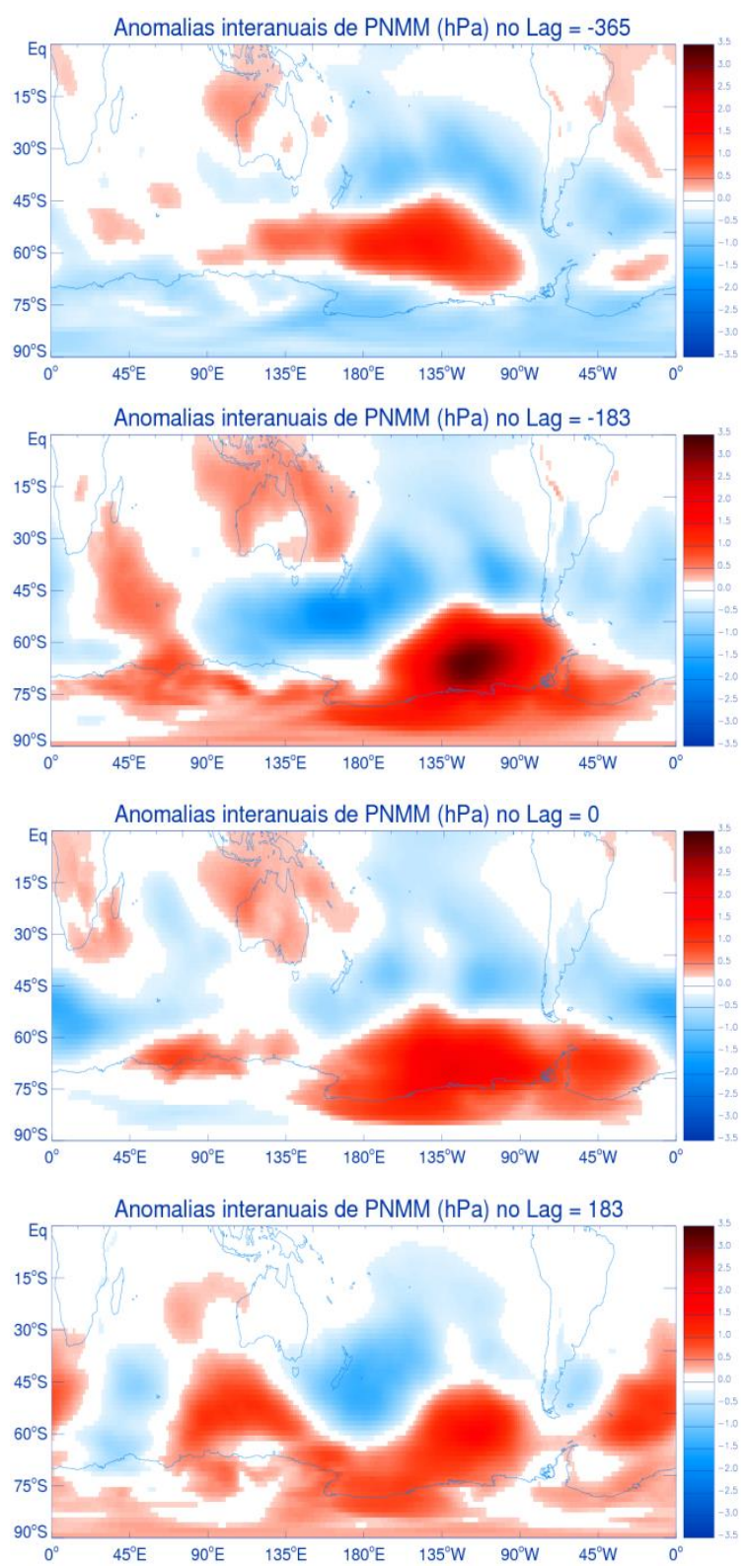

Figura 3.64: Composições defasadas das anomalias interanuais de PNMM (hPa) durante os eventos (a) ENGM e (b) EPGM no setor do MW, no período de verão (1989-2007), para (a) lag = -365, (b) lag $=-183$, (c) lag $=0$ e (d) lag $=+183$. 
a) ENGM
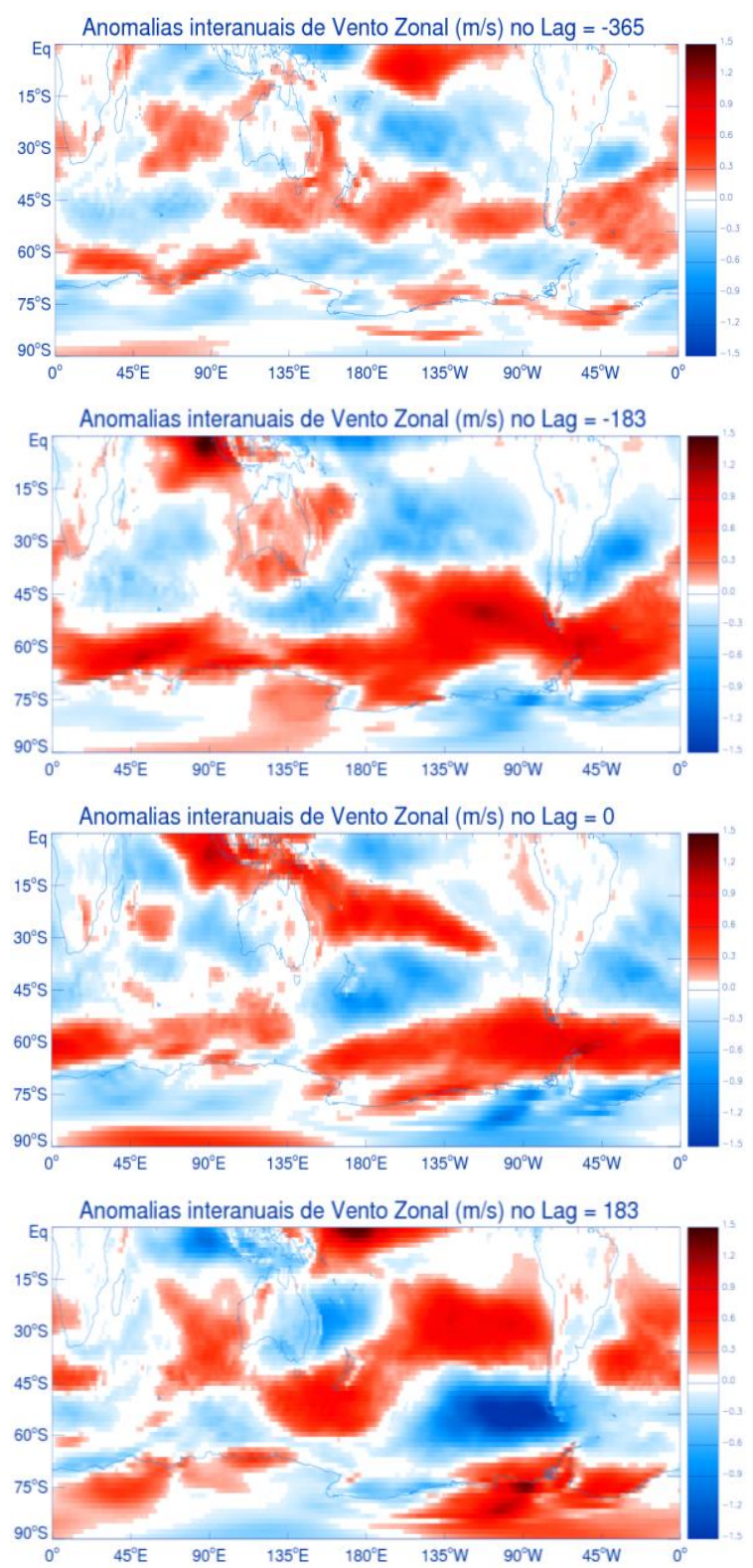

b) EPGM
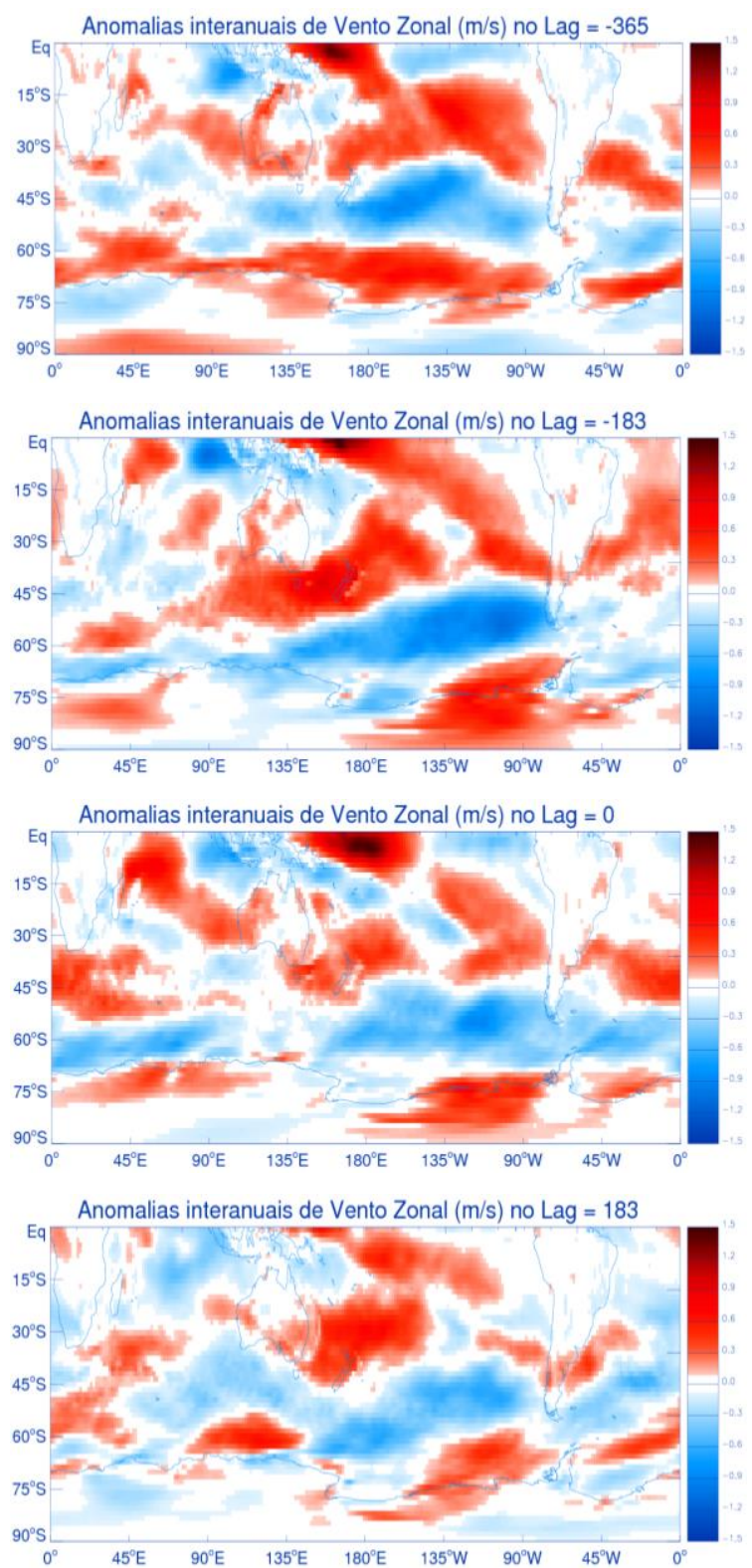

Figura 3.65: Similar à Figura 3.64, mas para as anomalias interanuais de vento zonal a $10 \mathrm{~m}(\mathrm{~m} / \mathrm{s})$. 
a) ENGM
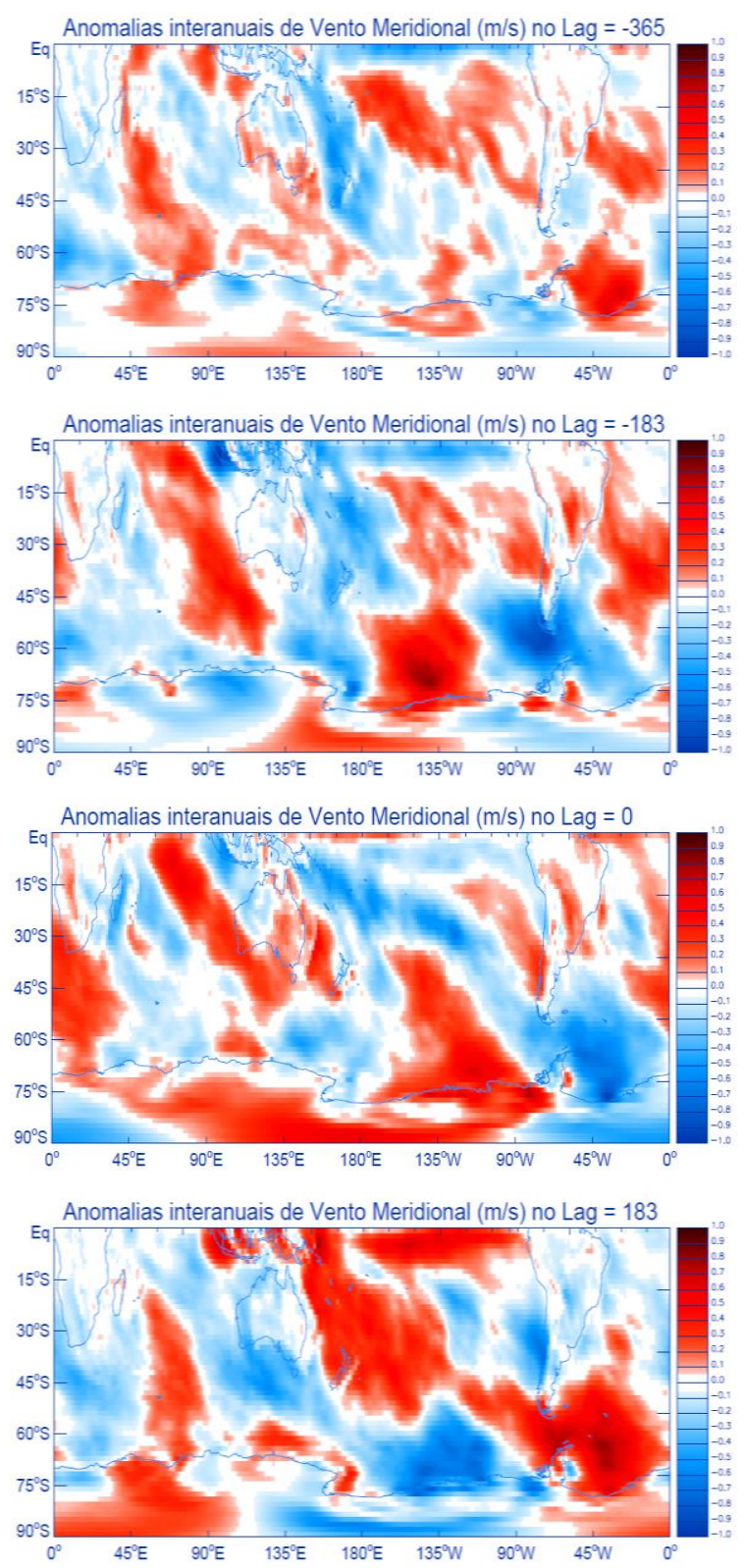

b) EPGM
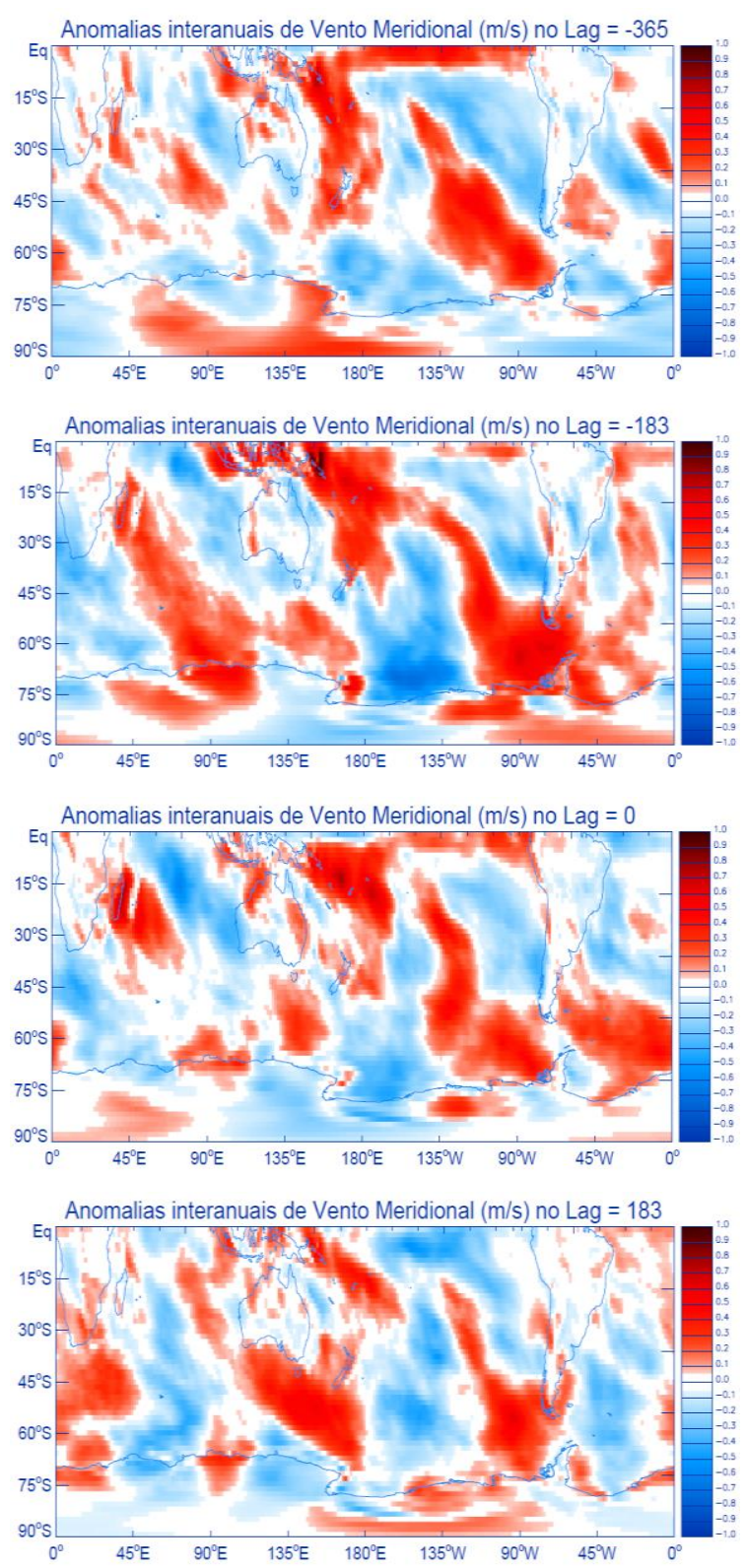

Figura 3.66: Similar à Figura 3.64, mas para as anomalias interanuais de vento meridional a $10 \mathrm{~m}$ $(\mathrm{m} / \mathrm{s})$. 
a) ENGM
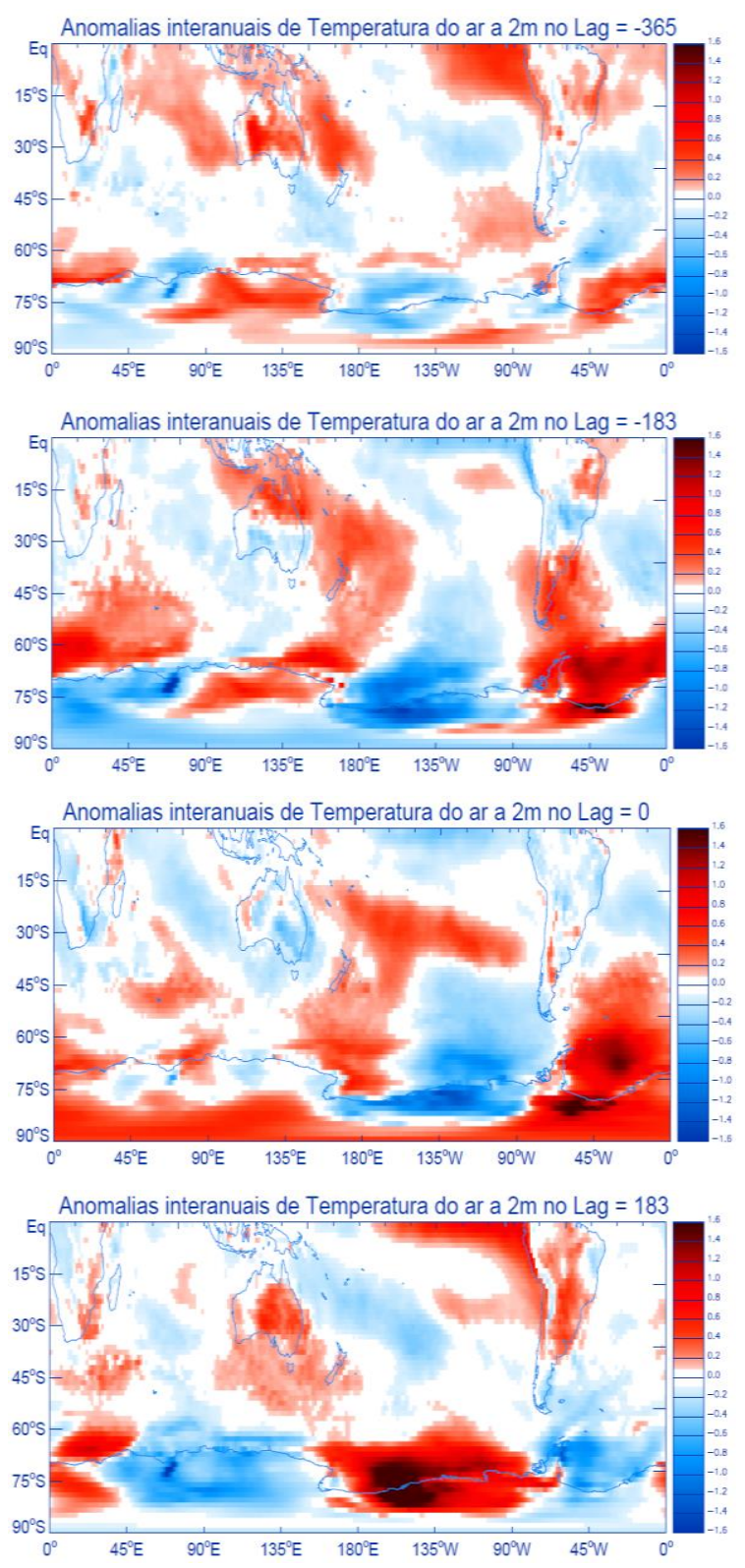

b) EPGM
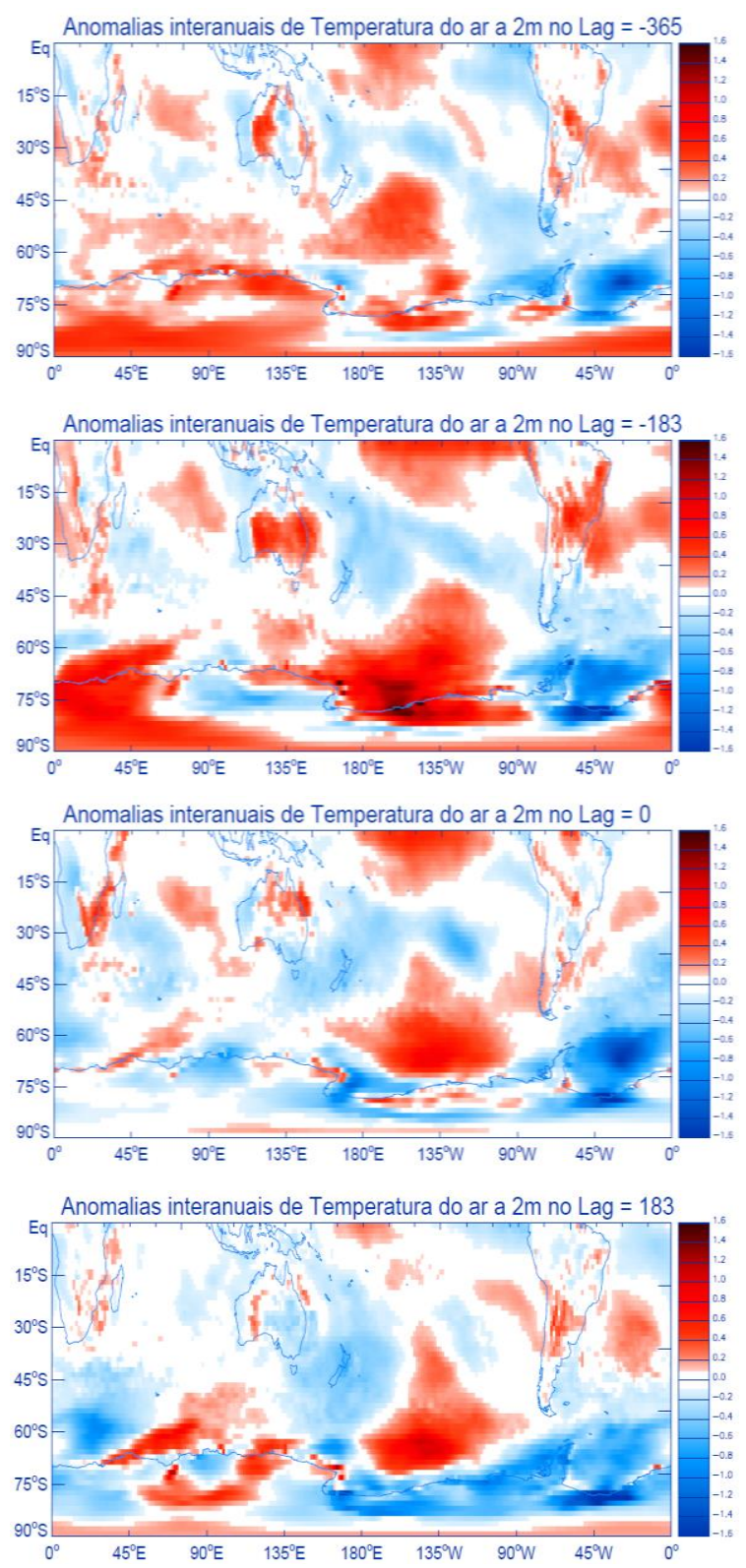

Figura 3.67: Similar à Figura 3.64, mas para as anomalias interanuais de temperatura do ar a $2 \mathrm{~m}$ $\left({ }^{\circ} \mathrm{C}\right)$. 
Portanto, na análise da influência da circulação atmosférica interanual na variabilidade extrema do gelo marinho na mesma escala de tempo, observou-se que no período de verão e inverno austral as características de circulação atmosférica e anomalias associadas ao fenômeno El Niño mostraram-se dominante sobre a variabilidade interanual da cobertura de gelo marinho nos setores dos MBA e MW. Contudo, é necessário ter cautela nessa consideração, pois as composições foram calculadas com um número pequeno de casos, impossibilitando o cálculo da significância estatística. No inverno, a partir do lag $=-365$ as anomalias positivas de temperatura do ar sobre a região do Pacífico equatorial estão associadas com as anomalias negativas de PNMM na região leste do Pacífico Sul e anomalias positivas sobre o setor dos MBA/sudeste do Pacífico Sul. Assim, há uma intensificação do escoamento de norte sobre os MBA, contribuindo para o aquecimento e, consequentemente, com os eventos ENGM neste setor. Simultaneamente há um enfraquecimento dos ventos de norte sobre a região do MW e, portanto, anomalias negativas de temperatura do ar, contribuindo para os eventos EPGM neste setor. Por outro lado, quando é observado resfriamento na região equatorial do Pacífico, as anomalias de PNMM sobre o leste do Pacífico Sul são positivas e sobre os MBA/sudeste do Pacífico Sul as anomalias são negativas. Portanto, há um enfraquecimento do escoamento de norte e, assim, anomalias negativas de temperatura do ar. Essa configuração anômala contribui para os eventos EPGM sobre os MBA. Ao mesmo tempo, sobre o MW há uma intensificação dos ventos de norte, contribuindo para as anomalias positivas de temperatura do ar e, deste modo, com os eventos ENGM neste setor. Durante o verão, o efeito das anomalias é igual ao inverno, porém está associado com os eventos ENGM/EPGM a partir do lag = -183. Assim, fases distintas do fenômeno El Niño contribuem para os eventos ENGM e EPGM com efeitos oposto entre o setor dos MBA e do MW. Ou seja, a fase de El Niño (La Niña) está associada com eventos ENGM (EPGM) nos MBA e com eventos EPGM (ENGM) no MW. Estes resultados estão de acordo com Yuan e Martinson (2000), Yuan e Martinson (2001), Yuan (2004). 


\subsection{Atividade ciclônica associada à variabilidade interanual da extensão do gelo marinho}

\subsubsection{Inverno austral}

A anomalia de densidade de ciclones entre os anos com as cinco maiores anomalias interanuais negativas menos as cinco maiores anomalias interanuais positivas de extensão de gelo marinho nos MBA no mês de julho (Tabela 2.2) foi positiva na região oeste-central do MW, no oeste do setor do Oceano Índico, na região central do setor do Oceano Pacífico Oeste, sobre a plataforma de gelo Ross e no oeste da Península Antártica (Figura 3.68a). Nestas três últimas regiões citadas, os valores de anomalias de densidade foram máximos, de até $+6,0 \times 10^{3}$ ciclones $\left({ }^{\circ} \text { lat }\right)^{-2}$. Nas demais regiões as anomalias foram negativas. A profundidade (Figura 3.68b) apresentou anomalias positivas em uma faixa entre o oeste dos MBA, setor do mar de Ross (com máxima de $+5,0 \mathrm{hPa}$ ), setor do Oceano Pacífico Oeste e oeste do setor do Oceano Índico, além do oeste do MW. No leste dos MBA e do MW as anomalias foram negativas, de até $-1,0 \mathrm{hPa}$. Em relação ao raio dos sistemas (Figura 3.68c) as anomalias foram predominantemente positivas sobre o Oceano Austral, praticamente sobre as regiões que apresentaram anomalias positivas de profundidade. Assim, as anomalias interanuais negativas de gelo marinho nos MBA, no mês de julho, estão associadas predominantemente com um aumento na profundidade e raio dos sistemas e alternância entre aumento e diminuição de densidade ao redor da Antártica.

As anomalias de densidade de sistemas em agosto foram predominantemente negativas no entorno do continente antártico, com valores de até $-5,0 \times 10^{3}$ ciclones $\left({ }^{\circ} \text { lat }\right)^{-2}$ no extremo leste do setor do Oceano Índico (Figura 3.68a). As anomalias positivas foram observadas na região leste do MW e oeste do setor do Oceano Índico. Analisando as anomalias de profundidade (Figura 3.68b), observa-se o predomínio de anomalias positivas no Oceano Austral (de até $+4,0 \mathrm{hPa}$ ). As anomalias de raio dos ciclones (Figura 3.68c) apresentaram valores predominantemente positivos no Oceano Austral. Desta forma, anomalias interanuais negativas de gelo marinho no setor dos MBA, no mês de agosto, estão associadas com diminuição na densidade de ciclones e aumento na profundidade e raio dos sistemas ao redor da Antártica.

A anomalia de densidade de sistemas no mês de setembro foi predominantemente positiva ao redor do continente, com valores de até $+5,0 \times 10^{3}$ ciclones $\left({ }^{\circ} \text { lat }\right)^{-2}$ sobre os MBA, região oeste do mar de Ross, leste do setor do Oceano Pacífico Oeste e extremo oeste do setor do Oceano Índico (Figura 3.68a). As anomalias negativas foram observadas nas 
demais regiões, com valores de até $-5,0 \times 10^{3}$ ciclones $\left({ }^{\circ} \text { lat }\right)^{-2}$ na região leste do setor do mar de Ross. A anomalia de profundidade (Figura 3.68b) ao redor do continente foi positiva no oeste e leste da Península Antártica, no extremo oeste e no leste do setor do Oceano Índico, sobre todo o setor do Oceano Pacífico Oeste e no oeste do setor do mar de Ross. No restante do Oceano Austral as anomalias foram negativas, de até $-5 \mathrm{hPa}$ na região central do $\mathrm{MW}$. Predominaram anomalias positivas de raio sobre o Oceano Austral (Figura 3.68c). Desta forma, no mês de setembro as anomalias interanuais negativas de gelo marinho no setor dos MBA estão associadas principalmente com maior densidade, profundidade e raio dos ciclones ao redor do continente antártico.

a)
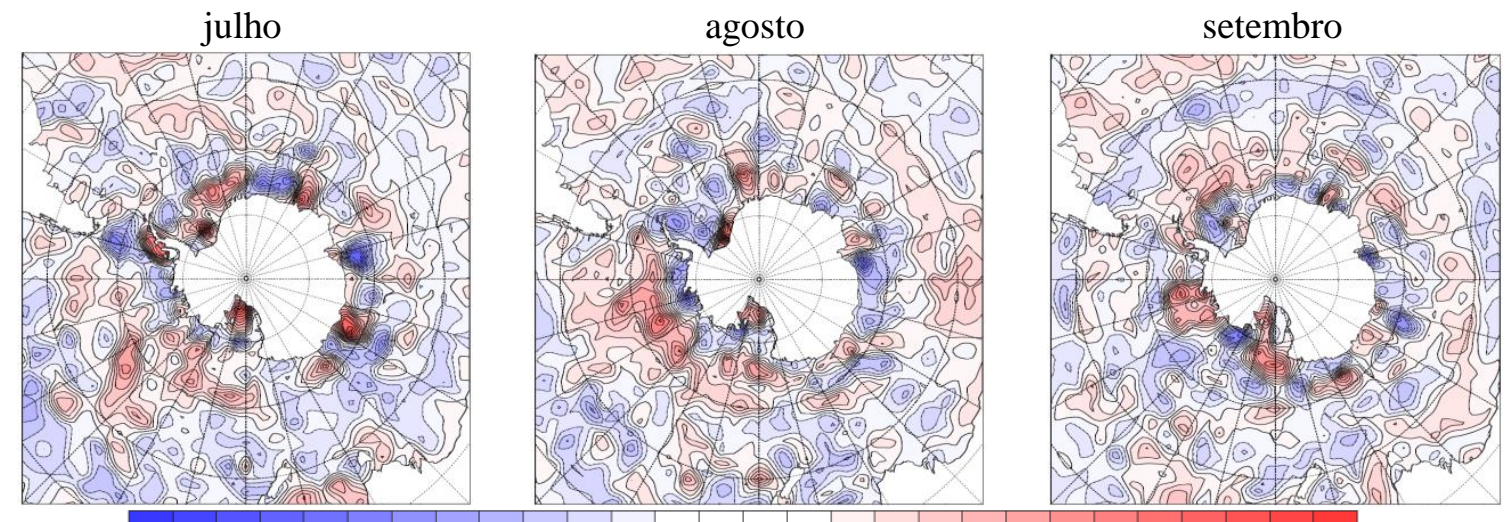

b)

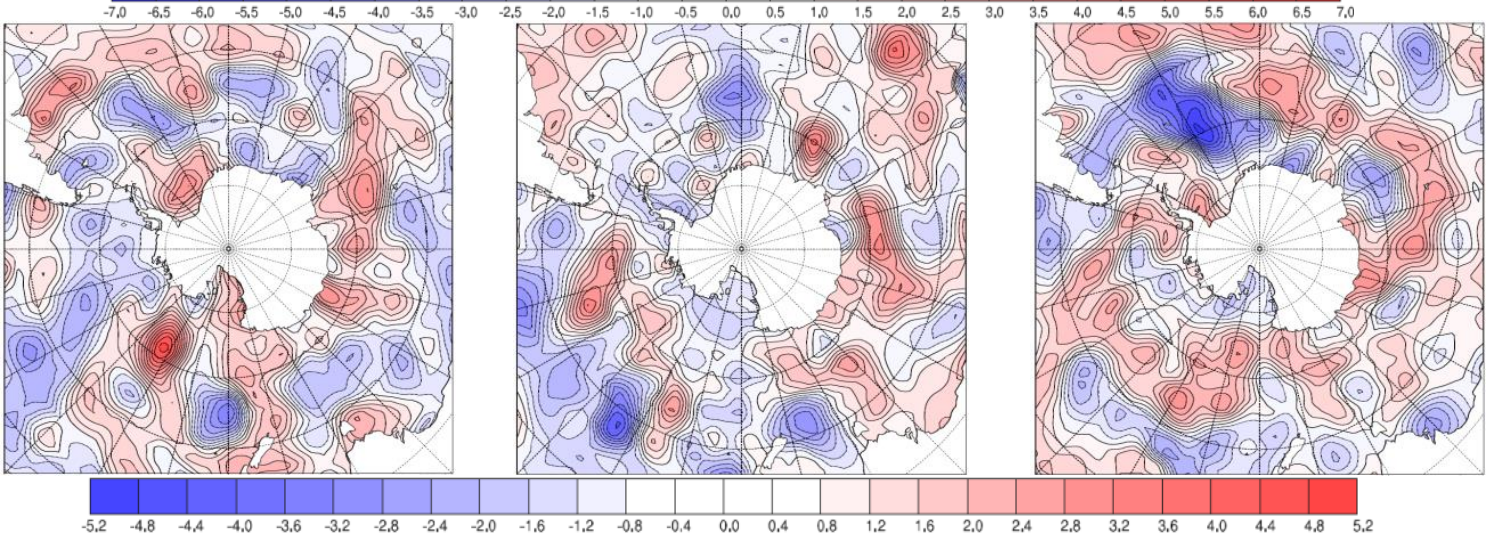

c)

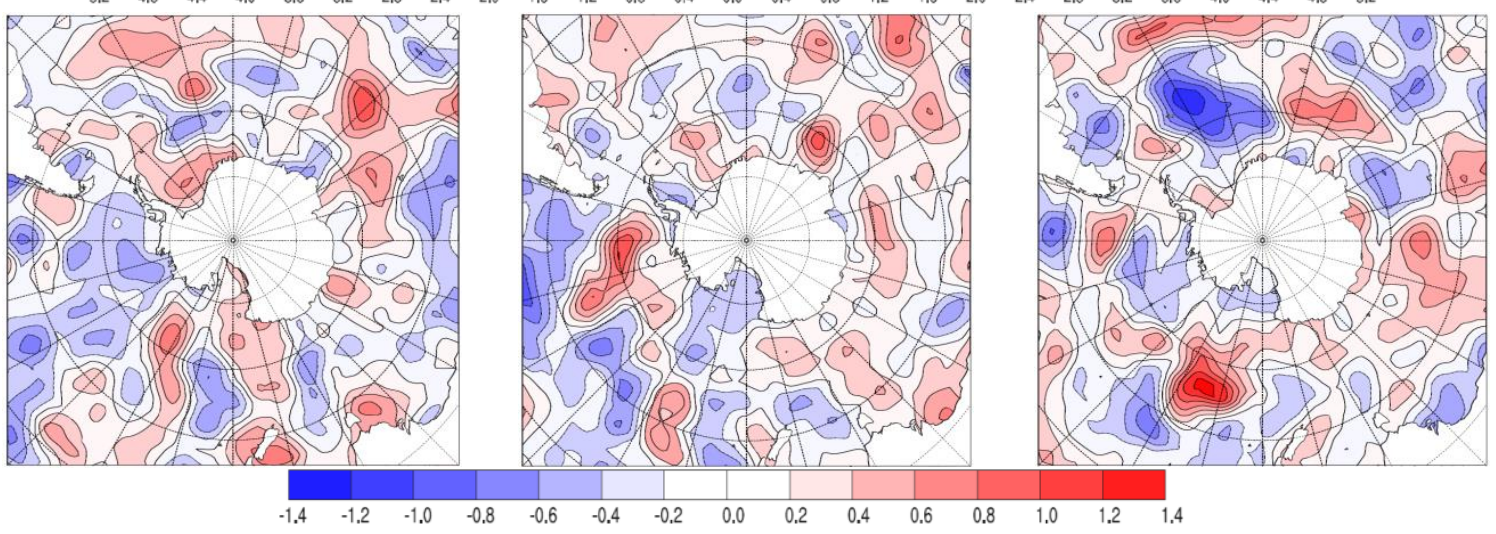

Figura 3.68: Composições de (a) densidade [número de sistemas por $10^{3}\left({ }^{\circ} \text { lat }\right)^{-2}$ ], (b) profundidade $(\mathrm{hPa})$ e (c) raio $\left({ }^{\circ}\right.$ lat) dos ciclones, entre os cinco meses com maiores anomalias interanuais negativas menos os cinco meses com maiores anomalias interanuais positivas de gelo marinho no setor dos MBA, nos meses de julho, agosto e setembro. 
Já em relação às anomalias de extensão de gelo marinho no setor do MW em julho (Tabela 2.3), as anomalias de densidade (Figura 3.69a) foram bastante variáveis ao redor do continente, apresentando anomalias negativas na região centro-oeste do MW, em grande parte do setor do Oceano Índico, na região central do setor do Oceano Pacífico Oeste e no leste do setor do mar de Ross. Os maiores valores negativos foram observados nos setores do Oceano Índico e no leste do mar de Ross, de até $-4,0 \times 10^{3}$ ciclones $\left({ }^{\circ} \text { lat }\right)^{-2}$. As anomalias positivas foram encontradas nas demais regiões, com valores de até $+7,0 \times 10^{3}$ ciclones $\left({ }^{\circ} \text { lat }\right)^{-2}$ na região leste do setor dos MBA. As anomalias de profundidade (Figura 3.69b) foram predominantemente positivas, variando entre $+1,0$ a $+3,0 \mathrm{hPa}$ no Oceano Austral, com exceção da região central do setor do mar de Ross e do noroeste da Península Antártica $(-3,0 \mathrm{hPa})$. Em relação às anomalias de raio dos sistemas (Figura 3.69c), os valores foram no geral negativos sobre o Oceano Austral. Portanto, retração de gelo marinho na escala interanual no setor do MW, no mês de julho, está associada principalmente com aumento/diminuição na densidade, aumento na profundidade e diminuição no raio dos sistemas ao redor da Antártica.

No mês de agosto, em relação às anomalias de gelo marinho no setor do MW, as anomalias de densidade de ciclones (Figura 3.69a) foram predominantemente negativas próximas ao continente antártico. As anomalias positivas foram observadas na região leste do setor do Oceano Índico, oeste e leste do Oceano Pacífico Oeste e setor do mar de Ross, o qual apresentou a maior anomalia positiva $\left(+5,0 \times 10^{3}\right.$ ciclones $\left.\left({ }^{\circ} \text { lat }\right)^{-2}\right)$. Predominaram anomalias negativas de profundidade ao redor da Antártica (Figura 3.69b), com valores de até $+3,0 \mathrm{hPa}$ no noroeste da Península Antártica. Valores de anomalias negativas também foram observados nos MBA, setor do Oceano Pacífico Oeste, região leste e oeste do setor do Oceano Índico, bem como sobre o MW. No restante da área as anomalias foram positivas, variando de +1 a $+3 \mathrm{hPa}$. As anomalias de raio (Figura 3.69c) foram predominantemente negativas no Oceano Austral, de até $+1,0^{\circ}$ lat no centro-oeste do MW. Portanto, retração de gelo marinho na escala interanual, no setor do MW em agosto, está relacionada predominantemente com menor densidade, profundidade e raio de sistemas sobre o Oceano Austral.

Em setembro, as anomalias de densidade apresentaram uma alternância entre valores positivos e negativos ao redor do continente, nas altas latitudes (Figura 3.69a). As anomalias positivas foram observadas no setor do MW, no extremo leste do setor do Oceano Índico, no extremo oeste e no leste do setor do Oceano Pacífico Oeste, na região oeste e leste (máxima anomalia positiva de $+5,0 \times 10^{3}$ ciclones $\left.\left({ }^{\circ} \text { lat }\right)^{-2}\right)$ do setor do mar de Ross e no oeste dos 
MBA. Já as anomalias negativas máximas foram de $-5,0 \times 10^{3}$ ciclones $\left({ }^{\circ} \text { lat }\right)^{-2}$ na região central do setor do mar de Ross. As anomalias de profundidade (Figura 3. 69b) foram predominantemente positivas ao redor da Antártica, com exceção do setor do MW e da região oeste do setor do Oceano Índico, que apresentaram valores de anomalia variando entre -1,0 e $-2,0 \mathrm{hPa}$. Predominaram anomalias positivas de raio (Figura 3. 69c) no Oceano Austral, com valores de até $+1,5^{\circ}$ lat na região centro-oeste do setor dos MBA e de $-1,0^{\circ}$ lat no leste do MW. Assim, retração de gelo marinho no setor do MW na escala interanual está associada com aumento/diminuição na densidade, maior profundidade e raio dos sistemas em superfície sobre as altas latitudes do Oceano Austral.

a)
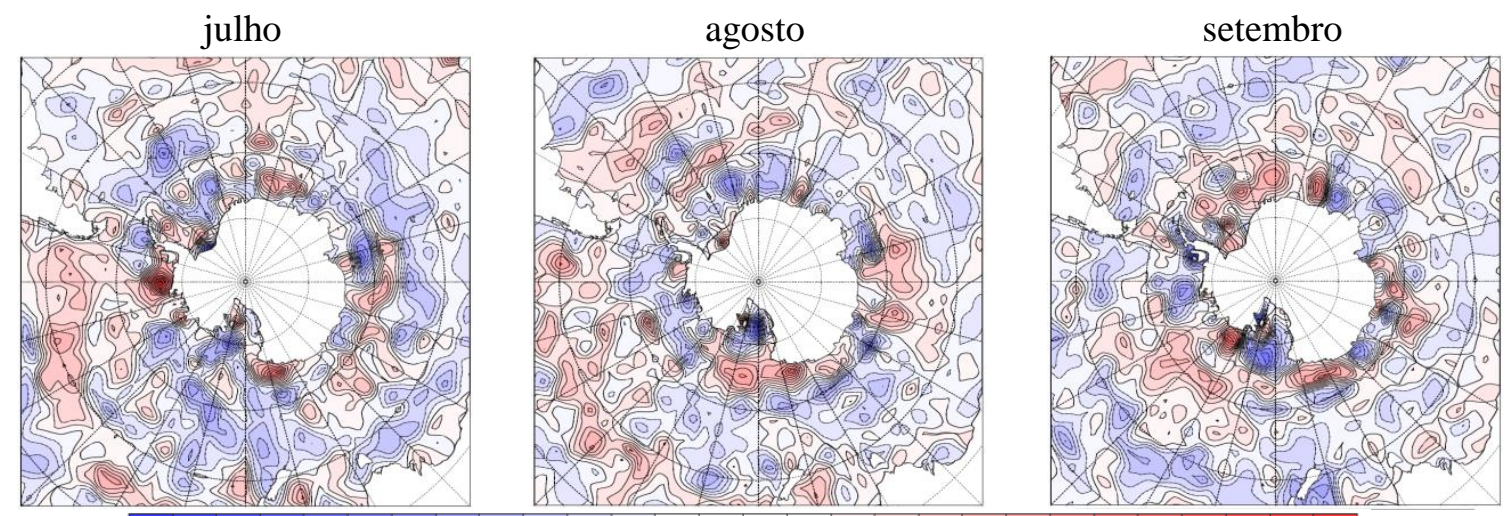

b)

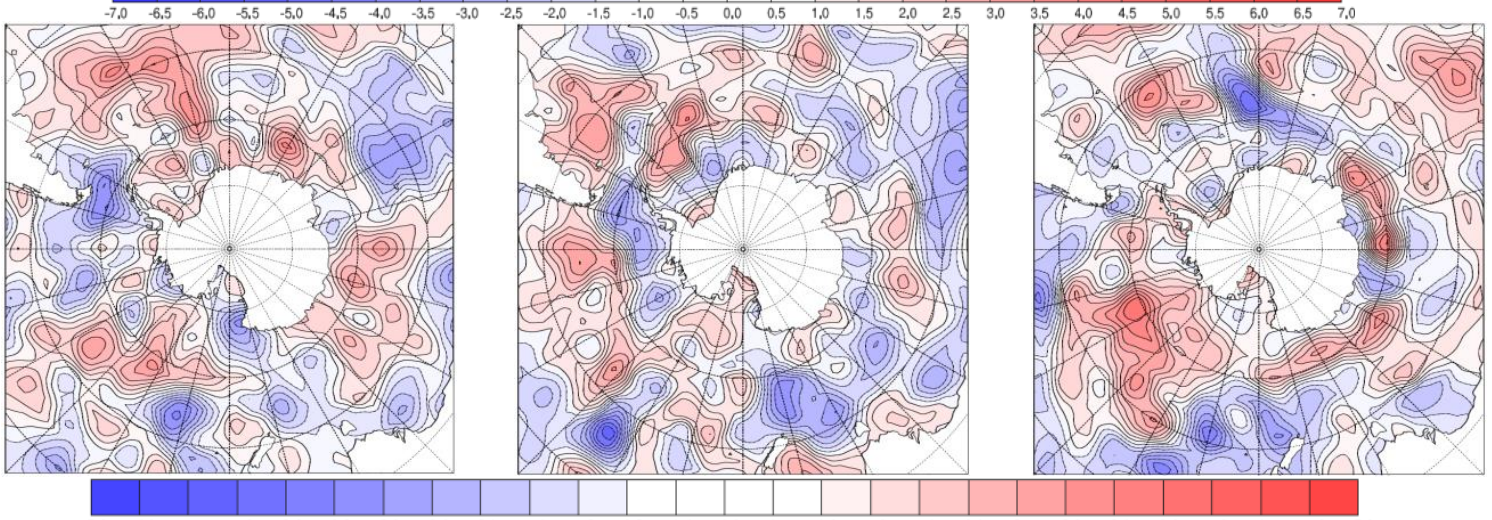

c)

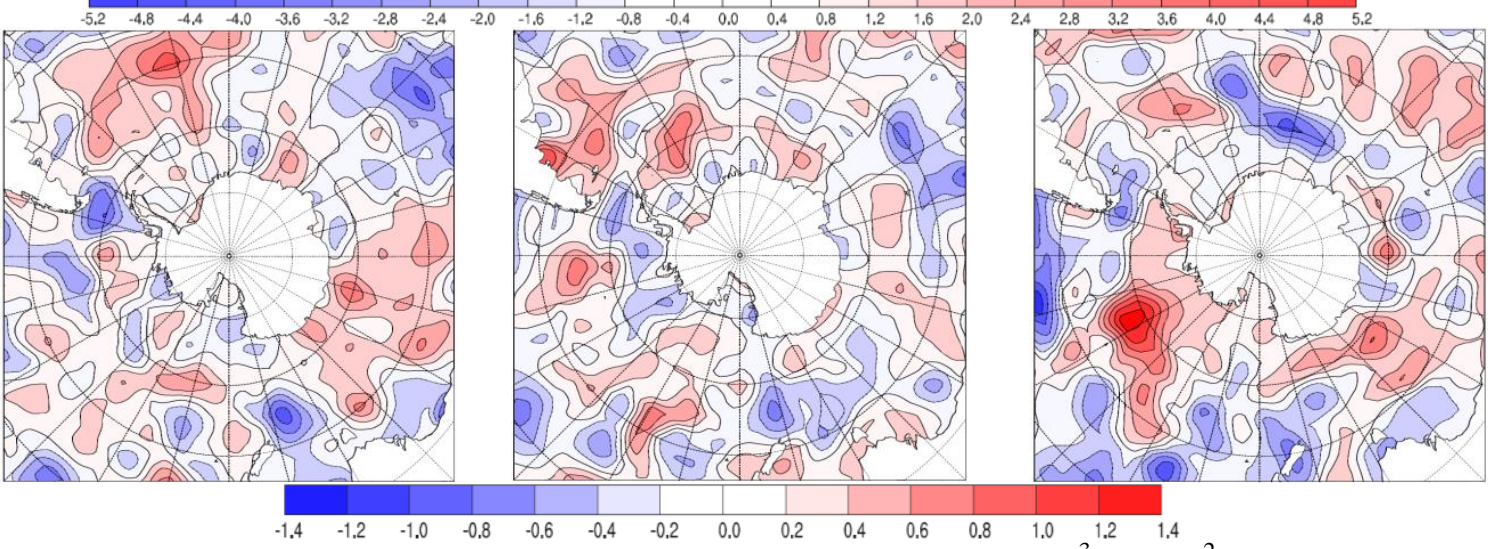

Figura 3.69: Composições de (a) densidade [número de sistemas por $10^{3}\left({ }^{\circ} \text { lat }\right)^{-2}$ ], (b) profundidade $(\mathrm{hPa})$ e (c) raio $\left({ }^{\circ}\right.$ lat) dos ciclones, entre os cinco meses com maiores anomalias interanuais negativas menos os cinco meses com maiores anomalias interanuais positivas de gelo marinho no setor do MW, nos meses de julho, agosto e setembro. 
Resumindo, verificou-se que durante o inverno austral a retração de gelo marinho no setor dos MBA (do MW) no mês de julho está associada predominantemente com um aumento na profundidade e aumento (diminuição) no raio dos sistemas, e alternância entre aumento e diminuição de densidade de ciclones na região costeira do Oceano Austral. No mês de agosto, estão associadas com uma diminuição na densidade de ciclones e aumento (diminuição) na profundidade e raio dos sistemas ao redor da Antártica. Em setembro, há uma maior (maior/menor) densidade e um aumento da profundidade e raio dos ciclones ao redor do continente antártico.

As anomalias negativas de gelo marinho nos MBA estão associadas com um aumento de profundidade e raio dos ciclones. As composições de anomalias interanuais de PNMM em relação aos eventos ENGM nos MBA durante o inverno (Figura 3.52) apresentaram no lag $=0$ anomalias predominantemente negativas sobre o Oceano Austral, o que contribuiria para uma maior profundidade e raio dos sistemas em superfície. Embora as composições de anomalias interanuais de PNMM no lag = 0 em relação aos eventos ENGM no MW (Figura 3.56) tenham sido predominantemente negativas, as anomalias de profundidade e raio apresentaram um comportamento variável entre os meses de inverno.

\subsubsection{Verão austral}

A partir da Figura 3.70a pode-se observar que no mês de janeiro a anomalia de densidade de ciclones entre os anos com as cinco maiores anomalias negativas menos as cinco maiores anomalias positivas de extensão de gelo marinho nos MBA (Tabela 2.2), na escala interanual, foi negativa nas altas latitudes ao redor do continente antártico (de até $-7,0 \times 10^{3}$ ciclones $\left({ }^{\circ} \text { lat }\right)^{-2}$ sobre o extremo oeste do mar de Ross), e positiva ao norte, em cerca de $60^{\circ} \mathrm{S}$. Simultaneamente predominaram anomalias negativas de profundidade próximo ao continente (Figura 3.70b), apresentando valores de até $-4,0$ hPa no setor do MW, com exceção da região central dos MBA e leste do setor do mar de Ross (de +2,0 hPa). Ao norte das anomalias positivas (negativas) de profundidade nas altas latitudes, são observadas anomalias negativas (positivas) nas latitudes médias. Já em relação às anomalias de raio (Figura 3.70c), observa-se o predomínio de anomalias negativas no Oceano Austral junto ao continente, com valores de até $-1,5^{\circ}$ lat no leste do MW. Portanto, em janeiro as anomalias interanuais negativas de extensão de gelo marinho nos MBA estão associadas no geral com 
menor (maior) densidade de sistemas nas altas (médias) latitudes, diminuição na profundidade e no raio dos ciclones ao redor da Antártica.

Em fevereiro, as anomalias de densidade positivas (de até $+7,0 \times 10^{3}$ ciclones $\left({ }^{\circ} \text { lat }\right)^{-2}$ a noroeste da Península Antártica) se intercalaram com as anomalias negativas (de até $-5,0 \times 10^{3}$ ciclones $\left({ }^{\circ} \text { lat }\right)^{-2}$ a sudoeste da Península Antártica e no extremo leste do setor do MW), próximas ao continente (Figura 3.70a). Da mesma forma, as anomalias de profundidade se intercalaram, com valores negativos na região leste do setor do MW, oeste dos MBA (ambos de até -5,0 hPa), leste do mar de Ross e no setor do Oceano Pacífico Oeste (ambos de até $-2,0 \mathrm{hPa}$ ). No restante da área as anomalias foram positivas de até $+4 \mathrm{hPa}$ na região oeste do setor do MW (Figura 3.70b). Contudo, predominaram anomalias negativas de profundidade nas altas latitudes do Oceano Austral. Ao redor do continente as anomalias de raio dos ciclones foram predominantemente negativas (Figura 3.70c), em que a região leste do MW apresentou anomalia de $-1,0^{\circ}$ lat. Destaca-se que no geral as regiões que apresentaram anomalias negativas de profundidade de sistemas, também apresentaram anomalias negativas de raio. Assim, no mês de fevereiro, as anomalias negativas interanuais de extensão de gelo marinho nos MBA esteve associada com maior/menor densidade, menor profundidade e raio dos sistemas ao redor do continente antártico.

No mês de março, as anomalias de densidade baseadas nas anomalias interanuais de gelo marinho dos MBA foram negativas no leste do MW (máximo de $-4,0 \times 10^{3}$ ciclones $\left(^{\circ}\right.$ lat $)^{-2}$ ), região central e extremo leste do setor do Oceano Pacífico Oeste, oeste do mar de Ross e sobre todo o setor dos MBA (Figura 3.70a). No restante da área as anomalias foram positivas. Ao norte das anomalias negativas (positivas), foram observadas anomalias positivas (negativas) de densidade. Em relação às anomalias de profundidade (Figura 3.70b), os valores foram predominantemente negativos. As anomalias foram positivas na região oeste (máximo de $+3,0 \mathrm{hPa}$ ) e leste da Península Antártica, no leste do MW (máximo de $+3,0 \mathrm{hPa}$ ) e no oeste do setor do Oceano Pacífico Oeste. O raio dos ciclones (Figura 3.70c) apresentou anomalias principalmente negativas, com valores de $-1,0^{\circ}$ lat no leste dos MBA. Assim, as anomalias negativas de extensão de gelo marinho nos MBA no mês de março estiveram associadas principalmente com alternância de anomalias positivas e negativas de densidade, menor profundidade e raio dos sistemas ao redor do continente antártico. 

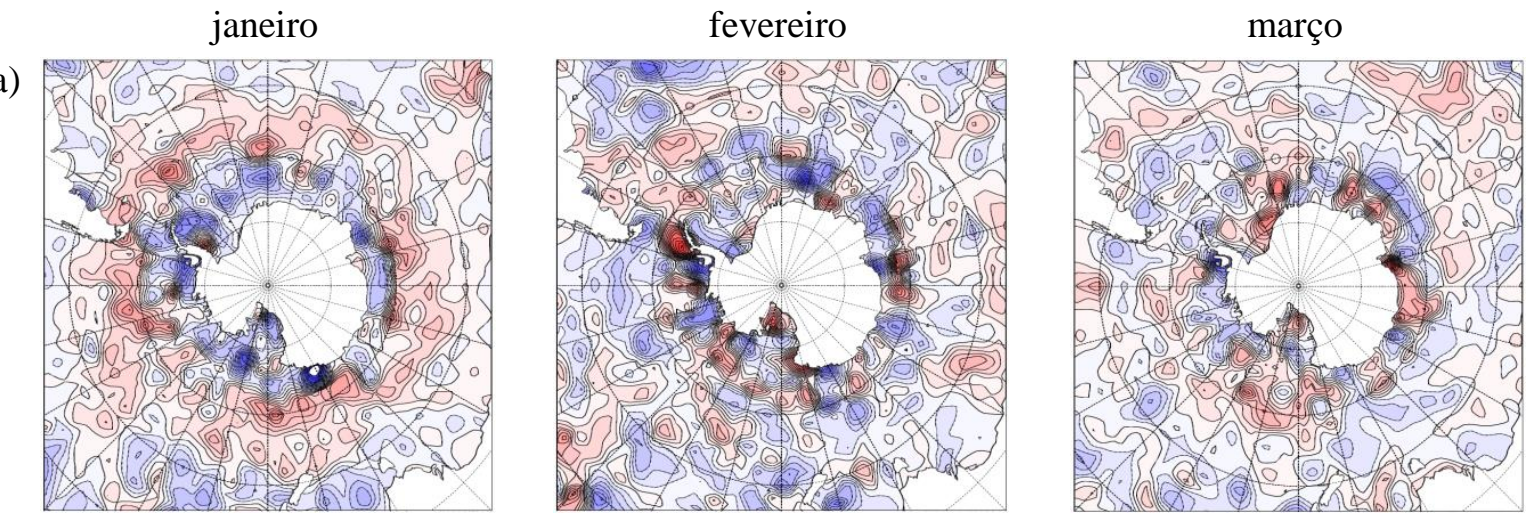

b)

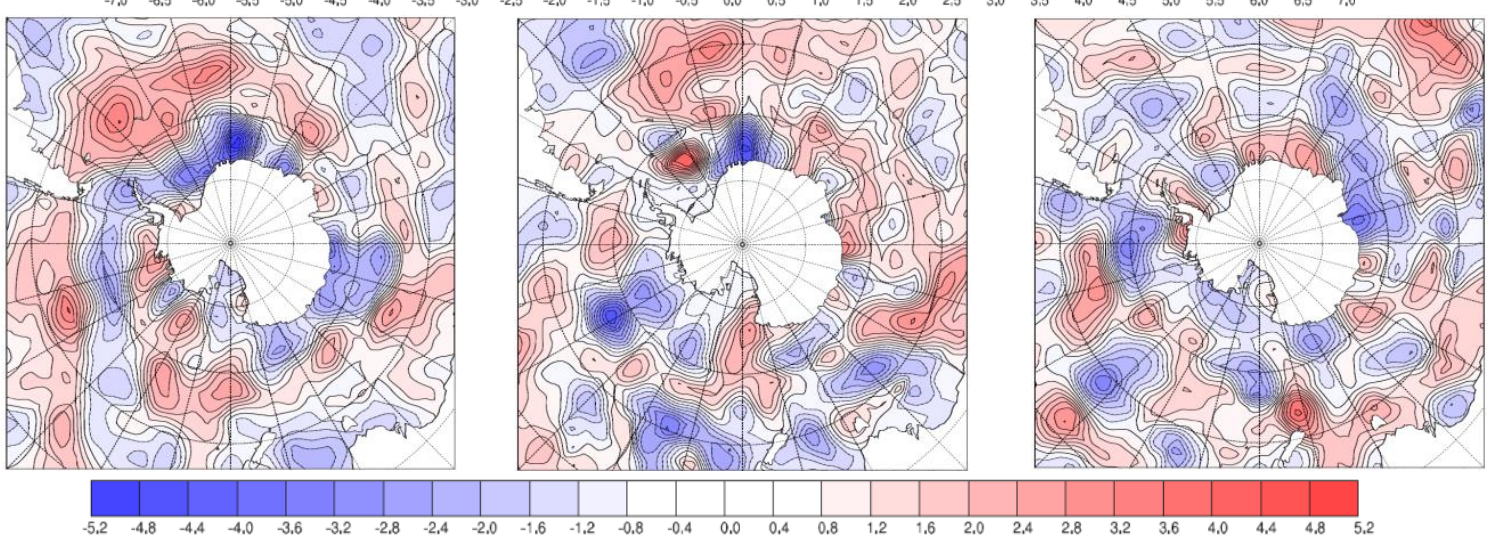

c)

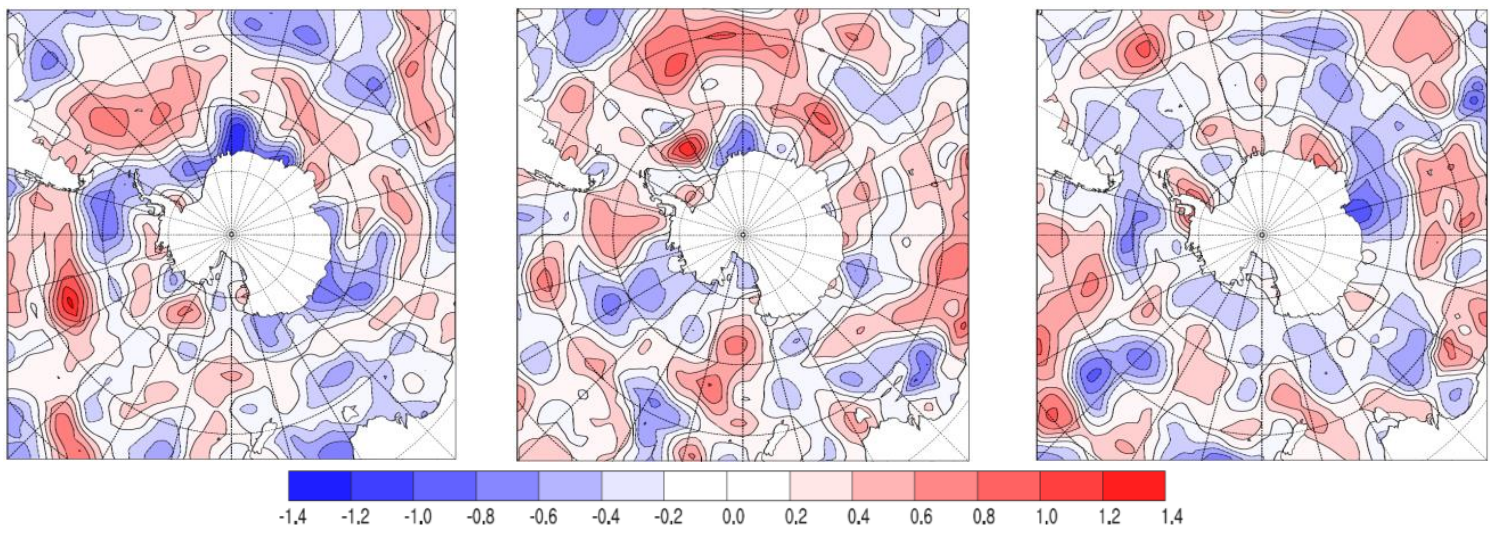

Figura 3.70: Composições de (a) densidade [número de sistemas por $10^{3}\left({ }^{\circ} \text { lat }\right)^{-2}$ ], (b) profundidade $(\mathrm{hPa})$ e (c) raio $\left({ }^{\circ}\right.$ lat) dos ciclones, entre os cinco meses com maiores anomalias interanuais negativas menos os cinco meses com maiores anomalias interanuais positivas de gelo marinho no setor dos MBA, nos meses de janeiro, fevereiro e março.

Em relação às anomalias interanuais de gelo marinho no setor do MW em janeiro (Tabela 2.3), a anomalia de densidade foi predominantemente positiva ao redor da Antártica, de até $+7,0 \times 10^{3}$ ciclones $\left({ }^{\circ} \text { lat }\right)^{-2}$, com exceção da região oeste do setor dos MBA. Concomitantemente, as anomalias de densidade foram negativas ao norte (Figura 3.71a). Predominaram anomalias positivas de profundidade dos ciclones (Figura 3.71b), com valores de até $+2,0 \mathrm{hPa}$. Algumas regiões apresentaram anomalias negativas, em especial o extremo 
oeste do setor do Oceano Índico. As anomalias de raio foram predominantemente positivas sobre o Oceano Austral, junto ao continente antártico (Figura 3.71c). Assim, retração de gelo marinho no MW na escala interanual em janeiro está relacionada principalmente com aumento na densidade, profundidade e raio dos sistemas sobre o Oceano Austral, em especial na região junto à costa da Antártica.

As anomalias de densidade no mês de fevereiro (Figura 3.71a) apresentaram um predomínio de anomalias positivas ao redor da Antártica, com exceção da região leste dos MBA, da região oeste do setor do mar de Ross, extremo oeste do setor do Oceano Pacífico Oeste e do Oceano Índico. As anomalias de profundidade (Figura 3.71b) foram positivas em grande parte do Oceano Austral, com valores de até $+4,0 \mathrm{hPa}$ no setor dos MBA. As anomalias negativas foram observadas no extremo leste do $\mathrm{MW}$ (de até $-3,0 \mathrm{hPa}$ ) e na região leste do setor do Oceano Índico (de até -1 hPa). Da mesma forma, predominaram anomalias de raio positivas sobre o Oceano Austral (Figura 3.71c), com valores de até $+1,0^{\circ}$ lat no extremo leste do setor do mar de Ross. Portanto, retração de gelo marinho no setor do MW na escala interanual em fevereiro esteve associada principalmente com aumento na densidade, profundidade e raio dos ciclones sobre o Oceano Austral, ao redor da Antártica.

No mês de março, as anomalias de densidade (Figura 3.71a) positivas se intercalaram com as anomalias negativas ao redor do continente, variando entre $-5,0 \times 10^{3}$ ciclones $\left({ }^{\circ} \text { lat }\right)^{-2}$ no setor do mar de Ross e $+6,0 \times 10^{3}$ ciclones $\left({ }^{\circ} \text { lat }\right)^{-2}$ nos MBA. Da mesma forma, as anomalias de profundidade dos sistemas (Figura 3.71b) apresentaram um comportamento com anomalias positivas e negativas intercaladas ao redor do continente, embora tenham predominado anomalias positivas de profundidade. Os valores negativos foram observados no leste do MW (máximo de -5,0 hPa), no oeste do setor do Oceano Pacífico Oeste e dos MBA. As anomalias positivas foram encontradas no restante da área, com valor máximo de $+4,0 \mathrm{hPa}$ na região leste dos MBA. As anomalias de raio (Figura 3.71c) foram principalmente positivas sobre o Oceano Austral, apresentando anomalias negativas de até $-1,0^{\circ}$ lat a sudoeste da Península Antártica e na região leste do MW. Assim, em março a retração de gelo marinho no MW está associada predominantemente com anomalias positivas/negativas de densidade, aumento na profundidade e raio dos sistemas ao redor da Antártica. 

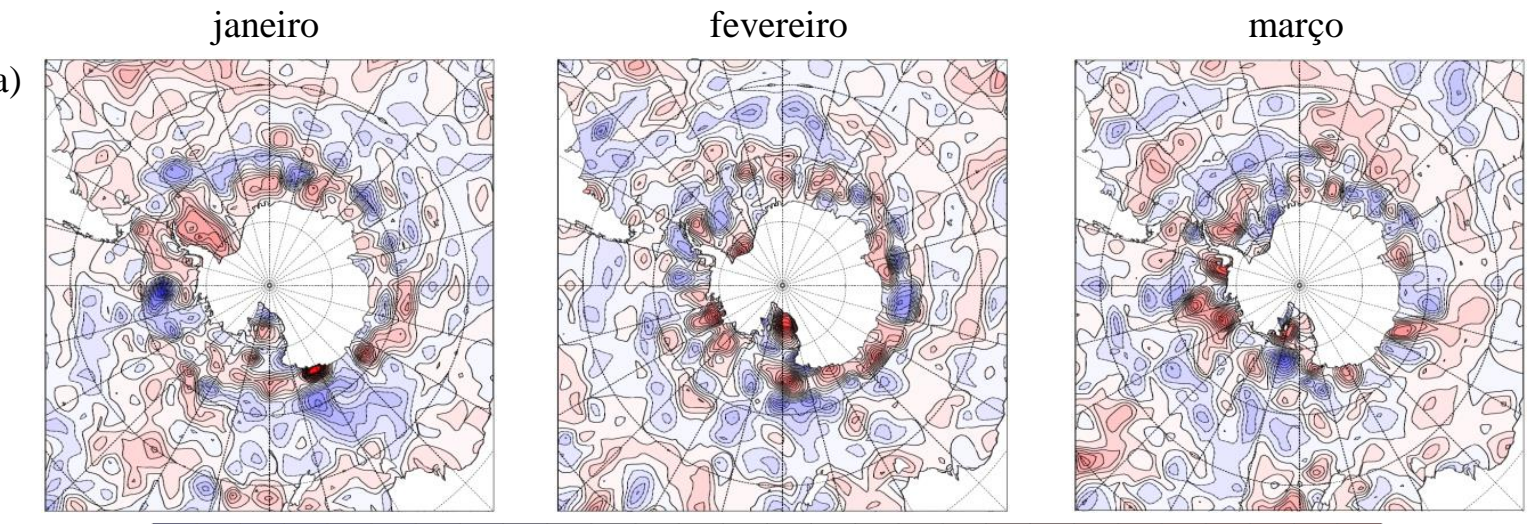

b)

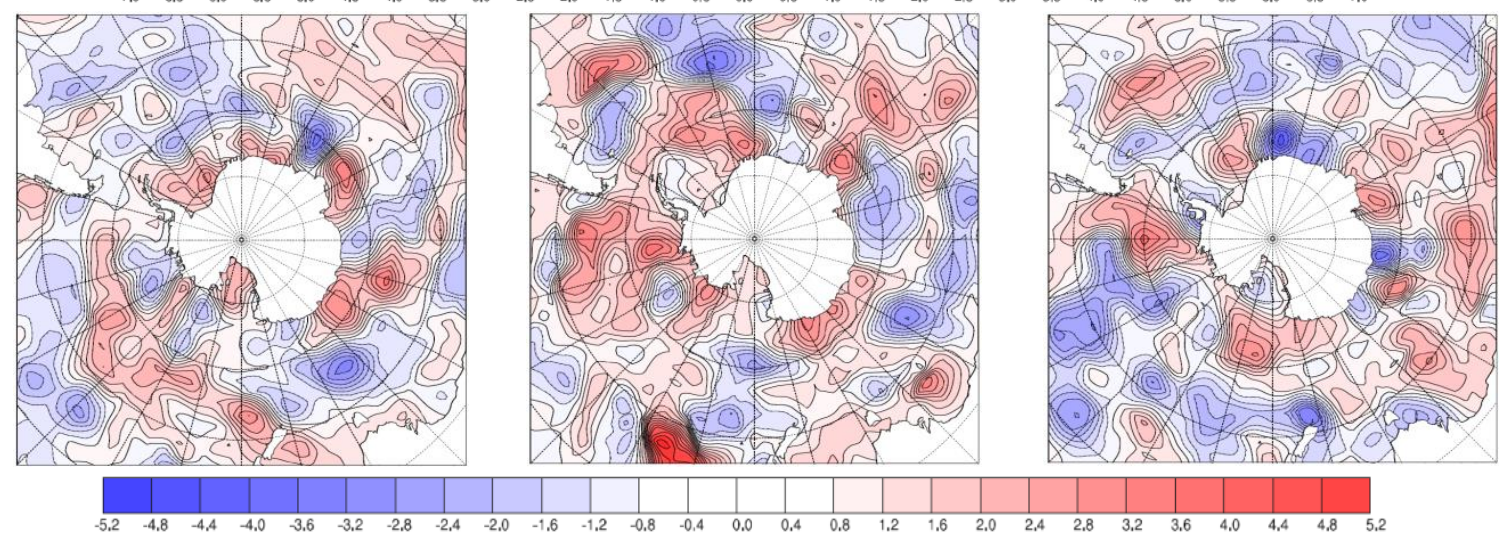

c)

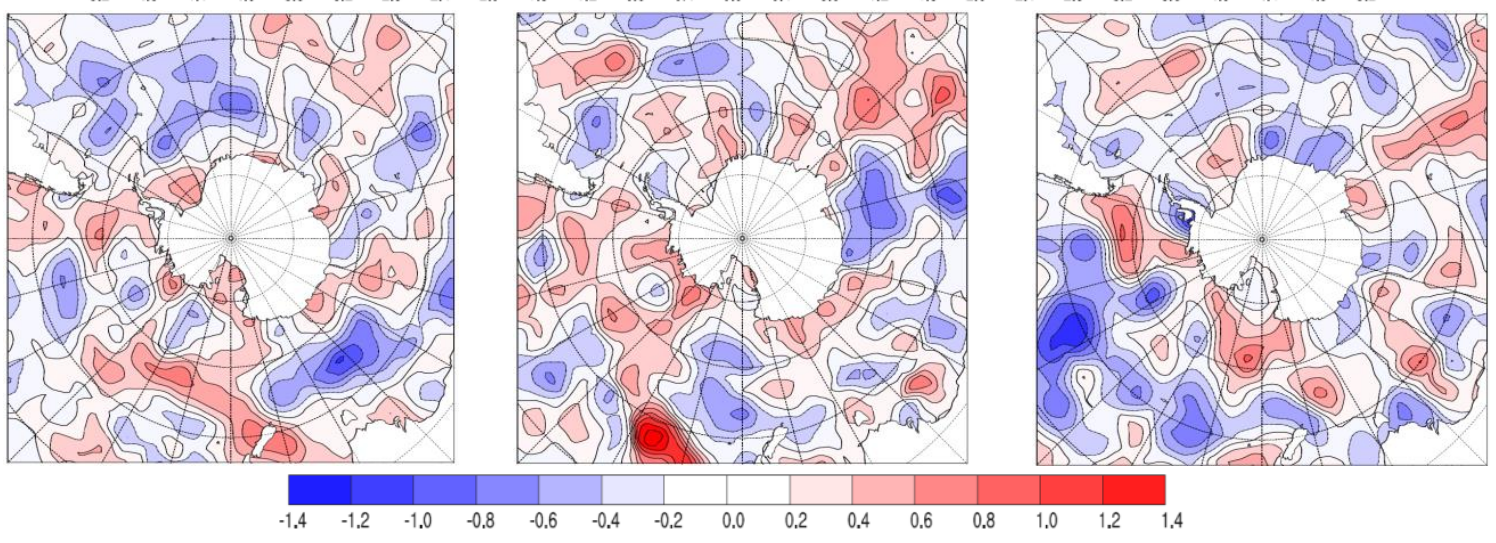

Figura 3.71: Composições de (a) densidade [número de sistemas por $10^{3}\left({ }^{\circ} \text { lat }\right)^{-2}$ ], (b) profundidade $(\mathrm{hPa})$ e (c) raio $\left({ }^{\circ}\right.$ lat) dos ciclones, entre os cinco meses com maiores anomalias interanuais negativas menos os cinco meses com maiores anomalias interanuais positivas de gelo marinho no setor do MW, nos meses de janeiro, fevereiro e março.

No verão austral, as anomalias negativas interanuais de extensão de gelo marinho nos MBA (no MW), no mês de janeiro, estão associadas principalmente com menor (maior) densidade de sistemas nas altas latitudes sobre o Oceano Austral e maior (menor) nas latitudes médias, diminuição (aumento) na profundidade e raio dos ciclones no Oceano Austral junto ao continente. Em fevereiro estiveram associadas com maior/menor (maior) densidade, menor (maior) profundidade e raio dos sistemas nas altas latitudes do Oceano Austral. Já no mês de 
março estiveram associadas com alternância de anomalias positivas e negativas de densidade, menor (maior) profundidade e raio dos sistemas em superfície. Assim, em todas as composições de diferenças, a retração de gelo marinho no setor dos MBA (do MW) esteve associada com menor (maior) profundidade e raio dos sistemas sobre o Oceano Austral. Associando esses resultados com as composições de anomalias interanuais de PNMM em relação aos eventos ENGM nos MBA no verão austral (Figura 3.60), observa-se que no lag = 0 sobre grande parte do Oceano Austral há um predomínio de anomalias positivas de PNMM, o que contribuiria para uma menor profundidade e raio dos sistemas em superfície. Por outro lado, em relação aos eventos ENGM no MW (Figura 3.64), verifica-se que no lag $=0$ há um predomínio de anomalias negativas de PNMM no Oceano Austral, o que contribuiria para um aumento de profundidade e raio dos ciclones.

Tanto no verão quanto no inverno austral o sinal da profundidade e raio aparece mais uniformemente distribuído quando comparado com a densidade. As anomalias de profundidade e raio estão em fase, posicionadas praticamente sobre as mesmas regiões ao redor da Antártica sobre o Oceano Austral, com exceção das anomalias de gelo marinho no MW no mês de julho. Da Equação 2.16 ( $c f$. seção 2.2) verifica-se que para um dado valor de Laplaciano, sistemas maiores terão maior profundidade (PEZZA; DURRANT; SIMMONDS, 2008). As anomalias de densidade e profundidade/raio podem ou não estar relacionadas, ou seja, um aumento na densidade pode não estar sempre associado com um aumento na profundidade/raio e vice-versa. Um aumento local de densidade de ciclones ao redor da costa da Antártica entre áreas principais de diminuição sugere um mecanismo complexo, com possível deslocamento norte-sul do padrão de ondas em extremos de extensão de gelo marinho. É possível que parte deste aumento na densidade esteja associado com a ocorrência de sistemas ciclônicos de mesoescala, tais como baixas polares, quando o gelo marino está reduzindo. As diferenças regionais em várias zonas longitudinais teria um impacto diferente em termos de tempestades e frentes que afetam os continentes (PEZZA; DURRANT; SIMMONDS, 2008).

Em vários casos foi observado aumento (diminuição) das anomalias de densidade, profundidade e raio em altas latitudes e diminuição (aumento) nas latitudes médias. Este processo é um reflexo do reajuste de massa, quando as células norte-sul de subsidência são latitudinalmente deslocadas. Quando a atividade de ciclones é reduzida (isto é, as pressões aumentam) em altas latitudes, por conservação de massa nas latitudes médias os movimentos ascendentes são maiores (ou seja, as pressões diminuem) (PEZZA; DURRANT; SIMMONDS, 2008). 


\section{Capítulo 4: Conclusões}

Neste trabalho foi investigada a interação entre os ciclones extratropicais e a variabilidade extrema do gelo marinho nas escalas de tempo de alta frequência e interanual, nos setores dos MBA e do MW, durante o verão e inverno austral entre 1989 e 2007.

Em relação aos padrões de circulação atmosférica de alta frequência no HS em eventos extremos de gelo marinho na mesma escala de tempo, verificou-se que os eventos ENGM e EPGM no setor dos MBA e do MW estão associados com as anomalias dos campos atmosféricos ocorridos a partir de três dias anteriores ao evento extremo. Ou seja, a anomalia ciclônica no oeste do setor, associada com as anomalias de ventos de oeste no norte e de ventos de leste no sul, e a anomalia anticiclônica no leste, associada com as anomalias de ventos de leste no norte e de ventos de oeste no sul, resultam em uma anomalia de ventos de norte e, consequentemente, a anomalias positivas de temperatura do ar. Essa configuração anômala contribui para os eventos ENGM através do derretimento do gelo marinho e, principalmente, do seu próprio transporte em direção às altas latitudes pelos ventos de norte anômalos. A atuação dos ventos no transporte de gelo marinho mostrou-se fundamental para determinar a sua variabilidade de alta frequência. Destaca-se que o vento é o principal responsável pela dinâmica do gelo marinho, particularmente no período de dias ou semanas, explicando até $70 \%$ do seu movimento (NSIDC, 2010). As anomalias de alta frequência dos campos atmosféricos em todos os casos (composições defasadas) de eventos EPGM apresentaram fases opostas em relação aos eventos ENGM. Portanto, fases distintas do trem de ondas induzem na modulação de extremos de gelo marinho opostos. Esses distúrbios de alta frequência aparecem como um padrão de trem de ondas número 4 entre as latitudes médias e altas ao redor do HS no inverno austral. No verão, esse padrão não está muito bem configurado.

Destaca-se que o trem de ondas associado aos eventos EPGM nos MBA, durante o inverno, afetam a América do Sul tropical e extratropical através das anomalias de temperatura do ar. Durante os eventos ENGM não é observada tal associação. Assim, evidencia-se uma possível relação entre a variabilidade de alta frequência do gelo marinho 
antártico e a modulação de eventos frios/quentes nas latitudes médias e baixas da América do Sul através da propagação de distúrbios de alta frequência, tais como ciclones e anticiclones associados a sistemas frontais.

No verão austral, o padrão das anomalias de alta frequência dos campos atmosféricos associado aos eventos ENGM/EPGM nos MBA e no MW foi similar ao inverno, porém as anomalias foram menos significativas e o trem de ondas persistiu por menos tempo. Isso porque durante o verão a atividade dos sistemas transientes é menos frequente que no inverno (SIMMONDS; KEAY, 2000a; SIMMONDS; KEAY; LIM, 2003). Além disso, Cavalieri e Parkinson (1981) verificaram que o rápido decaimento de gelo marinho no Oceano Austral estaria relacionado ao fluxo de calor do fundo para a superfície oceânica devido ao bombeamento de Ekman e apenas indiretamente relacionado com os sistemas de baixa pressão. Assim, durante o verão austral o impacto dos transientes sobre as variações de alta frequência da cobertura de gelo marinho nos MBA e MW é reduzido e, portanto, outros mecanismos são responsáveis por tais variações, tais como o bombeamento de Ekman, as correntes oceânicas, os fatores geográficos locais, entre outros.

Conhecendo os padrões atmosféricos associados aos extremos de gelo marinho de alta frequência, verificou-se qual o comportamento sinótico de casos específicos em fases distintas de El Niño, sabendo-se da existência de teleconexão entre este fenômeno e o gelo marinho antártico. Assim, nos estudos de caso em períodos de El Niño há uma intensificação do jato subtropical e um enfraquecimento do jato polar no Pacífico Sul, observado através das anomalias de alta frequência de vento zonal em 200 hPa. Há uma menor atuação dos ciclones extratropicais, predominando a circulação devido ao sistema de cristas e cavados. No evento ENGM (EPGM) a região leste (oeste) do cavado está posicionada sobre os MBA, contribuindo para o aporte de ar quente (frio) pelos ventos de norte (de sul). Observa-se que os padrões atmosféricos identificados estão de acordo com as composições defasadas no tempo das anomalias de alta frequência dos campos atmosféricos em eventos ENGM/EPGM nos MBA durante o inverno austral ( $c f$. seção 3.2.1.1). A configuração de menor atuação de sistemas ciclônicos na fase de El Niño é condizendo com os estudos feitos por Yuan (2004), pois o aquecimento tropical desloca a célula de circulação zonal para leste, de forma que o seu ramo ascendente ocorre no Pacífico tropical, intensificando e contraindo a Célula de Hadley nessa região. Consequentemente, a storm track desloca-se em direção ao equador no Pacífico Sul e sobre os MBA há uma menor atividade dos distúrbios transientes de alta frequência. A intensificação do jato subtropical, o enfraquecimento do jato polar e as mudanças na Célula de Hadley regional aparentemente resultam em um reforço da Célula de Ferrel no Pacífico Sul. 
Nos estudos de caso em fase de La Niña há um reforço do jato polar e uma maior atividade ciclônica sobre os MBA, apresentando os sistemas mais intensos em relação aos casos de El Niño e Neutro. No evento ENGM (EPGM) há uma associação entre os ventos de norte (de sul) com a vanguarda (retaguarda) dos sistemas ciclônicos em superfície. Ao contrário do El Niño, durante o período de La Niña o resfriamento tropical atenua e expande a Célula de Hadley sobre o Pacífico Sul. Consequentemente, a storm track desloca-se em direção ao polo nessa região e, assim, há uma maior atividade dos distúrbios de alta frequência sobre os MBA. As mudanças na corrente de jato (reforço no jato polar) e na Célula de Hadley regional resultam em um enfraquecimento da Célula de Ferrel no Pacífico Sul (YUAN, 2004).

Já nos estudos de caso em fase Neutra verificou-se uma intensificação do jato polar e uma atuação do sistema de cristas e cavados e de sistemas ciclônicos em superfície. Combinando os efeitos da posição do sistema cristas/cavados e dos ciclones, há diferentes influências nos eventos ENGM e EPGM. Embora as anomalias de circulação atmosférica durante a fase Neutra sejam muito semelhantes com as da fase de La Niña, verificou-se a atuação não somente de sistemas ciclônicos sobre os MBA, mas também de cristas e cavados. Contudo, o jato polar apresentou intensificação no setor, como observado no estudo de casos em eventos de La Niña. O padrão atmosférico associado com o evento ENGM nos MBA está em concordância com o observado na seção 3.2.1.1.

$\mathrm{Na}$ análise da influência da circulação atmosférica interanual na variabilidade extrema do gelo marinho antártico na mesma escala de tempo, observou-se que o fenômeno El Niño mostrou-se dominante sobre a variabilidade do gelo marinho nos setores dos MBA e MW durante o verão e inverno austral. Entretanto, é necessário ter cautela nessa consideração, pois as composições foram calculadas com um número pequeno de casos, impossibilitando o cálculo da significância estatística. No inverno, a partir do lag $=-365$ as anomalias positivas de temperatura do ar sobre a região do Pacífico equatorial estão associadas com as anomalias negativas de PNMM na região leste do Pacífico Sul e anomalias positivas sobre o setor dos MBA/sudeste do Pacífico Sul. Assim, há uma intensificação do escoamento de norte sobre os MBA, contribuindo para o aquecimento e, consequentemente, com os eventos ENGM neste setor. Simultaneamente há um enfraquecimento dos ventos de norte sobre a região do MW e, portanto, anomalias negativas de temperatura do ar, contribuindo para os eventos EPGM neste setor. Por outro lado, quando é observado resfriamento na região equatorial do Pacífico, as anomalias de PNMM sobre o leste do Pacífico Sul são positivas e sobre os MBA/sudeste do 
Pacífico Sul as anomalias são negativas. Portanto, há um enfraquecimento do escoamento de norte e, assim, anomalias negativas de temperatura do ar. Essa configuração anômala contribui para os eventos EPGM sobre os MBA. Ao mesmo tempo, sobre o MW há uma intensificação dos ventos de norte, contribuindo para as anomalias positivas de temperatura do ar e, deste modo, com os eventos ENGM neste setor. Durante o verão, o efeito das anomalias é igual ao inverno, porém está associado com os eventos ENGM/EPGM a partir do lag = 183. Assim, fases distintas do fenômeno El Niño contribuem para os eventos ENGM e EPGM com efeitos oposto entre o setor dos MBA e do MW. Ou seja, a fase de El Niño (La Niña) está associada com eventos ENGM (EPGM) nos MBA e com eventos EPGM (ENGM) no MW. Estes resultados estão de acordo com Yuan e Martinson (2000), Yuan e Martinson (2001), Yuan (2004).

Por fim, em relação às características dos ciclones extratropicais, em termos de densidade, profundidade e raio, em extremos de anomalias negativas e positivas de gelo marinho na escala interanual, verificou-se que durante o inverno austral a retração de gelo marinho no setor dos MBA (MW) no mês de julho está associada principalmente com um aumento na profundidade e aumento (diminuição) no raio dos sistemas, e alternância entre aumento e diminuição de densidade de ciclones ao redor da Antártica. No mês de agosto, estão associadas com uma diminuição na densidade de ciclones e aumento (diminuição) na profundidade e raio dos sistemas. Em setembro, há uma maior (maior/menor) densidade e um aumento da profundidade e raio dos ciclones. Assim, as anomalias negativas de gelo marinho nos MBA estão associadas com um aumento de profundidade e raio dos ciclones ao redor do continente antártico.

No verão austral, as anomalias negativas interanuais de extensão de gelo marinho nos MBA (MW) em janeiro estão associadas principalmente com menor (maior) densidade de sistemas nas altas latitudes sobre o Oceano Austral e maior (menor) nas latitudes médias, diminuição (aumento) na profundidade e raio dos ciclones no Oceano Austral junto ao continente. Em fevereiro estiveram associadas com maior/menor (maior) densidade, menor (maior) profundidade e raio dos sistemas ao redor da Antártica. Já no mês de março estiveram associadas com alternância de anomalias positivas e negativas de densidade, menor (maior) profundidade e raio dos sistemas em superfície. Assim, em todas as composições de diferenças, a retração de gelo marinho no setor dos MBA (MW) esteve associada com menor (maior) profundidade e raio dos sistemas sobre as altas latitudes do Oceano Austral.

No verão e inverno, o sinal da profundidade e raio aparece mais uniformemente distribuído quando comparado com a densidade. As anomalias de profundidade e raio estão 
em fase, posicionadas praticamente sobre as mesmas regiões ao redor da Antártica sobre o Oceano Austral, com exceção das anomalias de gelo marinho no MW no mês de julho. Da Equação 2.16 ( $c f$. seção 2.2) verifica-se que para um dado valor de Laplaciano, sistemas maiores terão maior profundidade (PEZZA; DURRANT; SIMMONDS, 2008). As anomalias de densidade e profundidade/raio podem ou não estar relacionadas, ou seja, um aumento na densidade pode não estar sempre associado com um aumento na profundidade/raio e viceversa. Um aumento local de densidade de ciclones ao redor da costa da Antártica entre áreas principais de diminuição sugere um mecanismo complexo, com possível deslocamento nortesul do padrão de ondas em extremos de gelo marinho. É possível que parte deste aumento na densidade esteja associado com a ocorrência de sistemas ciclônicos de mesoescala, tais como baixas polares, quando o gelo marino está reduzindo. As diferenças regionais em várias zonas longitudinais teria um impacto diferente em termos de tempestades e frentes que afetam os continentes (PEZZA; DURRANT; SIMMONDS, 2008). Em vários casos foi observado aumento (diminuição) das anomalias de densidade, profundidade e raio em altas latitudes e diminuição (aumento) nas latitudes médias. Este processo é um reflexo do reajuste de massa, quando as células norte-sul de subsidência são latitudinalmente deslocadas. Quando a atividade de ciclones é reduzida (isto é, as pressões aumentam) em altas latitudes, por conservação de massa nas latitudes médias os movimentos ascendentes são maiores (ou seja, as pressões diminuem) (PEZZA; DURRANT; SIMMONDS, 2008).

\subsection{Sugestões para trabalhos futuros}

Algumas questões relevantes surgem a partir deste estudo, que podem servir como tema de pesquisa para trabalhos futuros:

- Qual a contribuição dos ciclones extratropicais na variabilidade extrema de alta frequência do gelo marinho antártico em termos de fluxos de calor latente e sensível?

- Como as diferentes intensidades dos ciclones extratropicais contribuem para os fluxos de calor devido ao bombeamento de Ekman? Como este processo afeta o derretimento e formação de gelo marinho?

- Climatologicamente, como o fenômeno El Niño influencia na variabilidade de alta frequência do gelo marinho antártico? Quais os padrões atmosféricos associados, nesta mesma escala de tempo? 
- As variações de alta frequência do gelo marinho estão associadas a quais modos de variabilidade climática do Hemisfério Sul?

- Qual o suporte dinâmico da atmosfera na escala interanual para as variações nas características dos ciclones extratropicais em extremos negativos e positivos de gelo marinho antártico, na mesma escala temporal? 


\section{Referências bibliográficas}

ACKLEY, S. F. A review of sea-ice weather relationships in the Southern Hemisphere. Proceedings of the 17th General Assembly of IUGG on Sea Level, Ice and Climatic change, edited by I. Allison, IAHS, Publ., 131, p. 127-159, 1981.

ACKLEY, S. F.; KELHIER, T. E. Antarctic sea-ice dynamics and its possible climatic effects. AIDJEX Bull 33: p. 53-76, 1976.

AHLERT, S.; AQUINO, F. Mapa da Antártica. Climanálise, Boletim de Monitoramento e Análise Climática - $\quad$ CPTEC/INPE. Disponível em: <http://www6.cptec.inpe.br/revclima/boletim/>. Acesso em: 10 de junho de 2009.

BERBERY, E. H.; VERA, C. S. Characteristics of the Southern hemisphere winter storm track with filtered and unfiltered data. J. Atmos. Sci., 53, p. 468-481, 1996.

BERRISFORD, P.; DEE, D. P.; FIELDING, K.; FUENTES, M.; KALLBERG, P.; KOBAYASHI, S.; UPPALA, S. M. 'The ERA-Interim Archive'. ERA Report Series, No. 1. ECMWF: Reading, UK. 2009.

Bjerknes, J. On the structure of moving cyclones. Geofys. Publ., 1, p. 1-8, 1919.

BJERKNESS, J. e SOLBERG, H. Life Cycles of Cyclones and Polar Front Theory of Atmospheric Circulation. Geof. Publ. 3(1), p. 3-18, 1922.

BLOOMFIELD, P. Fourier analyses of time series: An introduction. New York. 1976.

BOIASKI, N. T. Extremos intra-sazonais de temperatura na Península Antártica e mecanismos atmosféricos associados. São Paulo, SP: Instituto de Astronomia, Geofísica e Ciências Atmosféricas. Originalmente apresentada como dissertação de mestrado, Universidade de São Paulo, 2007.

BROMWICH, D. H.; PARISH, T. R. Meteorology of the Antarctic. In: Meteorology of the Southern Hemisphere, edited by D. J. Karoly and D. G. Vincent, Meteorological Monographs, v. 27, number 49. American Meteorological Society, Boston, p. 175-200, 1998.

CARLETON, A. M. Antarctic sea-ice relationships with indices of the atmospheric circulation of the Southern Hemisphere. Climate Dyn., 3, p. 207-220, 1989.

CAVALCANTI, I. F. A.; KAYANO, M. T. Configurações dos distúrbios de alta frequência no Hemisfério Sul em uma simulação com MGCA CPTEC/COLA. In: XI Congresso Brasileiro de Meteorologia, 2000, Rio de Janeiro. XI Congresso Brasileiro de Meteorologia, 2000 .

CAVALCANTI, I.; KAYANO, M. T. High frequency patterns of the atmospheric circulation over the Southern Hemisphere and South American. Meteor. Atmos. Phys., 69, p. 179-193, 1999. 
CAVALIERI, D. J. et al. NASA Sea ice validation program for the DMSP SSM/I: final report. NASA Technical Memorandum 104559. National Aeronautics and Space Administration, Washington, D. C. 126 pg., 1992.

CAVALIERI, D. J.; PARKINSON, C. L. Antarctic sea ice variability and trends, 1979-2006. Geophysical Research Letters, 113, p. 1-19, 2008.

CAVALIERI, D. J.; PARKINSON, C. L. Large-scale variations in observed Antarctic sea ice extent and associated atmospheric circulation. Mon. Weather Rev., 109, p. 2323-2336, 1981.

CAVALIERI, D.; PARKINSON, C.; GLOERSEN, P.; ZWALLY, H. J. 1996, updated 19792007. Sea Ice Concentrations from Nimbus-7 SMMR and DMSP SSM/I Passive Microwave Data, [1989-2007]. Boulder, Colorado USA: National Snow and Ice Data Center. Digital media.

CCAMLR - Convention on the Conservation of Antarctic Marine Living Resources. General Introduction. Disponível em: <http://www.ccamlr.org/pu/e/gen-intro.htm>. Acesso em: 26 maio 2008.

CHATFIELD, C. The Analysis on Time Series - An Introduction. Chapman \& Hall, sixth edition, New York, 2004.

Chen, B., S. R. Smith, and D. H. Bromwich, Evolution of the tropospheric split jet over the Southern Pacific Ocean during the 1986-89 ENSO cycle. Mon. Weather Rev., 124, p. 17111731, 1996.

CIMSS - Cooperative Institute for Meteorological Satellite Studies. University of WisconsinMadison. Satellite application for Geoscience education. Disponível em: $<$ http://cimss.ssec. wisc.edu/>. Acesso em: 9 nov. 2011.

CUNNINGHAM C. A. C. Influências potenciais na circulação atmosférica do Hemisfério Sul de anomalias positivas e negativas na camada de gelo marinho no Mar de Ross. São José dos Campos, SP: Instituto Nacional de Pesquisas Espaciais. Originalmente apresentada como tese de doutorado, INPE, 2011.

CUNNINGHAM C. A. C.; BONATTI, J. P. Role of seaice in forcing the austral spring atmospheric circulation in the CPTEC AGCM. In: 10th Conference on Polar Meteorology and Oceanography, 2009, Madison. Proceedings of 10th Conference on Polar Meteorology and Oceanography, 2009.

D. P. DEEA; S. M. UPPALAA; A. J. SIMMONSA; P. BERRISFORDA; P. POLIA; S. KOBAYASHIB; U. ANDRAEC; M. A. BALMASEDAA; G. BALSAMOA; P. BAUERA; P. BECHTOLDA; A. C. M. BELJAARSA; L. VAN DE BERGD; J. BIDLOTA; N. BORMANNA; C. DELSOLA, R. DRAGANIA; M. FUENTESA; A. J. GEERA; L. HAIMBERGERE; S. B. HEALYA; H. HERSBACHA; E. V. H’OLMA; L. ISAKSENA; P. K०ALLBERGC; M. K*OHLERA; M. MATRICARDIA; A. P. MCNALLYA; B. M. MONGE-SANZF; J.-J. MORCRETTEA; B.-K. PARKG; C. PEUBEYA; P. DE ROSNAYA; C. TAVOLATOE; J.-N. TH'EPAUTA; F. VITARTA. The ERA-Interim reanalysis: configuration and performance of the data assimilation system. Quarterly Journal of the Royal Meteorological Society. 137, p. 553-597, April 2011. 
DRINKWATER, M. R. Satellite microwave radar observations of Antarctic sea ice. In: Analysis of SAR Data of the Polar Oceans, edited by C. TSATSOULIS and R. KWOK, p. 145-187, Springer-Verlag, New York, 1998.

DRINKWATER, M. R.; LIU, X. Active and passive microwave determination of the circulation and characteristics of Weddell and Ross sea ice. In: Proceedings of IGARSS'99, Rep. 99CH36293, p. 314-316, Inst. of Elect. and Elect. Eng., Hamburg, Germany, 28 de Junho 28 a 2 de Julho, 1999.

ENOMOTO, H.; OHMURA, A. The influences of atmospheric half-yearly cycle on the sea ice extent in the Antarctic. J. Geophys. Res., 95(C6), p. 9497-9511, 1990.

ESCOBAR, G. Tempo e clima no brasil. Jatos de altos níveis. 1. ed. São Paulo: Oficina de Textos, 463 p., 2009.

GARREAUD, R. D. Cold air incursions over subtropical South America: mean structure and dynamics. Monthly Weather Review, 128, p. 2544-2559, 2000.

GARREAUD, R.; BATTISTI, D. S. Interannual and interdecadal (ENSO-like) variability in the Southern Hemisphere tropospheric circulation. Journal of Climate, 12: 2113-2123, 1999.

GODFRED-SPENNING, C.R.; SIMMONDS, I. An analysis of Antarctic sea-ice and extratropical cyclone associations. Int. J. Climatol., 16(12), p. 1315-1332, 1996.

HAMILTON, M.; TARIFA, J. Synoptic aspects of a polar outbreak leading to frost in tropical Brazil, July 1972. Mon.Wea.Rev., 106, p. 1545-1556, 1978.

HARANGOZO, S. A. A search for ENSO teleconnections in the west Antarctic Peninsula climate in Austral winter. International Journal of Climatology, 20, p. 663-679, 2000.

HARTMANN, D. L. e MICHELSEN, M. L. Intraseasonal Periodicities in Indian Rainfall. J. Atmos. Sc., 46 (18), p. 2838-2862, 1989.

HARTMANN, D. L. Global Physical Climatology. Washington: Academic Press, v. 56, 1994.

HEIL, P.; MASSOM, R.A.; ALLISON, I.; WORBY, A.P.; LYTLE, V.I. Role of off-shelf to on-shelf transitions for East Antarctic sea ice dynamics during spring 2003. J. Geophys. Res., 114(C9), 2009.

HOSKINS, B. J. Dynamical processes in the atmosphere and the use of models. Quart. J. Roy. Meteor. Soc., 109, p. 1-21, 1983.

HOSKINS, B. J.; HODGES, K. I. A New Perspective on Southern Hemisphere Storm Tracks. Journal of Climate, v. 18 (20), p. 4108-4129, 2005.

HOSKINS, B. J.; KAROLY, D. J. The Steady Linear Response of a Spherical Atmosphere to Thermal and Orographic Forcing. J. Atmos. Sci., 38, p. 1179-1196, 1981.

INATSU, M.; HOSKINS, B. J. The zonal asymmetry of the southern hemisphere winter storm track. Journal of Climate, v. 17, n. 24, p. 4882-4892, 2004. 
JONES, D. A.; SIMMONDS, I. A climatology of Southern Hemisphere extratropical cyclones. Clim. Dynam. v. 9, p. 131-145, 1993.

JUSTINO, F.; HASTENREITER, F.; GRIMM, A.; SCHAEFER, C. Impacto da Concentração do dióxido de carbono atmosférico no gelo marinho antártico. Oecologia Brasiliensis, v. 11, p. 69-77, 2007.

KALNAY, E. E CO-AUTORES. The NCEP/NCAR Reanalysis 40-year Project. Bulletin of the American Meteorological Society, 77, p.437-471, 1996.

KANAMITSU, M.; EBISUZAKI, W.; WOOLLEN, J.; YANG, Shi-Keng; HNILO, J. J.; FIORINO, M.; POTTER, G. L. NCEP-DOE AMIP-II Reanalysis (R-2). Bulletin of the American Meteorological Society: vol. 83, No. 11, p. 1631-1643, 2002.

KAROLY, D. J. Southern Hemisphere circulation features associated with El Niño-Southern Oscillation events, J. Clim., 2, p. 1239-1252, 1989.

KING, J. C.; TURNER, J. Antarctic Meteorology and Climatology. 5ed. Cambridge: University Press, 409 p., 1997.

LAZZARA, Matthew A.; STEARNS, Charles R.; STAUDE, Jessica A.; KNUTH, Shelley L.. 10 years of Antarctic composite images. In: Antarctic Automatic Weather Station Annual Meeting, Antarctic Meteorological Research Center Annual Meeting, and Antarctic Mesoscale Prediction System (AMPS) Users' Workshop. Joint Annual Meetings, Madison, WI, 23-26 June 2003. Preprints. [Madison, WI], [University of Wisconsin-Madison, Space Science and Engineering Center], 2003.

L'ECUYER, J.; THOMPSON, D. W. J. Annular Modes Website. Disponível em: <http://www.atmos.colostate.edu/ao/introduction.html>. Acesso em: 15 abr. 2009.

LIM, E. -P.; SIMMONDS, I. Southern Hemisphere winter extratropical cyclone characteristics and vertical organization observed with the ERA-40 reanalysis data in 19792001. Journal of Climate, 20, p. 2675-2690, 2007.

LIMA, F. U. F. Variabilidade Extrema Intra-sazonal do Gelo Marinho Antártico e Relações com a Circulação Atmosférica. São Paulo, SP: Instituto de Astronomia, Geofísica e Ciências Atmosféricas. Originalmente apresentada como dissertação de mestrado, Universidade de São Paulo, 2007.

LIU, J.; Yuan, X.; RIND, D.; MARTINSON, D. G. Mechanism Study of the ENSO and Southern High Latitude Climate Teleconections. Geophysical Research Letters, vol. 29, No. 14, 1029/2002GL015143. 2002.

MARENGO, J. A.; CORNEJO, A.; SATYAMURTY, P.; NOBRE, C.; SEA, W. Cold surges in the tropical and extratropical South America. The strong event in June 1994. Monthly Weather Review, 125, p. 2759-2788, 1997.

MARSHALL, G. J. Trends in the Southern Annular Mode from observations and reanalyses. Journal of Climate, 16, p. 4134-4143, 2003.

MAYKUT, G. A. Energy exchange over young sea ice in the central Arctic. Journal of Geophysical Research. 83, p. 3646-58, 1978. 
MENÉNDEZ, C. G.; SERAFINI, Y. V.; LE TREUT, H. The effect of sea-ice on the transient atmospheric eddies of the Southern Hemisphere. Climate. Dyn., 15, p. 659-671, 1999a.

MENÉNDEZ, C. G.; SERAFINI, Y. V.; LE TREUT, H. The storm tracks and the energy cycle of the Southern Hemisphere: sensitivity to sea-ice boundary conditions. Ann. Geophys. Atmos. Hydros. Space Sci., 17, p. 1478-1492, 1999b.

MO, K. C.; HIGGINS, R. W. The Pacific-South American modes and tropical convection during the Southern Hemisphere Winter. Mon. Wea. Rev., 126, p. 1581-1596, 1998.

MURRAY, R. J.; SIMMONDS, I. A numerical scheme for tracking cyclone centres from digital data. Part I: Development and operation of the scheme. Australian Meteorological Magazine, 39, p. 155-166, 1991a.

MURRAY, R. J.; SIMMONDS, I. A numerical scheme for tracking cyclone centres from digital data. Part II: Application to January and July general circulation model simulations. Australian Meteorological Magazine, 39, p. 167-180. 1991b.

NSIDC - National Snow and Ice Data Center. All about sea ice. Disponível em: http://nsidc.org/seaice. Acesso em: outubro de 2010.

NSIDC- National Snow and Ice Data Center. Sea Ice Concentrations from Nimbus-7 SMMR and DMSP SSM/I Passive Microwave Data. Universidade do Colorado, Boulder. Disponível em: <http://nsidc.org/data/docs/daac/nsidc0051_gsfc_seaice.gd.html>. Acesso em: 01 jul. 2011.

PEZZA, A. B.; DURRANT, T.; SIMMONDS, I.; SMITH, I. Southern Hemisphere synoptic behavior in extreme phases of SAM, ENSO, sea ice extent, and southern Australia rainfall. J. Climate, 21(21), p. 5566-5584, 2008.

PEZZA, A. B.; SIMMONDS, I.; RENWICK, J. Southern Hemisphere cyclones and anticyclones: Recent trends and links with decadal variability in the Pacific Ocean. Int. J. Climatol., 27, p. 1403-1419, 2007.

PHYSICK, W. L. Winter depression tracks and climatological jet streams in the southern hemisphere during the FGGE year. Quart. J. Roy. Met. Soc., 107, p. 883-98, 1981.

RADOK, U.; STRETEN, N.; WELLER, G. E. Atmosphere and ice. Oceanus, 18, p. 16-27, 1975.

RIFFENBURGH, B. (Ed.). Encyclopedia of the Antarctic: índice A-K. New York: Routledge, 2007.

RIND., D., CHANDLER, M., LERNER, J., MARTINSON, D.G. \& YUAN, X. The climate response to basin-specific changes in latitudinal temperature gradients and the implications for sea ice variability. Journal of Geophysical Research, vol. 106, p. 20161-20173, 2001.

ROSS, B.; WALSH, J. E. Synoptic-scale influences of snow cover and sea-ice. Mon Weather Rev, 114, p. 1795-1810, 1986.

SABINE, C. L.; FEELY, R. A.; GRUBER, N.; KEY, R. M.; LEE, K.; BULLISTER, J. L.; WANNINKHOF, R.; WONG, C. S.; WALLACE, D. W.; TILBROOK, B.; MILLERO, F. J.; 
PENG, T. H.; KOZYR, A.; ONO, T.; RIOS, A. F. The Oceanic Sink for Anthropogenic CO2, Science, 305, p. 367-371, 2004.

SCAR - Scientific Committee on Antarctic Research. Some Antarctic Statistics. Disponível em: <http://www.scar.org>. Acesso em: 05 mar. 2009.

SCHMITT, C. Interannual Variability in Antarctic Sea Ice Motion. Baden-Baden: Universität Karlsruhe. Originalmente apresentada como tese de doutorado, Universität Karlsruhe, 2006.

SILVA, L. D. Storm-track na América do Sul e vizinhanças: climatologia, variabilidade e mudanças climáticas. Dissertação de Mestrado em Meteorologia, INPE, 88 p., 2010.

SIMMONDS, I.; BUDD, W. F. Sensitivity of the southern hemisphere circulation to leads in the Antarctic pack ice. Quart. J. Roy. Meteor. Soc., 117, p. 1003-1024, 1991.

SIMMONDS, I.; JACKA, T. H. Relationships between the interanual variability of Antarctic sea ice and the Southern Oscillation. J. Climate, 8, p. 637-647, 1995.

SIMMONDS, I.; KEAY, K. Mean Southern Hemisphere extratropical cyclones behavior in the 40-year NCEP-NCAR Reanalysis. J. Climate, 13, p. 873-885, 2000a.

SIMMONDS, I.; KEAY, K. Variability of Southern Hemisphere Extratropical Cyclone Behavior, 1958-97. J. Climate, 13, p. 550-561, 2000 b.

SIMMONDS, I.; KEAY, K.; LIM, E. P. Synoptic activity in the seas around Antarctica. Monthly Weather Review, 131, p. 272-288, 2003.

SIMMONDS, I.; MURRAY, R. J. Southern extratropical cyclone behavior in ECMWF analyses during the FROST Special Observing Periods. Weather and Forecasting, 14, p. 878-891, 1999.

SIMMONDS, I.; MURRAY, R. J.; LEIGHTON, R. M. A refinement cyclone tracking methods with data from FROST. Australian Meteorological Magazine (Special ed.), p. 3549, 1999.

SIMMONDS, I.; WU, X. R. Cyclone behaviour response to changes in winter Southern Hemisphere sea-ice concentration. Q. J. R. Meteor. Soc., 119(513), p. 1121-1148, 1993.

SIMÕES, J. C. Glossário da língua portuguesa da neve, do gelo e termos correlatos. Pesquisa Antártica Brasileira, 4, p. 119-154, 2004.

SPIEGEL, M. R. Estatística. São Paulo: Mcgraw-Hill do Brasil. 2 ed. Tradução, revisão e adaptação Carlos Augusto Crusius. 454 p, 1985.

SPIEGEL, M. R. Probabilidade e estatística. São Paulo: Mcgraw-hill, 518 p., 1977. Traduzido por Alfredo Alves de Faria.

SQUIRE, V.A. Sea ice. Science Progress, 69, p.19-43, 1984. 
STAMMERJOHN, S. E.; DRINKWATER, M. R.; SMITH, R. C.; LIU, X. Ice-atmosphere interactions during sea-ice advance and retreat in the western Antarctic Peninsula region. J. Geophys. Res., 108, 3329, doi:10.1029/2002JC001543, 2003.

STEFFEN, K. et al. The estimation of geophysical parameters using passive microwave algorithms. Chapt 10 In Microwave remote sensing of sea ice. Frank Carsey, editor. American Geophysical Union. Washington, D. C. p. 243-259, 1992.

TALJAARD, J. J. Synoptic meteorology of the Southern Hemisphere. Meteorology of the Southern Hemisphere, Meteorology. Monography, $\mathrm{n}^{\circ}$ 35, American Meteorological Society, p. 139-211, 1972.

THOMPSON, D. W. J.; WALLACE, J. M. Annular Modes in the Extratropical Circulation. Part I: Month-to-Month Variability. Journal of Climate, 13, p. 1000-1016, 2000.

TRENBERTH, K.E. Storm track in the Southern Hemisphere. J. Atmos. Sci., 48, p. 21592178, 1991.

TURNER, J.; COLWELL, S. R.; MARSHALL, G. J.; LACHLAN-COPE, T. A.; CARLETON, A. M.; JONES, P. D.; LAGUN, V; REID, P. A.; IAGOVKINA, S. Antarctic climate change during the last 50 years. International Journal of Climatology, 25, p. 279294, 2005.

VAN LOON, H.; KIDSON, J. W. The association between latitudinal temperature gradient and eddy transport. Part III. The Southern Hemisphere. Aust Meteorol Mag 42, p. 31-37, 1993.

VERA, C. S.; VIGLIAROLO, P. K. A diagnostic study of cold-air outbreaks over South America. Monthly Weather Review, 128, p. 3-24, 2000.

WADHAMS, P. Ice in the ocean. Amsterdam: Gordon and Breach Science Publishers. 351 p., 2000.

WALlACE, J. M.; HOBBS, P. V. Atmospheric Science: An Introduction Survey. 2. ed., Academic Press, 504 p., 2006.

WHITE, W. B.; PETERSON, R. G. An Antarctic circumpolar wave in surface pressure, temperature and sea-ice extent. Nature, 380, p. 699-702, 1996.

WILKS, D. S. Statistical Methods in the Atmospheric Sciences - An Introduction. 2 ed. Academic Press, New York, 2006.

XAVIER, T. M. B. S.; DA SILVA, J. F.; REBELLO, E. R. G. A técnica dos quartis e suas aplicações em Meteorologia, Climatologia e Hidrologia, com ênfase para as regiões brasileiras. Ed. Thesaurus. Brasília-DF, 2002.

YUAN, X. J. ENSO-related impacts on Antarctic sea ice: a synthesis of phenomenon and mechanisms. Antarctic Science, 16(4): p. 415-425, 2004.

YUAN, X., CANE, M.A. \& MARTINSON, D.G. Climate variation-cycling around the South Pole. Nature, 380, p. 673-674, 1996. 
YUAN, X.; LI, C. Climate modes in southern high latitudes and their impacts on Antarctic sea ice, J. Geophys. Res., 113, C06S91, 2008.

YUAN, X.; MARTINSON, D. G. Antarctic sea ice extent variability and its Global Connectivity, Journal of Climate, 3, p. 1697-1717, 2000.

YUAN, X.; MARTINSON, D. G. The Antarctic Dipole and its Predictability. Geophys. Res. Lett, vol. 28, No. 18, p. 3609-3612, 2001.

YUAN, X.; MARTINSON, D. G.; LIU, W. T.: The effect of air-sea-ice interaction on winter 1996 Southern Ocean subpolar storm distribution. J. Geophys. Res. - Atmosphere, 104(D2), p. 1991-2007, 1998.

ZWALLY, H. J. et al. Variability of Antarctic sea ice 1979 - 1998, Geophysical Research Letters, 107(C5), 3041, doi:10.1029/2000JC000733, 2002. 